Heloisa Guedes Mendonça

Análise Paramétrica do Efeito de Cargas de Esmagamento e Estrangulamento sobre um Tubo Flexível na Operação de Lançamento 

Heloisa Guedes Mendonça

Análise Paramétrica do Efeito de Cargas de Esmagamento e Estrangulamento sobre um Tubo Flexível na Operação de Lançamento

Dissertação apresentada à Escola Politécnica da Universidade de São Paulo para obtenção do título de Mestre em Ciências 

Heloisa Guedes Mendonça

\section{Análise Paramétrica do Efeito de Cargas de Esmagamento e Estrangulamento sobre um Tubo Flexível na Operação de Lançamento}

Dissertação apresentada à Escola Politécnica da Universidade de São Paulo para obtenção do título de Mestre em Ciências

ÁREA DE CONCENTRAÇÃO: ENGENHARIA NAVAL

ORIENTADOR: Prof. Dr.

Clóvis de Arruda Martins 
Este exemplar foi revisado e corrigido em relação à versão original, sob responsabilidade única do autor e com a anuência de seu orientador.

São Paulo, de de

Assinatura do autor:

Assinatura do orientador:

\section{Guedes Mendonça, Heloisa}

Análise Paramétrica do Efeito de Cargas de Esmagamento e

Estrangulamento sobre um Tubo Flexível na Operação de Lançamento / H. Guedes Mendonça -- versão corr. -- São Paulo, 2016.

$128 \mathrm{p}$.

Dissertação (Mestrado) - Escola Politécnica da Universidade de São Paulo. Departamento de Engenharia Naval e Oceânica.

1.Tubos Flexíveis 2.Instalação de tubos flexíveis 3.Mecânica offshore 4.Método dos Elementos Finitos 5.Análise estrutural I.Universidade de São Paulo. Escola Politécnica. Departamento de Engenharia Naval e Oceânica II.t. 


\section{AGRADECIMENTOS}

A Deus, por me guiar ao longo dessa caminhada, e pela força interior para vencer os desafios da vida.

Ao prof. Dr. Clóvis de Arruda Martins, pela inestimável oportunidade a mim concedida em trabalhar no Laboratório de Mecânica Offshore, de fundamental importância para aprofundar minha formação como engenheira; pela orientação e paciência, fundamentais para a conclusão deste trabalho.

Aos meus pais, pela confiança e apoio nas minhas escolhas pessoais, por todo o esforço dedicado a mim durante toda essa trajetória de estudos.

À ANP (Agência Nacional de Petróleo), pelo auxílio financeiro durante todo o programa de mestrado.

Ao Grupo PRYSMIAN, pela colaboração junto ao Laboratório de Mecânica Offshore (LMO) com informações técnico-científicas.

Aos colegas do LMO, principalmente ao Caio César Pereira Santos e Rafael Salles, pela solicitude e ajuda em problemas técnicos, e também pela simpatia e bom humor que tornam o ambiente de trabalho mais agradável e ameno. 



\section{RESUMO}

Tubos flexíveis são amplamente utilizados na indústria offshore. Essas estruturas são empregadas no transporte de fluidos, na exploração de petróleo em águas profundas. Suas diversas camadas conferem propriedades, como a resistência mecânica e a impermeabilidade, que são importantes em ambientes de condições adversas. A instalação é uma etapa crítica da vida útil dos tubos flexíveis, visto que os carregamentos de lançamento podem danificar a estrutura dos mesmos. As cargas predominantes durante essa etapa são o peso próprio da linha, os esforços de compressão radial que são impostos ao tubo pelas sapatas dos tensionadores e a pressão de estrangulamento aplicada ao tubo pelas armaduras de tração. A magnitude dessas cargas está diretamente associada à profundidade de lançamento. O presente trabalho tem como objetivo a análise qualitativa dos principais parâmetros responsáveis pela falha dos tubos flexíveis quando submetidos aos carregamentos de lançamento. O comportamento do tubo é investigado em função da variação das cargas de esmagamento (crushing) e de estrangulamento (squeezing) com a profundidade de lançamento da linha. Esse estudo é conduzido através da proposição de modelos numéricos baseados no método dos Elementos Finitos. Aspectos importantes de modelagem como a representação do perfil real das camadas metálicas e das sapatas e a avaliação dos contatos entre as camadas são considerados nos modelos propostos. Os parâmetros de investigação são: a quantidade de sapatas e seu ângulo de abertura; a adição da capa polimérica externa e o estudo de seu contato com as sapatas; a rigidez das sapatas; e a profundidade de falha do tubo com atuação simultânea dos carregamentos de esmagamento e estrangulamento. A avaliação da influência desses parâmetros na falha do tubo flexível durante o lançamento é o escopo deste trabalho. Essa análise ainda proporcionou a determinação das regiões de escoamento das camadas metálicas considerando cada uma das variáveis avaliadas. Através deste trabalho, foi possível perceber que todos os parâmetros investigados têm influência na falha do tubo flexível. Alguns, no entanto, como o tipo de contato entre a camada polimérica externa e as sapatas, e a atuação do carregamento de estrangulamento no tubo não atuam de maneira significativa na falha. Assim, foi eleita uma configuração de lançamento a favor da segurança para o tubo investigado com base nos parâmetros estudados. 


\begin{abstract}
Flexible pipes are widely used in the offshore industry. These structures are employed in the transportation of fluids in deep-water oil exploitation. Its several layers provide different properties as mechanical strength and tightness that are important for operation in harsh environment condition. The installation procedure is critical in the life cycle of flexible pipes since the installation loads can damage the pipe structure. The prevailing loads during this step are the pipe weight, radial compressive forces applied to the pipe by the shoes of the tensioners, and the squeezing loads applied to the pipe by the tensile armors. The extent of these loads is directly linked with the launching depth. The main goal of this dissertation is the qualitative analysis of the main parameters that leads the pipe to failure by the installation loads. The behavior of the pipe is investigated considering the change in crushing and squeezing loads with the launching depth. This analysis is done through numerical models based on the Finite Element Method. Important modeling assumptions such as the representation of the actual profile of the layers and shoes and contact-pair between the layers are features taken in account into the models presented. The parameters investigated are: the number of shoes and their opening angle; the addition of the external polymeric sheath, and the study of their contact with the shoes; the stiffness of the shoes; and the depth by which the failure of the tube occurs when the crushing and squeezing loads are applied. The scope of this work is the evaluation of these parameters in the tube failure during installation. This analysis also provided to determine the regions of layers yielding considering one of the variables. Through this work, it was noticed that all parameters investigated contribute to the tube failure. However, some of them such as the contact between the external polymeric sheath and shoes, and the squeezing load do affect significantly to failure. Therefore, a launching configuration was chosen respecting the safety of the pipe, and based on the parameters investigated.
\end{abstract}




\section{LISTA DE TABELAS}

Tabela 1 - Descrição das camadas com suas respectivas funções e critérios de projeto. 10

Tabela 2 - Dimensões do tubo flexível. .................................................................. 49

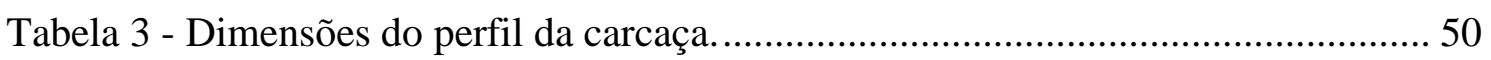

Tabela 4 - Dimensões do perfil da armadura de pressão.............................................. 51

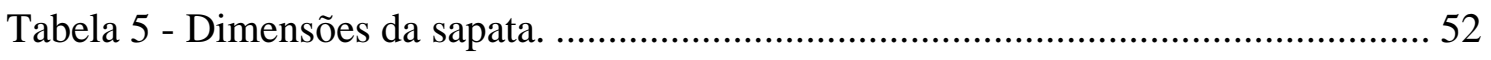

Tabela 6 - Propriedades dos materiais das camadas metálicas e poliméricas. ............... 54

Tabela 7 - Dados das Malhas geradas para as camadas tubo de 4 polegadas................ 58

Tabela 8 - Pares de contatos adotados entre as camadas............................................. 59

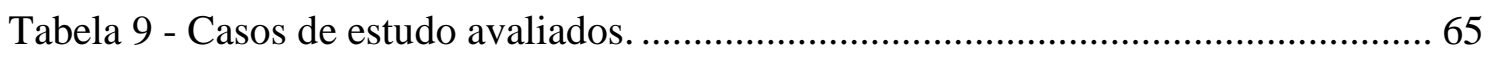

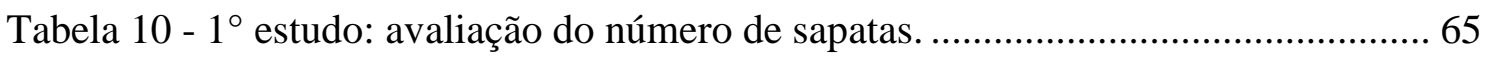

Tabela 11 - $2^{\circ}$ estudo: avaliação do ângulo de abertura das sapatas. .............................. 66

Tabela 12 - $3^{\circ}$ estudo: adição da capa plástica e análise do seu contato com as sapatas.

Tabela 13 - $4^{\circ}$ estudo: avaliação da rigidez da sapata.

Tabela 14 - $5^{\circ}$ estudo: avaliação da influência das cargas de esmagamento e estrangulamento na falha do tubo com a profundidade de lançamento........................... 68

Tabela 15 - Propriedades geométricas do tubo característico. ....................................... 70

Tabela 16 - Propriedades da linha flexível e condições ambientais para os casos de estudo.

Tabela 17 - Cargas de tração efetiva dinâmica e pressão de esmagamento em cada

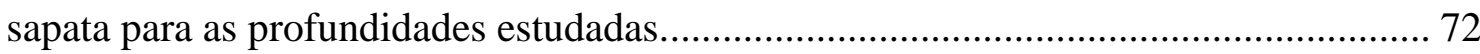

Tabela 18 - Regiões de escoamento das camadas metálicas para os cinco casos de

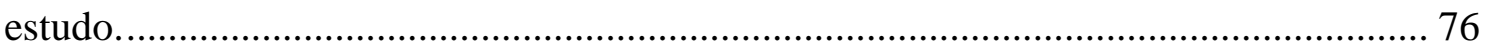

Tabela 19 - Dados de escoamento da carcaça com a variação do número de sapatas.... 78 Tabela 20 - Dados de escoamento da armadura de pressão com a variação do número de

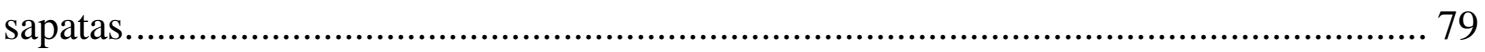

Tabela 21 - Dados de falha do tubo com a variação do número de sapatas. ................... 80 Tabela 22 - Dados de escoamento da carcaça com a variação do ângulo de abertura das sapatas

Tabela 23 - Dados de escoamento da armadura de pressão com a variação do ângulo de abertura das sapatas.

Tabela 24 -Dados de falha do tubo com a variação do ângulo de abertura das sapatas. 86 Tabela 25 - Dados de escoamento da carcaça com a adição da capa polimérica externa e a variação do contato entre o tubo e as sapatas.

Tabela 26 - Dados do escoamento da armadura de pressão com a adição da capa polimérica externa e a variação do contato entre o tubo e as sapatas......

Tabela 27 - Dados de falha do tubo com a adição da camada polimérica externa e variação do contato entre o tubo e as sapatas.

Tabela 28 - Dados de escoamento da carcaça com a variação da rigidez das sapatas. .. 96 
Tabela 29 - Dados de escoamento da armadura de pressão com a variação da rigidez das

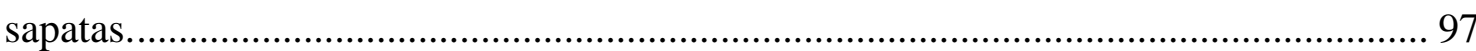

Tabela 30 - Dados de falha do tubo com a variação da rigidez das sapatas................... 98 Tabela 31 - Variação da Tensão de von Mises registrada nas camadas metálicas, de acordo com a profundidade de lançamento, e com aplicação dos carregamentos de esmagamento e estrangulamento.

Tabela 32 - Dados de escoamento da carcaça intertravada, a $500 \mathrm{~m}$ de profundidade, com a aplicação dos carregamentos de esmagamento e estrangulamento.

Tabela 33 - Dados de escoamento da armadura de pressão, a $600 \mathrm{~m}$ de profundidade, com a aplicação dos carregamentos de esmagamento e estrangulamento

Tabela 34 - Dados de falha do tubo, a $500 \mathrm{~m}$ de profundidade, com aplicação dos carregamentos de esmagamento e estrangulamento.

Tabela 35 - Variação da Tensão de von Mises resgistrada nas camadas metálicas, de acordo com a profundidade de lançamento, e com aplicação apenas do carregamento de esmagamento.

Tabela 36 - Dados de escoamento da carcaça intertravada, a $600 \mathrm{~m}$ de profundidade, com a aplicação do carregamento de esmagamento.

Tabela 37 - Dados de escoamento da armadura de pressão, a $600 \mathrm{~m}$ de profundidade, com aplicação do carregamento de esmagamento

Tabela 38 - Dados de falha do tubo, a $500 \mathrm{~m}$ de profundidade, com aplicação do carregamento de esmagamento.

\section{LISTA DE FIGURAS}

Figura 1 - Disposição do tubo flexível no mar com sua classificação: risers, flowlines e jumpers [36]

Figura 2 - Sistemas de produção (da esquerda para direita): plataforma fixa, TLP

(Tension Leg Platform), spar- buoy, semi-submersível e FPSO (Floating Production Storage Offloading) [29].

Figura 3 - Principais configurações de linhas flexíveis: (a) Catenária Livre; (b) Lazy S;

(c) Lazy Wave; (d) steep S; (e) steep wave e (f) lanterna chinesa [Clausen e D' Souza (2001)].

Figura 4 - Tubos flexíveis não-aderentes: (a) Rough bore, (b) Smooth bore [Coelho (2013)].

Figura 5- Tubo flexível não-aderente [15].

Figura 6 - Perfis das diversas camadas do tubo flexível com indicação da função e material [1].

Figura 7- Perfil da carcaça intertravada (Fonte: API 17B [3]).

Figura 8- Alguns perfis da armadura de pressão: (a) Perfil zeta, (b) Perfil C, (c) Perfil T (grampo de ligação) e (d) Perfil T (API 17B [3]). 
Figura 9- Navio Lançador [2].

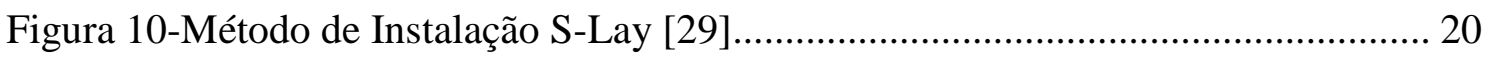

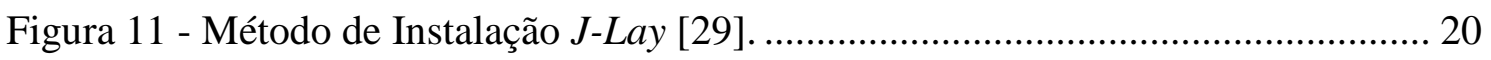

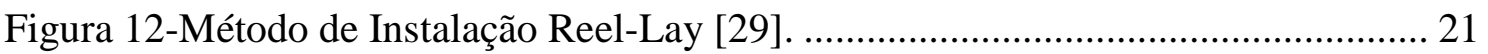

Figura 13- (a) Tensionador (azul) com sapatas (amarelo) [23]; (b) seção transversal do tubo com as cargas de esmagamento das sapatas [Sousa (2002)] ............................... 23

Figura 14 - Desenho esquemático do tubo flexível sob carregamento: (a) de 2 sapatas;

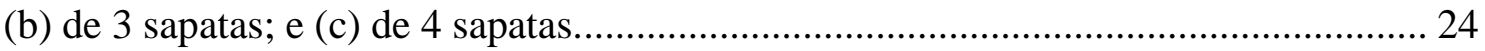

Figura 15 - Ação da carga de esmagamento no tubo flexível descrita por Cruz (1996). 25

Figura 16 - Efeito do Estrangulamento (squeezing) no tubo flexível descrito por Cruz

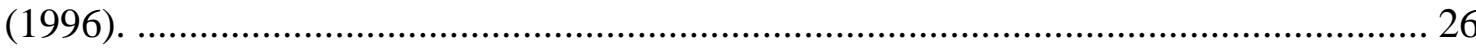

Figura 17 -Malha do modelo tridimensional composto pelas camadas do núcleo

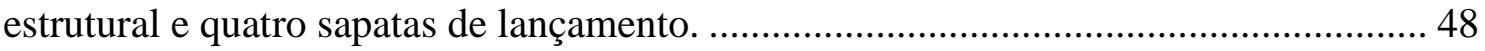

Figura 18 - Malha do modelo tridimensional composto pelas camadas do núcleo

estrutural, camada polimérica externa e quatro sapatas de lançamento. ......................... 48

Figura 19 - Perfil parametrizado da carcaça intertravada como indicado em Gay Neto e

Martins (2012) (a), e a seção transversal equivalente a dois passos (b)....................... 50

Figura 20- Perfil da armadura de pressão parametrizado (a) seção transversal da zeta

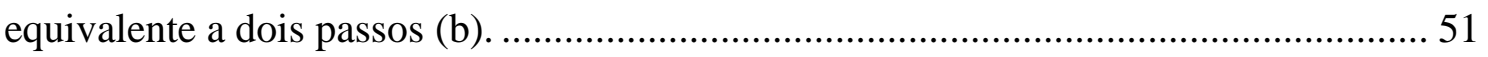

Figura 21 - Dimensões da sapata (a) e perfil da sapata (b)........................................... 52

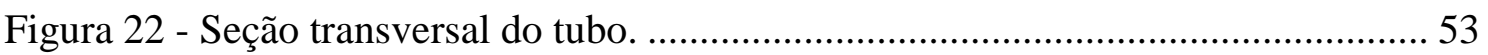

Figura 23- Curva de tensão x deformação para o material da camada polimérica interna.

Figura 24 - Curva do material da camada polimérica externa...................................... 56

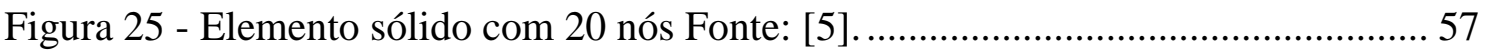

Figura 26 - Representação dos pares de contatos entre as camadas: (a) visão isométrica,

(b) visão frontal dos contatos entre os perfis da seção transversal.

Figura 27 - Acoplamento das extremidades da geometria para representar o tubo como infinito: (a) vista do acoplamento na seção transversal e (b) vista do acoplamento em

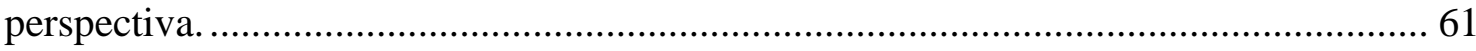

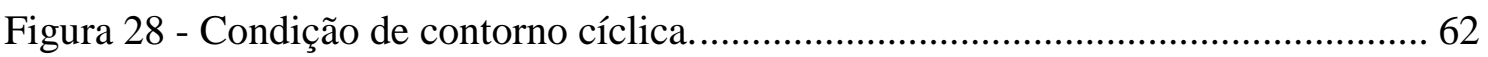

Figura 29 - Restrição do grau de liberdade de deslocamento na direção axial. ............. 62

Figura 30 - Tubo utilizado para o cálculo da rigidez flexional e da pressão de estrangulamento: (a) vista bidimensional; (b) vista tridimensional................................ 69

Figura 31 - Região de escoamento da carcaça para o caso com duas sapatas de lançamento................................................................................................ 73

Figura 32 - Região de escoamento da armadura de pressão para o caso de estudo com

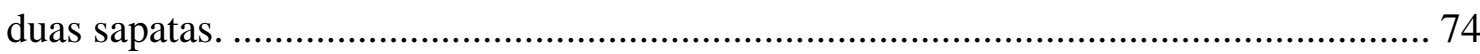

Figura 33 - Região de escoamento da armadura de pressão para o caso de estudo com 3

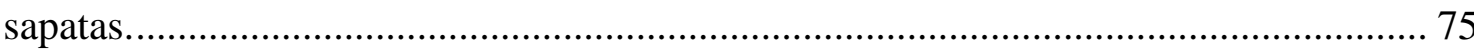

Figura 34 - Região de escoamento da armadura de pressão para o ângulo de abertura de

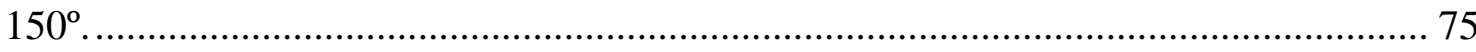

Figura 35 - Comparação entre o deslocamento radial da carcaça e da armadura de pressão para o caso com 2 sapatas 
Figura 36 - Comparação entre o deslocamento radial da carcaça e da armadura de pressão para o caso com 3 sapatas

Figura 37 - Comparação entre o deslocamento radial da carcaça e da armadura de pressão para o caso com 4 sapatas.

Figura 38 - Deslocamento radial das camadas metálicas com o carregamento de esmagamento aplicado por 2,3 e 4 sapatas até o ponto de falha.

Figura 39 - Tensão de von Mises [Mpa] registrada no ponto de falha para: (a) duas

sapatas; (b) três sapatas e (c) quatro sapatas.

Figura 40 - Relação da força de esmagamento $\mathrm{x}$ deslocamento radial da armadura de pressão com os ângulos de abertura variando de $120^{\circ}$ a $180^{\circ}$.

Figura 41- Relação da força de esmagamento x deslocamento radial para a carcaça intertravada com os ângulos de abertura das sapatas variando de $120^{\circ}$ a $180^{\circ}$.

Figura 42 - Tensão de von Mises [MPa] para os ângulos de abertura de: (a) $120^{\circ}$; (b)

$130^{\circ}$; (c) $140^{\circ}$; (d) $150^{\circ}$; (e) $160^{\circ}$; (f) $170^{\circ}$; e (g) $180^{\circ}$.

Figura 43 - Relação entre o carregamento de esmagamento e o ângulo de abertura das sapatas no momento da falha do tubo.

Figura 44 - Relação entre força de esmagamento x deslocamento radial para o caso de estudo com adição da capa polimérica externa e variação do contato entre o tubo e as sapatas

Figura 45 - Tensão de von Mises [MPa] registrada no ponto de falha, com a adição da capa polimérica externa, para os pares de contato entre o tubo e as sapatas: (a)

frictionless; (b) bonded; (c) rough.

Figura 46 - Relação força de esmagamento x deslocamento radial para a carcaça com a variação da rigidez das sapatas.

Figura 47 - Relação força de esmagamento x deslocamento radial para armadura de pressão com a variação da rigidez das sapatas.

Figura 48 - Tensão de von Mises [MPa] registrada no ponto de falha do tubo para rigidez das sapatas igual a: (a) $2.1 \mathrm{GPa}$; (b) $21 \mathrm{GPa}$; (c) $210 \mathrm{GPa}$; (d) $2100 \mathrm{GPa}$; (e) $21000 \mathrm{GPa}$; (f) $210000 \mathrm{GPa}$; (g) $2100000 \mathrm{GPa}$; e (h) $21000000 \mathrm{GPa}$.

Figura 49 - Tensão de von Mises [MPa] registrada no ponto de falha do tubo para para o carregamento I e profundidades de a: (a) $100 \mathrm{~m}$; (b) $200 \mathrm{~m}$; (c) $300 \mathrm{~m}$; (d) $400 \mathrm{~m}$; (e) $500 \mathrm{~m}$.

Figura 50 - Tensão de von Mises [MPa] registrada no ponto de falha do tubo para para o carregamento II e profundidades de a: (a) $100 \mathrm{~m}$; (b) $200 \mathrm{~m}$; (c) $300 \mathrm{~m}$; (d) $400 \mathrm{~m}$; (e) $500 \mathrm{~m}$.

Figura 51 - Relação entre força de esmagamento x deslocamento radial para armadura de pressão e carcaça intertravada para os carregamentos I e II a $100 \mathrm{~m}$ de profundidade.

Figura 52 - Relação entre força de esmagamento x deslocamento radial para armadura de pressão e carcaça intertravada para os carregamentos I e II a $200 \mathrm{~m}$ de profundidade.

Figura 53 - Relação entre força de esmagamento x deslocamento radial para armadura de pressão e carcaça intertravada para os carregamentos I e II a $300 \mathrm{~m}$ de profundidade. 
Figura 54 - Relação entre força de esmagamento x deslocamento radial para armadura de pressão e carcaça intertravada para os carregamentos I e II a $400 \mathrm{~m}$ de profundidade.

Figura 55 - Relação entre força de esmagamento x deslocamento radial para armadura de pressão e carcaça intertravada para os carregamentos I e II a $500 \mathrm{~m}$ de profundidade.

Figura 56 - Relação entre força de esmagamento x deslocamento radial para armadura de pressão e carcaça intertravada para os carregamentos I e II a $600 \mathrm{~m}$ de profundidade.

Figura 57 - Relação força de esmagamento x deslocamento radial para armadura de pressão e carcaça intertravada para os carregamentos I e II a 2000 m de profundidade.

Figura 58 - Curva tensão-deformação dos metais com o efeito do carregamento e descarregamento Fonte: Chakrabarty (2006).

Figura 59 - Representação do critério de escoamento no plano de tensão principal Fonte:

Chakrabarty (2006).

Figura 60 - Representação geométrica para o endurecimento isotrópico Fonte:

Chakrabarty (2006).

Figura 61 - Representação geométrica para o endurecimento cinemático Fonte: [24]. 120

Figura 62 - Exemplo de entrada dos parâmetros na rotina Pipe Design.

Figura 63 - Exemplo da saída dos parâmetros na rotina Pipe Design. 


\section{GLOSSÁRIO}

LMO - Laboratório de Mecânica Offshore.

Jumper - Trecho curto de tubo, podendo ser rígido ou flexível, usado para conectar dois dutos próximos ou um duto a um equipamento.

Flowline - Tubo flexível disposto no solo marinho utilizado tanto para o transporte do petróleo e gás natural quanto para a injeção de fluidos.

Riser - Linhas que transferem fluidos dos equipamentos submersos àqueles localizados na superfície marinha.

Spar- buoy - Plataforma vertical em formato cilíndrico ancorada no fundo do mar.

TLP - Tension leg Platform; é um sistema de produção flutuante ancorado ao fundo do mar por tubos de aço tracionados que permitem pouco movimento vertical (atirantado).

FPSO - Floating Production Storage Offloading; são unidades de produção flutuante de grande porte utilizadas na produção, armazenamento e transferência de petróleo.

Crushing - Carregamentos de esmagamento radiais impostos aos tubos pelas sapatas dos tensionadores de lançamento.

Squeezing - Carregamentos de estrangulamento impostos aos tubos pelas armaduras de tração durante a instalação da linha. 


\section{SUMÁRIO}

1. INTRODUÇÃ

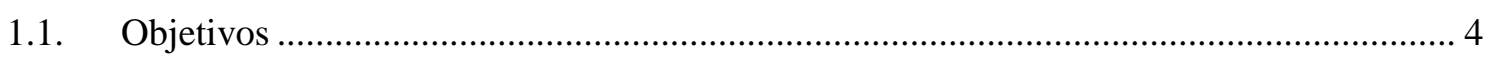

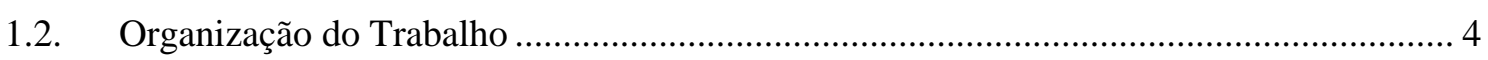

2. CARACTERÍSTICAS DO TUBO FLEXÍVEL ....................................................6

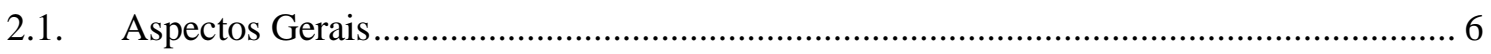

2.2. Seção Transversal de um Tubo Flexível Não-aderente ..................................................... 7

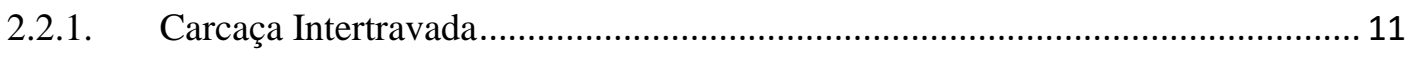

2.2.2. Camada Polimérica Interna ................................................................................ 13

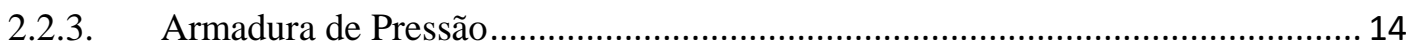

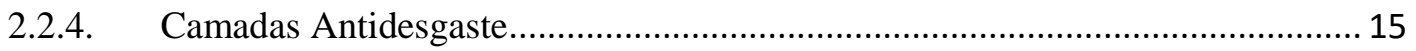

2.2.5. Fitas de Reforço a Compressão ........................................................................ 16

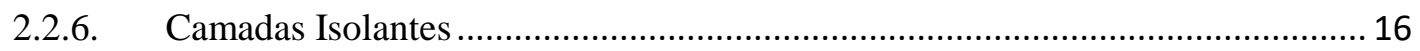

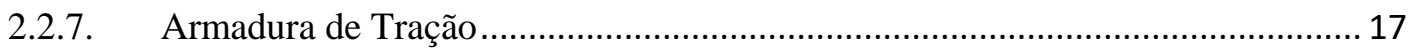

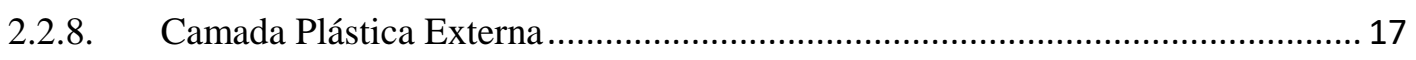

2.3. Normas Técnicas para Projeto e Operação dos Tubos Flexíveis ...................................... 18

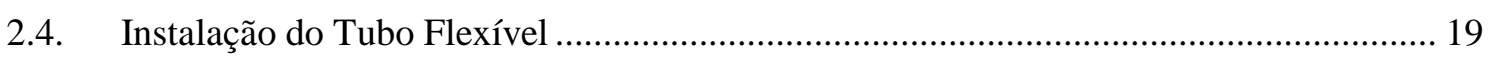

2.4.1. Cargas de Instalação da Linha Flexível............................................................... 22

2.4.1.1. Cargas de Esmagamento (crushing) ............................................................ 24

2.4.1.2. Cargas de Estrangulamento (squeezing)...................................................... 25

3. REVISÃO BIBLIOGRÁFICA............................................................................28

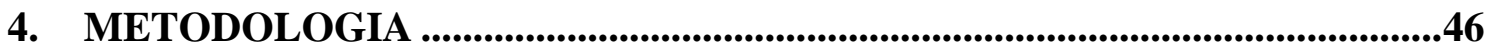

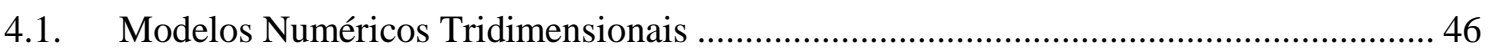

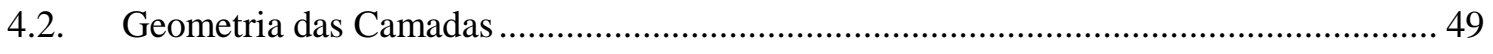

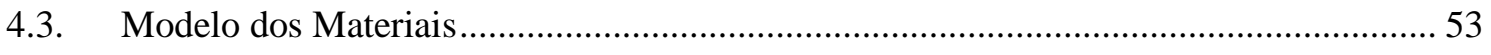

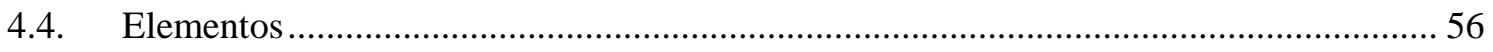

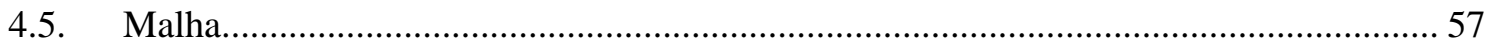

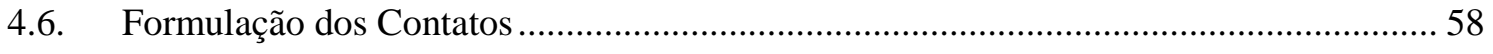

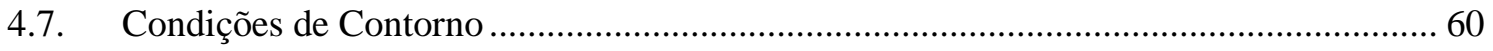

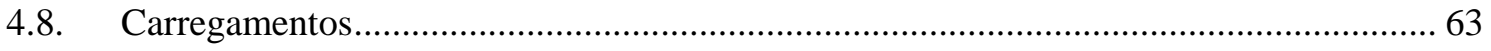

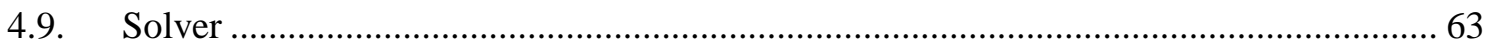

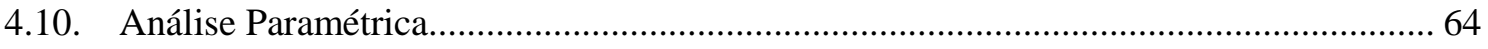




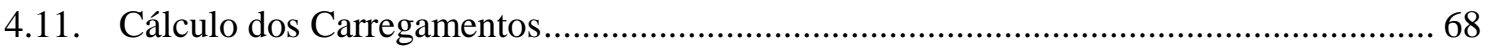

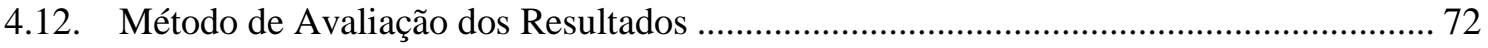

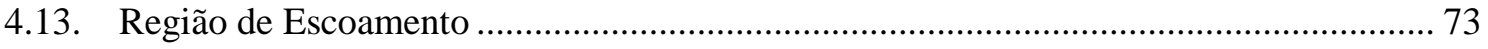

5. ANÁLISE DOS RESULTADOS.............................................................................77

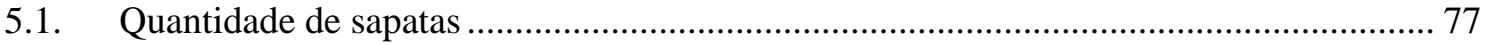

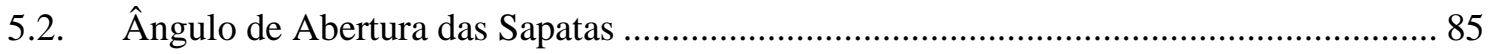

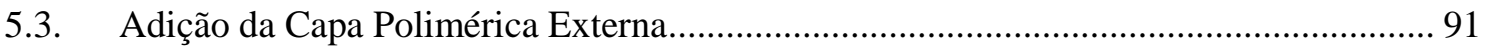

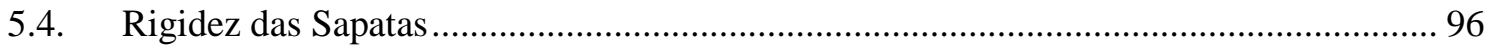

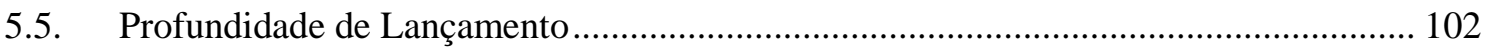

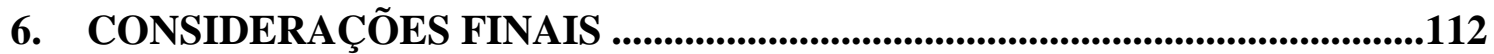

REFERÊNCIAS BIBLIOGRÁFICAS ......................................................................113

APÊNDICE A - MODELOS DE PLASTICIDADE DOS METAIS ...........................116

APÊNDICE B - MODELO ANALÍTICO APLICADO NO CÁLCULO DA PRESSÃO DE ESTRANGULAMENTO ....................................................................................................1 121 


\section{INTRODUÇÃO}

O marco inicial da exploração de petróleo no mar (offshore) ocorreu por volta de 1896, em Santa Bárbara, Califórnia, utilizando-se um poço em profundidade de $6 \mathrm{~m}$. Na década de 30, foi iniciada a exploração no Golfo do México e, na década de 70, no Mar do Norte. Essa extração chegou ao Brasil em 1968, no campo de Guaricema, na Bacia de Sergipe, segundo Shima e Tadahiro (2008).

Com a descoberta de várias bacias sedimentares marítimas, a exploração que antes era restrita a regiões de águas rasas, tornou-se um desafio com a descoberta de reservas em águas profundas. Tendo em vista as condições extremas de operação, que podem envolver lâminas d'água de mais de $2000 \mathrm{~m}$ de profundidade, a tecnologia de prospecção passou por um rápido aprimoramento. Nesse contexto, os tubos flexíveis destacaram-se e tornaram-se amplamente usados no mundo inteiro.

Os tubos empregados na exploração offshore podem ser flexíveis ou rígidos. Enquanto os tubos flexíveis são compostos por camadas metálicas e poliméricas, os tubos rígidos são construídos exclusivamente por aço. São classificados de acordo com a configuração assumida e a função desempenhada, podendo ser: jumper, flowline e riser. Em relação à configuração, o tubo pode ser suspenso (riser) ou em contato com o solo (flowline). O flowline é o tubo que, uma vez instalado, permanece assentado no fundo do mar, apresentando comportamento estático. O riser é o tubo responsável pela ligação entre o flowline e a plataforma, sendo projetado para suportar esforços dinâmicos. Estas estruturas também podem ser usadas em aplicações tanto estáticas quanto dinâmicas, em trechos de menor comprimento, sendo responsáveis por interligar equipamentos (jumpers). A Figura 1 apresenta as possíveis configurações do tubo flexível no mar. 


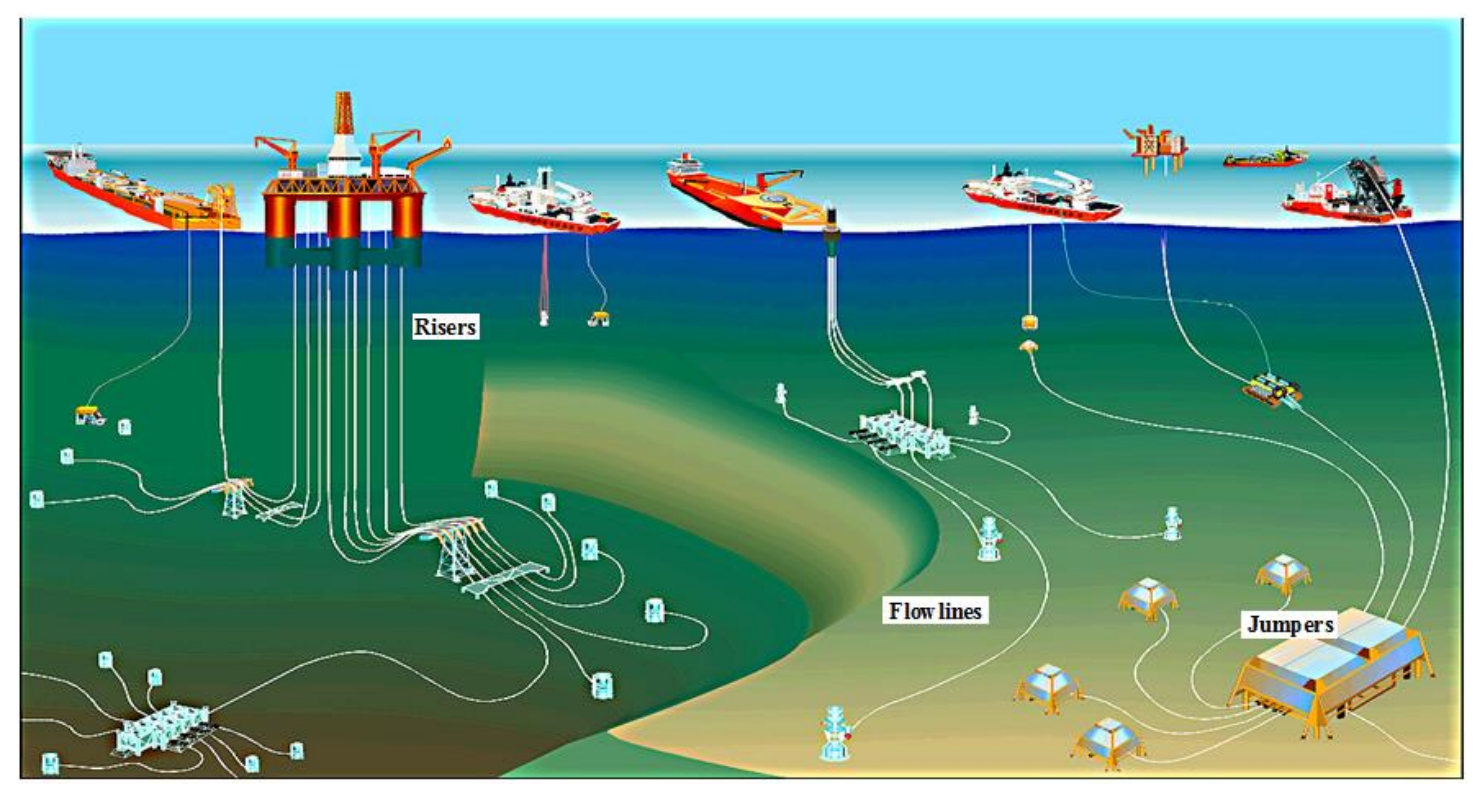

Figura 1 - Disposição do tubo flexível no mar com sua classificação: risers, flowlines e jumpers [37].

A maior vantagem de se usar tubos flexíveis é sua resistência em condições dinâmicas extremas. Além disso, o bom isolamento e a compatibilidades de suas propriedades químicas em relação ao ambiente de trabalho, rico em gases corrosivos como $\mathrm{CO}_{2}$ e $\mathrm{H}_{2} \mathrm{~S}$, representam vantagens adicionais quando comparados aos tubos rígidos. A diminuição dos custos de instalação, o aumento da vida operacional e a maior confiabilidade resultante da proteção contra a corrosão são vantagens adicionais em relação ao tubo rígido. Esses fatores contribuíram para que os tubos flexíveis fossem amplamente usados para a exploração de petróleo em alto mar. As linhas flexíveis podem ser usadas em diversas aplicações em uma unidade de produção flutuante. A produção, captação, exportação e a transferência do petróleo bruto são alguns exemplos.

No Brasil, as primeiras unidades de produção da Petrobras instaladas em alto mar foram plataformas fixas, que eram usadas para exploração de petróleo em águas rasas, no nordeste brasileiro, na década de 60 . No entanto, com a descoberta do petróleo em águas profundas, as unidades de produção flutuantes surgiram como nova alternativa. Essas unidades são classificadas de acordo com a função (produção, armazenamento, perfuração) e com a profundidade alcançada. A Figura 2 mostra ilustrações de algumas das principais tecnologias de produção. 


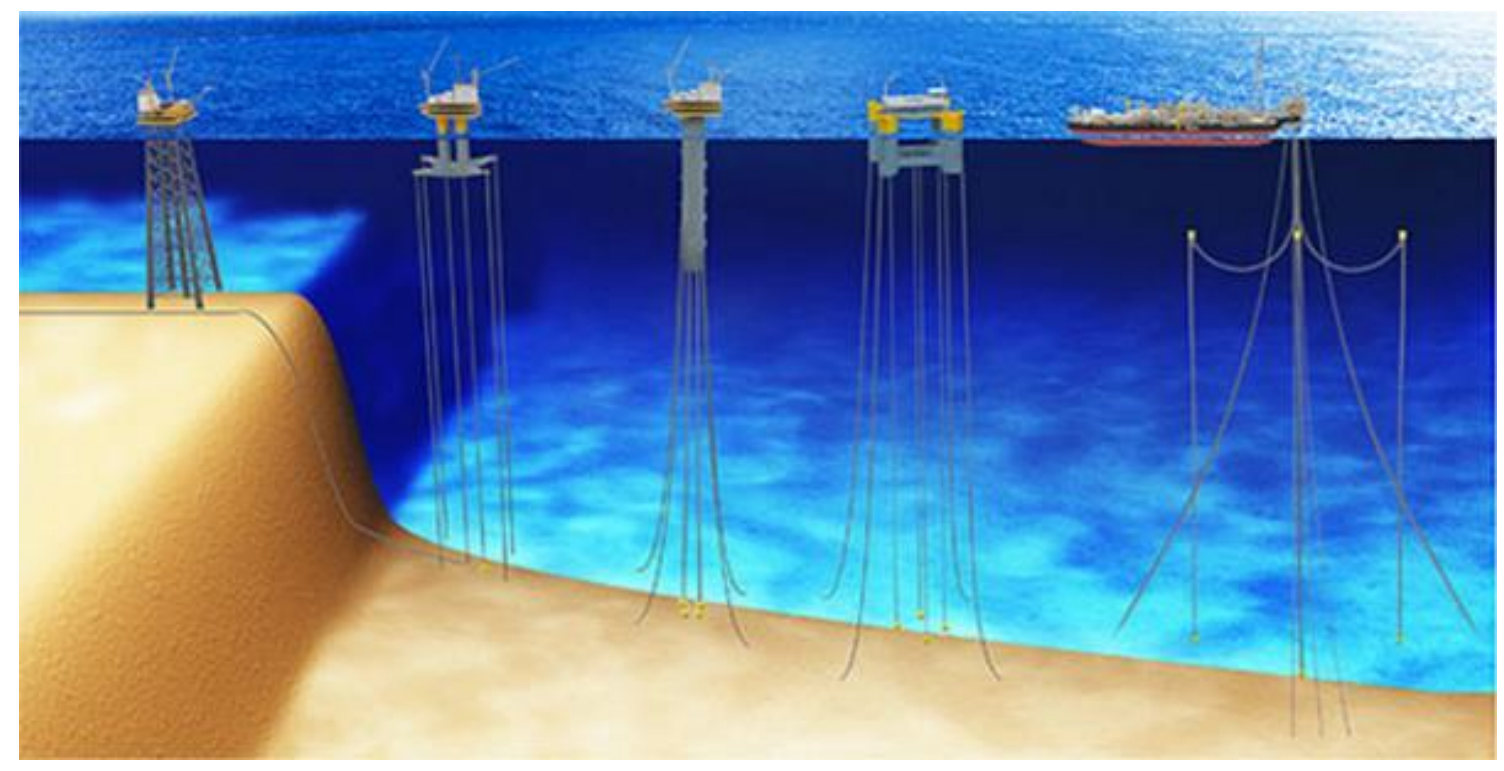

Figura 2 - Sistemas de produção (da esquerda para direita): plataforma fixa, TLP (Tension Leg Platform), spar- buoy, semi-submersível e FPSO (Floating Production Storage Offloading) [29].

São vários os tipos de carregamento que o tubo flexível suporta durante sua vida útil, tais como pressões internas e externas, cargas dinâmicas decorrentes de ação das correntes oceânicas, movimento do sistema flutuante, entre outros. Além desses carregamentos, aqueles resultantes da instalação necessitam de uma análise cuidadosa, uma vez que podem danificar estruturalmente as camadas e interromper a exploração. Por isso, entre as fases críticas de operação do tubo flexível, seu lançamento é uma das que requerem maior atenção. Nessa fase, são impostas várias cargas, destacando-se o peso próprio do tubo e as cargas de esmagamento aplicadas pelas sapatas dos tensionadores. Esses esforços podem comprometer estruturalmente o tubo e então causar o escoamento das camadas antes mesmo de chegar ao fundo do mar. Por isso, é necessário que se tenha uma boa previsão do comportamento estrutural do tubo quando submetido a esse tipo de carregamento. O limite da carga aplicada pelas sapatas ao tubo, durante o lançamento, também deve ser conhecido para que não ocorra falha das estruturas.

Alguns parâmetros, como a quantidade de sapatas, podem resultar na falha do tubo durante o lançamento. Assim, esse trabalho estará concentrado na análise qualitativa de parâmetros importantes da instalação do tubo flexível, sob uma perspectiva numérica. 


\subsection{Objetivos}

Esse trabalho tem como objetivos principais:

- Construir modelos tridimensionais por meio do Método dos Elementos Finitos para a representação de um tubo flexível não-aderente (unbonded). A partir da parametrização do tubo, serão representados a geometria real das camadas mais importantes para o estudo, seus contatos, materiais, condições de contorno e carregamentos;

- Avaliar parâmetros, como a quantidade de sapatas de lançamento e seu ângulo de abertura, juntamente com diferentes hipóteses de modelagem como a variação de contatos e a variação da rigidez do material das sapatas. Modelos tridimensionais desenvolvidos por meio do pacote computacional ANSYS Mechanical APDL versão 15.0 [5] são criados a fim de que as variáveis de estudo possam ser facilmente alteradas. Assim, é possível investigar os principais parâmetros com o objetivo de se avaliar isoladamente o efeito dos carregamentos de instalação em cada uma das camadas metálicas;

- $\quad$ Estabelecer o comportamento de falha do tubo flexível a partir da definição da ordem de escoamento das camadas metálicas, bem como a região em que ocorre. Partindo de um critério de análise puramente de tensão, obedecendo a norma 2409 da Petrobrás [32], será definida a falha do tubo para cada um dos parâmetros investigados. Os primeiros casos de estudo avaliarão apenas a influência do esmagamento (crushing). O último caso de estudo apresentará a falha da estrutura com os carregamentos conjuntos de esmagamento e estrangulamento. São então definidos os principais parâmetros envolvidos na falha do tubo durante o mecanismo da instalação.

\subsection{Organização do Trabalho}

O conteúdo desse trabalho será dividido por capítulo, conforme indicado a seguir: 
- Capítulo 2: descrição do tubo flexível com uma breve apresentação das possíveis configurações; caracterização das camadas concêntricas com respectivos materiais e propriedades; principais métodos de lançamento do tubo e os carregamentos envolvidos na instalação; apresentação das normas que serão usadas para definição dos critérios de falha.

- Capítulo 3 - apresentação da revisão bibliográfica com os principais trabalhos de natureza numérica e aqueles de caráter analítico e experimental que contribuíram para a elaboração da metodologia. Serão então abordados textos analíticos importantes para a compreensão da ação dos carregamentos de instalação no tubo flexível. O estado da arte da análise estrutural de tubos flexíveis do ponto de vista numérico é apresentado e suas principais contribuições são discutidas.

- Capítulo 4 - apresentação do modelo tridimensional desenvolvido em elementos finitos. São indicadas as considerações de modelagem levando em conta a aplicação de hipóteses simplificadoras a fim de diminuir a quantidade de graus de liberdade do problema, tornando-o manuseável. São apresentadas cada uma das camadas estudadas com suas características geométricas e seus parâmetros, propriedades do material, tipos de contatos e malha, condições de contorno e carregamentos. É apresentada a metodologia empregada para a elaboração do trabalho e os estudos paramétricos efetuados.

- Capítulo 5 - São listados e discutidos os resultados das análises paramétricas realizadas. O comportamento do tubo flexível quando submetido aos carregamentos de esmagamento e estrangulamento é caracterizado. Também são apresentadas as regiões de escoamento das camadas metálicas e a ordem de falha das mesmas. Os resultados são apresentados em forma de figuras e tabelas.

- Capítulo 6 - Aqui são indicadas as considerações finais sobre os resultados obtidos e sugestões para trabalhos futuros. 


\section{CARACTERÍSTICAS DO TUBO FLEXÍVEL}

\subsection{Aspectos Gerais}

Os tubos flexíveis são divididos basicamente em duas categorias: tubos de camadas aderentes (bonded) e tubos de camadas não-aderentes (unbonded). A diferença básica entre essas estruturas consiste na interação entre as camadas pois os tubos são fabricados a partir de diferentes processos. Nos tubos de camadas aderentes, estruturas de aço e poliméricas são coladas por meio de um processo de vulcanização. Esse processo faz com que as camadas permaneçam unidas e dependentes umas das outras. Segundo Bai (2014), a flexibilidade é obtida por meio de deformação axial e cisalhante da matriz do elastômero, nas quais os elementos de reforço são embutidos. Os tubos aderentes são utilizados apenas como jumper. Nos tubos não-aderentes, as estruturas são independentes e livres para se movimentarem relativamente umas às outras. Esse movimento, ao longo do tempo, pode gerar desgaste das estruturas. Os tubos não-aderentes são aplicados na exploração em águas profundas e serão analisados neste trabalho.

A estrutura do tubo é projetada para suportar os mais diversos tipos de carregamentos e apresenta resistência a pressões interna e externa, resistência ao colapso, flexibilidade, entre outras características. A linha flexível pode assumir diferentes configurações de acordo com o tipo de carregamento, como indicadas na Figura 3. Mais detalhes sobre a classificação e configurações podem ser encontrados na Norma API 17B [3]. 


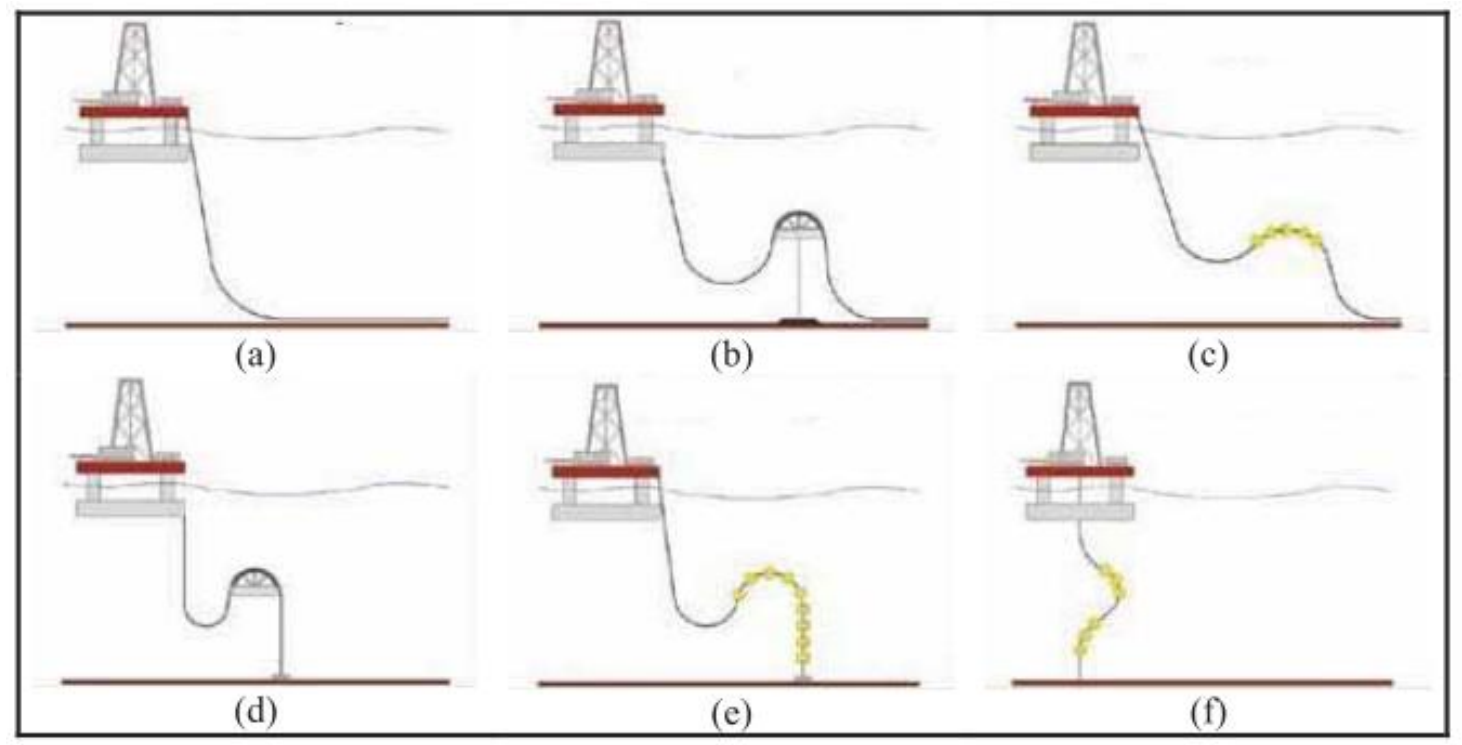

Figura 3 - Principais configurações de linhas flexíveis: (a) Catenária Livre; (b) Lazy S; (c) Lazy Wave; (d) steep S; (e) steep wave e (f) lanterna chinesa [Clausen e D' Souza (2001)].

\subsection{Seção Transversal de um Tubo Flexível Não-aderente}

O tubo flexível não-aderente é formado por diversas camadas concêntricas sequenciais de materiais poliméricos e metálicos com propriedades físicas e características geométricas específicas. São projetados de forma a combinar baixa rigidez flexional e alta rigidez axial. Os tubos flexíveis não-aderentes são divididos em duas categorias: tubos de parede rugosa (rough bore) e tubos de parede lisa (smooth bore). A diferença básica entre essas estruturas é a composição das camadas internas.

Os tubos de parede rugosa apresentam uma estrutura interna helicoidal, a carcaça intertravada, que é usada para transporte de fluido quando há presença de gás. A carcaça intertravada aumenta a rigidez radial do tubo flexível e evita o colapso da camada polimérica interna (liner) quando há queda de pressão abrupta do fluido transportado internamente. Esses tubos são usados para o transporte de uma vasta gama de fluidos e gases.

Os tubos de parede lisa são usados em aplicações em que não há difusão de gás ao longo da camada termoplástica interna, como injeção de água e produtos químicos. Assim, esses tubos possuem as mesmas estruturas do tubo de parede rugosa, exceto pela 
carcaça. A Figura 4 mostra um exemplo dessas duas categorias de tubos. Neste trabalho, o tubo estudado é o de parede rugosa
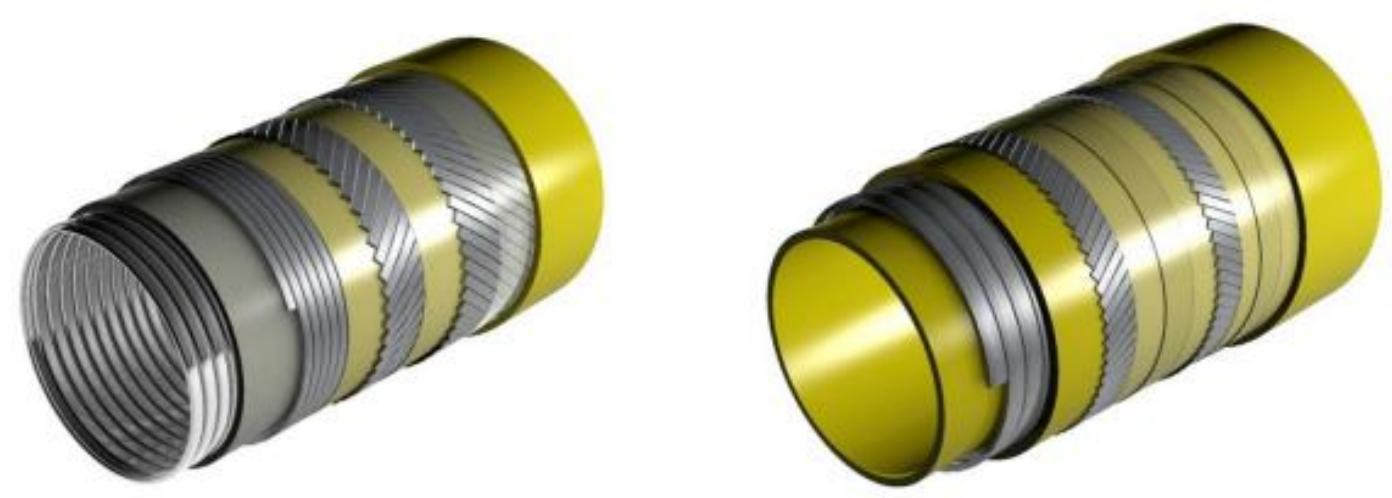

Figura 4 - Tubos flexíveis não-aderentes: (a) Rough bore, (b) Smooth bore [Coelho (2013)].

Como existe uma grande variedade de fabricantes de tubos flexíveis (PRYSMIAN, TECHNIP, GE OIL \& GAS, etc.) com projetos específicos para as áreas exploradas, não há um padrão geral para as camadas internas. Cada fabricante tem suas próprias especificidades com relação às geometrias, aos materiais e às camadas, que variam conforme os critérios de projeto e aplicação. Um modelo de tubo flexível não-aderente e suas principais camadas é apresentado na Figura 5. 


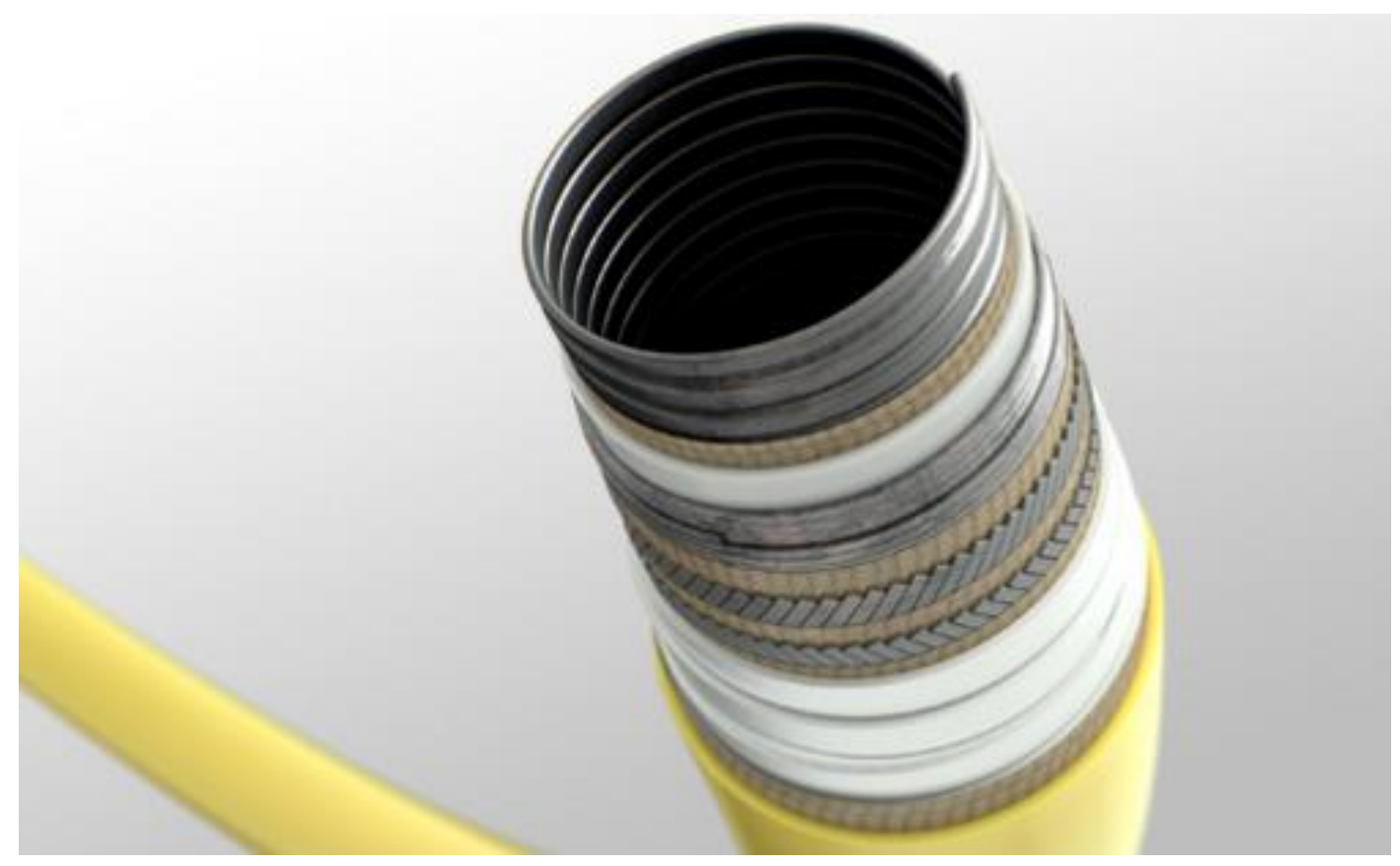

Figura 5- Tubo flexível não-aderente [15].

As camadas poliméricas e metálicas são as estruturas principais do tubo não-aderente. As camadas poliméricas desempenham função de vedação, conferindo estanqueidade à linha, enquanto que as camadas metálicas são formadas por perfis helicoidais e exercem função estrutural. Os polímeros apresentam grande diversidade no que concerne ao comportamento mecânico e, por isso, as camadas poliméricas refletem essa característica de acordo com a função que cada estrutura deve desempenhar. As principais camadas poliméricas são as fitas antidesgaste, as fitas de reforço à compressão, as camadas isolantes e as camadas poliméricas interna e externa. A Norma API 17J [4] apresenta com detalhes informações sobre função, materiais e requerimentos de projeto e fabricação do tubo flexível de camada não-aderente.

A Tabela 1 apresenta uma breve descrição dos materiais usuais, a função estrutural de cada camada e alguns dos critérios de projeto a serem considerados de acordo com a Norma API 17J e o tese de doutorado de Sousa (2005). O perfil usual de cada uma dessas estruturas, com exemplo de material e função, é indicado na Figura 6. Essas camadas serão explicadas com mais detalhes nos próximos subcapítulos. 
Tabela 1 - Descrição das camadas com suas respectivas funções e critérios de projeto.

\begin{tabular}{|c|c|c|c|}
\hline Camada & Material & Função & $\begin{array}{l}\text { Principais Critérios de } \\
\text { Projeto a serem consi- } \\
\text { derados }\end{array}$ \\
\hline $\begin{array}{l}\text { Carcaça inter- } \\
\text { travada }\end{array}$ & $\begin{array}{l}\text { - Aço Carbono } \\
\text { - Aço inoxidável ferrítico } \\
\text { - Aço inoxidável duplex } \\
\text { - Aços-liga com alto teor } \\
\text { de níquel }\end{array}$ & $\begin{array}{l}\text { - Resistência ao co- } \\
\text { lapso } \\
\text { - Resistência à abrasão }\end{array}$ & $\begin{array}{l}\text { - Colapso } \\
\text { - Erosão e corrosão } \\
\text { - Fadiga }\end{array}$ \\
\hline $\begin{array}{l}\text { Camada poli- } \\
\text { mérica interna }\end{array}$ & $\begin{array}{l}\text { - Nylon } 11 \\
\text { - HDPE (polietileno de } \\
\text { alta densidade) } \\
\text { - } P V D F \text { ( fluoreto de po- } \\
\text { livinilideno) }\end{array}$ & $\begin{array}{l}\text { - Estanqueidade à li- } \\
\text { nha } \\
\text { - Transmissão de es- } \\
\text { forços radiais }\end{array}$ & $\begin{array}{l}\text { - Variações de pressão e } \\
\text { temperatura } \\
\text { - Deformações resultan- } \\
\text { tes da flexão }\end{array}$ \\
\hline $\begin{array}{l}\text { Armadura de } \\
\text { pressão }\end{array}$ & $\begin{array}{l}\text { - Aço carbono de alta re- } \\
\text { sistência }\end{array}$ & $\begin{array}{l}\text { - Resistir a cargas radi- } \\
\text { ais resultantes de } \\
\text { pressões interna e ex- } \\
\text { terna }\end{array}$ & $\begin{array}{l}\text { - Resistência radial } \\
\text { - Controle de gaps entre } \\
\text { os arames }\end{array}$ \\
\hline $\begin{array}{l}\text { Camada anti- } \\
\text { desgaste }\end{array}$ & $\begin{array}{l}\text { - HDPE } \\
\text { - Nylon } 11 \\
\text { - Nylon } 12\end{array}$ & - Estanqueidade & $\begin{array}{l}\text { - Desgaste devido ao } \\
\text { movimento relativo en- } \\
\text { tre as camadas }\end{array}$ \\
\hline $\begin{array}{l}\text { Fitas de re- } \\
\text { forço à com- } \\
\text { pressão }\end{array}$ & $\begin{array}{l}\text { - Fibras de aramida } \\
\text { (Kevlar })\end{array}$ & $\begin{array}{l}\text { - Prevenir instabili- } \\
\text { dade das armaduras } \\
\text { (birdcaging) }\end{array}$ & $\begin{array}{l}\text { - Desgaste devido ao } \\
\text { movimento relativo en- } \\
\text { tre as camadas }\end{array}$ \\
\hline $\begin{array}{l}\text { Camadas iso- } \\
\text { lantes }\end{array}$ & $\begin{array}{l}\text { - Polipropileno (PP) } \\
\text { - PU (poliuretano) } \\
\text { - PVC (policloreto de vi- } \\
\text { nila) }\end{array}$ & - Isolamento térmico & $\begin{array}{l}\text { • Perda e retenção de ca- } \\
\text { lor }\end{array}$ \\
\hline $\begin{array}{l}\text { Armadura de } \\
\text { Tração }\end{array}$ & $\begin{array}{l}\text { - Aço carbono de alta re- } \\
\text { sistência }\end{array}$ & $\begin{array}{l}\text { - Resistência às cargas } \\
\text { axiais } \\
\text { - Resistência à pressão } \\
\text { interna }\end{array}$ & - Resistência axial \\
\hline $\begin{array}{l}\text { Camada plás- } \\
\text { tica externa }\end{array}$ & $\begin{array}{l}\text { - HDPE } \\
\text { - Nylon } 11 \\
\text { - Nylon } 12\end{array}$ & $\begin{array}{l}\text { - Proteger a linha con- } \\
\text { tra abrasão e corrosão } \\
\text { - Isolamento térmico }\end{array}$ & $\begin{array}{l}\text { - Flexão do tubo } \\
\text { - Elongação axial } \\
\text { - Cargas de instalação }\end{array}$ \\
\hline
\end{tabular}

Esse trabalho se concentrará na análise das camadas metálicas presentes no núcleo estrutural do tubo flexível, que é composto pela carcaça intertravada, camada polimérica interna e armadura de pressão. A camada polimérica externa é posteriormente adicionada às camadas do núcleo estrutural em um dos casos de estudo analisados. 

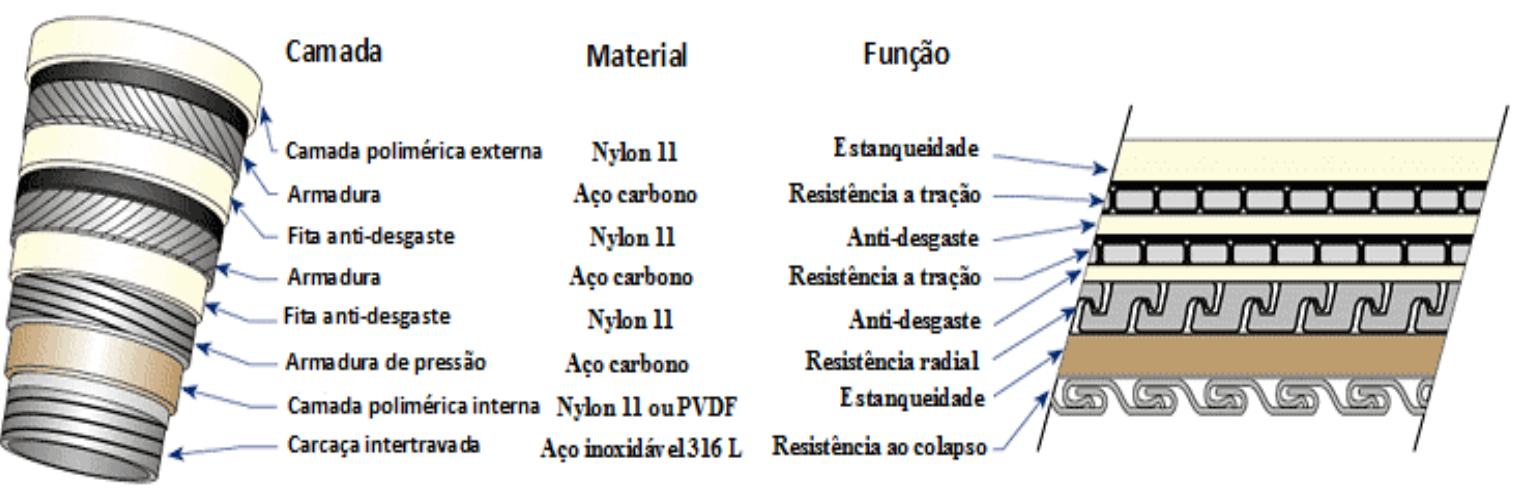

Figura 6 - Perfis das diversas camadas do tubo flexível com indicação da função e material [1].

\subsubsection{Carcaça Intertravada}

Esta é, geralmente, a camada mais interna do tubo flexível. É formada por um perfil metálico enrolado em formato helicoidal ao longo do eixo longitudinal do tubo. Sua construção é feita por meio do intertravamento de fitas de aço de pequeno passo de forma a se manter a flexibilidade da estrutura. A presença de folgas entre as fitas faz com que essa camada seja permeável ao transporte de fluidos. Como sua estrutura não apresenta vedação para evitar o vazamento de fluidos, é necessário que se tenha uma capa polimérica extrudada sobre ela para conferir estanqueidade.

Seu material geralmente é aço inoxidável e sua fabricação se dá por meio da conformação do aço a frio em formato de 'S' como indicado na Figura 7. Os principais aços usados nessa camada estão especificados na Norma API 17 B e são listados abaixo:

- Aços carbono;

- $\quad$ Aços inoxidáveis ferríticos (AISI 490 e 430);

- $\quad$ Aços austeníticos (AISI 304, 304L, 316, 316L);

- $\quad$ Aços inoxidáveis de alta liga (DUPLEX UNS S31803);

- $\quad$ Aços-liga com níquel (N08825). 
De acordo com King, Palmer e Roger (2008), o material é enrolado em torno de um mandril para formar um tubo contínuo, porém flexível. A carcaça é ainda eletricamente isolada das extremidades a fim de se evitar corrosão galvânica.

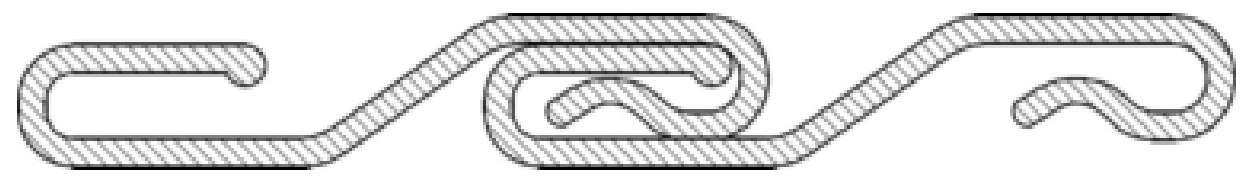

Figura 7- Perfil da carcaça intertravada (Fonte: API 17B [3]).

As principais funções dessa camada são:

- $\quad$ Prevenir o colapso da camada polimérica interna quando há queda abrupta da pressão interna do fluido;

- Prevenir o colapso resultante de carregamentos radiais como o estrangulamento e esmagamento;

- Resistência à abrasão.

Alguns requisitos importantes a serem considerados durante o projeto dessa camada são:

- A previsão do colapso com a indicação das cargas de operação máximas e mínimas, da ovalização e da flexão do tubo dentro do raio de curvatura permitido;

- $\quad$ Avaliação da fadiga nas fitas de aço;

- Verificação de propagação de trincas ao longo da fita de aço devido a carregamentos flexionais induzidos no intertravamento;

- $\quad$ Análise de cargas induzidas por expansão e contração térmica;

- Investigação da abrasão e corrosão.

Diferentes tipos de aço podem ser usados para o perfil da carcaça intertravada e a característica do material depende das propriedades do fluido escoado. Ao escoar, o fluido 
entra em contato direto com a carcaça e, portanto, essa camada tem que ser resistente à corrosão. Dentre as principais funções da carcaça indicadas anteriormente, podemos destacar a importância na resistência ao colapso devido à pressão hidrostática e a resistência à abrasão devida às partículas presentes no fluido.

\subsubsection{Camada Polimérica Interna}

Também conhecida como liner, sua montagem no tubo flexível é feita, usualmente, pela extrusão sobre a carca intertravada. Suas principais funções são a vedação da linha flexível e a diminuição do atrito entre a carcaça e a armadura de pressão. $O$ fator limitante da vida operacional da camada polimérica é a sua degradação resultante do contato direto com hidrocarbonetos. A escolha do polímero depende da temperatura de serviço. Segundo King, Palmer e Roger (2008), em baixas temperaturas, usam-se os materiais $H D P E$ e $N y l o n ~ 11$, que são viáveis até temperaturas em torno de $65^{\circ} \mathrm{C}$ a $95^{\circ} \mathrm{C}$. O limite preciso dessas temperaturas depende dos detalhes de fabricação. Para altas temperaturas (acima de $130^{\circ} \mathrm{C}$ ) é necessário que se tenha um material que seja estável termicamente. Materiais viáveis nessas condições são polímeros fluorados como polivinil difluorido (PVDF). A Norma API 17 B ainda lista, como possíveis materiais, o Nylon 12 e o polietileno reticulado (XLPE). De acordo com Sousa (2005), essa camada deve ser feita com polímeros com propriedades termoplásticas extrudáveis, flexíveis e estabilizadas quanto ao calor, impacto e desgaste.

A espessura da camada polimérica interna é função de vários parâmetros, como a temperatura do fluido de operação, sua composição e pressão. De acordo com Bai (2014), a espessura média dessa camada varia entre 5 a $8 \mathrm{~mm}$, mas também são fabricadas com espessura de até $13 \mathrm{~mm}$. 


\subsubsection{Armadura de Pressão}

Essa estrutura é muito comum em tubos que trabalham com altas pressões internas; pode haver mais de uma camada desse tipo de acordo com a aplicação. A armadura de pressão é feita com arames enrolados em formato de hélice, com alto ângulo de assentamento, em torno de $90^{\circ}$ em relação ao eixo longitudinal do tubo. Braestrup et al (2005) dão detalhes do processo de fabricação dessa camada, que se dá pela pré-conformação dos arames durante sua fabricação. Isso proporciona o encaixe dessa camada no diâmetro externo da capa polimérica interna, com o mínimo de rigidez flexional residual. As folgas existentes nessa camada e na carcaça intertravada devem ser controladas a fim de se evitar o travamento. A Figura 8 apresenta alguns dos perfis usuais para a armadura de pressão. De acordo com Bai (2014), o perfil da armadura de pressão é escolhido de modo a evitar extrusão da camada polimérica interna.

Suas principais funções são suportar carregamentos externos e internos radiais: cargas de esmagamento (crushing), cargas de estrangulamento (squeezing) e também cargas de pressão hidrostática. Além disso, tem a função estrutural de suportar a camada polimérica interna. Dessa forma, a armadura de pressão é projetada para resistir a esforços que a carcaça intertravada não suportaria, aumentando assim a resistência ao colapso do tubo. O comportamento da armadura de pressão e da carcaça, quando sujeitos a cargas de esmagamento, depende do limite ao escoamento e da rigidez flexional do tubo.

O material usado para a fabricação dessa camada é usualmente aço carbono. Dependendo da aplicação, podem ser usados aços com alto, médio ou baixo teor de carbono. A escolha do teor de carbono dessa camada depende do ambiente em que o tubo flexível vai operar. Segundo Sousa (2005), aços com alto teor de carbono são usados em ambientes que exigem alta resistência mecânica do tubo. Em condições agressivas de funcionamento, a melhor escolha são aços com baixo e médio teor de carbono. 


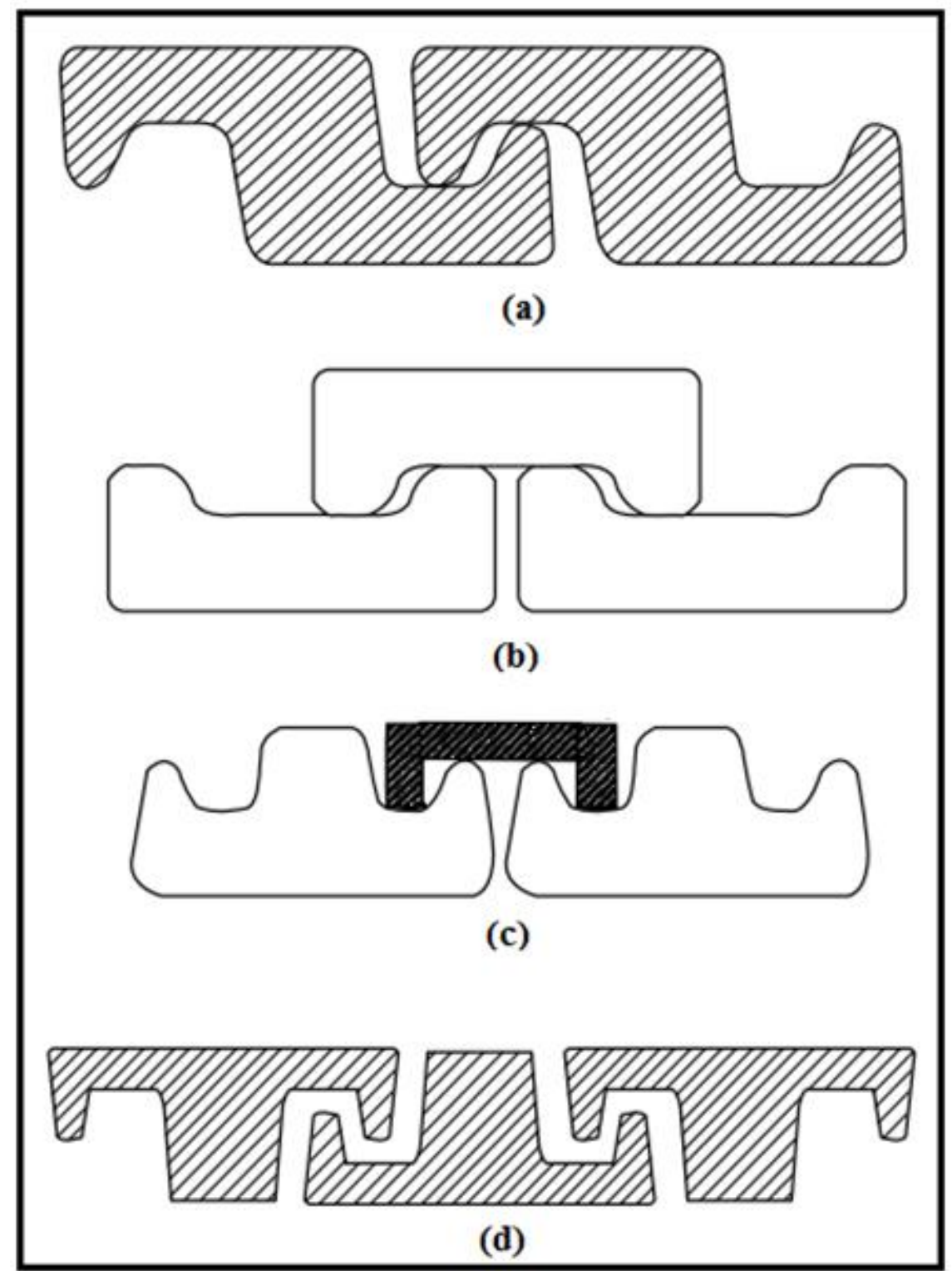

Figura 8- Alguns perfis da armadura de pressão: (a) Perfil zeta, (b) Perfil C, (c) Perfil T (grampo de ligação) e (d) Perfil T (API 17B [3]).

\subsubsection{Camadas Antidesgaste}

$\mathrm{O}$ atrito entre as camadas dos tubos flexíveis não-aderentes é um problema recorrente, uma vez que as estruturas são construídas de modo que sejam livres para deslizarem umas sobre as outras. Com o objetivo de minimizar esse atrito, são usadas camadas poliméricas antidesgaste. Usualmente, são extrudadas entre a armadura de pressão e a armadura de tração interna, bem como entre as armaduras de tração. O objetivo é diminuir o 
desgaste dos arames quando eles entram em contato, como resultado dos carregamentos externos, diminuindo então a falha por fadiga. Fitas antidesgaste também podem ser usadas para certificar que as armaduras permanecerão na posição do assentamento. Além disso, essas camadas também conferem estanqueidade ao vazamento de fluidos internos. Os materiais recomendados pela API 17 B para essas estruturas são o polietileno de alta densidade (HDPE), polietileno reticulado (XLPE), Nylon 11, Nylon 12 e o polivinil difluorido (PVDF).

\subsubsection{Fitas de Reforço a Compressão}

Em virtude das altas profundidades de trabalho dos tubos flexíveis, a compressão axial pode se tornar um esforço relevante. Essa compressão pode levar os arames das armaduras de tração à instabilidade, causando o fenômeno conhecido como birdcaging, ou gaiola de passarinho.

As fitas de reforço são feitas de polímero altamente resistente, sendo frequentemente usada a fibra de aramida - Kevlar. Essas fitas são posicionadas sobre a armadura de tração interna, com o objetivo de melhorar a rigidez do tubo flexível à compressão.

\subsubsection{Camadas Isolantes}

Apesar de os tubos flexíveis apresentarem propriedades térmicas melhores que as dos tubos rígidos, isolantes térmicos adicionais podem ser necessários em grandes profundidades. Dentre as condições extremas de operação dos tubos flexíveis em águas profundas, as baixas temperaturas podem ser um fator limitante. As camadas isolantes são, então, usadas na redução das perdas térmicas do fluido através do tubo.

As fitas isolantes são compostas de material térmico isolante, como o policloreto de vinila (PVC), polipropileno (PP) e o poliuretano (PP). São enroladas em torno das 
armaduras de tração e ficam posicionadas entre a armadura externa de tração e a camada polimérica externa.

\subsubsection{Armadura de Tração}

São compostas, normalmente, em números pares de camadas de armaduras enroladas em sentidos contrários. São definidas como armadura interna e externa de tração de acordo com o posicionamento em relação à linha, mais interno ou externo. Usualmente, a estrutura apresenta duas camadas, mas para aplicação em ambientes de alta pressão pode ser necessário o uso de quatro camadas. As armaduras de tração são feitas tipicamente de um arame retangular enrolado em formato helicoidal e conformados sobre uma base estrutural que serve de suporte. Os ângulos de assentamento são, normalmente, na faixa de $30^{\circ}$ e $55^{\circ}$ em relação ao eixo longitudinal do tubo. Para ângulos de assentamento de $55^{\circ}$, têm-se linhas mais resistentes à torção.

Essas camadas são fabricadas, assim como a armadura de pressão, com aço carbono. O teor de carbono depende das condições de aplicação. São frequentemente usados os aços com alto teor de carbono em função das elevadas tensões que surgem nessas estruturas durante a operação. A armadura de tração tem a função de resistir a cargas radiais, axiais e também conferir rigidez à torção ao tubo flexível.

\subsubsection{Camada Plástica Externa}

Essa camada protege as armaduras do contato com a água, evitando, assim, a corrosão e abrasão da linha. A camada plástica externa também é extrudada sobre as armaduras. O material mais usado em sua fabricação é o polietileno de alta densidade (HDPE) em virtude das boas propriedades de adesão, extensibilidade, resistência à abrasão, resistência elétrica e de baixa absorção de água. Além disso, pode ainda ser usado como material de fabricação o polietileno de média densidade (MDPE), o Nylon 11 e o Nylon 12. 
As poliamidas são usadas em aplicações dinâmicas devido a sua alta resistência. O MDPE, no entanto, é usado em aplicações estáticas.

\subsection{Normas Técnicas para Projeto e Operação dos Tubos Flexíveis}

Para que os tubos flexíveis possam operar com adequado nível de segurança, é necessário que sejam atendidos critérios de projeto, fabricação e de operação. Diversas entidades estabelecem normas que definem os padrões de qualidade dos tubos flexíveis: American Petroleum Institute (API), International Organisation for Standardization (ISO), Petróleo Brasileiro S.A. (Petrobrás) e a Det Norske Veritas (DNV). Algumas Normas da API e Petrobrás são citadas com recorrência nesse trabalho, destacando-se:

- API RECOMENDED PRACTICE 17B: Aborda aspectos gerais dos tubos flexíveis. Informações sobre aplicações, descrição dos componentes, considerações de projeto, transporte e instalação são apresentadas, entre outros tópicos.

- ANSI/API SPECIFICATION 17J: Essa norma define os critérios para especificação de tubos flexíveis de camadas não-aderentes. Requisitos fundamentais, como materiais usados, condições de funcionamento, projeto e fabricação, são abordados com detalhes.

- $\quad$ N-2409 PETROBRAS: Essa norma traz uma compilação de regulamentos da ISO, API, ASTM (American Society for Testing and Materials) e ASME (American Society of Mechanical Engineers) para definição de padrões de operação dos tubos flexíveis. Especificações sobre a ovalização, fatores de utilização das camadas, entre outros itens são listados nessa norma.

No Capítulo 3, serão explicados detalhadamente os critérios da norma N-2409 aplicados nesse trabalho para análise da falha das camadas metálicas do núcleo estrutural. 


\subsection{Instalação do Tubo Flexível}

A instalação das linhas flexíveis é uma das etapas mais difíceis da sua vida operacional. É a etapa crítica para a configuração flowline. Os vários esforços atuantes na estrutura incluem, além dos esforços dinâmicos, o peso próprio da linha e cargas compressivas radiais. A instalação é feita por meio de navios lançadores, como o indicado na Figura 9. São várias as metodologias de lançamento. As mais comumente usadas em águas profundas são a S-lay, J-lay e reeling-lay. Bai (2014) apresentam com detalhes os métodos de lançamento e suas vantagens e desvantagens.

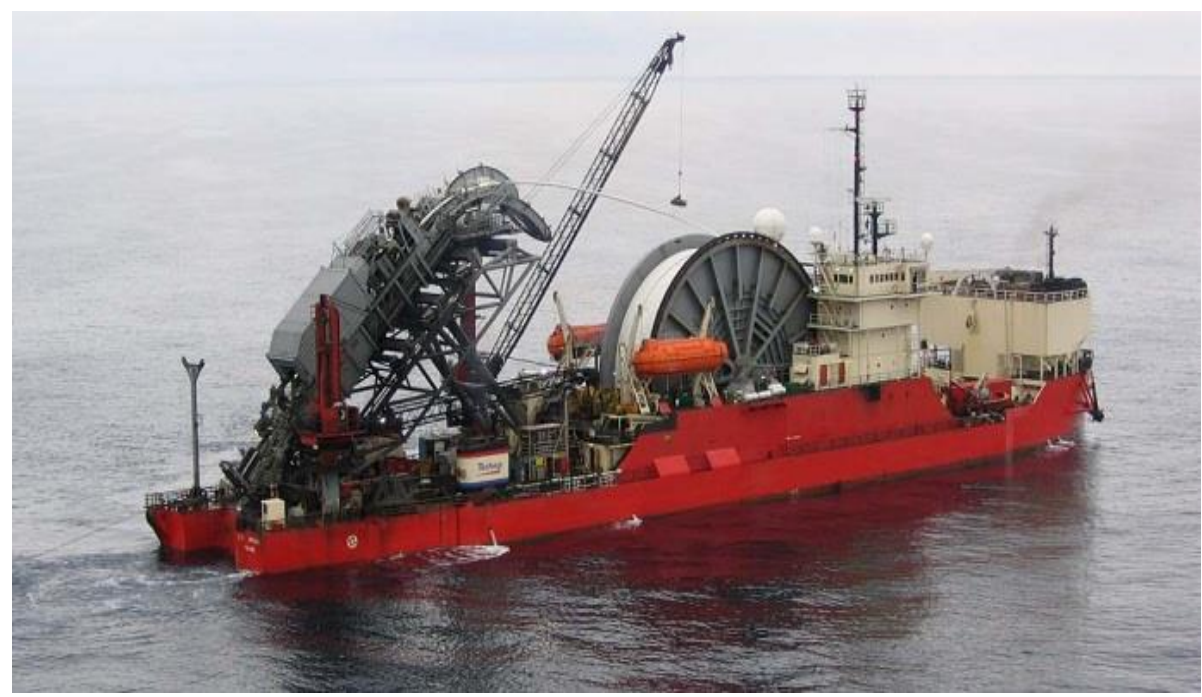

Figura 9- Navio Lançador [2].

O método S-lay leva esse nome pelo formato de 'S' do tubo flexível entre a plataforma e o fundo do mar durante o lançamento, como indicado na Figura 10. O tubo é suportado por uma estrutura circular, que pode ser flutuante ou não, equipada com roletes e conhecida como stinger (ou rampa de lançamento). O objetivo do stinger é controlar a flexão do tubo durante o lançamento, e sua curvatura corresponde ao momento de flexão máximo. Esse método é muito usado para o lançamento de linhas flexíveis em águas profundas. 


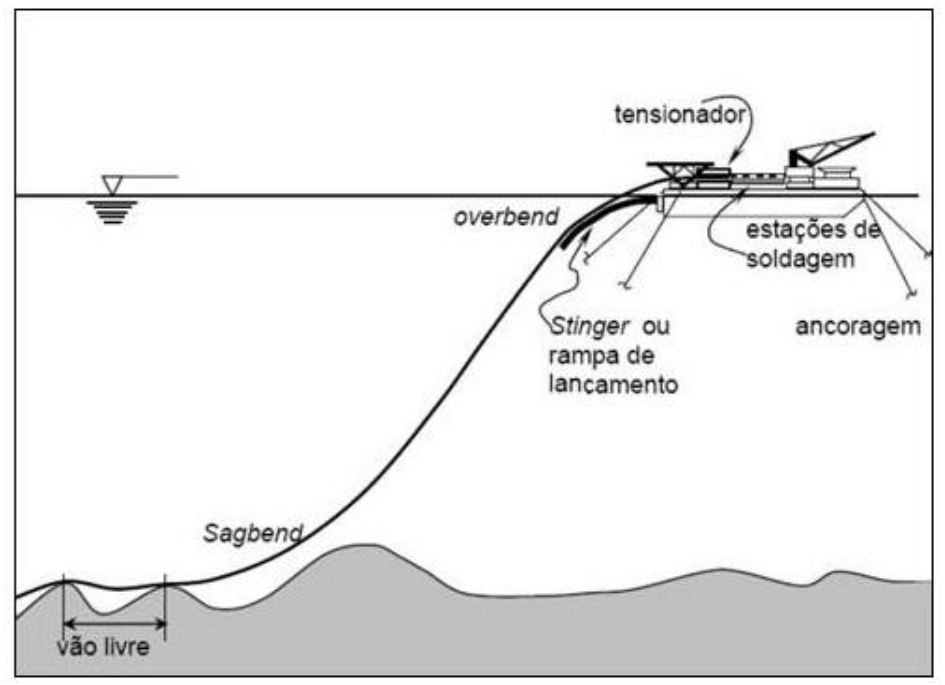

Figura 10-Método de Instalação S-Lay [29].

O método J-lay é assim chamado pela configuração do tubo durante o lançamento em formato de J, como indicado na Figura 11.

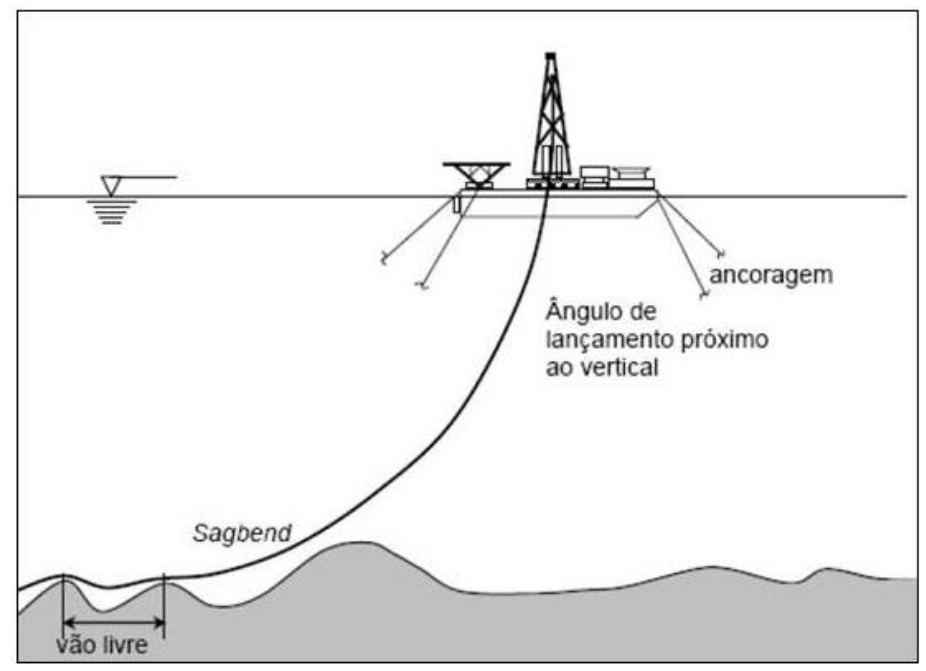

Figura 11 - Método de Instalação J-Lay [29].

O método Reel-lay, indicando na Figura 12, é a técnica mais recente de lançamento entre todos aqui apresentados. A vantagem desse método é que podem ser lançados 
tubos de grandes comprimentos por meio de carretéis e rodas de lançamento. Esse método é relativamente mais rápido que os outros.

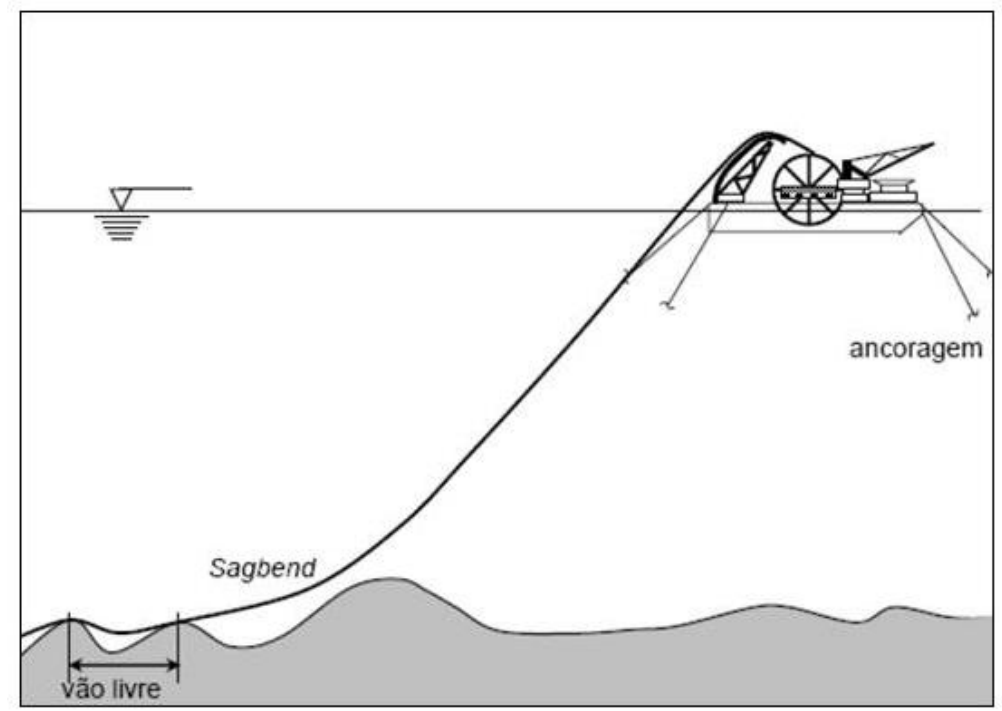

Figura 12-Método de Instalação Reel-Lay [29].

Segundo Sousa (2005) e Cruz (1996), os principais equipamentos de um navio de lançamento são:

- Tracionadores lineares esses tracionadores são equipamentos que podem apresentar de duas a quatro lagartas (caterpillars) de lançamento (detalhados na seção seguinte). Cada lagarta se movimenta radialmente de forma a regular sua posição com a do tubo flexível. Essas estruturas aplicam cargas radiais através de sapatas e sustentam o peso próprio da linha por meio do atrito. Também são dispostas em esteiras rolantes, denominadas lagartas e aparecem no formato de "U" ou de "V".

- Espaço para armazenamento das linhas flexíveis: podem ser cestas rotativas com eixo vertical ou carretéis com eixos horizontais. As cestas são maiores e mais usuais no lançamento de linhas flexíveis. 
- $\quad$ Sistema de posicionamento dinâmico: tem a função de manter a posição sobre a trilha de lançamento. Também podem ser usados para inspeção da linha flexível no fundo do mar e monitoramento das operações.

- $\quad$ Equipamentos para manuseio de tubos: roldanas e roletes para passagem das linhas, guinchos, guindastes, entre outros.

\subsubsection{Cargas de Instalação da Linha Flexível}

A expansão da exploração de petróleo em lâminas d'água, cada vez mais profundas, representa grandes desafios ao projeto dos tubos flexíveis e à instalação dessas estruturas. O tubo flexível é submetido a vários carregamentos durante seu lançamento, inclusive o seu próprio peso. Com isso, o aumento do peso da linha quando lançada em águas profundas pode comprometer a utilização do tubo ao final do lançamento.

Em todos os sistemas de lançamento descritos anteriormente é necessário que se tenha um equipamento para o controle da descida do tubo flexível - o tensionador. Esse equipamento é responsável pela sustentação do peso próprio do tubo que, por meio do atrito com as sapatas, controla a descida da linha. Essas estruturas possuem lagartas, como indicado na Figura 13, que aplicam pressão aos tubos flexíveis por meio de sapatas que, por sua vez, são movimentados com tração contínua. As lagartas são controladas individualmente e os carregamentos são distribuídos igualmente. Os tensionadores devem ser projetados a fim de atender às variações de diâmetro do tubo, e o controle da pressão aplicada deve ser tal que evite a deformação permanente das camadas.

Os principais carregamentos resultantes da instalação do tubo flexível são indicados abaixo:

- Carregamento axial resultante do peso próprio do tubo e dos movimentos impostos pelo navio de lançamento;

- Flexão durante a passagem pela roda de lançamento (método reel lay); 
- Cargas radiais impostas pelo "colar hidráulico" durante a passagem pela roda de lançamento (método reel lay).

- Carregamentos de compressão radial resultantes das cargas de esmagamento do tubo (crushing) pelas sapatas dos tensionadores e estrangulamento do núcleo do tubo pelas armaduras de tração (squeezing).

De acordo com Sousa (2002), os tensionadores possuem de duas a quatro lagartas, como indicado na Figura 14, com sapatas com ângulos de abertura que variam entre $120^{\circ}$ e $180^{\circ}$.

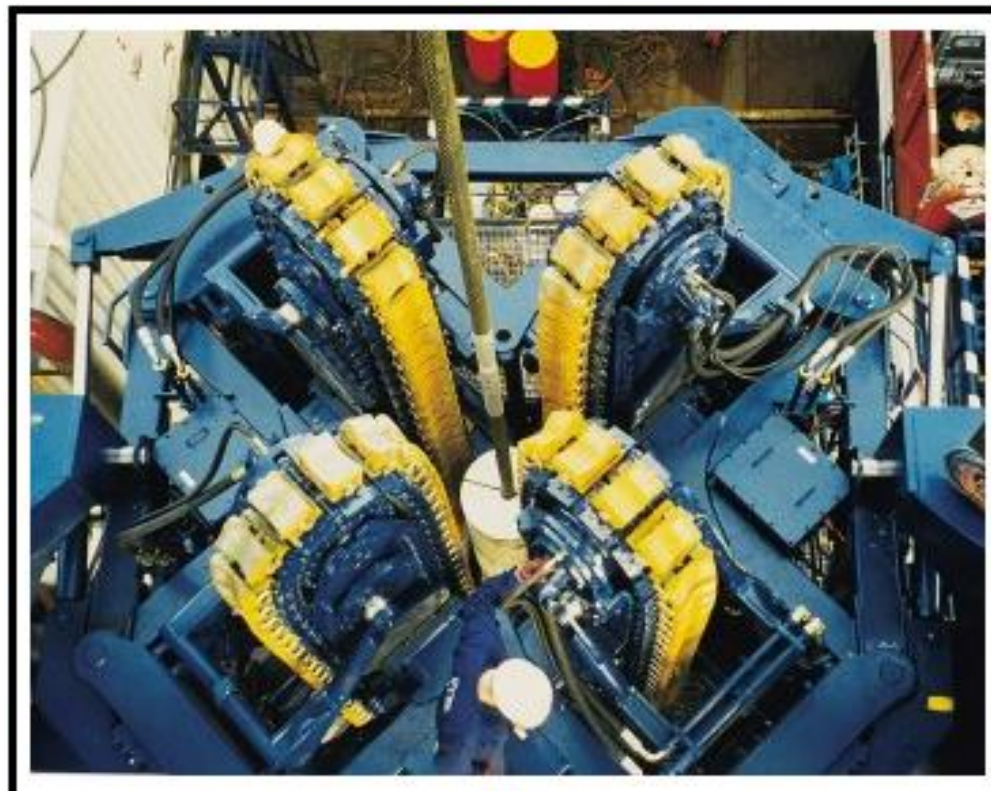

(a)

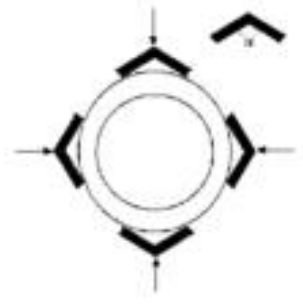

(b)

Figura 13- (a) Tensionador (azul) com sapatas (amarelo) [23]; (b) seção transversal do tubo com as cargas de esmagamento das sapatas [Sousa (2002)]. 


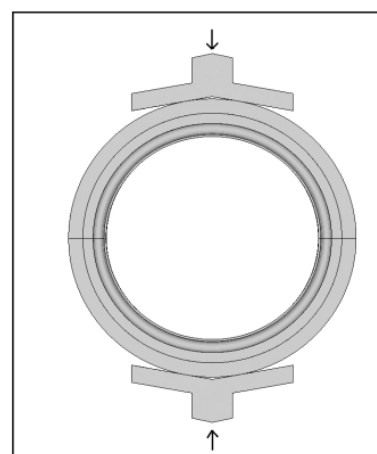

(a)

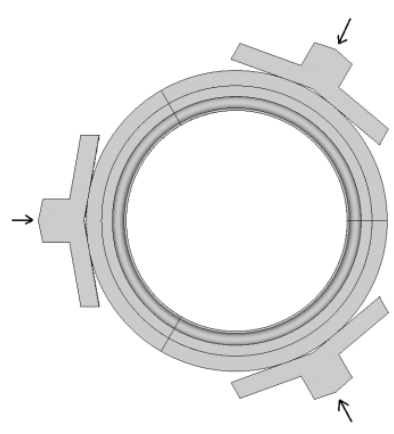

(b)

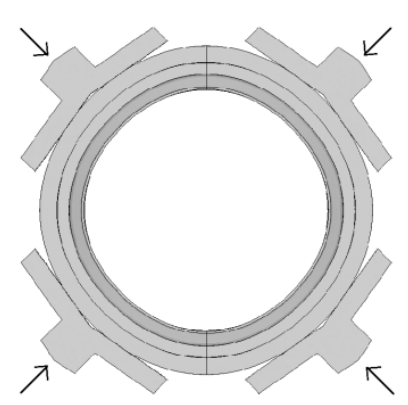

(c)

Figura 14 - Desenho esquemático do tubo flexível sob carregamento: (a) de 2 sapatas; (b) de 3 sapatas; e (c) de 4 sapatas.

Neste trabalho serão feitas análises paramétricas do comportamento do tubo flexível quando submetido aos carregamentos de esmagamento e estrangulamento. Esses esforços são abordados com mais detalhes nas seções seguintes.

\subsubsection{Cargas de Esmagamento (crushing)}

Os carregamentos de esmagamento impostos pelas sapatas dos tensionadores ao tubo flexível têm como função a sustentação do peso próprio da linha quando lançada em alto mar. Essa sustentação se dá por meio do atrito entre o tubo flexível e a sapatas. O comportamento das cargas de esmagamento é explorado e explicado com detalhes por Cruz (1996), Sousa (2001) e Sousa (2002). De acordo com Cruz (1996), a carcaça intertravada e a armadura de pressão são as camadas que apresentam maior resistência ao esmagamento. As camadas poliméricas interna e externa, bem como as armaduras de tração, atuam na transferência desse carregamento. A Figura 15 apresenta um esquema da aplicação e transferência dos carregamentos de esmagamento pelas sapatas dos tensionadores até as camadas mais internas do tubo. 


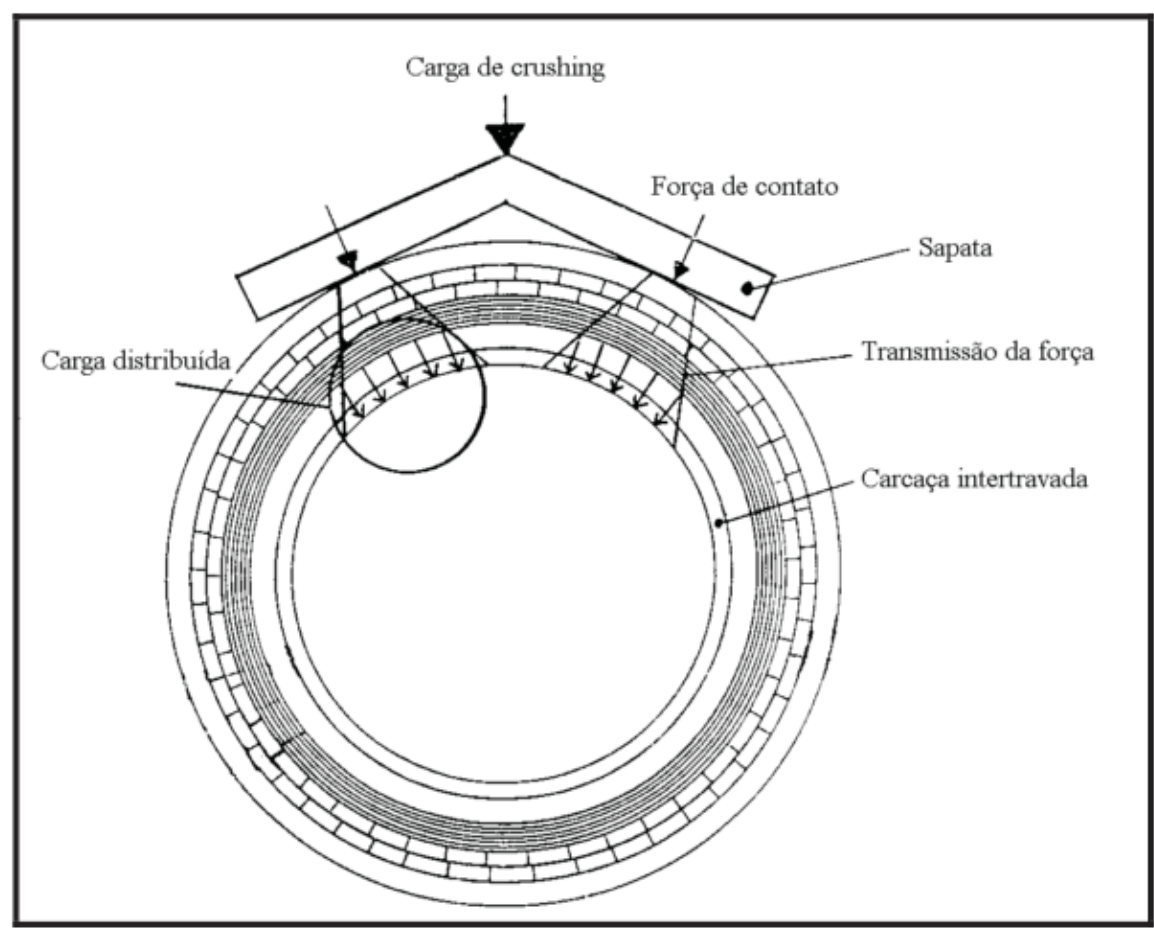

Figura 15 - Ação da carga de esmagamento no tubo flexível descrita por Cruz (1996).

Neste trabalho serão usados vários modelos desenvolvidos em elementos finitos a fim de se analisar parametricamente a resposta das cargas de esmagamento nas camadas do tubo flexível. São levantadas várias perguntas as quais se espera que sejam respondidas com os modelos analisados:

\subsubsection{Cargas de Estrangulamento (squeezing)}

Durante o lançamento, as armaduras de tração são distendidas sobre as camadas a elas internas do tubo flexível, induzindo um carregamento compressivo radial que é conhecido como estrangulamento. Assim, as armaduras de tração atuam estrangulando as camadas internas do tubo. Os carregamentos são transmitidos pelas camadas poliméricas até a carcaça intertravada e a armadura de pressão, que então são estranguladas como ilustrado na Figura 16. Segundo Sousa (2005), os principais efeitos desse carregamento no tubo flexível são: 
- Rompimento dos arames da armadura de tração;

- Colapso mecânico da armadura de pressão e/ ou da carcaça intertravada em função das elevadas cargas.

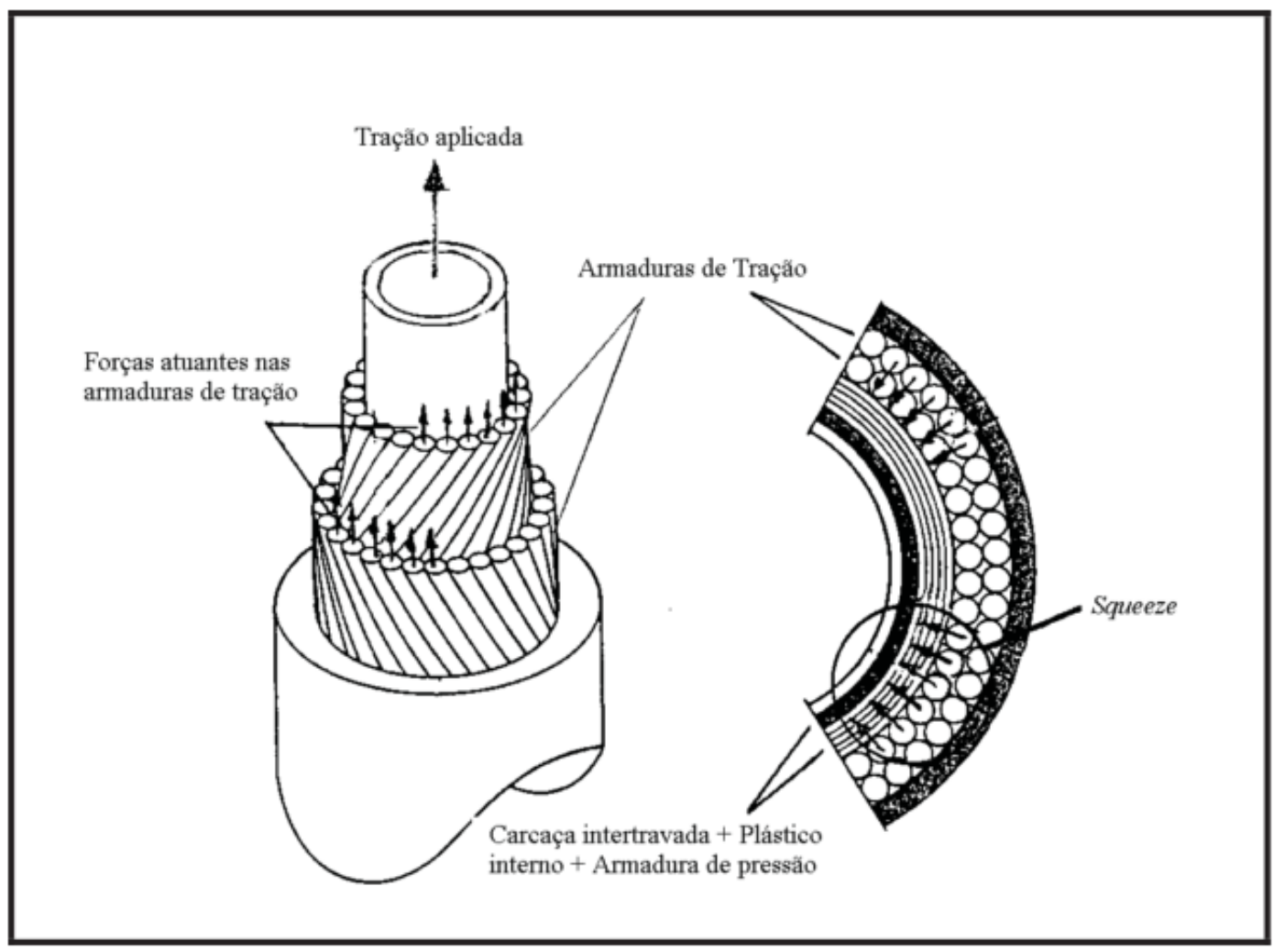

Figura 16 - Efeito do Estrangulamento (squeezing) no tubo flexível descrito por Cruz (1996).

As armaduras de tração não serão representadas nos modelos numéricos apresentados neste trabalho, mas a pressão de estrangulamento será avaliada por meio da distribuição uniforme desse carregamento na superfície externa da camada polimérica externa.

Neste trabalho serão usados vários modelos desenvolvidos em elementos finitos a fim de se analisar parametricamente a resposta das cargas de esmagamento nas camadas do tubo flexível. São levantadas várias perguntas as quais se espera que sejam respondidas com os modelos analisados: 
1. Qual a influência da quantidade de lagartas e do ângulo de abertura das sapatas na distribuição do carregamento e na falha das camadas metálicas?

2. Qual a sequência de falha das camadas metálicas?

3. Como a camada polimérica externa e a variação do seu contato com a sapata pode influenciar na falha do tubo?

4. Qual a influência da rigidez da sapata no escoamento das camadas metálicas?

5. Como as cargas de esmagamento e estrangulamento variam com a profundidade de lançamento e de que maneira afetam estruturalmente as camadas metálicas do tubo?

6. Qual a contribuição do squeezing para a falha do tubo flexível quando comparado ao carregamento de crushing? 


\section{REVISÃO BIBLIOGRÁFICA}

A descoberta das bacias petrolíferas no Golfo do México, no Mar do Norte e no litoral brasileiro fomentou o desenvolvimento da indústria offshore. A necessidade de uma estrutura que apresentasse flexibilidade, estanqueidade e alta resistência para operar em águas profundas representou um grande desafio para esse setor da engenharia. Nesse cenário, os tubos flexíveis despontaram como uma solução para a extração do petróleo. O alto custo de exploração, e as grandes perdas de ordem econômica e ambiental, decorrentes de falhas, estimulou vários pesquisadores a dedicaram seus trabalhos nessa área.

No estado da arte, existem vários trabalhos de caráter analítico, experimental e numérico dedicados à solução de problemas estruturais da linha flexível. Cada uma dessas abordagens pode ser comparativamente mais vantajosa em relação às outras dependendo do problema tratado.

Os trabalhos de natureza analítica remetem à Teoria da Elasticidade a fim de estabelecer o comportamento constitutivo, equilíbrio de forças e relações cinemáticas. Diferenciam-se, basicamente, na formulação e hipóteses levantadas, mas os princípios são equivalentes. São amplamente aplicados em casos nos quais as simplificações adotadas na formulação não afetam os resultados almejados.

Por outro lado, também é encontrada uma série de trabalhos com representação dos tubos flexíveis pelo Método dos Elementos Finitos. A maior vantagem desse método é a possibilidade de tratar não linearidades de materiais, geometrias e contatos. Apesar do alto custo computacional, esse método tem sido amplamente usado, dado que oferece uma maior quantidade de informações sobre o comportamento das estruturas. Esse será o método abordado nessa dissertação.

Os estudos experimentais também são recorrentes, e utilizados para fins comparativos com resultados numéricos e analíticos. A maior dificuldade desse método reside no alto custo dos aparatos necessários para reproduzir os casos investigados. 
Os textos estudados são de natureza analítica, numérica, analítico-numérica e numérico-experimental. Diante da vasta quantidade de publicações no assunto, esse capítulo destacará aqueles textos que lidam com o problema das cargas de instalação, principalmente o esmagamento e o estrangulamento, e trabalhos desenvolvidos em elementos finitos que foram relevantes para construção do modelo estudado nesta dissertação:

a) Féret e Bournazel (1987) apresentam uma metodologia analítica para o estudo local de tubos flexíveis não-aderentes submetidos a carregamentos axissimétricos como forças e momentos axiais e pressões internas e externas. Esse trabalho foi um dos primeiros a tratar do comportamento estrutural do tubo flexível. Tornou-se, portanto, uma contribuição importante para muitos estudos subsequentes.

Hipóteses simplificadoras foram adotadas para tratar do contato entre as camadas, e a função das camadas plásticas. Com isso, foi possível transformar o modelo proposto em uma ferramenta útil para a verificação imediata do comportamento estrutural do tubo.

O comportamento flexional do tubo flexível é abordado pelos autores com um tratamento matemático elegante a partir do uso de uma geodésica para descrever o caminho elástico do tendão. A curva descrita é definida por meio das equações de Euler. São considerados os efeitos de escorregamento entre as camadas, mudança do ângulo de assentamento e mudança da curvatura do perfil. Com isso, os autores preveem o cálculo do raio de contato dos tendões, crucial para previsão de fadiga. A ferramenta analítica também permite a análise da variação da tensão e coeficiente de atrito em virtude das mudanças de tensão quando há cargas dinâmicas.

Este trabalho é frequentemente referenciado na literatura, seja para fins comparativos como Sousa et al. (2001) ou até mesmo para deduzir novas ferramentas analíticas. Assim o fazem Martins, Pesce e Aranha (2003), para o cálculo do estrangulamento do tubo pelas armaduras de tração.

b) Martins, Pesce e Aranha (2003) propõem uma metodologia analítica para a investigação do comportamento estrutural da carcaça intertravada quando submetida a carregamentos de esmagamento. Os autores apresentam um tratamento analítico meticuloso 
do problema. São usadas funções de forma e séries de Fourier para obtenção dos carregamentos, além da análise de instabilidade por meio do parâmetro adimensional de carga. Há também a previsão do carregamento de estrangulamento imposto ao tubo pelas armaduras de tração. O cálculo do carregamento de estrangulamento é derivado do modelo analítico de Féret e Bournazel (1987).

c) Ramos (2001) apresenta em sua tese de doutorado uma metodologia analítica generalista para análise estrutural de tubos flexíveis e umbilicais. O equacionamento de vários carregamentos combinados tais quais torção, flexão e tração são tratados por meio da teoria da elasticidade e das equações de Love para barras curvas. Hipóteses simplificadoras são adotadas e o atrito não é tratado. Por meio deste trabalho é possível obter a pressão de contato entre as camadas resultante do estrangulamento imposto às mesmas pelas armaduras de tração. O cálculo da pressão de squeezing apresentada na metodologia desta dissertação se baseia neste trabalho, que será tratado no Apêndice B.

d) Ramos e Pesce (2004) apresentam um trabalho derivado da tese de Ramos (2001) para o cálculo das tensões e deformações em várias camadas dos tubos flexíveis. Com isso são determinadas as rigidezes axial, torcional e flexional do tubo. São tratadas quatro configurações do tubo flexível submetido a diferentes carregamentos. Duas delas são a configuração deformada e não deformada do tubo flexível, sem carregamento e com aplicação de cargas axissimétricas, respectivamente. As outras duas configurações são utilizadas para a análise da rigidez flexional do tubo, no qual são aplicados momentos flexionais considerando a ausência e presença de deslizamento da armadura de tração em relação às camadas adjacentes. O cálculo da rigidez flexional obtido pelo método analítico é então comparado a resultados experimentais presentes na literatura, indicando a viabilidade do método matemático.

e) Sousa et al. (2001) se destacam entre os primeiros autores a tratarem do problema das cargas em instalação em tubos flexíveis a partir de modelos numéricos. Cargas essas que requerem atenção quando os tubos são lançados em altas profundidades. Para isso, os autores desenvolveram um modelo tridimensional em elementos finitos a fim de analisar carregamentos de tração e esmagamento. Toma-se, para fins comparativos, o modelo 
analítico de Féret e Bournazel (1987) para o cálculo das tensões axiais e ensaios experimentais de esmagamento realizados na Petrobras. O peso próprio do tubo e o esmagamento imposto pelo sistema de tensionamento são indicados como os principais carregamentos de instalação. Os autores ainda mencionam o estrangulamento do tubo pelas armaduras de tração. No entanto, não o incluem na investigação.

O modelo tridimensional é composto pela carcaça intertravada, armadura de pressão, armaduras de tração e pelas camadas plásticas. A fim de simplificar a geometria da carcaça e da armadura de pressão foram adotadas camadas equivalentes. A mesma rigidez do tubo real é considerada no modelo numérico para o cálculo da espessura equivalente. Essa simplificação, no entanto, requer correções nas propriedades físicas dos materiais e nas tensões registradas nas camadas.

São usados elementos de viga para as armaduras de tração e elementos de casca para todas as outras camadas. O comportamento não-linear do problema é registrado pela representação dos contatos entre as camadas. Os contatos entre as camadas metálicas e plásticas, e entre as armaduras de tração interna e externa foram representados com comportamentos distintos. Enquanto o primeiro permite o escorregamento entre as camadas, o segundo só representa a compressão, levando a rigidez dos elementos a zero quando em tração.

Apesar das simplificações adotadas no modelo analítico de Féret e Bournazel (1987), o resultado das tensões axiais apresenta valores próximos aos numéricos. Para o ensaio experimental são tomadas duas amostras: a primeira apenas com a carcaça e a camada polimérica interna, e a outra com todas as camadas do tubo. O trabalho apresenta resultados relevantes para se entender a resistência das camadas quando submetidas ao esmagamento, apesar de o modelo em elementos finitos ser de baixa hierarquia. Foi possível identificar a importância não só da carcaça intertravada na resistência aos carregamentos radiais como também da armadura de pressão e até mesmo das armaduras de tração. O cuidado em analisar a resistência do tubo flexível ao esmagamento a partir de análise numérica e experimental, e as considerações feitas sobre as cargas de instalação são de grande valor para elaboração da metodologia desta dissertação. 
f) Sousa et al. (2002) tratam do problema do esmagamento durante a instalação dos tubos flexíveis. Para isso, é proposto um modelo analítico para avaliação das tensões nas camadas de pressão sob qualquer quantidade de lagartas e ângulos de abertura das sapatas. Um modelo numérico de baixa hierarquia é apresentado como ferramenta de comparação. Apesar de o modelo analítico partir de hipóteses simplificadoras, são apresentados resultados importantes em relação à rigidez radial do tubo e o comportamento das camadas de pressão.

O modelo analítico proposto pelos autores parte da teoria de vigas de Timoshenko e da reformulação da teoria de Chen, Nielsen e Colquhoun (1992). As simplificações assumidas são: (i) apenas as camadas de pressão resistem às cargas de esmagamento; (ii) as camadas de pressão são representadas como anéis, sem atrito interno; (iii) as cargas de esmagamento são radiais e concentradas; (iv) as camadas plásticas estão sempre em contato com as camadas de pressão; (v) a força total que atua no tubo é igual à soma das forças nas camadas de pressão; (vi) o comportamento do tubo é considerado linear elástico. Adota-se ainda a hipótese de que os deslocamentos da carcaça e da armadura de pressão são iguais. Um modelo numérico bidimensional é usado para fins comparativos. A simetria do carregamento e da estrutura é aproveitada para diminuir o número de graus de liberdade do modelo numérico. Apesar de o atrito entre as camadas não ser representado, não linearidades geométricas são consideradas.

Em relação à rigidez radial, percebe-se que quanto maior o número de lagartas, menor é a tensão e os deslocamentos na carcaça intertravada e na armadura de pressão. Essa proporção ainda é mantida para diferentes ângulos de abertura da sapata. Observase também que a carcaça resiste à maior parte do carregamento aplicado. Os autores também consideram desprezíveis os efeitos da não linearidade geométrica já que os resultados dos deslocamentos radiais do modelo numérico são próximos aos analíticos. Considerando que as camadas não foram representadas com seu perfil real, os efeitos da não linearidade geométrica podem se tornar evidentes nesses casos.

Os resultados alcançados neste trabalho são importantes como uma primeira análise do esmagamento em tubos flexíveis. Representa, portanto, uma referência importante do ponto de vista teórico, para compreensão dos efeitos dos carregamentos de instalação. 
No entanto, como os próprios autores ressaltam, deve-se levar em consideração não linearidades dos materiais e contribuição de outras camadas, além da carcaça e armadura de pressão, na resistência ao esmagamento.

g) Gay Neto, Martins e Pesce (2009) apresentam uma análise numérica-experimental do esmagamento em tubos flexíveis considerando apenas a carcaça como camada resistente. Os autores descrevem o modelo numérico com considerações sobre escolha dos elementos, tipo de contato e seus algoritmos, bem como o comportamento dos materiais. Esse detalhamento é de grande relevância para a formulação de algumas das hipóteses de modelagem dessa dissertação.

Neste trabalho, apenas a carcaça é avaliada no estudo do esmagamento. A camada polimérica interna também é representada, mas apenas com a função de transferir o carregamento. O modelo tridimensional proposto foi baseado no trabalho sobre colapso publicado por Gay Neto e Martins (2009), com o mesmo perfil de carcaça intertravada que, posteriormente, foi usado por Gay Neto et al.(2012). A carcaça é considerada como um anel, com seu perfil real, no entanto o efeito helicoidal é desconsiderado. No trabalho de Gay Neto e Martins (2009), constatou-se que o efeito do passo é desprezível para o colapso da carcaça. Dessa forma, a não representação do efeito helicoidal da carcaça não é considerada crítica para efeitos de estudo do esmagamento.

Em relação ao modelo numérico também são feitas observações importantes sobre a malha da camada polimérica interna que é pouco discretizada em comparação à malha da carcaça. O principal objetivo é evitar penetrações da camada plástica nos vazios da carcaça e, consequentemente, problemas de convergência. As condições de contorno foram adotadas de modo a simplificar o problema, diminuindo o número de graus de liberdade. Dessa forma, como foram usadas duas sapatas, usou-se simetria de meio anel por meio de acoplamento cinemático na região de corte. Além disso, usaram-se restrições nodais a fim de evitar movimentos de corpo rígido. Para se obter uma melhor convergência pelo método de interação Newton-Raphson, os autores escolheram aplicar deslocamentos às sapatas em detrimento de forças. Tal abordagem também condiz com o aparato experimental em que são aplicados deslocamentos incrementais ao tubo. 
O modelo estudado leva em consideração não-linearidades tanto de contatos, geométricas e até mesmo físicas através do comportamento de material adotado. No entanto, a correlação entre os resultados numéricos e experimentais só ocorre no regime linear elástico, sendo o modelo numérico conservador. Foi notada uma variação de rigidez mais rápida para o modelo numérico. Os autores atribuem essa diferença de resultados a uma escolha inadequada do comportamento do material. Ressaltam, portanto, a importância de se considerar o encruamento resultante do processo de conformação do aço para fabricação da carcaça.

As considerações sobre o perfil da carcaça, a não representação do efeito helicoidal, as considerações de modelagem como a diferença na discretrização da malha da carcaça e da camada plástica serão adotadas nesta dissertação. Essa referência é, portanto, de extrema relevância para a elaboração da metodologia deste mestrado.

g) Franzini et al. (2011) apresentam uma comparação teórico-experimental de ensaios de tração-compressão de protótipos de tubos flexíveis. O modelo analítico é baseado no trabalho de Martins, Pesce e Aranha (2003) que leva em consideração a combinação de cargas concentradas de esmagamento e estrangulamento resultantes da compressão das sapatas dos tensionadores. O modelo ainda leva em consideração a ovalização inicial. Os ensaios são baseados no mapeamento interno da carcaça deformada até que a deformação plástica se torne evidente. A análise de sensibilidade com relação à ovalização inicial e o passo das armaduras de pressão também são levados em consideração. Os autores usam o modelo de Martins, Pesce e Aranha (2003) bem como o trabalho de Pesce et al. (2010) que combina crushing e colapso. Esses trabalhos são usados para fins de comparação com o modelo proposto nesse trabalho que trata de uma combinação de cargas de esmagamento e estrangulamento pelas armaduras de tração para representar deformações geométricas da armadura de pressão.

Esse trabalho é associado a outra publicação que apresenta técnicas de medição e resultados experimentais sobre o esmagamento para duas amostras diferentes: uma de duas polegadas e meia e outra de quatro polegadas.

As considerações teóricas e o modelo analítico apresentado nesse trabalho foram baseados na metodologia de anel equivalente proposto por Martins, Pesce e Aranha 
(2003). São apresentadas as equações que regem o colapso molhado e o esmagamento. Ao final, propõe-se uma metodologia para a análise de fatores de correção geométrica da carcaça por meio dos ensaios experimentais de esmagamento.

O modelo em elementos finitos considera o perfil real da carcaça intertravada exceto pelo passo que é desprezado na análise do colapso. A carcaça é modelada como um anel com a mesma seção transversal do perfil real da carcaça. São usados elementos de primeira ordem do ANSYS para modelar a carcaça. A fim de representar a cinemática da carcaça por meio de uma sequência infinita de anéis é considerado o acoplamento entre os graus de liberdade das extremidades do perfil da carcaça em cada passo. Os planos de simetria são considerados e apenas um quarto da geometria foi representado. Ainda nas condições de contorno foi aplicada uma restrição axial na camada plástica interna a fim de evitar movimento de corpo rígido. A única carga considerada é a de esmagamento, que é aplicada diretamente à carcaça. Apesar de os contatos na geometria interna da carcaça serem considerados sem atrito (frictionless), a não linearidade geométrica é levada em consideração. Além do método padrão interativo Newton-Raphson de resolução do ANSYS foi necessário adicionar também o procedimento de "comprimento do arco (arc-lenght)". O modelo ainda prevê a ovalização inicial do tubo que pode ser encontrada na norma API 17B.

O material da carcaça foi modelado como não linear elasto-plástico. Os autores apontam para o encruamento durante o processo de conformação da carcaça que pode mudar significativamente a tensão de escoamento. A modelagem foi feita com o comportamento do material linear elástico antes do escoamento e bilinear com endurecimento cinemático após o escoamento. A camada polimérica foi modelada como não linear elástica.

O modelo para o esmagamento representa as condições físicas testadas, a carcaça intertravada e a inclusão das camadas plásticas adjacentes. As mesmas considerações do modelo do colapso são usadas para o esmagamento exceto para a simetria, que aqui é usada apenas como metade do anel. No esmagamento não há pressões externas atuantes, apenas um par de forças opostas. Um deslocamento vertical é imposto na face superior do tubo enquanto que a face inferior é fixada. Esse procedimento tenta reproduzir as condições de contorno do experimento. 
A comparação entre os experimentos de esmagamento com os resultados obtidos na parametrização numérica foi usada para obter um valor representativo da tensão de escoamento da carcaça conformada. O mesmo experimento de esmagamento foi usado para ajustar o modelo analítico de anel equivalente. Uma metodologia teórico-experimental foi então construída para lidar com a predição do colapso molhado. Esse trabalho apresenta conclusões importantes sobre o comportamento da carcaça e armadura de pressão quando submetidos a carregamentos de esmagamento e será importante para análise das camadas ao longo dessa dissertação.

h) Gay Neto e Martins (2012) tratam do problema do colapso, em que o tubo flexível pode chegar à falha quando submetido a altas pressões hidrostáticas. O colapso molhado é o objetivo de estudo do trabalho. Esse fenômeno ocorre quando a capa plástica externa é danificada, e a pressão é suportada pela carcaça intertravada. O problema é então tratado por meio de modelos numéricos, com a representação apenas da carcaça e da camada polimérica interna. Questões tais como a influência do ângulo de assentamento da carcaça e a ovalização inicial são levantadas como pontos relevantes para a investigação do colapso. As conclusões advindas dessas questões bem como a representação do perfil parametrizado da carcaça, também apresentado por Gay Neto, Martins e Pesce (2009), serão adotados nesta dissertação.

São propostos dois modelos para o estudo do colapso: o primeiro traz a representação real do perfil da carcaça intertravada com a influência do ângulo de assentamento e o segundo apresenta uma simplificação do perfil, sendo representado como um anel. A espessura equivalente do anel foi calculada de acordo com uma modificação no fator de sobreposição proposta pelos autores, baseada na metodologia de Martins, Pesce e Aranha (2003). Uma forma alternativa de cálculo foi aplicada a partir do procedimento de Sousa et al. (2001). Simplificações foram feitas nos modelos de elementos finitos a fim de tornar o problema mais simples do ponto de vista computacional e de convergência. Dessa forma, o comprimento infinito do tubo foi simulado por meio de acoplamento cinemático dos graus de liberdade nas extremidades da seção do perfil. Condições de contorno também foram impostas a fim de evitar movimento de corpo rígido. Os contatos foram tratados de maneira detalhada, com a descrição desde os elementos escolhidos até a rigidez de 
contato adotada. Todas essas considerações de modelagem foram relevantes para a elaboração do modelo apresentado na metodologia dessa dissertação.

Os resultados deste trabalho indicam que o ângulo de assentamento, representado no modelo completo, não apresenta grande influência nos resultados do colapso. Além disso, uma importante conclusão é que uma maior ovalização inicial diminui a resistência ao colapso do tubo. Essa dissertação não tratará da ovalização, no entanto a conclusão acerca do ângulo de assentamento será aplicada para a construção da carcaça.

i) Pesce et al. (2012) apresentam uma melhoria do modelo analítico publicado por Martins, Pesce e Aranha (2003) e dos trabalhos de Pesce et al. (2010) e Franzini et al. (2011). Ainda se baseando no conceito de anel equivalente esse trabalho traz a discussão de uma metodologia para avaliar uma análise elasto-plástica. Esse modelo considera uma ação combinada das cargas de estrangulamento e esmagamento aplicadas pelas sapatas das lagartas de lançamento e também representa os efeitos da ovalização inicial. Além disso, têm-se modelos numéricos e experimentais para provar a pertinência das hipóteses do modelo analítico.

Esse modelo extrapola os trabalhos citados anteriormente, que apresentam apenas o comportamento linear elástico, com a representação do comportamento elasto-plástico. São consideradas três camadas do tubo flexível, a carcaça, a camada polimérica interna e a armadura de pressão, sendo que a capa polimérica interna é considerada não resistente. Apresenta-se uma metodologia para o cálculo das seções retangulares das camadas resistentes a partir do momento de inércia mínimo de cada uma delas. Para isso, são feitas as seguintes hipóteses: (i) o anel equivalente é formado por dois anéis resistentes equivalentes que são a armadura de pressão e a carcaça; (ii) a camada polimérica é considerada como um anel intermediário e não resistente; (iii) os anéis resistentes têm a seção transversal retangular, estruturalmente equivalente às da carcaça e da armadura de pressão, (iv) a espessura de todos os três materiais do anel equivalente permanecem constantes durante o carregamento, (v) os materiais da camada interna e externa são caracterizados pelo comportamento elasto-plástico, sem distinção entre tração e compressão, (vi) a seção transversal plana antes da deformação permanece plana após a deformação, (vii) o estado 
de tensão é predominantemente uniaxial, (viii) não há formação de vazios (gaps) na interface entre os três materiais, (ix) Apenas o processo de carregamento é considerado, até o ponto da falha.

Dentre todas as hipóteses citadas, os autores destacam a que merece mais atenção, que é a cinemática, uma vez que há duas possibilidades de comportamento: (i) a seção transversal compreende todas as camadas e uma única rotação caracteriza toda a seção, (ii) a camada intermediária pode sofrer distorção e cada camada tem sua própria rotação. O primeiro caso é considerado válido na vizinhança do perfil da seção transversal onde a curvatura determina o máximo ou mínimo local e nesse caso tem-se ainda um limite superior para a rigidez flexional. No segundo caso, têm-se seções não simétricas na vizinhança, como seções com curvatura nula. Além disso, a plastificação ocorre no limite inferior. Por ser mais simplificado apenas o primeiro caso foi detalhado.

Os autores apresentam o modelo elasto-plástico para o primeiro caso, limite superior para rigidez flexional. Posteriormente são mostradas as equações de equilíbrio, o eixo neutro e a rigidez residual. Apresenta-se ainda o modelo elasto-plástico para o segundo caso que é quando se tem o caso de rigidez flexional do limite inferior.

Uma das principais contribuições desse trabalho foi a avaliação analítica do comportamento do efeito de distorção da camada intermediária nas hipóteses de modelagem. A hipótese de não distorção provou-se válida na vizinhança das seções simétricas. Nos dois casos de carga concentrada, a rigidez flexional equivalente aproximou-se de um valor no limite inferior, correspondendo à distorção da camada intermediária ao longo do seu comprimento de arco. Pesce et al. (2012) bem como Franzini et al. (2011) são referência importantes para análise do comportamento do tubo flexível quando carregados radialmente.

j) Malta et al. (2013) apresentam uma metodologia efetiva para avaliar as tensões no núcleo estrutural do tubo flexível submetido a cargas de esmagamento durante o lançamento usando o Método dos Elementos Finitos. Os autores criaram um modelo tridimensional, construído no ANSYS, com os perfis reais da carcaça intertravada e da arma- 
dura de pressão para representar o núcleo estrutural. Modelos similares com simplificações geométricas foram criados com o objetivo de se avaliar a relevância da representação precisa dos perfis do núcleo estrutural.

Algumas das hipóteses de simulação foram: (i) a representação do tubo como um modelo tridimensional restrito, ou seja, sem a consideração do efeito helicoidal das armaduras metálicas, (ii) o tubo e as sapatas foram considerados infinitos e uma série de acoplamentos foram feitos para representar esse efeito, (iii) as sapatas foram consideradas mais rígidas que as outras estruturas, (iv) o modelo foi considerado cíclico com 3 sapatas e com espaçamento de $120^{\circ}$ entre o centro de duas sapatas adjacentes, (v) apenas o núcleo estrutural foi considerado pois é a região que suporta os carregamentos radiais, (vi) Os efeitos de estrangulamento das armaduras de tração não foram levados em consideração nessa análise, (vii) o passo da carcaça e da armadura de pressão são iguais. É importante ressaltar as simplificações adotadas pelos autores pois as mesmas são aplicadas nesta dissertação.

As malhas foram feitas com elementos de primeira ordem para a camada polimérica interna e a sapata e de segunda ordem para a carcaça e armadura de pressão. O modelo tridimensional restrito é composto pela carcaça intertravada, armadura de pressão e pela camada polimérica interna (liner). Foram construídos três modelos adicionais a fim de se avaliar a espessura equivalente das camadas metálicas: um primeiro com armadura de pressão com espessura equivalente; o segundo da carcaça intertravada com espessura equivalente e o terceiro com ambas as camadas metálicas apresentando a espessura equivalente. As camadas metálicas do núcleo estrutural foram representadas como anel equivalente. A malha da capa polimérica interna é mais grosseira que a da carcaça para evitar efeitos de penetração que podem causar dificuldades de convergência. As sapatas foram modeladas como materiais rígidos uma vez que não se tem interesse em avaliar tensões nessa região. A geometria, material, malha e condições de contorno foram parametrizadas a fim de se facilitar mudanças de parâmetros. Nas condições de contorno adotou-se uma restrição circunferencial nas duas extremidades a fim de se ter uma condição cíclica. A sapata foi considerada restrita na direção axial de modo a se mover apenas no sentido radial de compressão do tubo. A fim de evitar movimento de corpo rígido a armadura de pressão e a camada polimérica foram restritas na direção axial. 
$\mathrm{O}$ acoplamento entre as faces das camadas permitiu que o modelo simulasse o comportamento de tubo infinito, uma vez que o comportamento entre os nós das faces opostas é igual. Todos os pares de contato foram considerados sem atrito (frictionless), exceto entre a carcaça e a capa polimérica interna que são considerados colados (bonded) para evitar separação entre as camadas. Quanto às propriedades dos materiais, as camadas metálicas foram consideradas com modelo bilinear e endurecimento isotrópico enquanto a camada plástica foi considerada multilinear elástica. As hipóteses de modelagem mencionadas são de fundamental importância para análise paramétrica apresentada nesta dissertação. Como são gerados vários modelos a partir da investigação de vários parâmetros, é necessário que sejam feitas simplificações para tornar a análise exequível.

A metodologia usada para o cálculo espessura equivalente foi a mesma proposta por Martins, Pesce e Aranha (2003). Em relação às cargas de esmagamento, foram usadas as normas API e PETROBRAS que consideram a ovalização como um parâmetro importante a ser analisado para esse tipo de carregamento.

Nesse trabalho, usou-se como parâmetro de análise o deslocamento radial e o limite de escoamento em cada camada a fim de avaliar o fator de utilização e previsão do ponto de falha. Os mesmos critérios foram empregados nesta dissertação para análise do impacto dos parâmetros de análise no escoamento dos tubos flexíveis.

Em todos os casos analisados, ao final da aplicação máxima de carga, o campo de tensões foi suficientemente alto para provocar o escoamento de todas as camadas. Percebeu-se que um alto nível de tensão foi encontrado na região imediatamente abaixo das sapatas. O campo de tensões apresentou-se maior na região de aplicação de carga tanto na armadura de pressão quanto na carcaça e também na região das condições de contorno cíclicas. As regiões que apresentaram uma maior deformação foram as mesmas que apresentaram maiores tensões. A camada polimérica interna atingiu maiores deformações uma vez que sua rigidez é menor.

Uma consideração importante desse trabalho foi que o modelo de anel equivalente resultou na queda da rigidez radial da camada. Quando ambas as camadas foram modeladas como anel equivalente os deslocamentos radiais apresentaram valores maiores, mas o deslocamento axial resultou menor. Para a carcaça, a metodologia de anel equivalente 
comprometeu sua capacidade de deformar na direção axial enquanto que para a armadura de pressão a diferença mostrou-se irrelevante. Percebeu-se que o modelo de anel equivalente alterou a mudança da sequência de escoamento das camadas nos modelos em que cada uma é modelada com espessura equivalente, isoladamente. No entanto, para o caso em que as duas camadas foram modeladas com anel equivalente o escoamento se dá de forma simultânea. Exceto pelo caso em que as duas camadas foram modeladas como anéis equivalentes, todos os outros obedeceram à regra do fator de utilização da norma N2409 da Petrobrás.

Malta et al. (2013) apresentam os principais métodos de análise de falha do tubo flexível que são por meio da ovalização e do fator de utilização. Além de considerar as hipóteses de modelagem indicadas nesse artigo, essa dissertação também usará como critério de falha do tubo as mesmas normas com os mesmos parâmetros propostos pelos autores.

k) Gay Neto et al. (2013) apresentam um estudo da integridade e cinemática das camadas do tubo flexível quando submetido a carregamentos de esmagamento. Com esse objetivo, foi construído um modelo em elementos finitos $2 \mathrm{D}$ em que foram representadas as camadas metálicas interna e externa e a camada polimérica interna. A variação da quantidade de carregamentos de esmagamento combinada à alteração dos tipos de contato entre as camadas forneceu resultados relevantes para o entendimento da cinemática do problema.

A cinemática do esmagamento foi investigada com a variação do número de carregamentos igualmente espaçados e por meio da aplicação de diferentes tipos de contatos: frictionless, frictional (dois coeficientes de atrito diferentes) e bonded. Certa atenção foi dada à camada polimérica interna para os casos de atrito uma vez que a mudança no comportamento das camadas metálicas pode ser substancial. As camadas metálicas e poliméricas do modelo bidimensional foram modeladas, respectivamente, com material de comportamento elasto-plástico bilinear e multilinear elasto-plástico. Como não há aplicação de carregamentos cíclicos, os autores desconsideram o efeito plástico da camada polimérica interna. Para as camadas metálicas, no entanto, o efeito plástico é essencial para que a variação da rigidez possa ser acompanhada ao longo do carregamento e para avaliar das tensões locais nas regiões que sofrem plastificação. Detalhes do modelo como 
tipo de elemento usado, convergência de malha, propriedades dos materiais, entre outras especificidades são listados e podem ser consultados na referência para uma melhor compreensão do pré-processamento. O modelo foi analisado considerando-se não linearidades de contato e de material. A não linearidade geométrica também foi respeitada apesar da representação 2D das camadas. O método de análise foi o Newton-Raphson, padrão do ANSYS.

A principal contribuição desse artigo é o estudo do comportamento desses parâmetros com a variação dos contatos. Apesar de o modelo abordado ser bidimensional, as conclusões são importantes para análise tridimensional do esmagamento proposto ao longo deste trabalho. Conclusões importantes sobre a mudança na plastificação das camadas de acordo com o contato e a variação da rigidez com a mudança do raio são úteis para o estudo detalhado da mecânica do esmagamento.

1) Gay Neto et al. (2016) apresentam um estudo do colapso seco do tubo flexível, caso em que a camada polimérica externa não é danificada, com todas as camadas da estrutura atuando conjuntamente na resistência ao carregamento externo. Tanto o tubo reto quanto o curvilíneo foram estudados. Os autores propuseram três modelos para análise do colapso: (i) um modelo tridimensional completo publicado por Gay Neto et al. (2012), (ii) um modelo tridimensional simplificado com o perfil da carcaça intertravada representado como espessura equivalente, (iii) um modelo bidimensional em que a carcaça intertravada e a armadura de pressão são tratadas como anel equivalente. Em todos os modelos são consideradas as camadas do núcleo estrutural (mais resistentes ao colapso) e a camada polimérica externa. As considerações de modelagem e os resultados do colapso apresentados nesse trabalho são relevantes para essa dissertação.

O modelo tridimensional completo é usado como referência para análise dos resultados dos modelos simplificados. Como se deseja avaliar a influência da curvatura do tubo nos resultados do colapso foram representados dezenas de passos da carcaça intertravada, apesar do alto custo computacional. A malha de todo o modelo foi construída com elementos sólidos de segunda ordem do ANSYS. O comportamento do material da carcaça e da armadura de pressão foi considerado como bilinear elasto-plástico com endurecimento isotrópico. Já os materiais das camadas plásticas são considerados como 
multilinear elasto-plásticos, com encruamento isotrópico. Os materiais escolhidos assumem o mesmo comportamento quando submetidos a carregamentos de tensão e deformação. Além disso, foram considerados todos os pares de contato e as condições de contorno foram aplicadas por meio de nós piloto. O carregamento foi aplicado à superfície da camada polimérica externa. Os mesmo elementos e materiais adotados para modelagem do modelo tridimensional completo também foram usados no pré-processamento do modelo de esmagamento apresentado ao longo desta dissertação.

O modelo tridimensional simplificado foi modelado em formato de anel com ângulo de assentamento desprezível já que não é relevante para o problema do colapso. Os autores apresentam uma discussão sobre a representação real das camadas metálicas já que os passos não são iguais. Optou-se pela representação do perfil real da armadura de pressão que apresenta maior rigidez radial e, portanto, maior resistência ao colapso ao passo que a carcaça intertravada foi apresentada com a espessura equivalente a partir da metodologia de cálculo de Gay Neto e Martins (2012). Os mesmos elementos, materiais e pares de contatos do modelo completo também foram aplicados ao modelo simplificado. Foram desconsideradas as penetrações da camada polimérica interna na carcaça intertravada e da camada polimérica externa na armadura de pressão, embora os contatos entre essas camadas tenham sido representados como bonded (colado). A ovalização foi medida no diâmetro interno da armadura de pressão. Como foram representados apenas dois passos da armadura de pressão, foram feitos acoplamentos cinemáticos nas extremidades do perfil para garantir a condição de periodicidade para deslocamentos e tensões. O tipo de contato entre a armadura de pressão e a camada polimérica externa é um dos casos de análise paramétrica a ser estudado ao longo deste trabalho de mestrado, dessa forma o artigo em questão é uma referência importante.

Os autores discutem a importância da escolha apropriada das condições de contorno para evitar pressões nulas na integração ao longo da superfície externa do tubo. Três condições de contorno diferentes aplicadas no sistema de coordenadas cartesianos foram propostas a fim de avaliar os resultados.

O modelo bidimensional simplificado foi modelado de forma a respeitar as mesmas configurações de contato do modelo tridimensional simplificado. A metodologia de 
espessura equivalente foi aplicada tanto à carcaça quanto à armadura de pressão. O comportamento das camadas metálicas foi modelado como estado plano de tensão e o das camadas poliméricas como estado plano de deformação.

Esse artigo apresenta conclusões importantes para o andamento deste trabalho uma vez que a representação do modelo completo para análise paramétrica do esmagamento é inviável pelo longo tempo de processamento de cada caso. A metodologia do anel equivalente com a representação de dois passos do perfil das camadas metálicas será a abordagem usada na construção dos modelos analisados neste trabalho.

m) A Norma 2409 da Petrobrás define os critérios para avaliação dos resultados, anteriormente mencionada no subcapítulo 2.3 (introdução). Essa norma cita, entre outros tópicos, procedimentos para o projeto de tubos flexíveis considerando as cargas impostas durantes a operação e a instalação. Para análise de carregamentos resultantes do procedimento de instalação usa-se um fator de utilização. De acordo com essa norma, a carcaça intertravada ou a armadura de pressão pode atingir a tensão de escoamento do material conquanto que a outra camada respeite o fator de utilização. Esse limite é definido pela razão entre o valor da tensão analisada na camada metálica e a tensão de escoamento do material como indicado na Eq.(1). O tubo falha quando essa razão é superior a 0,8.

$$
f u=\frac{\sigma_{v m}}{\sigma_{y}}
$$

em que

$f u$ é o fator de utilização;

$\sigma_{v m}$ é a tensão de von Mises registrada no subsstep de carga analisado;

$\sigma_{y}$ é o limite de escoamento do material metálico.

A norma apresenta ainda procedimentos a serem adotados no ensaio de esmagamento que são descritos a seguir:

“O tubo tem que ser posicionado, sem nenhuma pressão interna, no aparato de teste. Antes de se aplicar a carga compressiva, a amostra é uniformemente tracionada até que a tensão 
de lançamento seja alcançada. Essa carga é mantida constante, com variação máxima de $4 \%$, durante todo o período de teste. A carga compressiva radial é aumentada de zero até a carga máxima permitida pelo projeto, com incrementos de até $1 \%$ da carga máxima por segundo. O carregamento mantido constante por um intervalo de tempo de pelo menos 1 hora." A ovalização é então obtida pela seção deformada a partir da Norma API 17B como indicado na Eq. (2):

$$
O v=\frac{D_{\max }-D_{\min }}{D_{\max }+D_{\min }}
$$

A aplicação do carregamento de esmagamento será implementada similarmente ao indicado pela norma 2409, com adição incremental de carga. A ovalização, no entanto, não será tratada nesta dissertação. Os critérios de análise serão exclusivamente de tensão, como será detalhado na metodologia. 


\section{METODOLOGIA}

Nesse capítulo são apresentados os procedimentos para construção dos modelos em elementos finitos. As etapas de elaboração dos modelos são detalhadamente apresentadas de modo a justificar as configurações adotadas. São explicitados os aspectos dos estudos paramétricos realizados e a metodologia aplicada a cada um dos casos. Por fim, são indicadas as regiões de investigação para cada um dos casos estudados, a partir da Norma 2409.

\subsection{Modelos Numéricos Tridimensionais}

O Método dos Elementos Finitos tem se destacado como uma ferramenta para solução de problemas da engenharia em vista da possibilidade de se representar geometrias complexas, diversos carregamentos e condições de contorno, além de uma série de problemas físicos. A viabilidade da solução de equações lineares e, principalmente, não lineares consiste em uma das vantagens fundamentais desse método. Apesar disso, a reprodução de problemas de forma fidedigna pode resultar em um alto custo computacional e dificuldades de convergência que podem tornar a análise inviável. Em vista disso, por vezes é necessário que sejam feitas simplificações no modelo investigado a fim de tornar o estudo exequível.

Diante da dificuldade em representar o tubo flexível, com seu real comprimento e geometria, é indispensável que sejam adotadas hipóteses de modelagem a fim de simplificar o problema. Como o objetivo deste trabalho é a análise dos parâmetros envolvidos na falha dos tubos flexíveis durante o lançamento, as hipóteses de modelagem são essenciais para diminuição de graus de liberdade do sistema. Consequentemente, tem-se também uma economia do tempo computacional, tornando o estudo comparativo factível. 
O ANSYS Mechanical APDL (ANSYS Parametric Design Language) versão 15.0 [5] foi o pacote comercial eleito para a construção dos modelos em elementos finitos. Esse programa é amplamente usado tanto no meio acadêmico como também na indústria. A linguagem de programação APDL combina comandos dos ANSYS com funções desenvolvidas em FORTRAN, que são executadas por meio de macros. A principal justificativa para escolha deste pacote é a possibilidade de construção de modelos parametrizados e automatização de tarefas por meio de linhas de comando, primordiais para a realização deste trabalho e sua disponibilidade no laboratório que abrigou este trabalho.

O estudo é feito com base em dois modelos fundamentais que se diferem apenas na composição das camadas. O primeiro é formado pelas camadas que compõem o núcleo estrutural: carcaça intertravada, camada polimérica interna e armadura de pressão, como indicado na Figura 17. O segundo contém as camadas do núcleo estrutural com a adição da camada polimérica externa, como apontado na Figura 18. As sapatas dos tensionadores são representadas em todos os casos.

O procedimento de investigação de um modelo em elementos finitos por meio de um pacote comercial é usualmente realizado através de duas etapas: o pré-processamento e o pós-processamento. Durante o pré-processamento são definidas as características do modelo tais como: geometrias, propriedades dos materiais, tipos de elementos, formulação dos contatos, condições de contorno, carregamentos aplicados, o tipo de análise e o solver. Na fase de pós-processamento são avaliados os resultados desejados a partir do problema proposto. Assim, os próximos subcapítulos serão dedicados à apresentação e justificativa da seleção de cada um dos itens dessas etapas necessários para construção do modelo proposto nesta dissertação. 


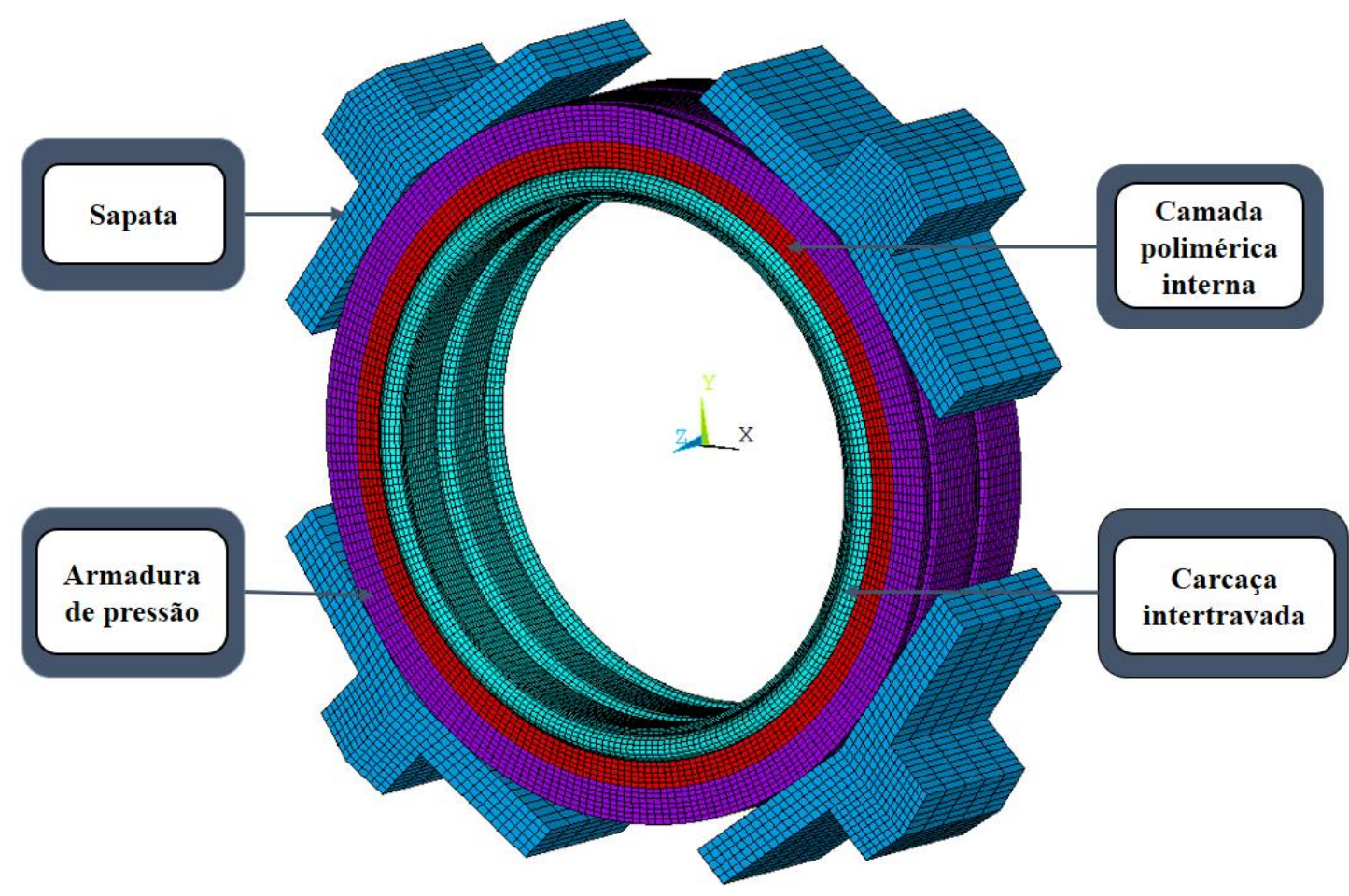

Figura 17 -Malha do modelo tridimensional composto pelas camadas do núcleo estrutural e quatro sapatas de lançamento.

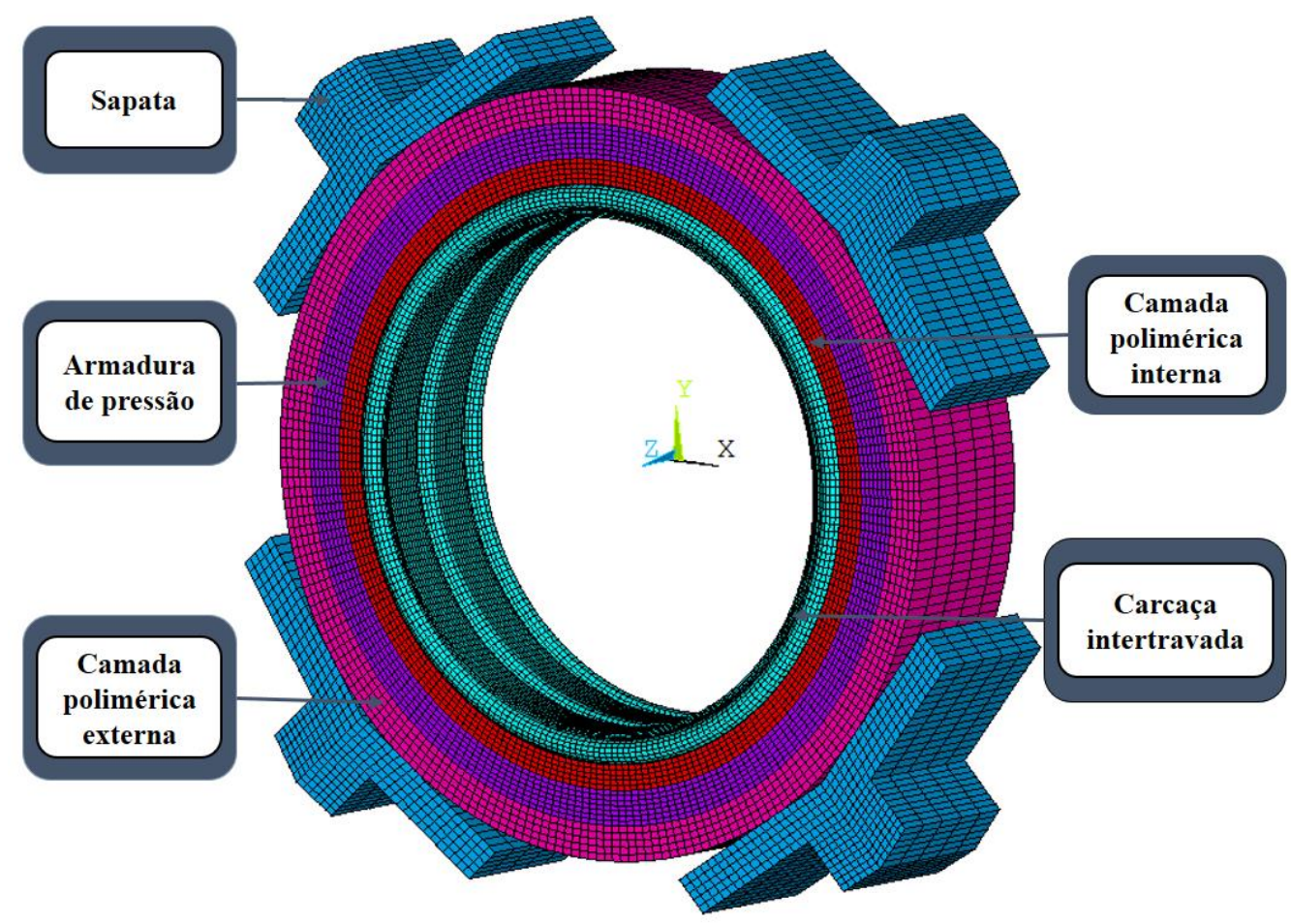

Figura 18 - Malha do modelo tridimensional composto pelas camadas do núcleo estrutural, camada polimérica externa e quatro sapatas de lançamento. 


\subsection{Geometria das Camadas}

Um tubo flexível não aderente, de parede rugosa, e com 4 polegadas de diâmetro interno foi adotado como referência para este trabalho. A espessura das camadas e o comprimento do passo da hélice estão indicados na Tabela 2.

Tabela 2 - Dimensões do tubo flexível.

\begin{tabular}{|l|c|}
\hline \multicolumn{2}{|c|}{ Propriedades Geométricas do Tubo } \\
\hline Diâmetro interno [mm] & 101,6 \\
\hline Espessura da carcaça [mm] & 6,5 \\
\hline Espessura da armadura de pressão [mm] & 7,0 \\
\hline Passo de hélice [mm] & 16,0 \\
\hline
\end{tabular}

Entre as várias camadas presentes no tubo flexível, a carcaça intertravada e a armadura de pressão possuem uma maior dificuldade em ser representadas em razão da complexidade da seção transversal e do perfil helicoidal. Assim, são assumidas as seguintes simplificações:

- O efeito helicoidal das camadas não é representado;

- A carcaça intertravada e a armadura de pressão são posicionadas de forma a se obter o mesmo passo de hélice;

- Os perfis da carcaça e da armadura de pressão são construídos de forma a se representar dois passos de hélice.

Neste trabalho, foi adotado o perfil da carcaça intertravada proposto por Gay Neto e Martins (2012), onde também são encontradas suas dimensões, como indicado na Figura 19 e Tabela 3. Os autores construíram um perfil em S, semelhante à geometria real da carcaça. 


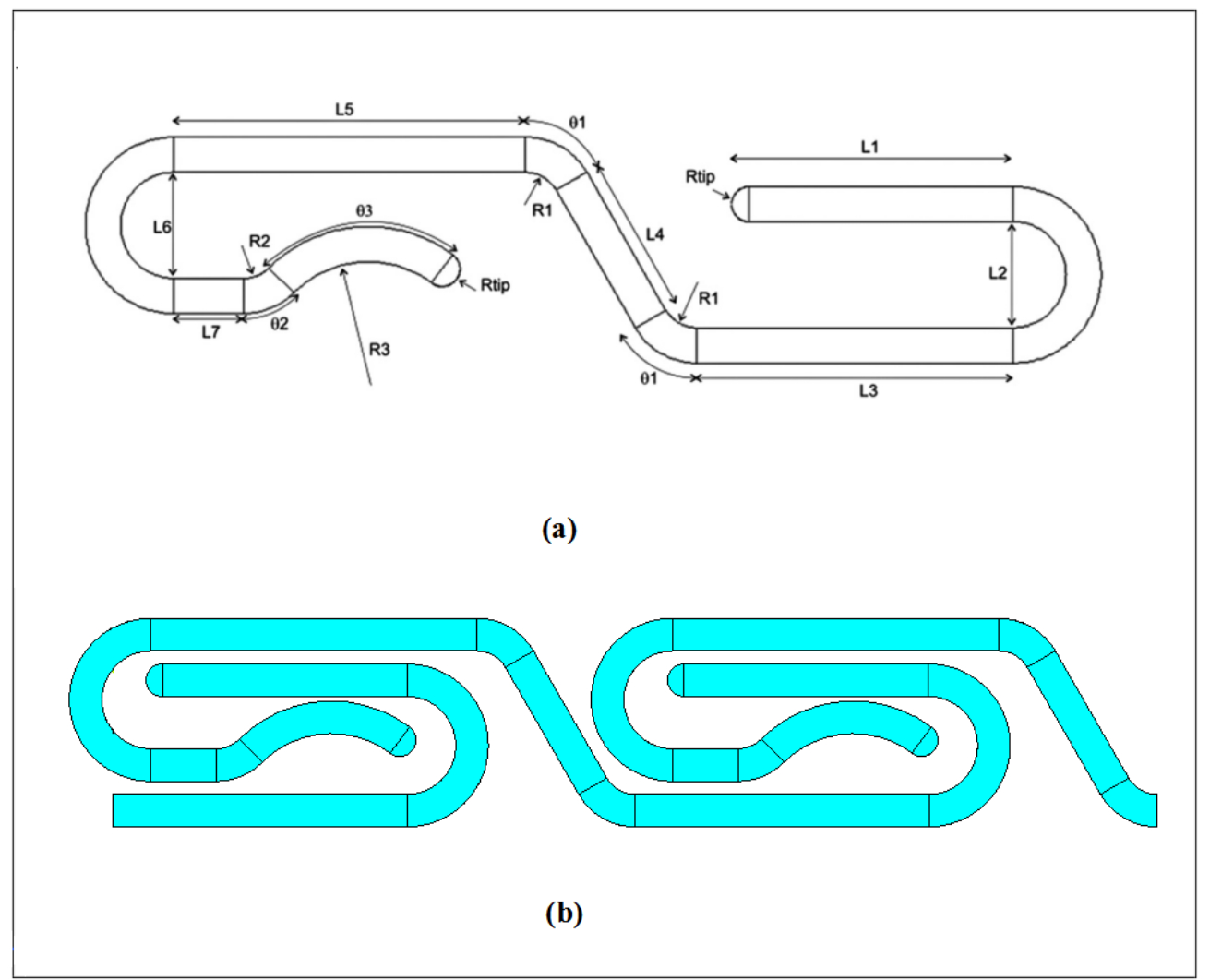

Figura 19 - Perfil parametrizado da carcaça intertravada como indicado em Gay Neto e Martins (2012) (a), e a seção transversal equivalente a dois passos (b).

Tabela 3 - Dimensões do perfil da carcaça.

\begin{tabular}{|c|c|c|c|}
\hline \multicolumn{4}{|c|}{ Perfil da Carcaça } \\
\hline $\mathbf{L}_{\mathbf{1}}[\mathrm{mm}]$ & 8,0 & $\mathrm{R}_{\mathbf{1}}[\mathrm{mm}]$ & 1,0 \\
\hline $\mathbf{L}_{\mathbf{2}}[\mathrm{mm}]$ & 3,0 & $\mathrm{R}_{2}[\mathrm{~mm}]$ & 1,0 \\
\hline $\mathbf{L}_{\mathbf{3}}[\mathrm{mm}]$ & 9,0 & $\mathrm{R}_{\mathbf{3}}[\mathrm{mm}]$ & 3,0 \\
\hline $\mathbf{L}_{\mathbf{4}}[\mathrm{mm}]$ & 4,5 & $\mathrm{R}_{\text {tip }}[\mathrm{mm}]$ & 0,5 \\
\hline $\mathbf{L}_{\mathbf{5}}[\mathrm{mm}]$ & 10,0 & $\theta_{1}[$ graus $]$ & 60 \\
\hline $\mathbf{L}_{\mathbf{6}}[\mathrm{mm}]$ & 3,0 & $\theta_{2}$ [graus $]$ & 45 \\
\hline $\mathbf{L}_{\mathbf{7}}[\mathrm{mm}]$ & 2,0 & $\theta_{3}$ [graus] & 90 \\
\hline
\end{tabular}

O perfil adotado para armadura de pressão, em formato de Z (zeta), é apresentado no trabalho de Gay Neto e Martins (2012). Sua seção transversal e dimensões da geometria parametrizada podem ser vistos na Figura 20 e Tabela 4, respectivamente. 


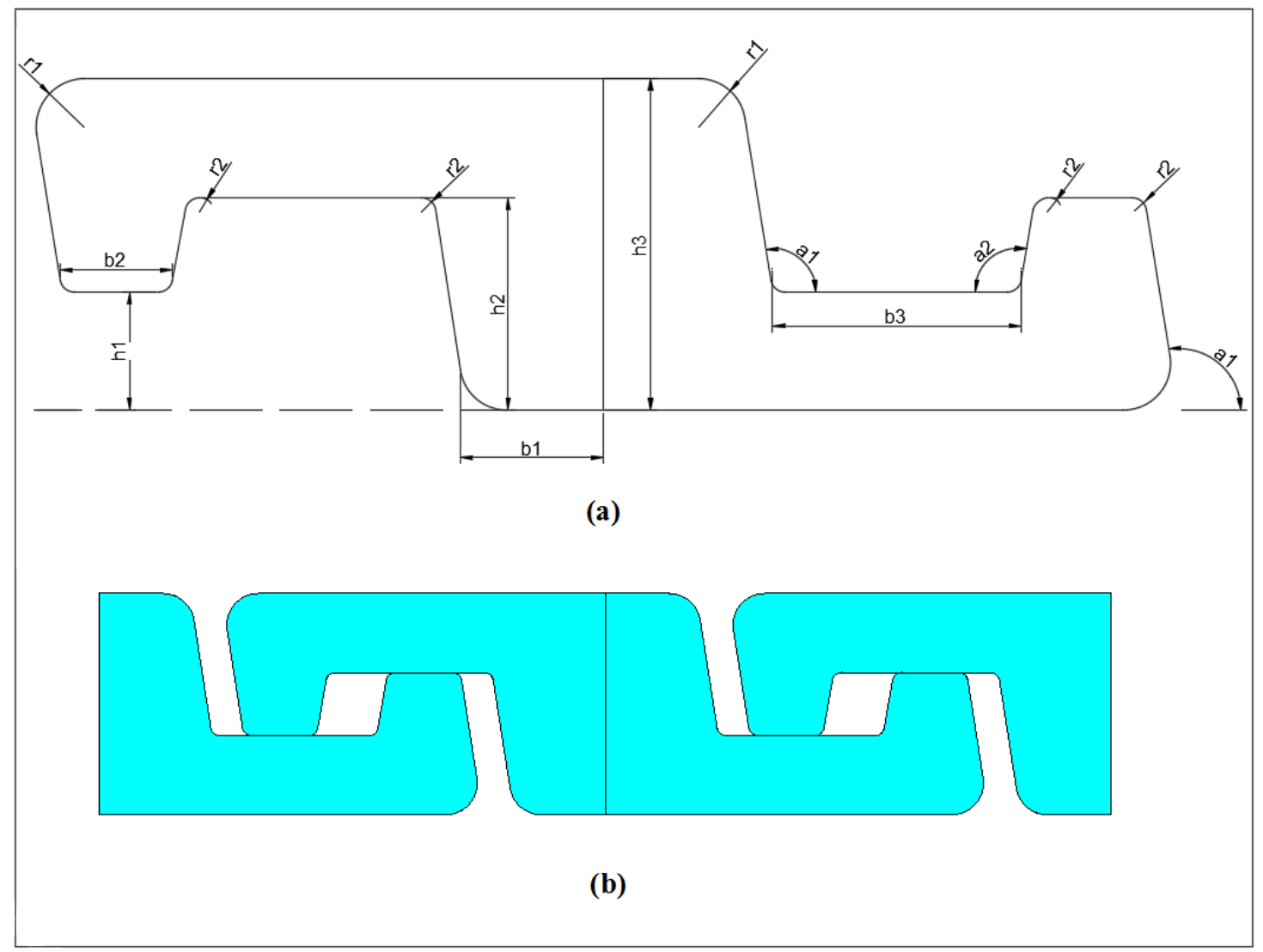

Figura 20- Perfil da armadura de pressão parametrizado (a) seção transversal da zeta equivalente a dois passos (b).

Tabela 4 - Dimensões do perfil da armadura de pressão.

\begin{tabular}{|c|c|c|c|}
\hline \multicolumn{4}{|c|}{ Perfil da Carcaça } \\
\hline $\boldsymbol{b}_{\mathbf{1}}[\mathrm{mm}]$ & 2,87 & $h_{1}[$ graus $]$ & 2,5 \\
\hline $\boldsymbol{b}_{\mathbf{2}}[\mathrm{mm}]$ & 2,3 & $h_{2}[$ graus $]$ & 4,5 \\
\hline $\boldsymbol{b}_{\mathbf{3}}[\mathrm{mm}]$ & 5,2 & $h_{3}[$ graus $]$ & 7,0 \\
\hline $\boldsymbol{r}_{\mathbf{1}}[\mathrm{mm}]$ & 1,0 & $a_{1}[$ graus $]$ & 99 \\
\hline $\boldsymbol{r}_{\mathbf{2}}[\mathrm{mm}]$ & 0,3 & $a_{2}[$ graus $]$ & 100 \\
\hline
\end{tabular}

As sapatas foram representadas com o perfil apresentado no trabalho de Malta $e t$ al. (2013), com detalhes e dimensões indicados na Figura 21 e Tabela 5. Exceto pelo ângulo de abertura (dimensão $c_{5}$ ), que é um dos parâmetros avaliados, todos as outras dimensões são mantidas constantes. 


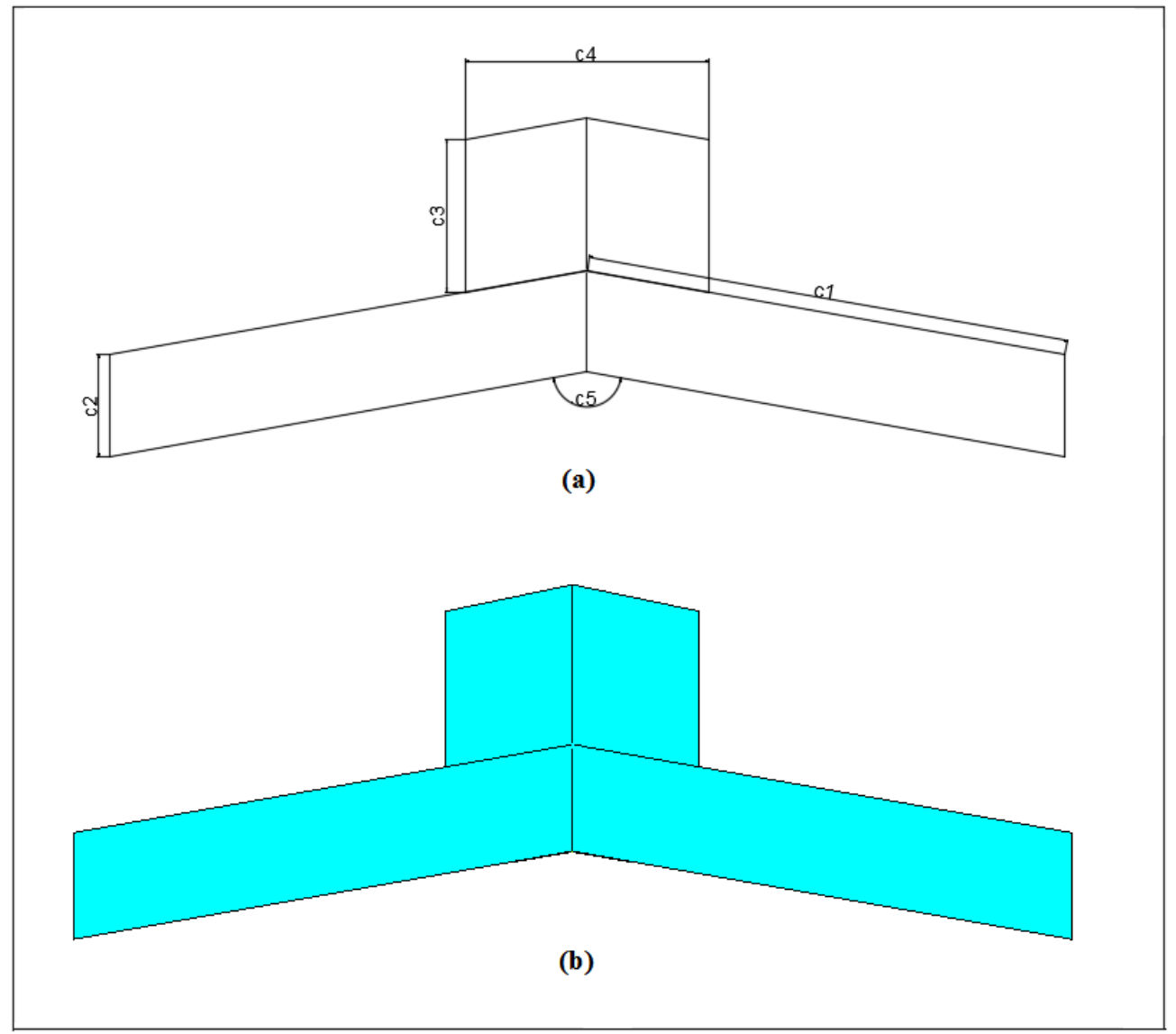

Figura 21 - Dimensões da sapata (a) e perfil da sapata (b).

Tabela 5 - Dimensões da sapata.

\begin{tabular}{|c|c|}
\hline \multicolumn{2}{|c|}{$\begin{array}{c}\text { Parâmetros do Perfil da sa- } \\
\text { pata }\end{array}$} \\
\hline $\mathrm{c}_{1}[\mathrm{~mm}]$ & 40,0 \\
\hline $\mathrm{c}_{2}[\mathrm{~mm}]$ & 8,4 \\
\hline $\mathrm{c}_{3}[\mathrm{~mm}]$ & 12,6 \\
\hline $\mathrm{c}_{4}[\mathrm{~mm}]$ & 20,0 \\
\hline $\mathrm{c}_{5}$ [graus] & $120-180$ \\
\hline
\end{tabular}

A construção das camadas poliméricas não impõe grandes dificuldades dada a simplicidade do seu perfil, sendo necessário como dimensões apenas sua espessura e a largura do passo das camadas metálicas. 
Após a definição do perfil de cada uma das camadas, a geração da geometria tridimensional é feita no ANSYS APDL por meio da extrusão das áreas indicadas na Figura 22 ao longo de um caminho, que é definido por um setor de circunferência. A opção de se representar apenas uma seção do tubo se deve à simetria do problema em relação ao carregamento de esmagamento, como será explicado na subseção que trata das condições de contorno. A geometria da sapata é gerada após a construção do volume do tubo, através da extrusão do seu perfil por um caminho definido na direção axial, e de comprimento equivalente à largura do passo das camadas metálicas.

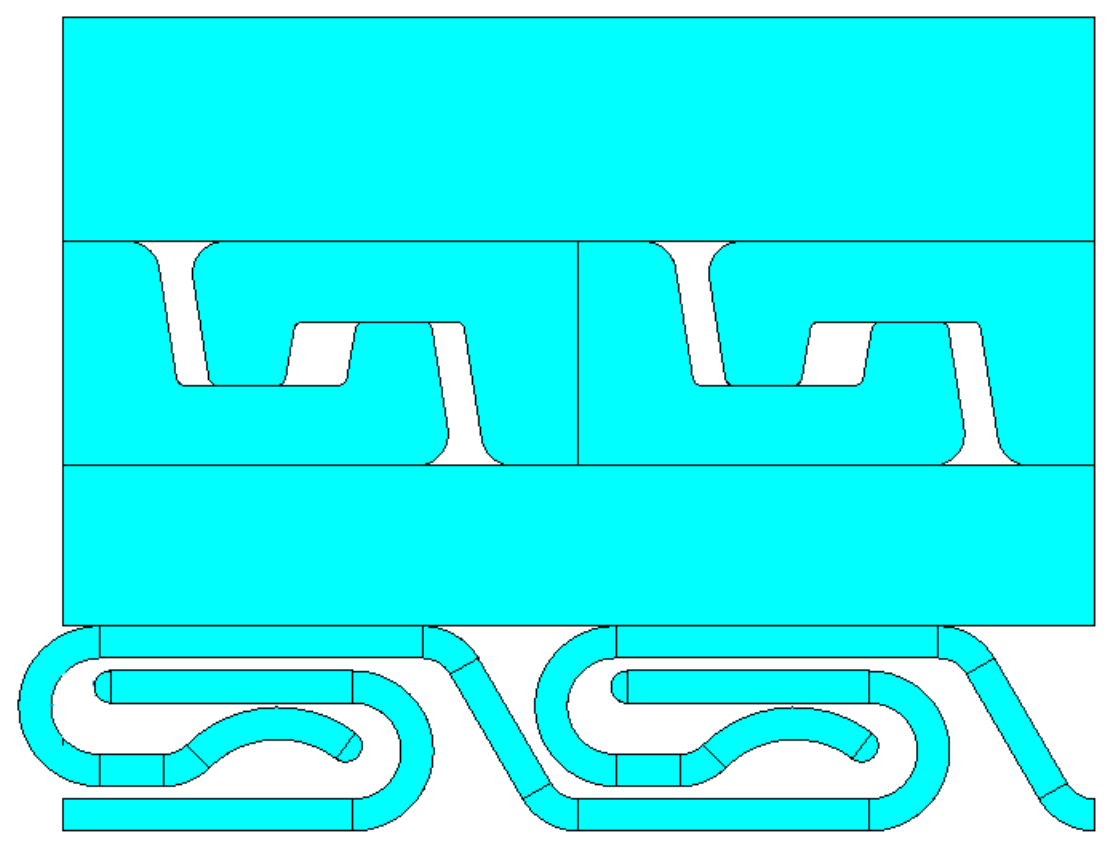

Figura 22 - Seção transversal do tubo.

\subsection{Modelo dos Materiais}

Foram usados dois modelos de materiais: um para a definição do comportamento das camadas metálicas e o outro das camadas poliméricas. As propriedades básicas de entrada para cada camada foi o módulo de elasticidade e o coeficiente de Poisson, como 
indicado na Tabela 6. Para as camadas metálicas foram definidos adicionalmente o módulo tangente do regime plástico e o limite de escoamento que é primordial para o estudo da falha das camadas metálicas.

Tabela 6 - Propriedades dos materiais das camadas metálicas e poliméricas.

\begin{tabular}{|c|c|c|c|c|}
\hline Propriedades & $\begin{array}{c}\text { Carcaça Inter- } \\
\text { travada }\end{array}$ & $\begin{array}{c}\text { Armadura de } \\
\text { Pressão }\end{array}$ & $\begin{array}{c}\text { Camada Poli- } \\
\text { mérica in- } \\
\text { terna }\end{array}$ & $\begin{array}{c}\text { Camada Poli- } \\
\text { mérica Externa }\end{array}$ \\
\hline $\begin{array}{c}\text { Módulo de Elasti- } \\
\text { cidade [GPa] }\end{array}$ & 192.5 & 207 & 0,330 & 0,570 \\
\hline $\begin{array}{c}\text { Coeficiente de } \\
\text { Poisson }\end{array}$ & 0,3 & 0,3 & 0.45 & 0.45 \\
\hline $\begin{array}{c}\text { Limite de Escoa- } \\
\text { mento [MPa] }\end{array}$ & 600 & 650 & 5 & - \\
\hline $\begin{array}{c}\text { Módulo Tangente } \\
\text { [MPa] }\end{array}$ & 2000 & 10483 & - & - \\
\hline
\end{tabular}

Para armadura de pressão foi usado aço carbono enquanto para a carcaça intertravada foi utilizado o aço austenítico 316. Os dados dos materiais contidos na Tabela 6 são baseados no trabalho de Malta et al. (2013). O comportamento do material das camadas metálicas foi representado como elasto-plástico bilinear com endurecimento isotrópico (representado no ANSYS como BISO). O modelo bilinear é assim definido devido ao gráfico de tensão versus deformação que é determinado por duas curvas: a primeira é a região linear elástica e a segunda é a região plástica em que a inclinação é dada pelo módulo tangente. Esse modelo de material adota o critério de escoamento de von Mises acoplado com hipóteses de endurecimento isotrópico.

Em relação às camadas poliméricas interna e externa, foram escolhidos o Nylon 11 e o HDPE (polietileno de alta densidade), respectivamente. O comportamento do material escolhido para essas camadas foi o multilinear elástico com endurecimento isotrópico (indicado no ANSYS como MISO). Esse modelo é similar ao bilinear com endurecimento isotrópico, exceto pela curva tensão versus deformação que é formada por vários 
pontos no regime plástico. Como não há carregamentos cíclicos nesse trabalho, o comportamento plástico das camadas poliméricas não é relevante. As curvas do comportamento elasto-plástico de cada um dos materiais foram levantadas a partir de resultados experimentais obtidos para a armadura de pressão e carcaça intertravada, e são indicadas nas Figura 23 e Figura 24. O Apêndice A apresenta uma descrição detalhada dos critérios de plastificação e modelos de materiais adotados.

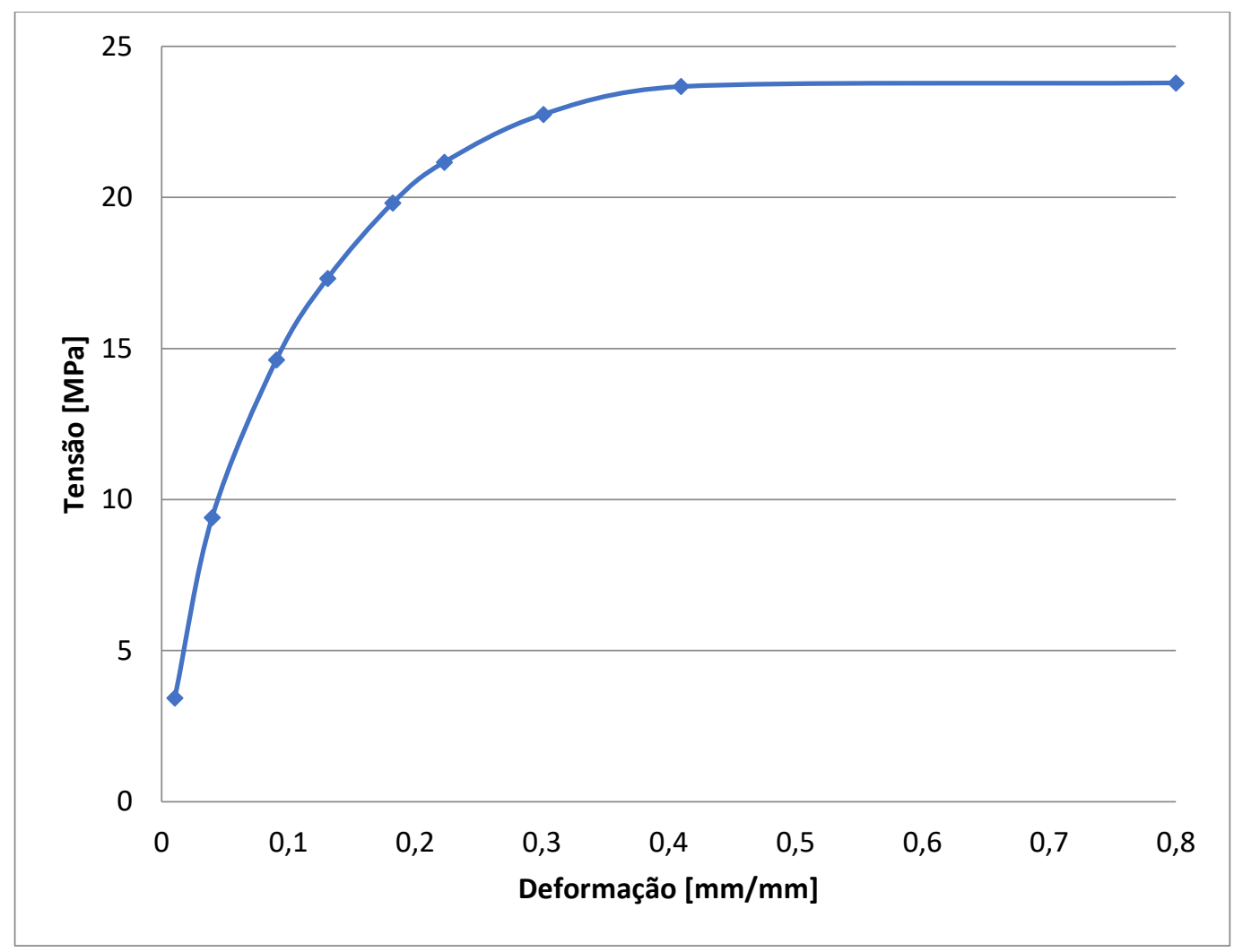

Figura 23- Curva de tensão x deformação para o material da camada polimérica interna. 


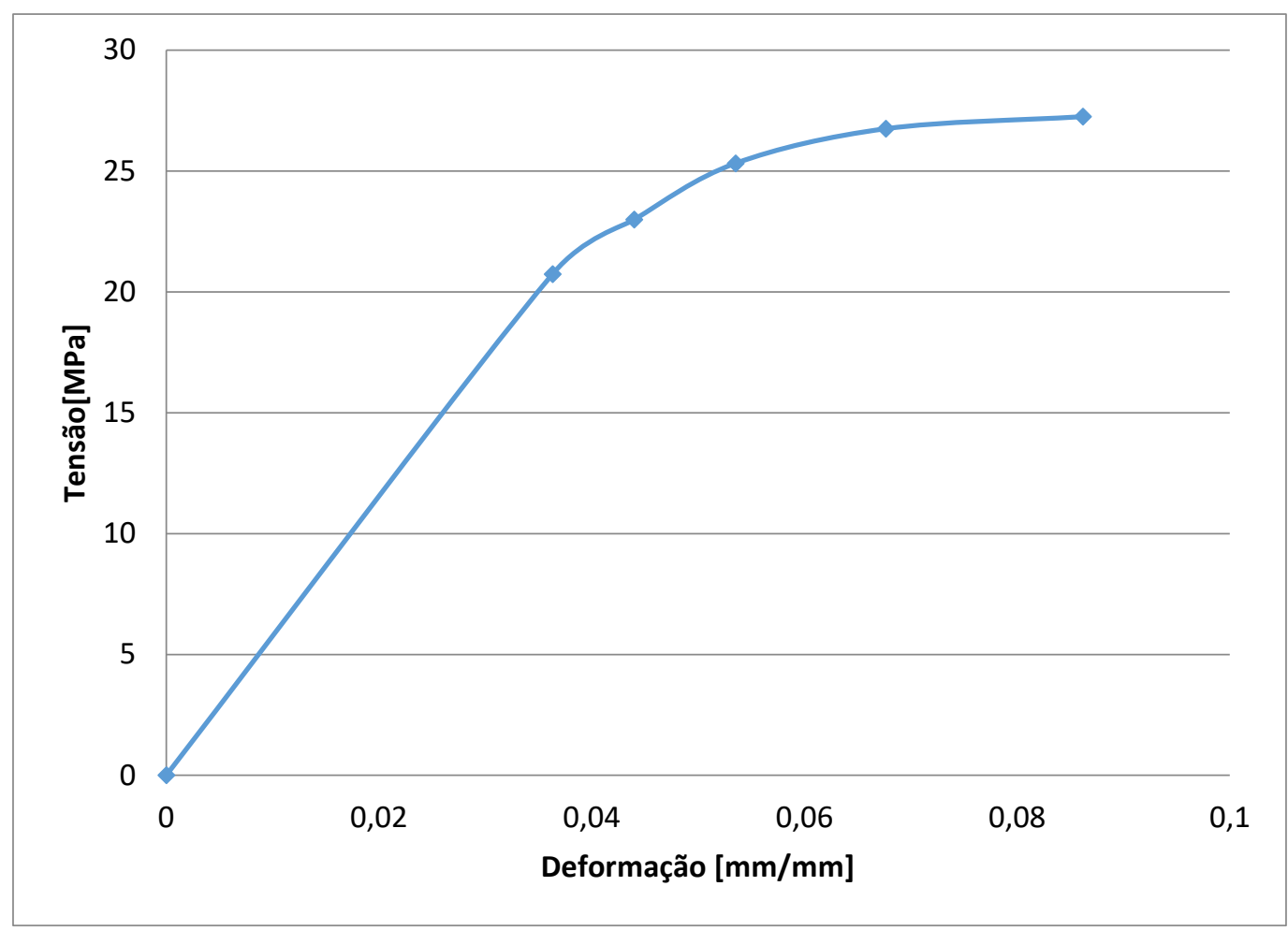

Figura 24 - Curva do material da camada polimérica externa.

Para as sapatas foi adotado o modelo de material linear elástico, inicialmente com um módulo de elasticidade alto, da ordem de $10^{15}$, a fim de representar a elevada rigidez dessa estrutura. A rigidez da sapata é também um parâmetro de análise deste trabalho, que será descrito no subcapítulo de análise paramétrica

\subsection{Elementos}

Foram usados dois tipos de elementos para a modelagem do tubo:

- Elementos sólidos tridimensionais: aplicados à carcaça intertravada, à armadura de pressão, às camadas poliméricas e à sapata.

- Elementos de contato: para representação das interações entre as camadas adjacentes e os contatos internos da armadura de pressão e carcaça intertravada. 
Todas as camadas foram modeladas com elementos sólidos tridimensionais de interpolação quadrática, SOLID186 (20 nós), como indicado na Figura 25. Esse elemento suporta plasticidade, hiperelasticidade, grandes deflexões e grandes deformações. É apropriado para o emprego em estudos que apresentam não-linearidades, como é o caso deste trabalho. Para os contatos entre as camadas foram usados elementos de superfícies tridimensionais CONTA174 e TARGE170, que são compatíveis com o SOLID186 e suportam escorregamento, atrito e contato colado.

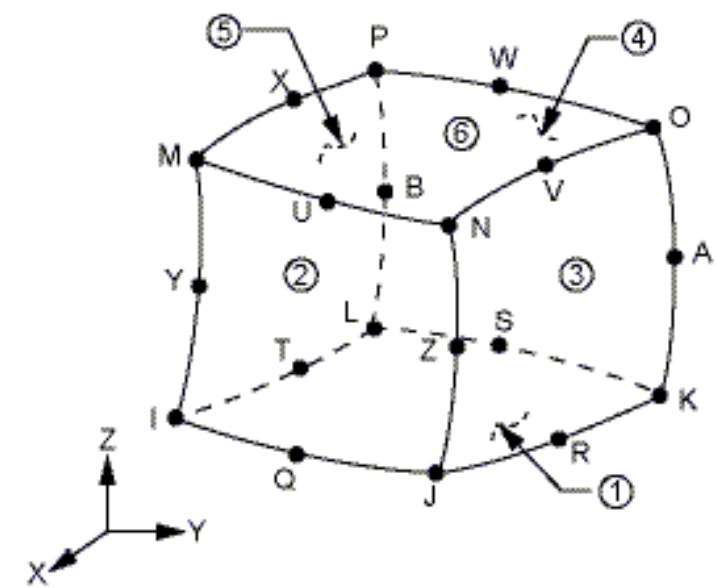

Figura 25 - Elemento sólido com 20 nós Fonte: [5].

\subsection{Malha}

As malhas das camadas metálicas foram modeladas de forma a serem mais refinadas do que a malha das camadas poliméricas a fim de evitar penetração e, consequentemente, problemas de convergência. Como a função das camadas poliméricas é apenas a transferência dos carregamentos entre as camadas metálicas, a sua malha é pouco discretizada. Além disso, é necessário que se tenha precisão do campo de tensões nas camadas metálicas para investigar a região de escoamento. A malha da sapata não representa grande preocupação uma vez que a principal função dessa estrutura é a transferência do carregamento de esmagamento ao tubo e, por isso, também foi pouco discretizada. 
A Tabela 7 apresenta os principais aspectos das malhas geradas para cada uma das camadas estudadas. A malha da carcaça intertravada foi desenvolvida de forma estruturada e extrudada ao longo do caminho de construção da geometria. Elementos hexaédricos são predominantes apesar de haver elementos prismáticos nos cantos arredondados do perfil. A malha da armadura de pressão é formada por elementos prismáticos enquanto que a malha da sapata contém elementos hexaédricos.

Tabela 7 - Dados das Malhas geradas para as camadas tubo de 4 polegadas.

\begin{tabular}{|l|c|c|c|c|}
\hline \multicolumn{1}{|c|}{ Camada* } & Malha & $\begin{array}{c}\text { Número de } \\
\text { nós }\end{array}$ & $\begin{array}{c}\text { Número de } \\
\text { Elementos }\end{array}$ & $\begin{array}{c}\text { Números de } \\
\text { Graus de li- } \\
\text { berdade** }\end{array}$ \\
\hline Carcaça intertravada & $60 \times 32 \times 3$ & 130068 & 25319 & 151914 \\
\hline Camada Polimérica interna & $60 \times 5 \times 5$ & 8014 & 1499 & 8994 \\
\hline Armadura de pressão & $60 \times 32 \times 7$ & 81495 & 25919 & 77757 \\
\hline Total & - & 219577 & 52737 & 238665 \\
\hline * Número de divisões circunferenciais x Número de divisões longitudinais x Número de divi- \\
sões radiais. \\
** Não são descontados os graus de liberdades restringidos \\
\hline
\end{tabular}

\subsection{Formulação dos Contatos}

Em todos os modelos foram considerados os contatos entre as camadas adjacentes bem como os contatos internos que ocorrem na carcaça intertravada e armadura de pressão. A formulação de contato usada foi o contato superfície a superfície (surface-to-surface), comumente aplicado quando há interação entre duas superfícies. Os contatos implementados são indicados na Figura 26 e Tabela 8, respectivamente. 
Tabela 8 - Pares de contatos adotados entre as camadas.

\begin{tabular}{|l|c|}
\hline \multicolumn{1}{|c|}{ Pares de contato } & Tipo de contato \\
\hline Contato entre carcaça e camada polimérica interna & \multirow{2}{*}{ bonded } \\
\hline Contatos internos da carcaça & \multirow{2}{*}{ frictionless } \\
\hline Contatos internos da armadura de pressão & \\
\hline Contato entre armadura de pressão e camada polimérica interna & \\
\hline Contato entre armadura de pressão e sapatas & \\
\hline
\end{tabular}

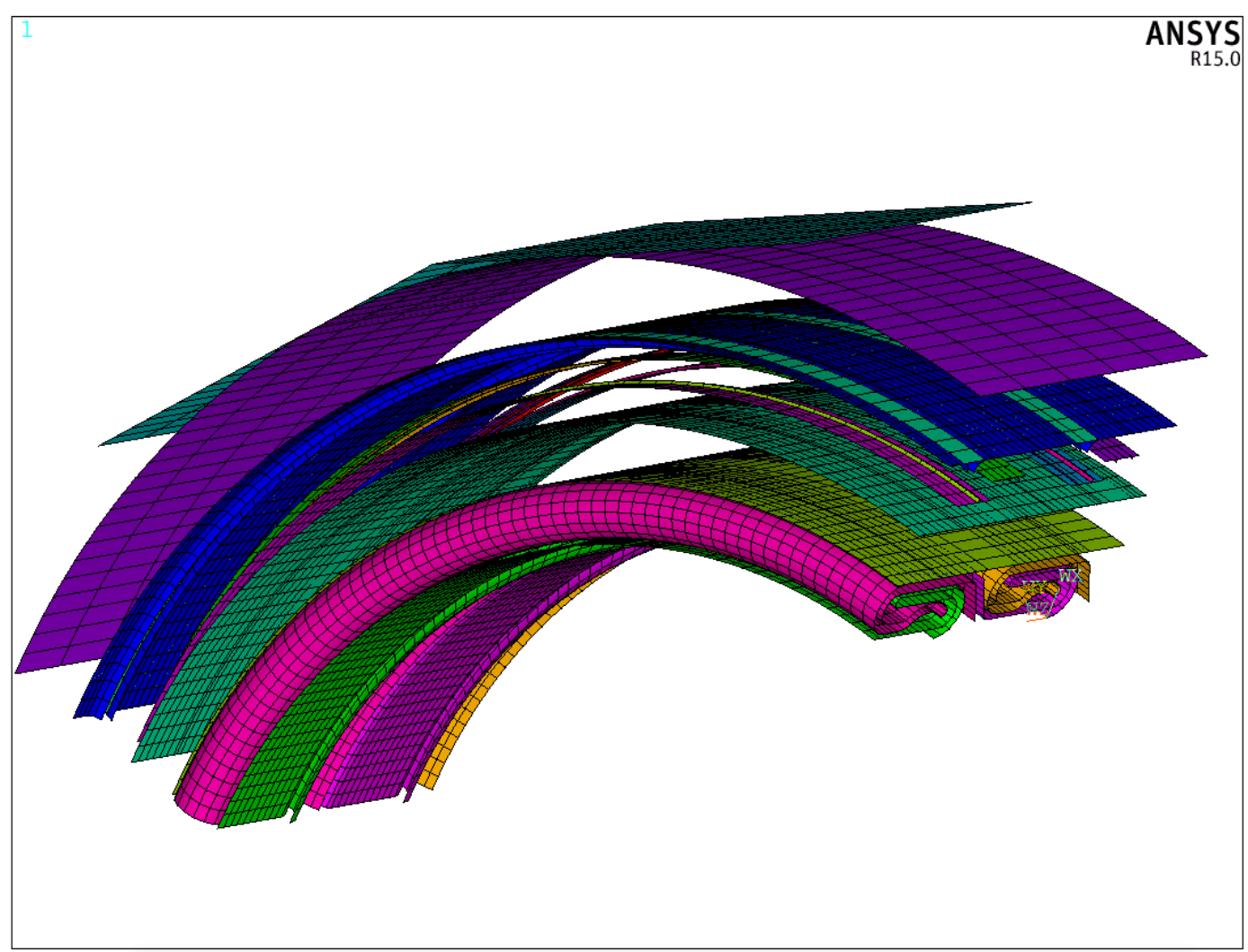

Figura 26 - Representação dos pares de contatos entre as camadas: (a) visão isométrica, (b) visão frontal dos contatos entre os perfis da seção transversal.

No contato colado (bonded) as superfícies são unidas em todas as direções evitando o movimento entre as camadas. Já o contato sem atrito (frictionless) permite o deslizamento entre as superfícies uma vez que o coeficiente de atrito é nulo. O algoritmo de contato escolhido para todos os pares foi a função de penalidade. A rigidez de contato é 
atualizada a cada iteração de acordo com a tensão média dos elementos adjacentes e seu valor varia de entre 10 e 0,1 dependendo do tipo de contato adotado.

\subsection{Condições de Contorno}

Como a representação do comprimento real do tubo aumentaria os graus de liberdade do sistema foram aplicadas condições de contorno ao modelo a fim de simplificá-lo e tornar a investigação paramétrica exequível:

i. Aplicou-se a condição de periodicidade nas extremidades da geometria com a finalidade de se representar o tubo como sendo contínuo e infinito como indicado na Figura 27.

ii. Condições cíclicas foram aplicadas nas seções transversais do perfil a fim de diminuir o esforço computacional do problema. Dessa forma, os graus de liberdade na região de corte são acoplados a fim de se representar a simetria entre as seções dos anéis representados. Dessa forma, para indicar um caso com 4 sapatas têm-se a representação de 1/4 do anel. Essa condição é representada na Figura 28.

iii. A simplificação adotada em i garante que o tubo seja tratado com um comprimento infinito. Com isso, pode ocorrer flexão do tubo em relação à sua linha central ainda que o carregamento aplicado seja apenas de esmagamento. Esse fenômeno causa movimento de corpo rígido, resultando em matriz de rigidez singular. Para evitar esses problemas são impostas restrições axiais à armadura de pressão e às camadas poliméricas como indicado na Figura 29.

iv. O deslocamento da sapata foi restrito de forma a se movimentar apenas na direção radial, no sentido de aplicação das forças compressivas radiais impostas às sapatas. 


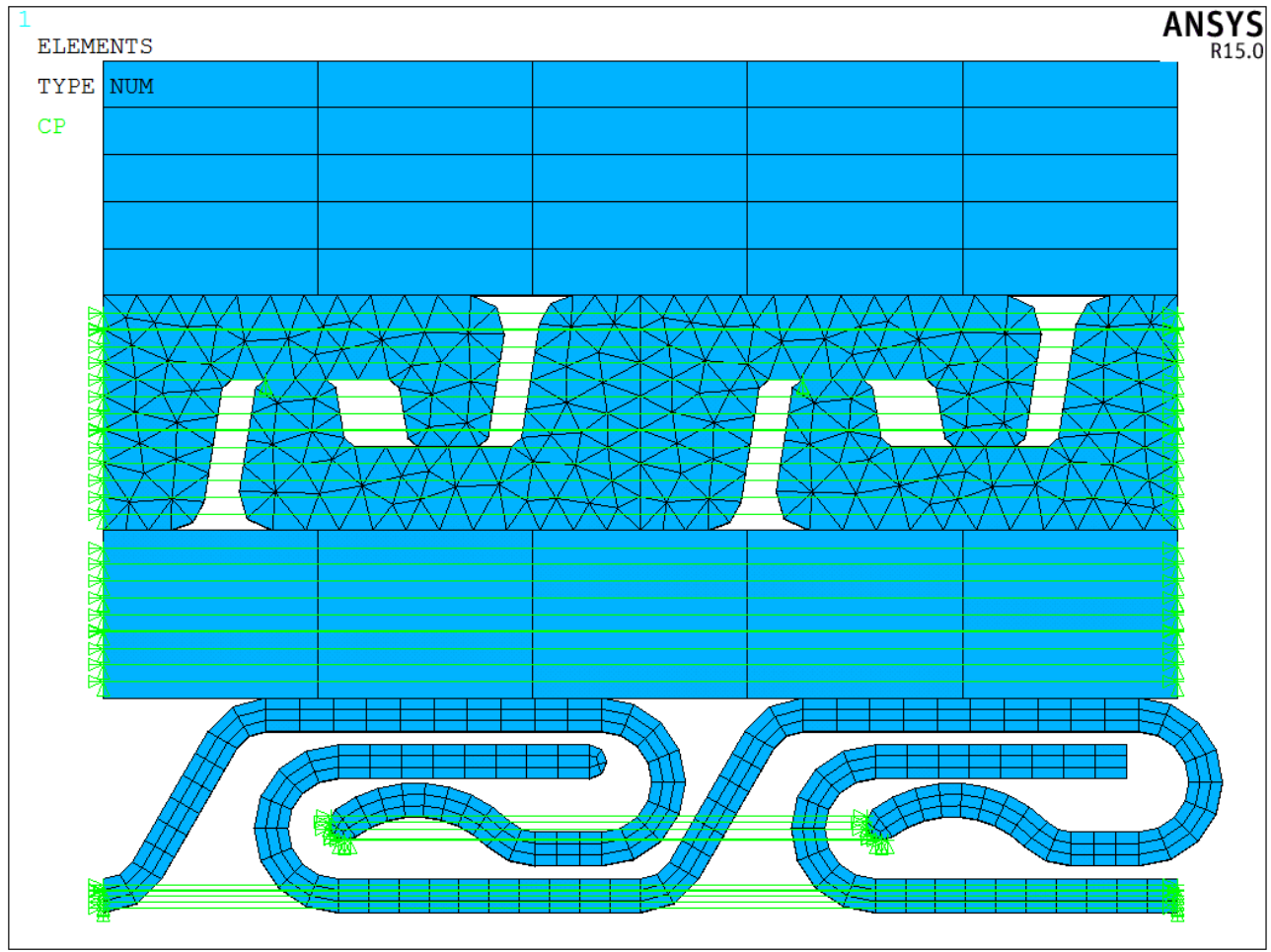

(a)

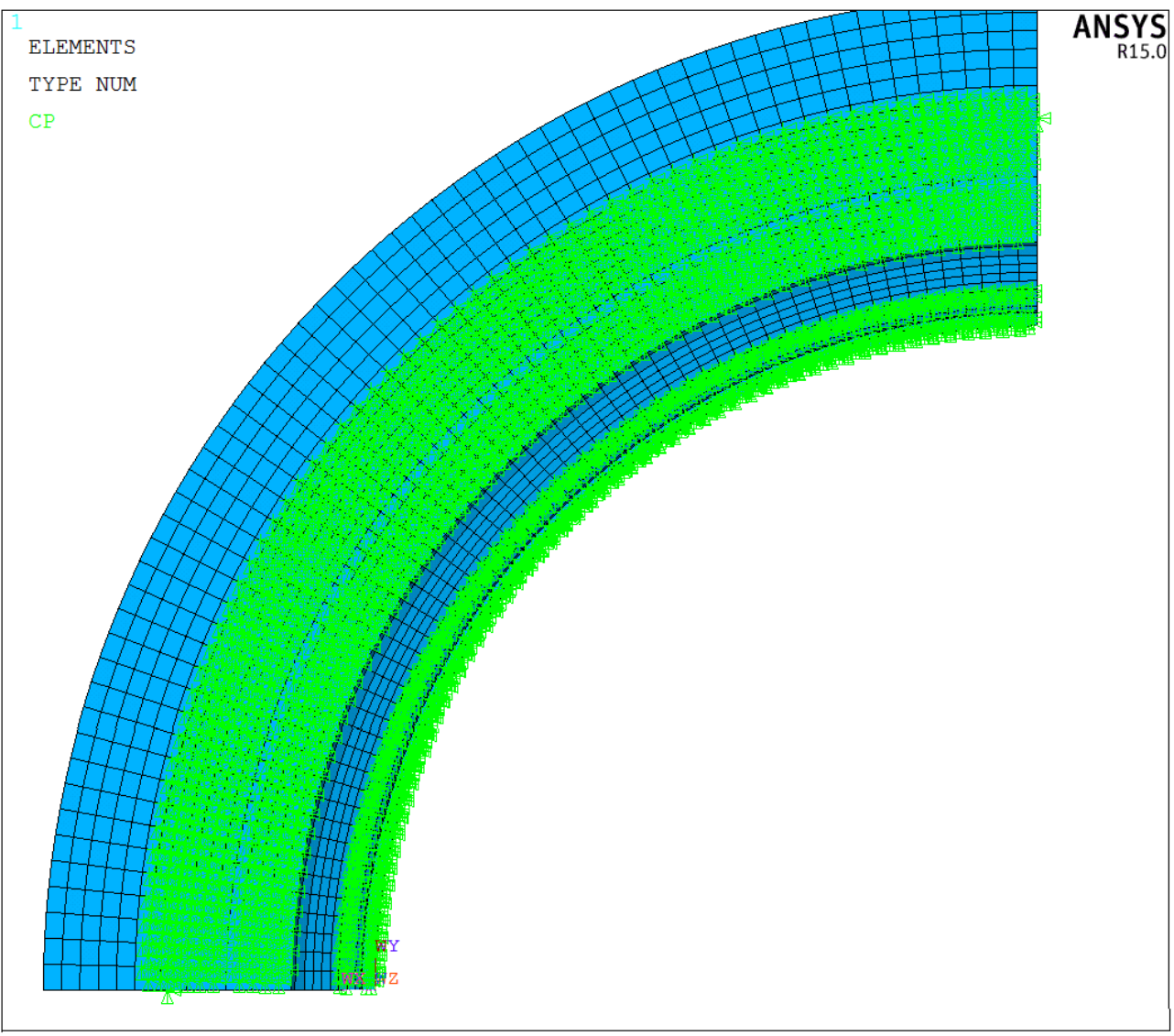

(b)

Figura 27 - Acoplamento das extremidades da geometria para representar o tubo como infinito: (a) vista do acoplamento na seção transversal e (b) vista do acoplamento em perspectiva. 


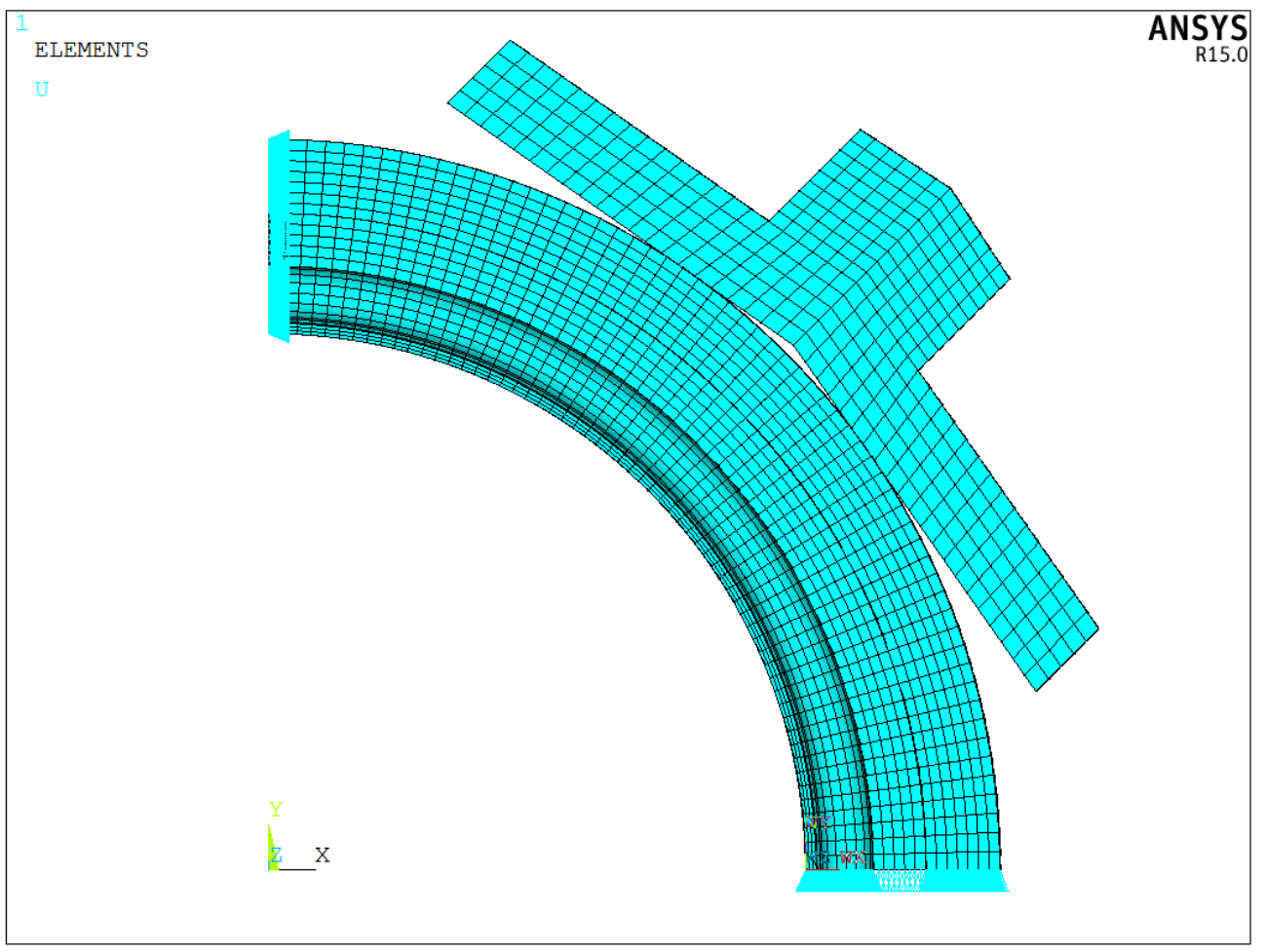

Figura 28 - Condição de contorno cíclica.

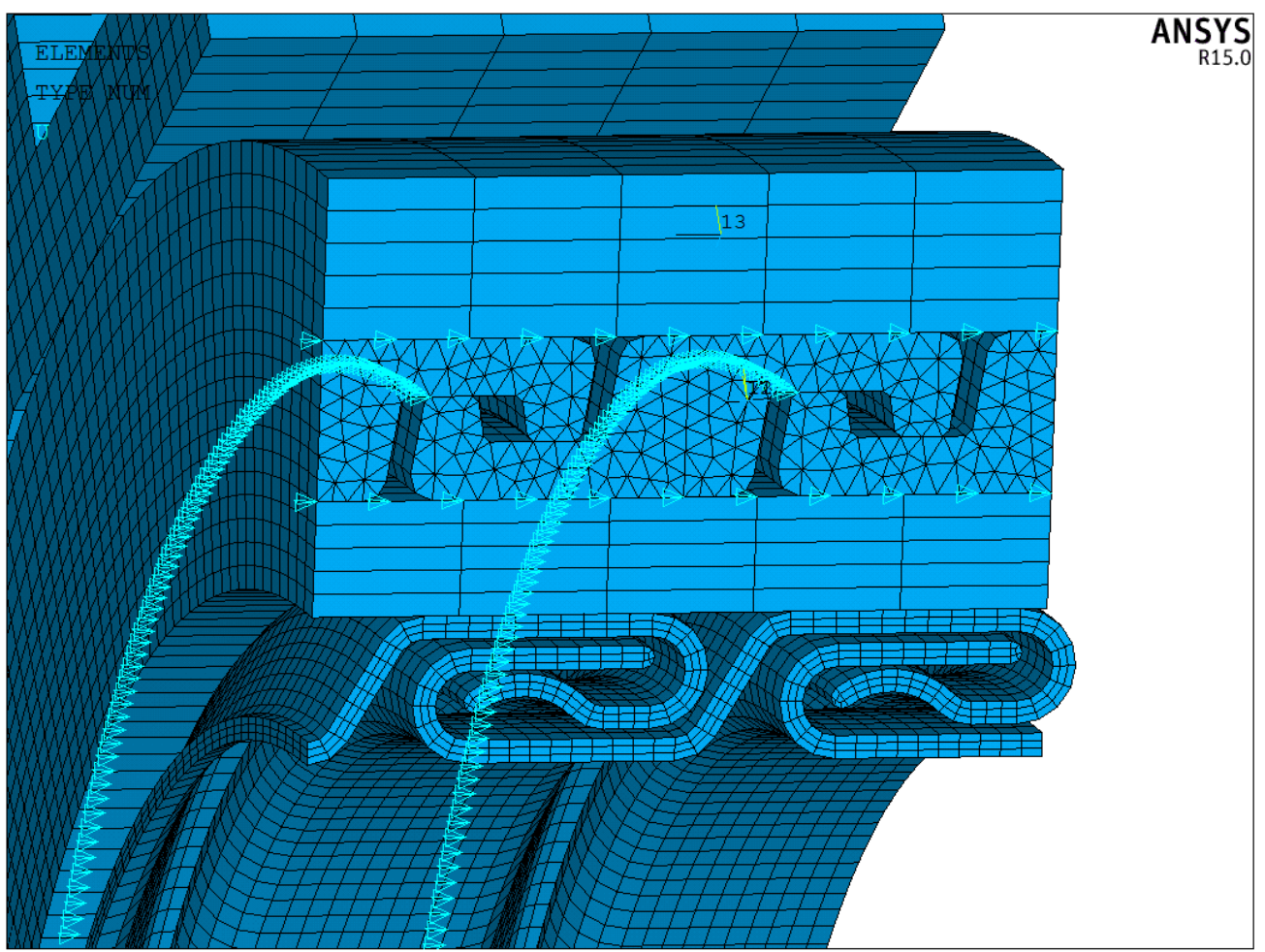

Figura 29 - Restrição do grau de liberdade de deslocamento na direção axial. 


\subsection{Carregamentos}

Foram aplicados dois carregamentos radiais ao tubo: a carga de esmagamento e a de estrangulamento, já mencionadas no subcapítulo 2.4. Em um primeiro momento, foi analisada apenas a atuação do esmagamento no tubo flexível a fim de se determinar a falha do tubo segundo a norma 2409 para alguns dos casos abordados. A força de esmagamento foi aplicada estaticamente à superfície superior da sapata, distribuída aos nós, variando linearmente em incrementos percentuais de carga (substeps) de zero até o valor máximo atribuído, de $75 \mathrm{kN}$.

Posteriormente, foram aplicados os carregamentos de esmagamento e estrangulamento, simultaneamente, com o intuito de investigar qual o limite de profundidade que o tubo estudado pode operar sem que ocorra sua falha durante o lançamento.

A carga de estrangulamento foi aplicada, de maneira similar à de esmagamento, à superfície externa da armadura de pressão, uma vez que a geometria da armadura de tração não foi representada.

\subsection{Solver}

Em Elementos Finitos, a análise da solução é escolhida a partir da natureza do problema estudado: estática ou dinâmica. Usualmente, problemas estáticos não-lineares são resolvidos pelo método de Newton Paphson. Por isso, foi adotada a análise implícita baseada no método de solução de Newton Raphson, em que a matriz de rigidez é atualizada a cada iteração. Esse método é aplicado para solução de problemas não lineares, sendo adequado para estudos estáticos, em que os deslocamentos não são função do tempo. A solução é baseada em equações de equilíbrio resolvidas para percentuais incrementais de carga (substeps). A análise implícita foi empregada em todos os modelos, não apresentando problemas de convergência. 
O processo de discretização em elementos finitos se dá inicialmente pela equação não linear abaixo:

$$
[K]\{u\}=\left\{F_{e}\right\}
$$

Em que:

[K] é a matriz de coeficientes, e função dos graus de liberdade desconhecidos;

$\{\mathrm{u}\}$ é o vetor de graus de liberdade desconhecidos;

$\{F\}$ é o vetor de forças externas aplicadas;

O Método de Newton-Raphson é um processo interativo de solução de equações não-lineares, e pode ser escrito como:

$$
\begin{array}{r}
{\left[K_{i}\right]\left\{\Delta u_{i}\right\}=\left\{F_{e}\right\}-\left\{F_{i}\right\}} \\
\left\{u_{i+1}\right\}=\left\{u_{i}\right\}+\left\{\Delta u_{i}\right\}
\end{array}
$$

Em que:

$\left[K_{i}\right]$ é a matriz Jacobiana;

O Subscrito i representa a interação analisada;

$\left\{F_{i}\right\}$ é o vetor de cargas internas dos elementos;

O termo do lado direito da Eq. 4 é o resíduo, e a matriz jacobiana bem como o vetor de forças internas são atualizados a cada interação a partir dos resultados da interação anterior. A solução final apresenta o resultado para o estado de equilíbrio.

\subsection{Análise Paramétrica}

Neste trabalho, a falha do tubo flexível será endereçada a partir da norma 2409, que se resume ao escoamento de uma das camadas metálicas respeitando-se o fator de segurança da outra. Seriam necessários vários estudos para se ter uma previsão assertiva da falha do tubo durante o lançamento. Desta forma, foram selecionados apenas aqueles parâmetros que foram considerados mais importantes na falha. A Tabela 9 apresenta os casos de estudo realizados. 
Tabela 9 - Casos de estudo avaliados.

\begin{tabular}{|c|c|c|}
\hline Estudo & Carregamento & Parâmetro investigado \\
\hline $\mathbf{1}^{\circ}$ & esmagamento & Quantidade de sapatas \\
\hline $\mathbf{2}^{\circ}$ & esmagamento & Ângulo de abertura das sapatas \\
\hline $\mathbf{3}^{\circ}$ & esmagamento & $\begin{array}{c}\text { Adição da camada polimérica } \\
\text { externa e seu contato com as } \\
\text { sapatas }\end{array}$ \\
\hline $\mathbf{4}^{\circ}$ & esmagamento & \begin{tabular}{c} 
Variação de rigidez das sapatas \\
\hline $\mathbf{5}^{\circ}$
\end{tabular} \\
\hline
\end{tabular}

Para os casos $1^{\circ}$ ao $4^{\circ}$ foi avaliada a falha considerando-se apenas o esmagamento do tubo pelas sapatas dos tensionadores. Para isso, foi adotada uma carga de $75 \mathrm{kN}$ para estes casos a fim de certificar a plastificação da carcaça intertravada e da armadura de pressão . Para o $5^{\circ}$ caso as cargas de esmagamento e estrangulamento foram calculadas considerando-se a profundidade de lançamento da linha. Os parâmetros investigados em cada um dos casos da Tabela 9 são indicados nas Tabela 10 a Tabela 14.

O primeiro estudo, Tabela 10 , retrata como as camadas metálicas falham quando o lançamento do tubo é feito com diferentes quantidades de sapatas, 2, 3 e 4 . O ângulo de abertura da sapata foi mantido em $160^{\circ}$.

Tabela 10 - $1^{\circ}$ estudo: avaliação do número de sapatas.

\begin{tabular}{|c|c|c|}
\hline Caso & $\begin{array}{c}\text { Ângulo de abertura } \\
\text { [graus] }\end{array}$ & $\begin{array}{l}\text { Número de } \\
\text { sapatas }\end{array}$ \\
\hline NS1 & \multirow{3}{*}{160} & 2 \\
\hline NS2 & & 3 \\
\hline NS3 & & 4 \\
\hline
\end{tabular}


O segundo estudo é apresentado na Tabela 11 em que são indicadas as análises para variação do ângulo de abertura das sapatas, de $120^{\circ}$ a $180^{\circ}$. Uma configuração de lançamento com 4 sapatas foi escolhida para proceder com a análise.

Tabela 11 - $2^{\circ}$ estudo: avaliação do ângulo de abertura das sapatas.

\begin{tabular}{|c|c|c|}
\hline Caso & $\begin{array}{c}\text { Ângulo de abertura } \\
\text { [graus] }\end{array}$ & \multirow{2}{*}{ Número de sapatas } \\
\hline OA1 & 120 \\
\hline OA2 & 130 \\
\hline OA3 & 140 \\
\hline OA4 & 150 \\
\hline OA5 & 160 \\
\hline OA6 & 170 \\
\hline OA7 & 180 \\
\hline
\end{tabular}

O terceiro caso de estudo é indicado na Tabela 12, em que a capa plástica foi adicionada ao núcleo estrutural a fim de se prever o comportamento das camadas metálicas durante o esmagamento. Além disso, foram avaliados diferentes tipos de contato entre a capa plástica e a armadura de pressão: frictionless (sem atrito), bonded (colado) e rough (atrito infinito). A configuração de lançamento escolhida foi de quatro sapatas e um ângulo de abertura de $160^{\circ}$.

A Tabela 13 apresenta o quarto caso de estudo, em que foram analisados módulos de elasticidade das sapatas com ordens de grandeza distintas a fim de analisar a qual a influência da rigidez desta estrutura na falha do tubo. 
Tabela 12 - $3^{\circ}$ estudo: adição da capa plástica e análise do seu contato com as sapatas.

\begin{tabular}{|c|c|c|c|}
\hline Caso & $\begin{array}{c}\text { Ângulo de abertura } \\
\text { [graus] }\end{array}$ & Tipo de contato & Número de sapatas \\
\cline { 1 - 1 } CT1 & & frictionless & \multirow{2}{*}{} \\
\cline { 1 - 1 } CT2 & \multirow{2}{*}{160} & bonded & \\
\cline { 1 - 1 } CT3 & & rough & \\
& & & \\
\hline
\end{tabular}

Tabela 13 - $4^{\circ}$ estudo: avaliação da rigidez da sapata.

\begin{tabular}{|c|c|c|c|}
\hline Caso & $\begin{array}{c}\text { Ângulo de abertura } \\
\text { [graus] }\end{array}$ & $\begin{array}{c}\text { Módulo de } \\
\text { elasticidade } \\
\text { [GPa] }\end{array}$ & Número de sapatas \\
\hline RS1 & \multirow{9}{*}{160} & 0,21 & \multirow{9}{*}{4} \\
\hline RS2 & & 2,1 & \\
\hline RS3 & & 21 & \\
\hline RS4 & & 210 & \\
\hline RS5 & & 2100 & \\
\hline RS6 & & 21000 & \\
\hline RS7 & & 210000 & \\
\hline RS8 & & 2100000 & \\
\hline RS9 & & 21000000 & \\
\hline
\end{tabular}

Por fim, a Tabela 14 apresenta as profundidades de lançamento investigadas para os casos em que os carregamentos de esmagamento e estrangulamento atuam conjuntamente. Foram analisadas várias profundidades, em intervalos de $100 \mathrm{~m}$, até que fosse atingida aquela em que o tubo investigado sofre escoamento. Para isso, foi usada a configuração de tensionador com quatro sapatas e ângulo de abertura de $160^{\circ}$. 
A metodologia de cálculo dos carregamentos de esmagamento e estrangulamento é apresentada no próximo subcapítulo.

Tabela 14 - $5^{\circ}$ estudo: avaliação da influência das cargas de esmagamento e estrangulamento na falha do tubo com a profundidade de lançamento.

\begin{tabular}{|c|c|c|c|}
\hline Caso & $\begin{array}{c}\text { Ângulo de abertura } \\
\text { [graus] }\end{array}$ & $\begin{array}{c}\text { Profundidade } \\
\text { de lançamento } \\
\text { [m] }\end{array}$ & Número de sapatas \\
\hline PL1 & \multirow{6}{*}{160} & 100 & \multirow{6}{*}{4} \\
\hline PL2 & & 200 & \\
\hline PL3 & & 300 & \\
\hline PL4 & & 400 & \\
\hline PL5 & & 500 & \\
\hline PL6 & & 600 & \\
\hline
\end{tabular}

\subsection{Cálculo dos Carregamentos}

Foi escolhido um tubo flexível característico com 11 camadas para o cálculo da rigidez flexional e da pressão de estrangulamento. Esse cálculo foi feito por meio da rotina computacional PipeDesign, desenvolvida pela equipe do LMO. Essa rotina é baseada na formulação analítica do trabalho de RAMOS (2001), já mencionado no capítulo 3, e detalhada no Apêndice B. As camadas do tubo e suas dimensões são apresentadas na Figura 30 e Tabela 15.

A tração dinâmica efetiva que atua no tubo foi calculada por meio do programa Poliflex, desenvolvido também no LMO. Partindo-se de um ângulo de lançamento da linha de $3^{\circ}$, e a rigidez flexional calculada pelo PipeDesign para uma profundidade de $100 \mathrm{~m}$ foi possível estimar a tração dinâmica máxima para cada uma das profundidades de lançamento investigadas. O movimento imposto ao topo, a frequência e o período de 
oscilação da onda, o coeficiente de arrasto, entre outras variáveis foram escolhidas de modo a se ter uma configuração de lançamento plausível, e são indicadas na Tabela 16.

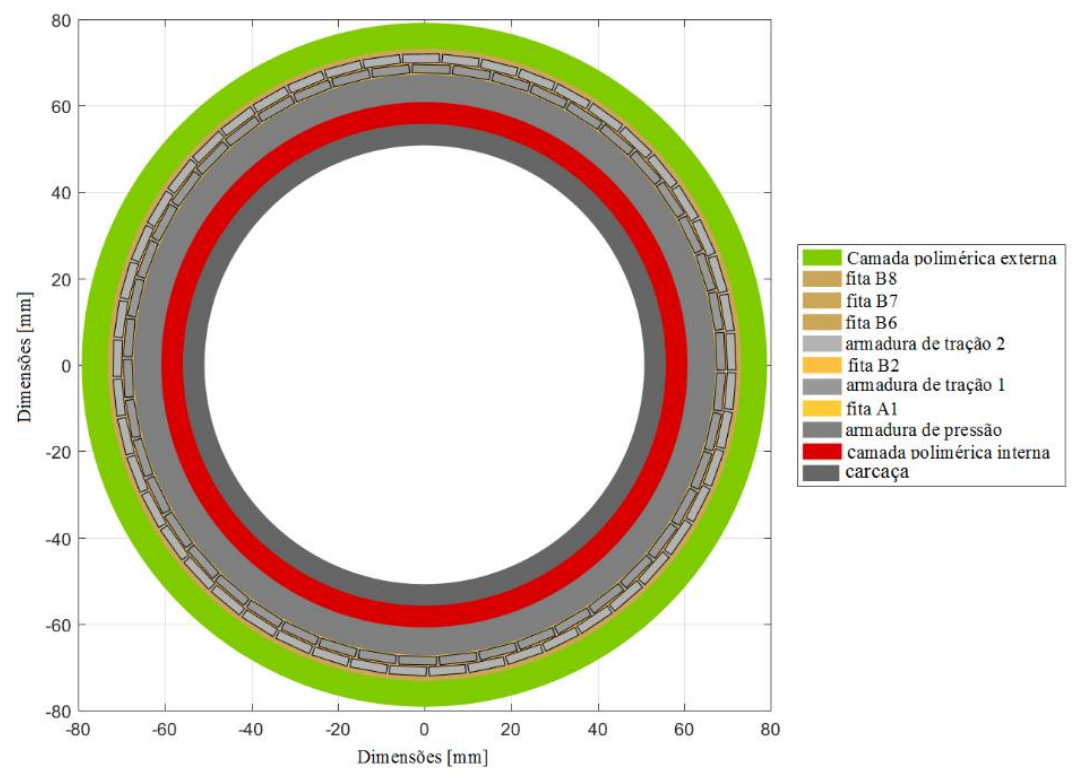

(a)

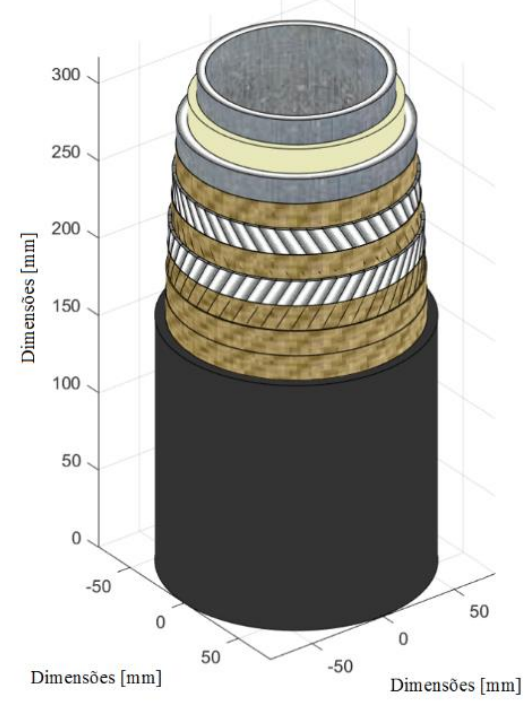

(b)

Figura 30 - Tubo utilizado para o cálculo da rigidez flexional e da pressão de estrangulamento: (a) vista bidimensional; (b) vista tridimensional 
Tabela 15 - Propriedades geométricas do tubo característico.

\begin{tabular}{|c|c|c|c|c|c|}
\hline Camadas & Material & $\begin{array}{l}\text { Número } \\
\text { de arames }\end{array}$ & $\begin{array}{c}\text { Ângulo de } \\
\text { assentamento } \\
\text { [graus] }\end{array}$ & $\begin{array}{c}\text { Espessura } \\
{[\mathrm{mm}]}\end{array}$ & $\begin{array}{c}\text { Diâmetro } \\
\text { interno } \\
\text { [mm] }\end{array}$ \\
\hline Carcaça & AISI 316L & 1 & -87.97 & 5 & 111.6 \\
\hline $\begin{array}{c}\text { Camada } \\
\text { polimérica } \\
\text { interna }\end{array}$ & Nylon 11 & - & - & 5 & 121.6 \\
\hline $\begin{array}{c}\text { Armadura de } \\
\text { pressão }\end{array}$ & Aço carbono & 1 & -88.58 & 6.45 & 134.5 \\
\hline Fita A1 & Polipropileno & - & - & 0.22 & 134.94 \\
\hline $\begin{array}{c}\text { Armadura de } \\
\text { tração } 1\end{array}$ & Aço galvanizado & 46 & 36 & 2 & 138.94 \\
\hline Fita B2 & Polipropileno & - & - & 0.44 & 139.82 \\
\hline $\begin{array}{l}\text { Armadura de } \\
\text { tração } 2\end{array}$ & Aço galvanizado & 49 & -34 & 2 & 143.82 \\
\hline Fita B6 & Polipropileno & - & - & 0.22 & 144.26 \\
\hline Fita B7 & Material fibroso & - & - & 0.8 & 145.86 \\
\hline Fita B8 & Polipropileno & - & - & 0.24 & 146.34 \\
\hline $\begin{array}{c}\text { Camada } \\
\text { polimérica } \\
\text { externa }\end{array}$ & HDPE & - & - & 6 & 158.34 \\
\hline
\end{tabular}


Tabela 16 - Propriedades da linha flexível e condições ambientais para os casos de estudo.

\begin{tabular}{|c|c|}
\hline \multicolumn{2}{|c|}{ Propriedades do tubo flexível e condições ambientais } \\
\hline Rigidez axial (EA) & $138949,15[\mathrm{kN}]$ \\
\hline Rigidez flexional (EI) & $3,56\left[\mathrm{kNm}{ }^{2}\right]$ \\
\hline Peso no ar & $0,423[\mathrm{kN} / \mathrm{m}]$ \\
\hline Arrasto normal & 1,0 \\
\hline Arrasto tangencial & 0,1 \\
\hline Massa adicional & 1,0 \\
\hline Densidade da água & $1024\left[\mathrm{~kg} / \mathrm{m}^{3}\right]$ \\
\hline Amplitude da onda & $2[\mathrm{~m}]$ \\
\hline Período de oscilação da onda & $10[\mathrm{~s}]$ \\
\hline Movimento imposto ao topo & $2[\mathrm{~m}]$ \\
\hline
\end{tabular}

Partiu-se de um coeficiente de atrito entre o tubo e as sapatas de 0,5 e comprimento de $5 \mathrm{~m}$ para cada uma das sapatas. Assim, a carga de esmagamento necessária para sustentar o peso da linha flexível durante o lançamento pode então ser calculada a partir de Martins, Pesce e Aranha (2003):

$$
F_{e s m}=\frac{F_{t}}{n_{s t} L_{s t} \mu}
$$

Sendo:

$F_{e s m}$ a força de esmagamento atuante em cada sapata;

$n_{s t}$ é a quantidade de sapatas do tensionador;

$L_{s t}$ é o comprimento de cada sapata;

$\mu$ é o coeficiente de atrito entre as sapatas e o tubo.

A Tabela 17 indica a tração efetiva e a força de esmagamento para cada profundidade de lançamento. Também são apresentadas as respectivas pressões de estrangulamento. 
Tabela 17 - Cargas de tração efetiva dinâmica e pressão de esmagamento em cada sapata para as profundidades estudadas.

\begin{tabular}{|c|c|c|c|c|}
\hline $\begin{array}{c}\text { Profundidade } \\
\text { [m] }\end{array}$ & $\begin{array}{c}\text { Ângulo de } \\
\text { lançamento } \\
\text { [graus] }\end{array}$ & $\begin{array}{c}\text { Tração efetiva } \\
\text { no topo }[N]\end{array}$ & $\begin{array}{c}\text { Força de } \\
\text { esmagamento } \\
\text { por sapata[N] }\end{array}$ & $\begin{array}{c}\text { Pressão de } \\
\text { estrangulamento } \\
\text { [MPa] }\end{array}$ \\
\hline 100 & \multirow{6}{*}{3} & 40343 & 4034,3 & 0,699 \\
\hline 200 & & 81838 & 8183,8 & 1,42 \\
\hline 300 & & 123194 & 12319,4 & 2,13 \\
\hline 400 & & 164684 & 16468,4 & 2,85 \\
\hline 500 & & 206142 & 20614,2 & 3,57 \\
\hline 600 & & 247802 & 24780,2 & 4,29 \\
\hline
\end{tabular}

\subsection{Método de Avaliação dos Resultados}

Uma vez definida a metodologia de estudo, é necessário que se estabeleçam os resultados a serem analisados bem como os critérios de avaliação. Como já mencionado nos capítulos anteriores, esse trabalho tem por objetivo a análise da falha dos tubos flexíveis durante o lançamento. Essa falha é definida a partir do escoamento das camadas metálicas, que são responsáveis por resistir aos carregamentos radiais. Os critérios para avaliação dos resultados são baseados na Norma 2409 da Petrobrás, indicada no subcapítulo 2.3. Essa norma cita vários modos de falha, agrupados de acordo com a região em que ocorrem. De acordo com essa norma, a falha do tubo quando submetido a carregamentos de compressão radiais ocorrerá quando uma das camadas metálicas atingir o limite de escoamento dado que a outra respeite o fator de utilização. Esse limite é definido pela razão entre o valor da tensão de von Mises registrada na camada metálica e a tensão de escoamento do material, como já indicado na Eq.(1). O tubo falha quando essa razão for igual ou superior a 0,8 .

Os resultados das tensões foram observados no passo de carga (substep) anterior ao escoamento para se ter uma previsão conservadora da falha das camadas metálicas. A 
tensão de von Mises foi analisada a partir da média das tensões registradas em elementos da região crítica. Essa região crítica, que é basicamente a superfície de escoamento da carcaça intertravada e da armadura de pressão, varia de acordo com cada caso de estudo tratado. Dado isso, foi necessário que fosse feita uma investigação minuciosa das camadas metálicas em cada um dos passos incrementais de carga para se definir onde ocorre a falha. O próximo capítulo apresenta a região de análise para todos os casos de estudo.

\subsection{Região de Escoamento}

Neste subcapítulo serão apresentadas as superfícies de escoamento da carcaça intertravada e da armadura de pressão para os casos de estudo tratados nesta dissertação. A região de plastificação da carcaça é a mesma para todos os parâmetros investigados, e está indicada na Figura 31. As superfícies críticas são indicadas pela numeração 1 e 2 , localizadas na extremidade do perfil.

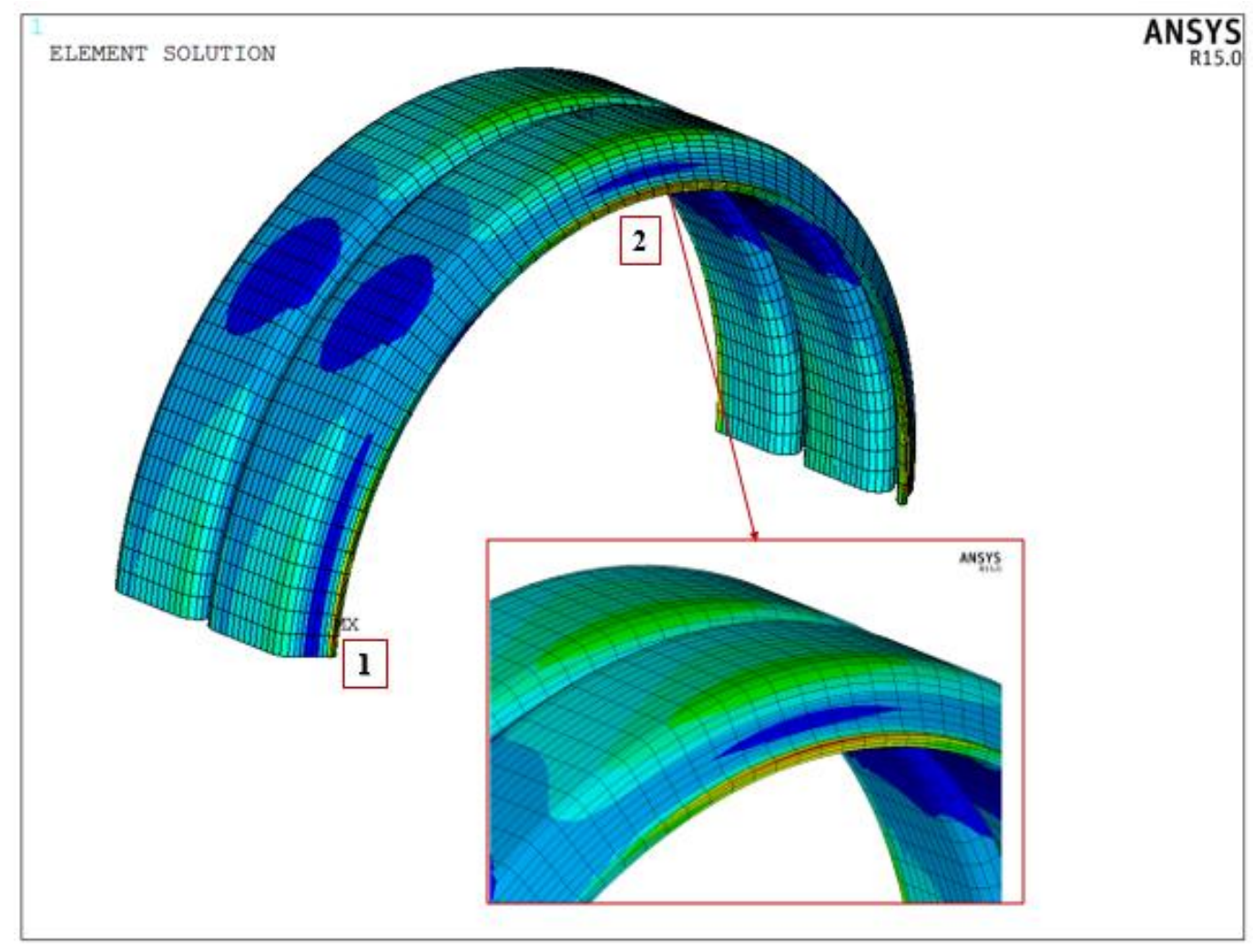

Figura 31 - Região de escoamento da carcaça para o caso com duas sapatas de lançamento. 
As regiões de escoamento da armadura de pressão são distintas para os casos em que se tem variação na quantidade de sapatas e ângulo de abertura. A Figura 32 e Figura 33 indicam a região de plastificação para os casos de lançamento com duas e três sapatas, respectivamente.

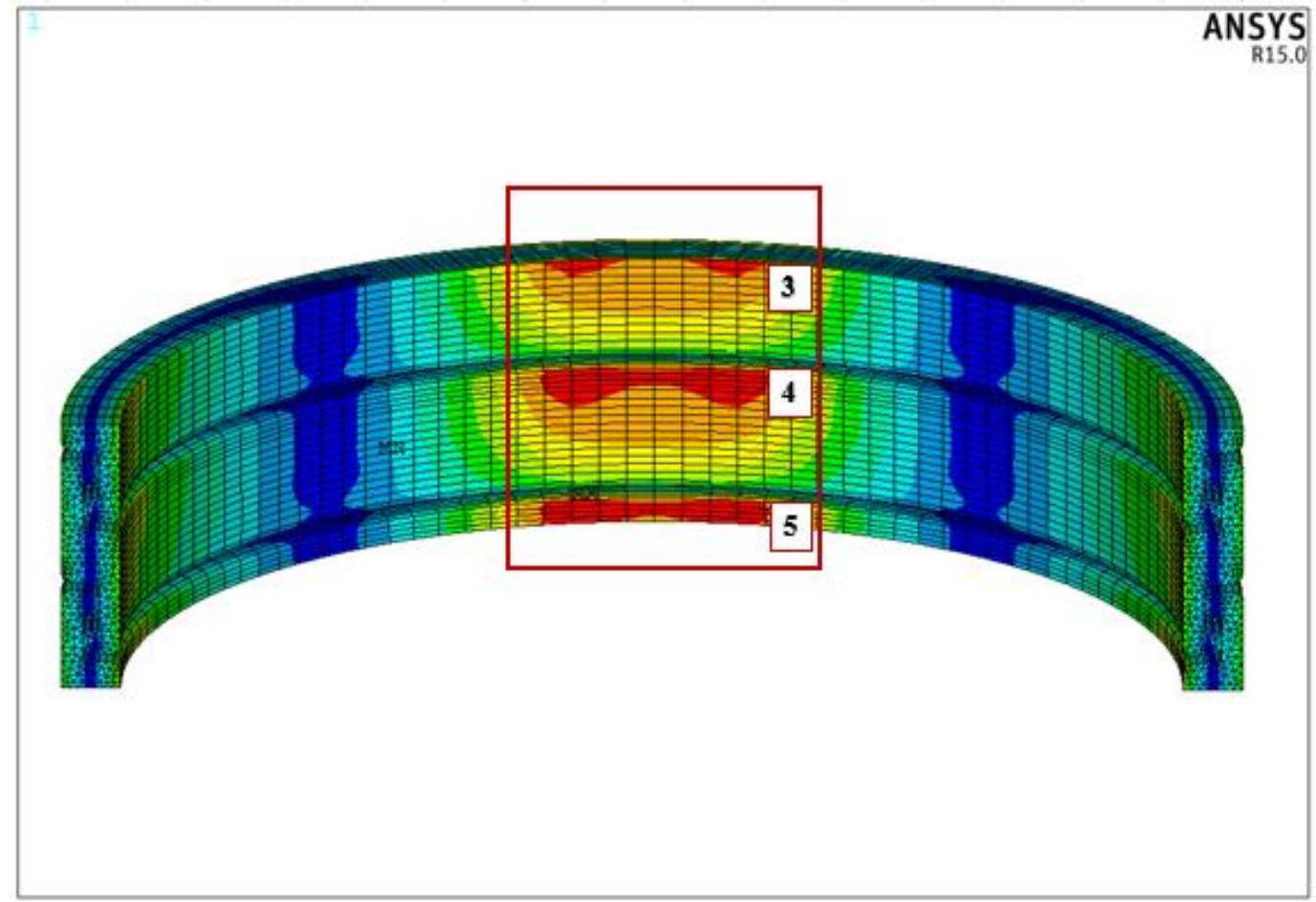

Figura 32 - Região de escoamento da armadura de pressão para o caso de estudo com duas sapatas.

A Figura 34 apresenta as regiões de plastificação da armadura de pressão para os casos em que se têm ângulo de abertura de $120^{\circ}, 130^{\circ}, 140^{\circ}$ e $150^{\circ}$. Para os ângulos de $160^{\circ}, 170^{\circ}$ e $180^{\circ}$ a região crítica é a mesma do caso com três sapatas, indicado na Figura 33. Com isso, pode-se afirmar que em vista de todos os parâmetros analisados neste trabalho, a quantidade de sapatas e seu ângulo de abertura são os únicos responsáveis pela alteração da superfície de plastificação da armadura de pressão. A Tabela 18 apresenta a descrição dessas superfícies para todos os casos de estudo efetuados. 


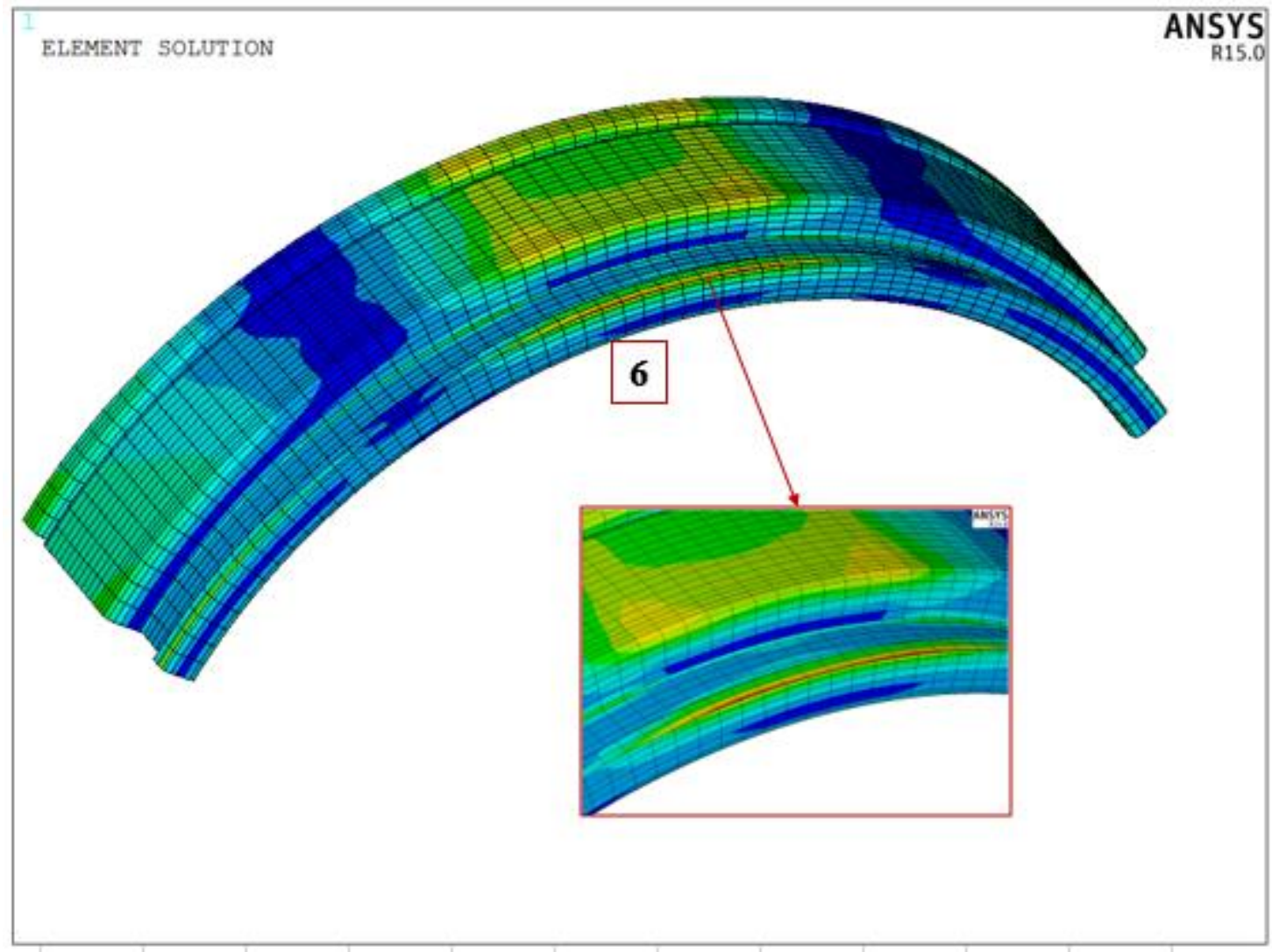

Figura 33 - Região de escoamento da armadura de pressão para o caso de estudo com 3 sapatas.

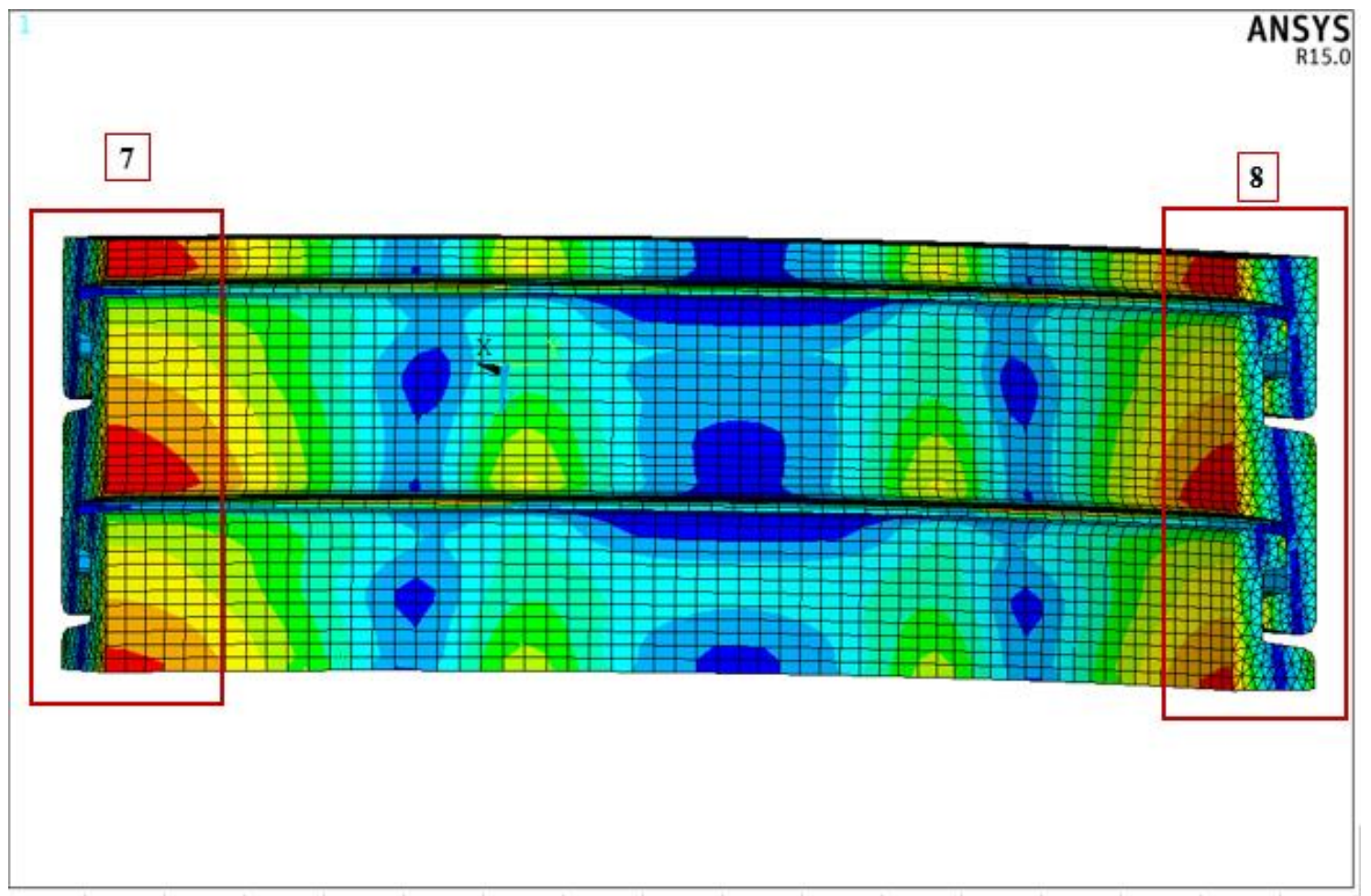

Figura 34 - Região de escoamento da armadura de pressão para o ângulo de abertura de $150^{\circ}$. 
Tabela 18 - Regiões de escoamento das camadas metálicas para os cinco casos de estudo.

\begin{tabular}{|c|c|c|c|}
\hline & Caso de estudo & $\begin{array}{c}\text { Região de } \\
\text { escoamento da } \\
\text { carcaça } \\
\end{array}$ & $\begin{array}{c}\text { Região de escoamento } \\
\text { da armadura de } \\
\text { pressão }\end{array}$ \\
\hline \multirow[t]{3}{*}{$1^{\circ}$} & NS1 & \multirow[t]{3}{*}{1 e 2} & 3,4 e 5 \\
\hline & NS2 & & \multirow[t]{2}{*}{6} \\
\hline & NS3 & & \\
\hline \multirow[t]{7}{*}{$2^{\circ}$} & OA1 & \multirow[t]{7}{*}{1 e 2} & \multirow[t]{4}{*}{7 e 8} \\
\hline & OA2 & & \\
\hline & OA3 & & \\
\hline & OA4 & & \\
\hline & OA5 & & \multirow[t]{3}{*}{6} \\
\hline & OA6 & & \\
\hline & OA7 & & \\
\hline \multirow[t]{3}{*}{$3^{\circ}$} & CT1 & \multirow[t]{3}{*}{1 e 2} & \multirow[t]{3}{*}{6} \\
\hline & $\mathrm{CT} 2$ & & \\
\hline & CT3 & & \\
\hline \multirow[t]{9}{*}{$4^{\circ}$} & RS1 & \multirow{9}{*}{1 e 2} & \multirow[t]{9}{*}{6} \\
\hline & RS2 & & \\
\hline & RS3 & & \\
\hline & RS4 & & \\
\hline & RS5 & & \\
\hline & RS6 & & \\
\hline & RS7 & & \\
\hline & RS8 & & \\
\hline & RS9 & & \\
\hline \multirow[t]{6}{*}{$5^{\circ}$} & PL1 & \multirow[t]{6}{*}{1 e 2} & \multirow[t]{6}{*}{6} \\
\hline & PL2 & & \\
\hline & PL3 & & \\
\hline & PL4 & & \\
\hline & PL5 & & \\
\hline & PL6 & & \\
\hline
\end{tabular}




\section{ANÁLISE DOS RESULTADOS}

Como já mencionado no subcapítulo 4.12, a investigação dos parâmetros estudados obedeceu apenas ao critério de tensão. Os deslocamentos radiais também foram analisados, mas unicamente com o intuito de se prever a variação da rigidez do tubo com as variáveis de lançamento. Após a avaliação minuciosa de cada caso de estudo foi possível identificar uma configuração de sapata que proporciona ao tubo a capacidade de suportar carregamentos de esmagamento elevados sem que ocorra sua falha; também foi observado que parâmetros como o contato entre o tubo e sapata, bem como a rigidez da sapata não influenciam de maneira substancial na falha do tubo; e, por fim, foi avaliado o impacto do estrangulamento e esmagamento na falha do tubo com a variação da profundidade de lançamento. Nos próximos subcapítulos serão detalhados os resultados obtidos para os cinco casos estudados.

\subsection{Quantidade de sapatas}

As principais características avaliadas durante a seleção de um tensionador são o número de sapatas e o limite de carregamento que pode ser aplicado ao tubo. Com o intuito de avaliar como a quantidade de sapatas pode influenciar na resistência do tubo flexível aos carregamentos de esmagamento foram estudados os casos de tensionador com 2, 3 e 4 sapatas. Para essa análise foi adotada uma sapata com geometria em V e ângulo de abertura de $160^{\circ}$ como indicado na Figura 21 .

Foi imposto um carregamento de esmagamento de $75 \mathrm{kN}$ a fim de se alcançar o escoamento das camadas metálicas para os casos estudados. Esse carregamento foi aplicado linearmente em cada uma das sapatas, com incrementos percentuais (2\%) do valor máximo. Distribuindo-se essa carga pelo comprimento da sapata têm-se 2343,75 $\mathrm{N} / \mathrm{mm} / \mathrm{sapata}$. Como o escoamento das camadas ocorre entre dois instantes incrementais de carga, o ponto aqui analisado foi aquele referente ao passo anterior à plastificação. 
Foram avaliados os pontos de escoamento da carcaça e da armadura de pressão separadamente, e por fim, foi analisado o momento da falha segundo a norma 2409.

A Tabela 19 apresenta os resultados obtidos para o passo de tempo imediatamente anterior ao escoamento da carcaça intertravada e o fator de utilização para armadura de pressão nesse mesmo instante. Observa-se que o carregamento de esmagamento responsável pelo início do escoamento na carcaça é superior em 37,5\% e 212,5\% para os casos com duas e quatro sapatas, respectivamente, quando comparado ao caso com três sapatas. Para o caso NS3, em que se têm quatro sapatas, o fator de utilização da armadura de pressão não é respeitado. Isso indica que, para essa situação, a falha da armadura de pressão ocorre antes daquela da carcaça intertravada.

Tabela 19 - Dados de escoamento da carcaça com a variação do número de sapatas.

\begin{tabular}{|c|c|c|c|}
\hline \multicolumn{3}{|c|}{ Escoamento da carcaça } \\
\hline Caso & NS1 & NS2 & NS3 \\
\hline $\begin{array}{c}\text { Foça de esmaga- } \\
\text { mento [N/mm/sa- } \\
\text { pata] }\end{array}$ & 187,500 & 375,000 & 796,875 \\
\hline $\begin{array}{c}\text { Tensão na carcaça } \\
{[\text { MPa] }}\end{array}$ & 530,409 & 585,137 & 576,743 \\
\hline $\begin{array}{c}\text { Tensão na arma- } \\
\text { dura de pressão } \\
{[\text { [MPa] }}\end{array}$ & 318,796 & 444,220 & 671,682 \\
\hline $\begin{array}{c}\text { Fator de utilização } \\
\text { na armadura de } \\
\text { pressão (N2409) }\end{array}$ & 0,490 & 0,683 & 1,033 \\
\hline
\end{tabular}

A Tabela 20 apresenta os dados para escoamento da armadura de pressão e o fator de utilização para a carcaça intertravada. Para os casos com duas e três sapatas de lançamento, NS1 e NS2, a carcaça é a primeira camada a sofrer escoamento. No caso com 4 sapatas, NS3, a falha da armadura de pressão é anterior à da carcaça. O fator de utilização não é atendido em nenhum dos casos observados. 
Tabela 20 - Dados de escoamento da armadura de pressão com a variação do número de sapatas.

\begin{tabular}{|c|c|c|c|}
\hline \multicolumn{3}{|c|}{ Escoamento da armadura de pressão } \\
\hline Caso & NS1 & NS2 & NS3 \\
\hline $\begin{array}{c}\text { Força de esmaga- } \\
\text { mento [N/mm/sa- } \\
\text { pata] }\end{array}$ & 375,000 & 515,625 & 750,000 \\
\hline $\begin{array}{c}\text { Tensão na arma- } \\
\text { dura de pressão } \\
{[\text { [MPa] }}\end{array}$ & 631,730 & 610,154 & 632,407 \\
\hline $\begin{array}{c}\text { Tensão na carcaça } \\
\text { [MPa] }\end{array}$ & 1051,940 & 809,228 & 542,880 \\
\hline $\begin{array}{c}\text { Fator de utilização } \\
\text { na carcarcaça } \\
\text { (N2409) }\end{array}$ & 1,753 & 1,349 & 0,905 \\
\hline
\end{tabular}

Os resultados para a falha do tubo são indicados na Tabela 21. Percebe-se que, respeitando o fator de utilização, a carcaça é a primeira camada a falhar para as configurações de lançamento com duas e três sapatas. Quando o lançamento é realizado com a configuração de quatro sapatas, a carcaça intertravada sofre o escoamento posteriormente à armadura de pressão. Esse último caso é semelhante ao comportamento do tubo flexível quando lançado em águas profundas, em que a carcaça intertravada suporta um carregamento maior, sendo a última camada a falhar. 
Tabela 21 - Dados de falha do tubo com a variação do número de sapatas.

\begin{tabular}{|c|c|c|c|}
\hline \multicolumn{3}{|c|}{ Falha do Tubo } \\
\hline Caso & NS1 & NS2 & NS3 \\
\hline $\begin{array}{c}\text { Força de esmaga- } \\
\text { mento [N/mm/sa- } \\
\text { pata] }\end{array}$ & 281,250 & 421,875 & 609,375 \\
\hline $\begin{array}{c}\text { Tensão na carcaça } \\
\text { [MPa] }\end{array}$ & 793,610 & 659,830 & 440,234 \\
\hline $\begin{array}{c}\text { Tensão na arma- } \\
\text { dura de pressão } \\
{[\text { MPa] }}\end{array}$ & 475,005 & 499,340 & 513,462 \\
\hline $\begin{array}{c}\text { Fator de utilização } \\
\text { N2409 }\end{array}$ & 0,731 & 0,768 & 0,734 \\
\hline
\end{tabular}

As Figuras 35, 36 e 37 apresentam a comparação entre o deslocamento radial da carcaça e armadura de pressão. Para o caso com duas sapatas, a carcaça apresenta deslocamento menor em relação ao da armadura de pressão. Esse comportamento se inverte para os casos com três e quatro sapatas, em que a carcaça passa a ter maiores deslocamentos. Pode-se observar também que a reprodução do comportamento bilinear do material ocorre para valores de tensão muito acima daqueles registrados durante o escoamento, indicando o caráter conservador de análise adotada neste trabalho. 


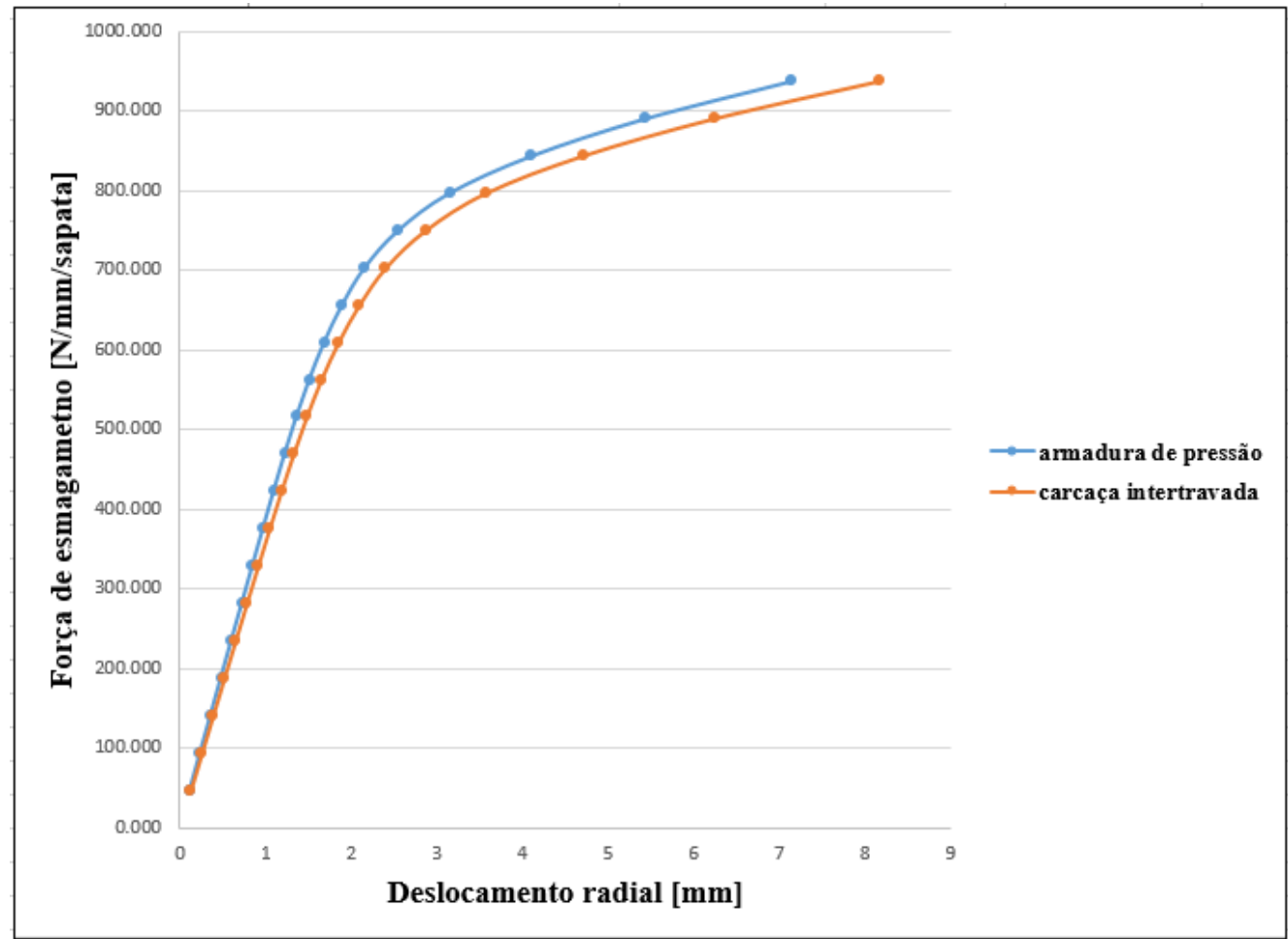

Figura 35 - Comparação entre o deslocamento radial da carcaça e da armadura de pressão para o caso com 2 sapatas.

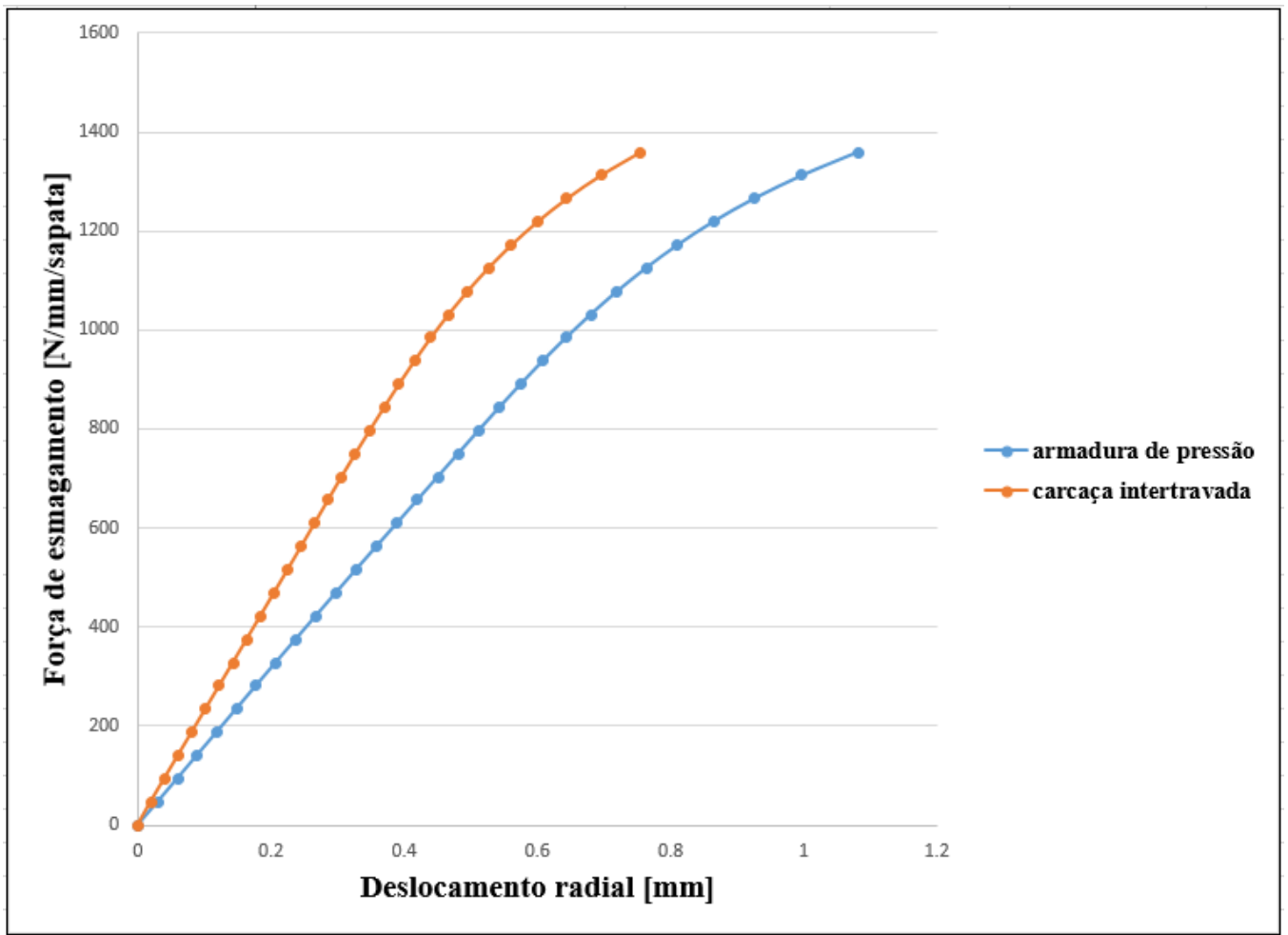

Figura 36 - Comparação entre o deslocamento radial da carcaça e da armadura de pressão para o caso com 3 sapatas. 


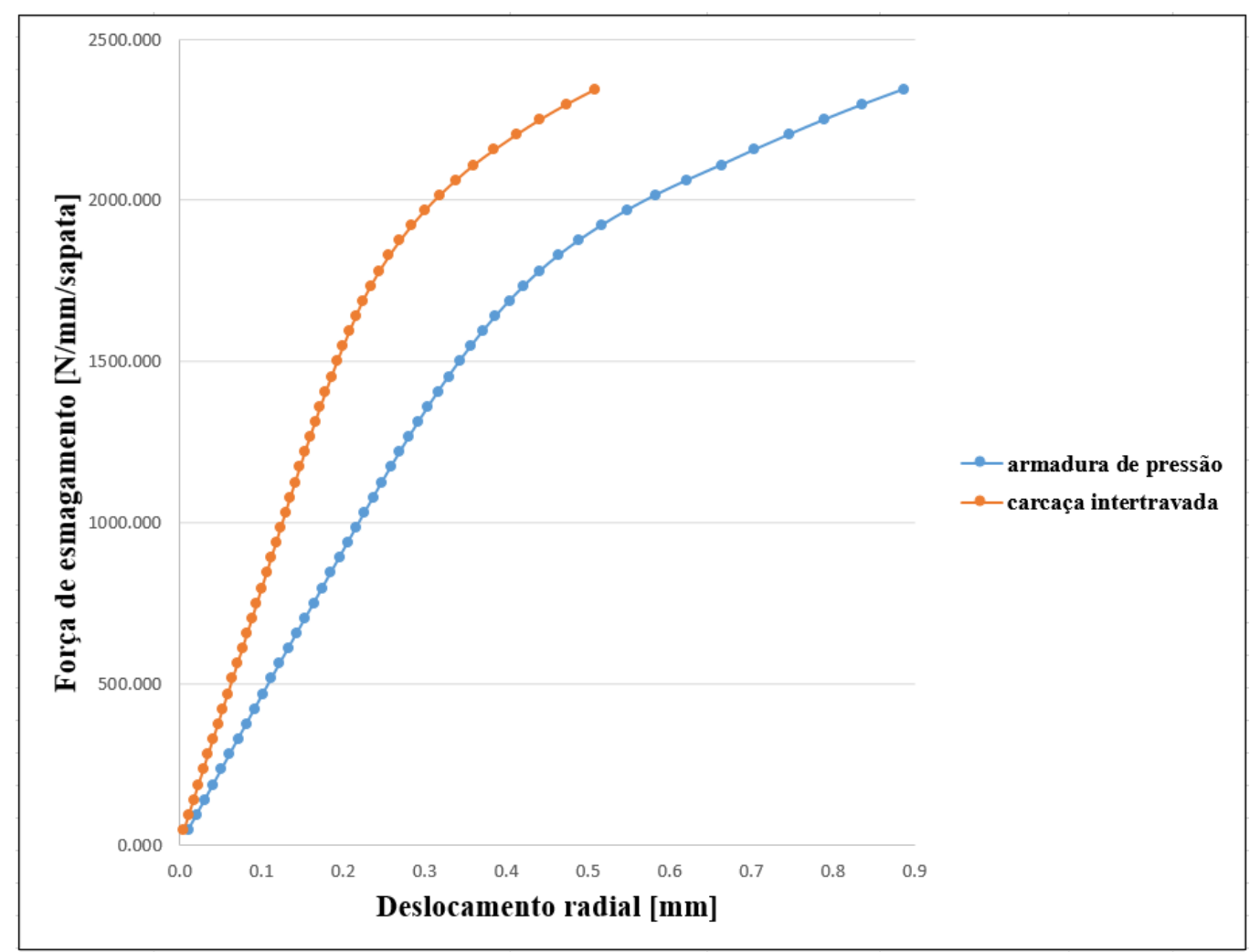

Figura 37 - Comparação entre o deslocamento radial da carcaça e da armadura de pressão para o caso com 4 sapatas.

A Figura 38 apresenta a comparação entre a evolução dos deslocamentos radiais das camadas metálicas até o ponto de falha. Nota-se que o caso com duas sapatas é o mais crítico, pois o tubo falha com aplicação de carregamentos de esmagamento inferiores quando comparado aos outros casos. Percebe-se que a melhor configuração do tensionador é aquele com composição de quatro sapatas. Como o tubo é utilizado de maneira uniforme, o material disponível é melhor aproveitado na resposta estrutural. Assim, o tubo falha quando submetido a carregamentos de esmagamento elevados.

As distribuições de tensões no núcleo estrutural do tubo flexível podem ser observadas na Figura 39 para os casos NS1, NS2 e NS3. Para os três casos, as regiões de maior concentração de tensão para a carcaça são aquelas localizadas no diâmetro interno e fora da região de transição das sapatas. Para a armadura de pressão, as maiores tensões são registradas na região da sapata. 
A partir dos resultados apresentados ao longo deste primeiro estudo foi possível eleger a configuração de lançamento mais segura do ponto de vista da falha do tubo flexível. Com isso, o tensionador composto por quatro sapatas foi adotado nos casos de estudo subsequentes.

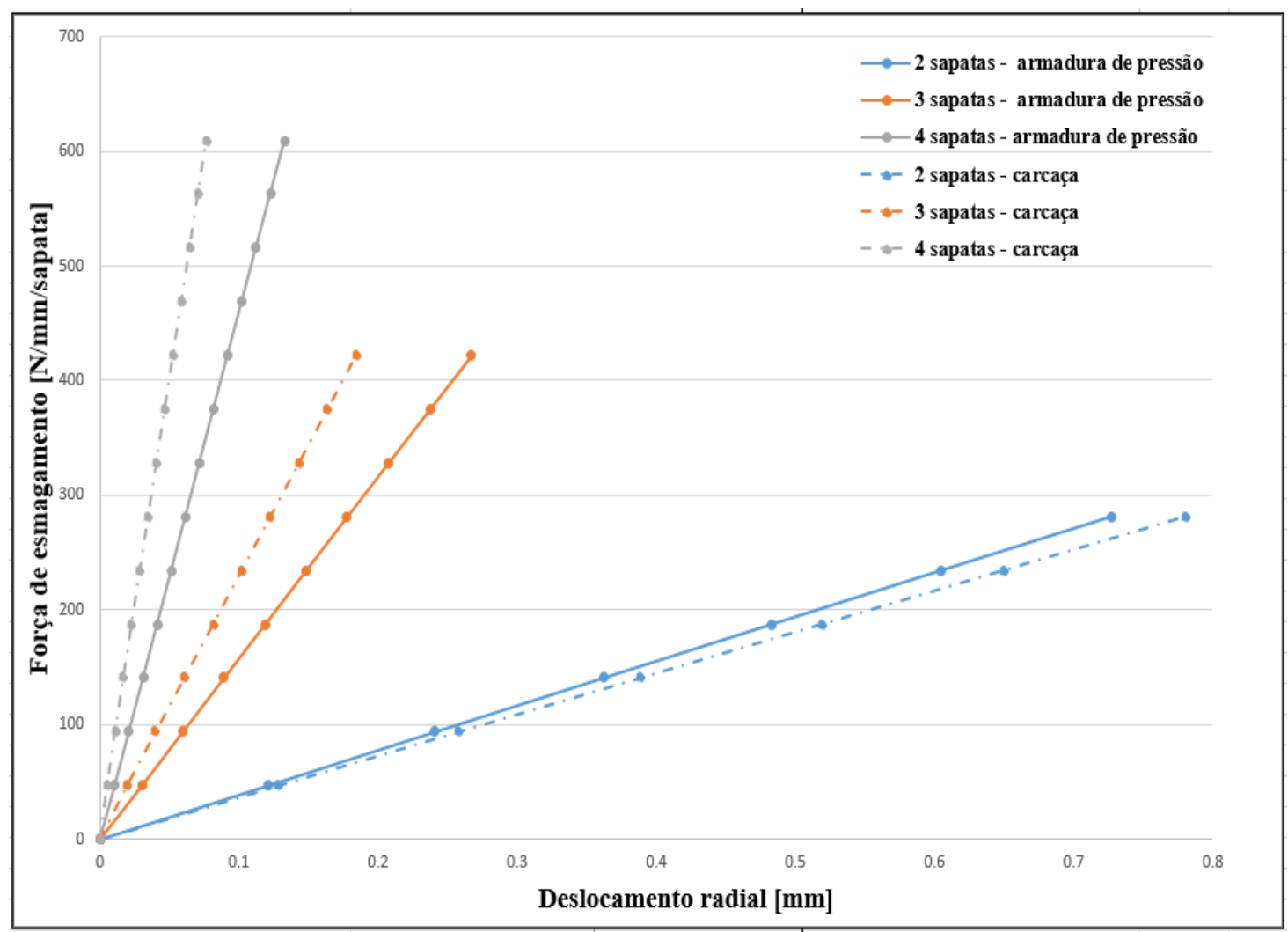

Figura 38 - Deslocamento radial das camadas metálicas com o carregamento de esmagamento aplicado por 2,3 e 4 sapatas até o ponto de falha. 


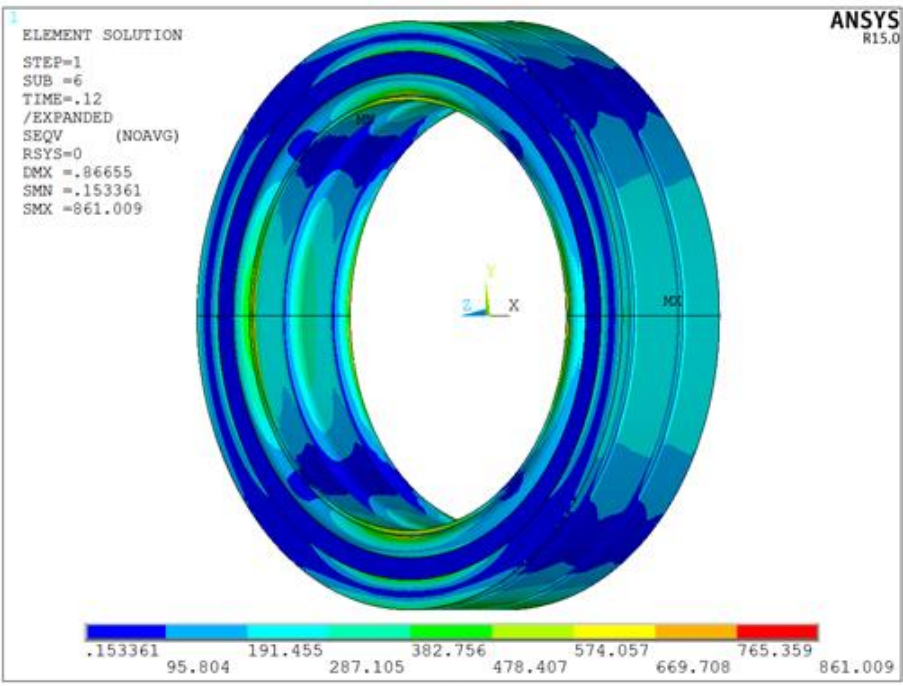

(a)

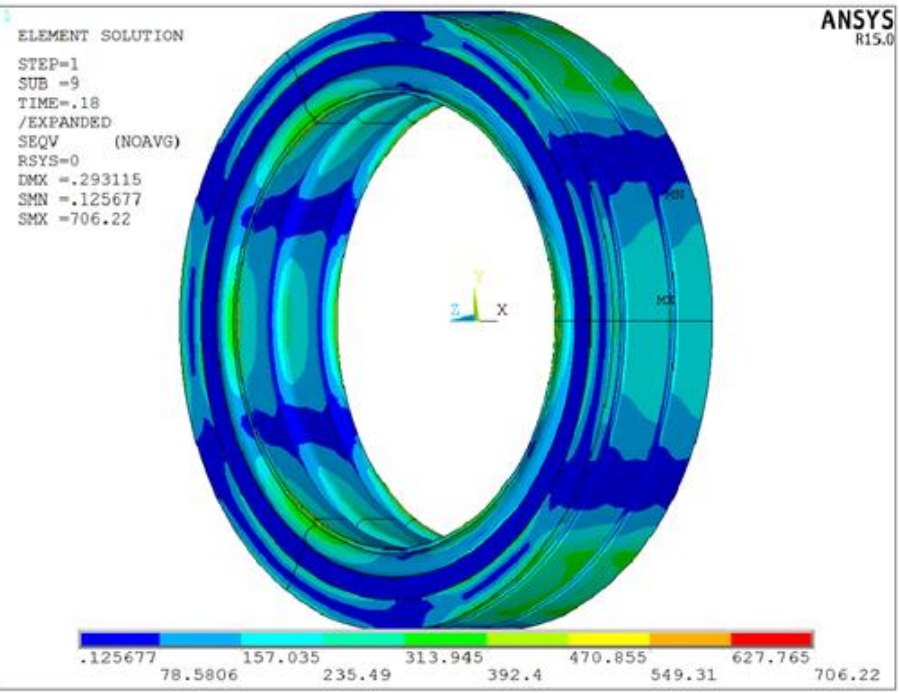

(b)

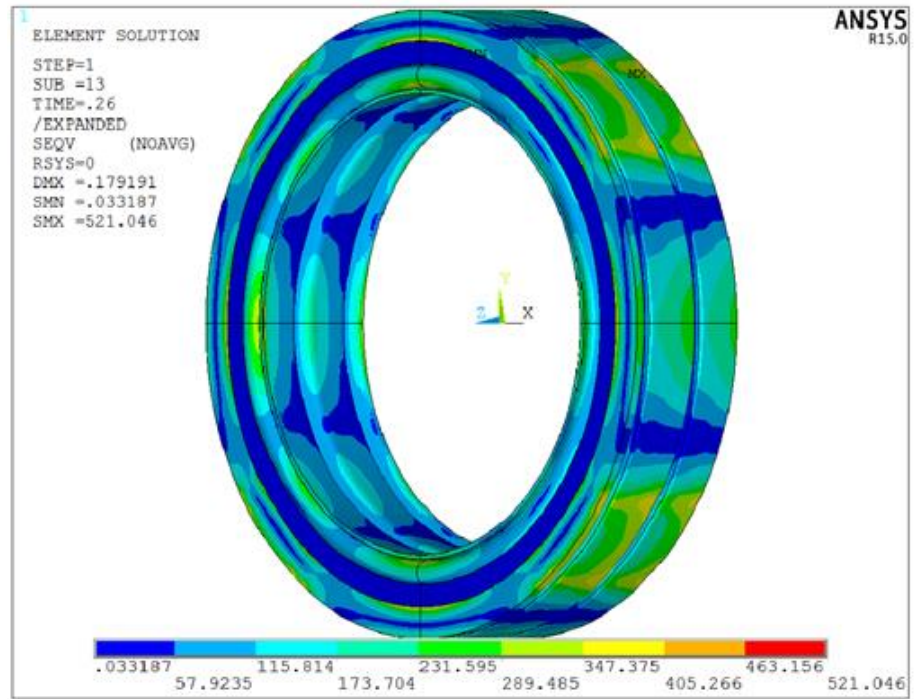

(c)

Figura 39 - Tensão de von Mises [Mpa] registrada no ponto de falha para: (a) duas sapatas; (b) três sapatas e (c) quatro sapatas. 


\section{2. Ângulo de Abertura das Sapatas}

O segundo caso de estudo apresenta uma análise comparativa entre os ângulos de abertura das sapatas e a influência desse parâmetro no escoamento das camadas metálicas. A Tabela 22 indica a carga de esmagamento, a tensão registrada na armadura de pressão e o fator de utilização dessa camada no momento do escoamento da carcaça intertravada. A Tabela 23 apresenta os mesmos dados, porém para o escoamento da armadura de pressão. O ponto de falha do tubo segundo a Norma 2409 é indicado na Tabela 24.

Tabela 22 - Dados de escoamento da carcaça com a variação do ângulo de abertura das sapatas.

\begin{tabular}{|c|c|c|c|c|}
\hline \multicolumn{5}{|c|}{ Escoamento da carcaça } \\
\hline Caso & $\begin{array}{c}\text { Força de esma- } \\
\text { gamento } \\
\text { [N/mm/sapata] }\end{array}$ & $\begin{array}{c}\text { Tensão na car- } \\
\text { caça [MPa] }\end{array}$ & $\begin{array}{c}\text { Tensão na ar- } \\
\text { madura de } \\
\text { pressão [MPa] }\end{array}$ & $\begin{array}{c}\text { Fator de utili- } \\
\text { zação N2409 }\end{array}$ \\
\hline OA1 & 1031,250 & 585,280 & 644,680 & 0,992 \\
\hline OA2 & 1921,875 & 591,523 & 661,070 & 1,017 \\
\hline OA3 & 2015,625 & 598,149 & 662,498 & 1,019 \\
\hline OA4 & 1125,000 & 597,748 & 642,210 & 0,988 \\
\hline OA5 & 796,875 & 576,743 & 673,622 & 1,036 \\
\hline OA6 & 703,125 & 597,102 & 655,480 & 1,008 \\
\hline OA7 & 656,250 & 592,478 & 663,390 & 1,021 \\
\hline
\end{tabular}

Excetuando-se os casos OA1 e OA4, ângulos de $120^{\circ}$ e $150^{\circ}$, a armadura de pressão sofre plastificação antes da carcaça. As camadas metálicas resistem a um maior carregamento de esmagamento para o ângulo de abertura de $140^{\circ}$. Comparativamente, o ângulo de $180^{\circ}$ é o caso crítico já que suporta uma carga 67,43\% menor. Percebe-se ainda, pela Tabela 24 que para os ângulos de $120^{\circ}$ e $150^{\circ}$ o tubo apresenta pontos de falha muito próximos, uma diferença relativa de apenas 5,5\% no carregamento de esmagamento. $\mathrm{O}$ mesmo comportamento é percebido para os ângulos de $130^{\circ}$ e $140^{\circ}$ em que essa diferença cai para $3 \%$. 
Tabela 23 - Dados de escoamento da armadura de pressão com a variação do ângulo de abertura das sapatas.

Escoamento da armadura de pressão

\begin{tabular}{|c|c|c|c|c|}
\hline Caso & $\begin{array}{c}\text { Força de esma- } \\
\text { gamento } \\
\text { [N/mm/sapata] }\end{array}$ & $\begin{array}{c}\text { Tensão na ar- } \\
\text { madura de } \\
\text { pressão [MPa] }\end{array}$ & $\begin{array}{c}\text { Tensão na car- } \\
\text { caça [MPa] }\end{array}$ & $\begin{array}{c}\text { Fator de utili- } \\
\text { zação N2409 }\end{array}$ \\
\hline OA1 & 1078,125 & 649,730 & 611,850 & 1,020 \\
\hline OA2 & 1359,375 & 631,940 & 413,183 & 0,689 \\
\hline OA3 & 1546,875 & 647,138 & 456,181 & 0,760 \\
\hline OA4 & 1171,875 & 649,370 & 622,209 & 1,037 \\
\hline OA5 & 750,000 & 634,281 & 542,884 & 0,835 \\
\hline OA6 & 468,750 & 600,086 & 397,979 & 0,663 \\
\hline OA7 & 375,000 & 584,522 & 336,980 & 0,562 \\
\hline
\end{tabular}

Tabela 24 -Dados de falha do tubo com a variação do ângulo de abertura das sapatas.

\begin{tabular}{|c|c|c|c|c|}
\hline \multicolumn{5}{|c|}{ Falha do Tubo } \\
\hline Caso & $\begin{array}{c}\text { Força de esma- } \\
\text { gamento } \\
\text { [N/mm/sapata] }\end{array}$ & $\begin{array}{c}\text { Tensão na car- } \\
\text { caça [MPa] }\end{array}$ & $\begin{array}{c}\text { Tensão na ar- } \\
\text { madura de } \\
\text { pressão [MPa] }\end{array}$ & $\begin{array}{c}\text { Fator de utili- } \\
\text { zação N2409 }\end{array}$ \\
\hline OA1 & 843,750 & 477,634 & 525,630 & 0,796 \\
\hline OA2 & 1546,875 & 471,112 & 656,120 & 0,785 \\
\hline OA3 & 1593,750 & 469,973 & 650,288 & 0,723 \\
\hline OA4 & 890,625 & 473,117 & 507,230 & 0,789 \\
\hline OA5 & 656,250 & 474,551 & 554,762 & 0,791 \\
\hline OA6 & 562,500 & 477,680 & 719,282 & 0,796 \\
\hline OA7 & 515,625 & 464,140 & 678,800 & 0,774 \\
\hline
\end{tabular}

Em relação à melhor distribuição de tensões no tubo, pode-se perceber que para os ângulos de $150^{\circ}$ e $160^{\circ}$ as camadas metálicas falham quase simultaneamente, com uma diferença no carregamento resistido pela carcaça e pela armadura de pressão de apenas 
$4,08 \%$ e 6,13\%, respectivamente. Isso indica que esses ângulos de abertura proporcionam uma distribuição mais homogênea dos carregamentos de esmagamento.

A relação entre a força de esmagamento e o deslocamento radial da armadura de pressão até o momento da falha, para cada um dos ângulos avaliados, é indicada na Figura 40. Essa mesma relação é apresentada na Figura 41 para a carcaça intertravada.

O deslocamento radial da carcaça intertravada e da armadura de pressão para os ângulos de $120^{\circ}$ e $150^{\circ}$ são semelhantes até o ponto de falha. $\mathrm{O}$ mesmo pode ser notado para os de $170^{\circ}$ e $180^{\circ}$. Os deslocamentos radiais da armadura de pressão são superiores aos da carcaça para todos os casos.

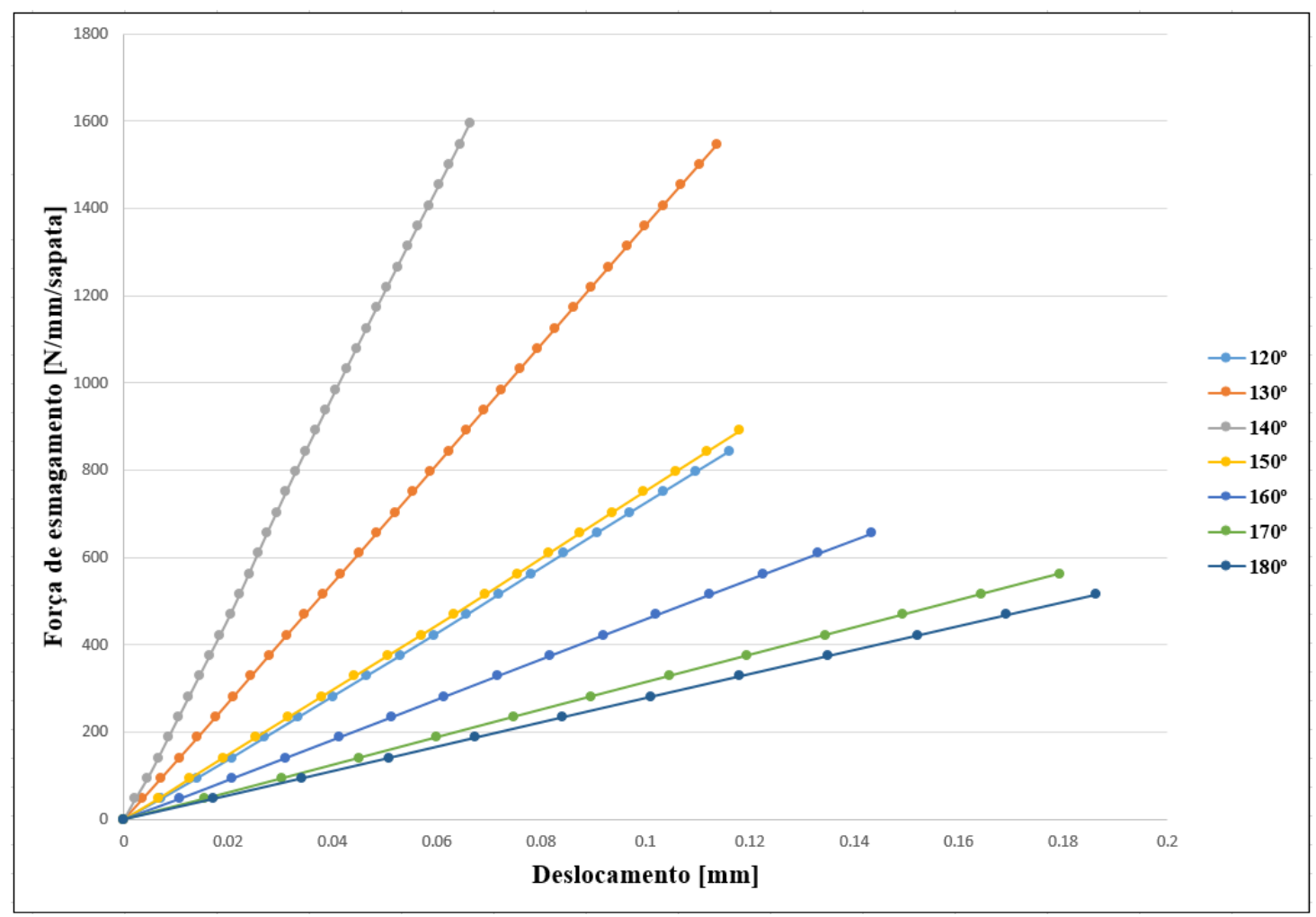

Figura 40 - Relação da força de esmagamento x deslocamento radial da armadura de pressão com os ângulos de abertura variando de $120^{\circ}$ a $180^{\circ}$. 


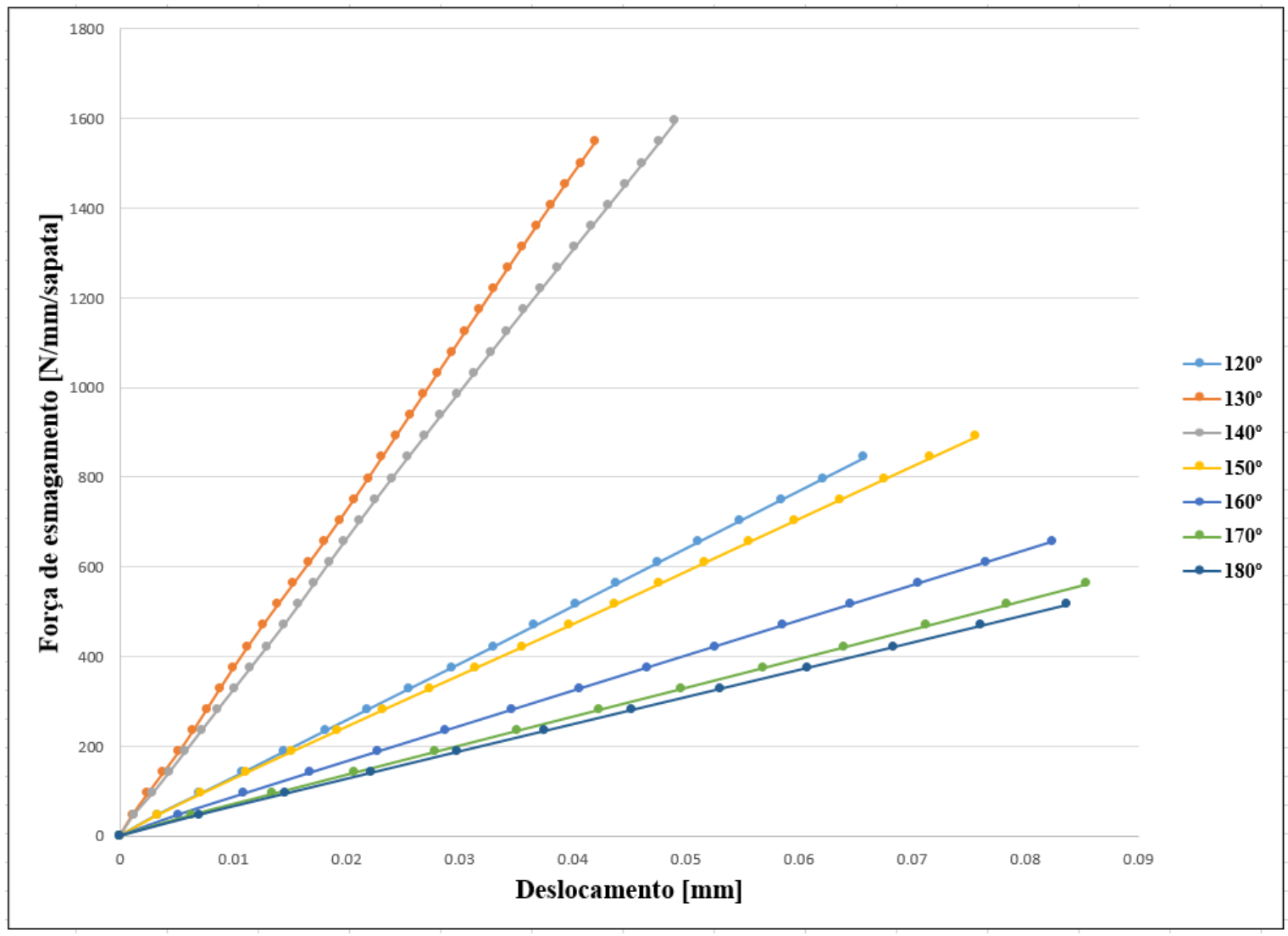

Figura 41- Relação da força de esmagamento x deslocamento radial para a carcaça intertravada com os ângulos de abertura das sapatas variando de $120^{\circ}$ a $180^{\circ}$.

A Figura 42 apresenta as tensões de von Mises registradas no tubo para os ângulos de $120^{\circ}, 130^{\circ}, 140^{\circ}, 150^{\circ}, 160^{\circ}$ e $180^{\circ}$, respectivamente. 

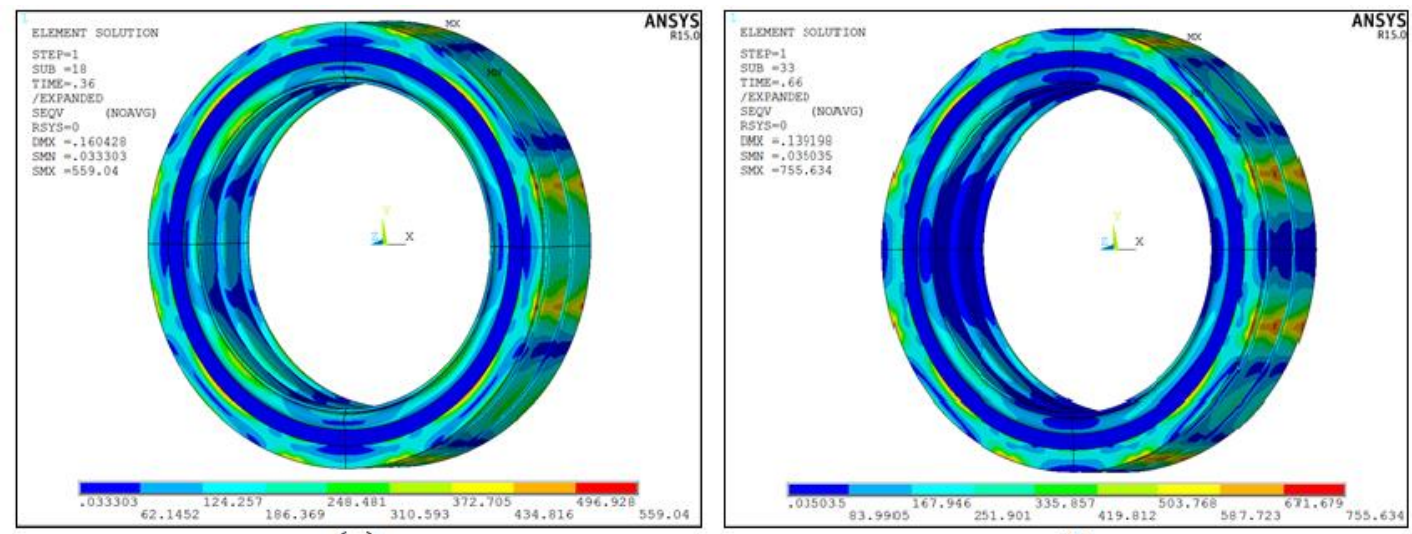

(a)

(b)

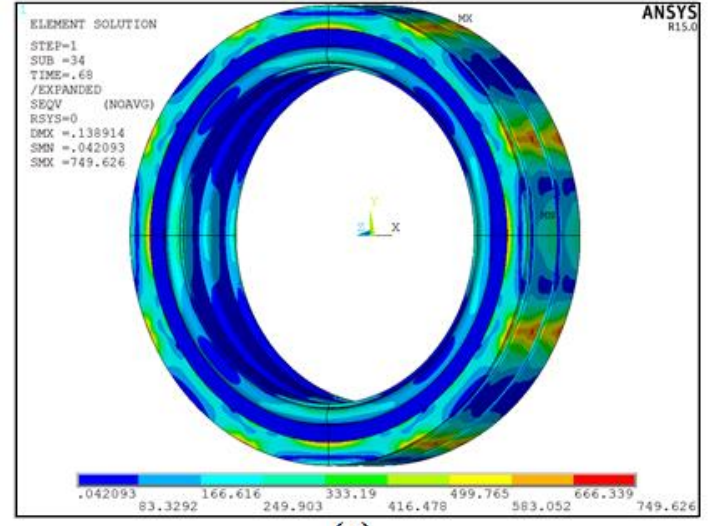

(c)

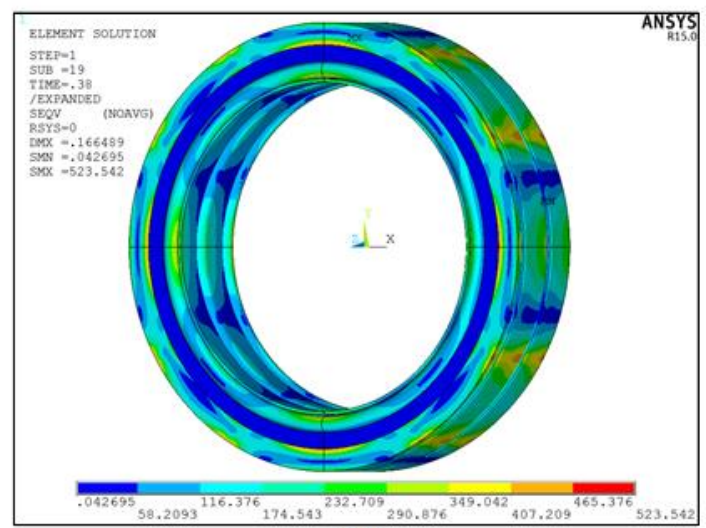

(d)

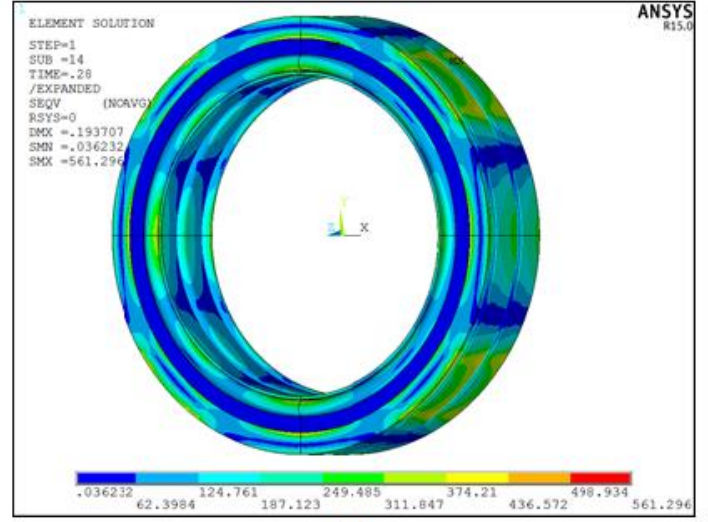

(e)

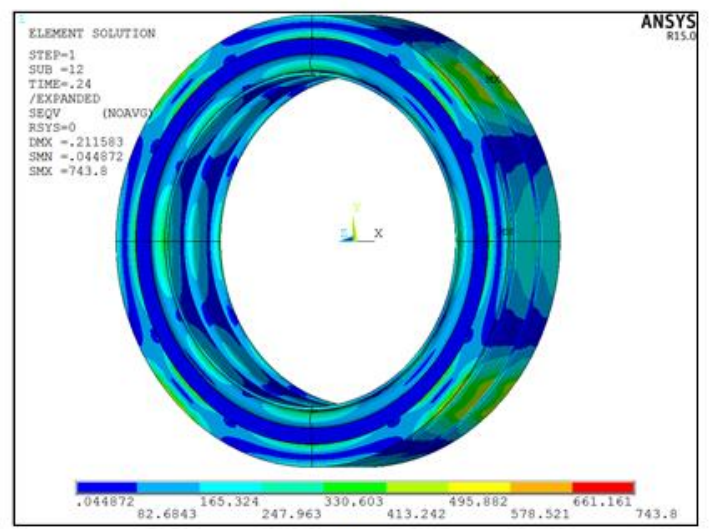

(f)

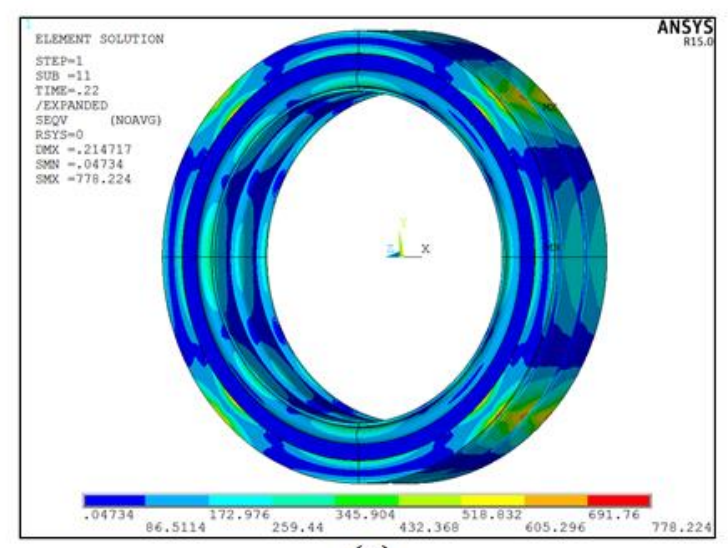

(g)

Figura 42 - Tensão de von Mises [MPa] para os ângulos de abertura de: (a) $120^{\circ}$; (b) $130^{\circ}$; (c) $140^{\circ}$; (d) $150^{\circ}$; (e) $160^{\circ}$; (f) $170^{\circ}$; e (g) $180^{\circ}$. 
A Figura 43 apresenta o comportamento de falha do tubo para todos os ângulos de abertura das sapatas estudados ao longo dessa seção.

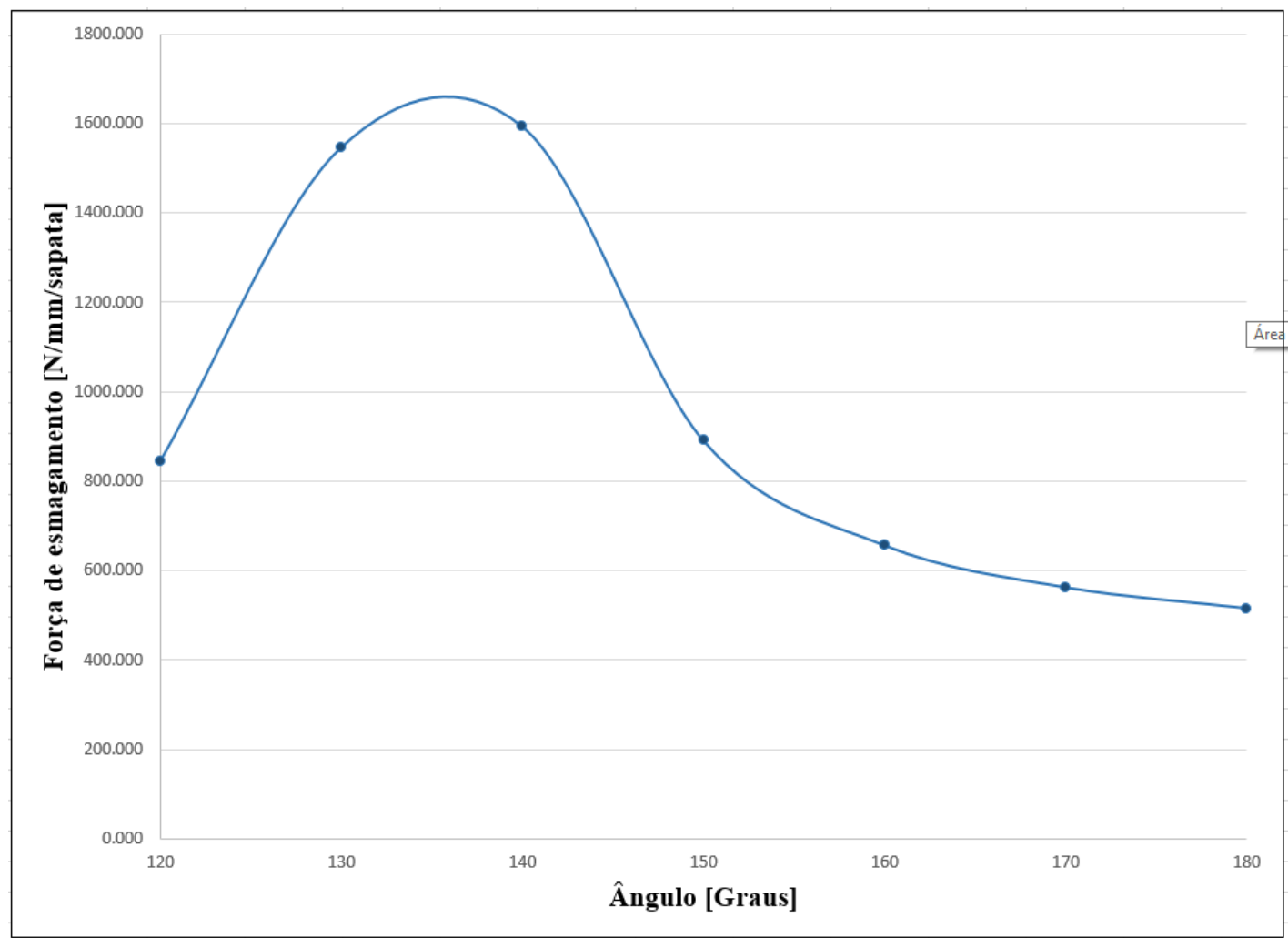

Figura 43 - Relação entre o carregamento de esmagamento máximo e o ângulo de abertura das sapatas no momento da falha do tubo.

Como a escolha da configuração da sapata está relacionada com a profundidade de lançamento, é possível identificar a combinação de quatro sapatas com ângulos de abertura de $130^{\circ}$ e $140^{\circ}$ como sendo as mais apropriadas para instalação do tubo em águas profundas. Também é necessário avaliar a ordem de falha das camadas metálicas a fim de garantir a segurança daquela camada mais crítica para a aplicação desejada. 


\subsection{Adição da Capa Polimérica Externa}

A análise do comportamento de falha do tubo com adição da capa polimérica externa foi feita para uma configuração de lançamento com quatro sapatas e ângulo de abertura de $160^{\circ}$. Além disso, foi avaliada a influência do tipo de contato entre essa camada e as sapatas. Como já mencionado no subcapítulo 4.10, foram considerados os contatos: sem atrito com escorregamento (frictionless), caso CT1; colado (bonded), caso CT2; e atrito infinito (rough).

A Tabela 25 apresenta as tensões de von Mises registradas no momento de falha da carcaça, e o fator de utilização da armadura de pressão. A Tabela 26 indica os mesmos resultados, porém para o escoamento da armadura de pressão. Por fim, a Tabela 27 aponta as tensões registradas nas camadas metálicas no limite do carregamento de esmagamento resistido pelo tubo.

Ao contrário do que ocorre para o caso OA5(ângulo $160^{\circ}$ sem a camada polimérica externa), a carcaça é a primeira camada a falhar para os casos CT1, CT2 e CT3. No entanto, pode-se perceber que assim como no caso OA5, uma distribuição de tensão mais homogênea entre as camadas metálicas é mantida. Comparando os casos com mesmo par de contato entre o tubo e as sapatas, OA5 e CT1, verifica-se que a adição da camada plástica faz com que o tubo diminua em 3,79\% a carga de crushing suportada. Isso indica que a adição da capa plástica diminui a resistência da carcaça ao esmagamento já que seu escoamento ocorre para um carregamento menor de $11,7 \%$ menor no caso CT1 se comparado ao caso AO5. Já para a armadura de pressão há um aumento na resistência ao crushing de $3 \%$ para o caso CT1 em relação ao OA5. Isso indica que a adição da capa polimérica externa aumenta a distribuição de tensões na carcaça intertravada, antecipando sua falha em relação à armadura de pressão.

Pela Tabela 27 percebe-se que há diferença no carregamento de falha de acordo com o tipo de contato adotado. Tomando-se como base o contato frictionless, os contatos bonded e rough apresentam um limite de falha $22,15 \%$ e $3,7 \%$ inferior, respectivamente. No entanto, como o coeficiente de atrito adotado no caso CT3 é elevado, o contato por 
atrito com coeficientes realistas pode vir a apresentar comportamentos próximos ao frictionless.

Tabela 25 - Dados de escoamento da carcaça com a adição da capa polimérica externa e a variação do contato entre o tubo e as sapatas.

\begin{tabular}{|c|c|c|c|}
\hline \multicolumn{4}{|c|}{ Escoamento da carcaça } \\
\hline Caso & CT1 & CT2 & CT3 \\
\hline $\begin{array}{c}\text { Foça de esmaga- } \\
\text { mento [N/mm/sa- } \\
\text { pata] }\end{array}$ & 703,125 & $609 ., 375$ & 703,125 \\
\hline $\begin{array}{c}\text { Tensão na carcaça } \\
{[\text { [MPa] }}\end{array}$ & 580,955 & 587,748 & 592,158 \\
\hline $\begin{array}{c}\text { Tensão na arma- } \\
\text { dura de pressão } \\
{[\text { [MPa] }}\end{array}$ & 577,039 & 603,148 & 593,490 \\
\hline $\begin{array}{c}\text { Fator de utilização } \\
\text { N2409 }\end{array}$ & 0,888 & 0,928 & 0,913 \\
\hline
\end{tabular}

Tabela 26 - Dados do escoamento da armadura de pressão com a adição da capa polimérica externa e a variação do contato entre o tubo e as sapatas.

Escoamento da armadura de pressão

\begin{tabular}{|c|c|c|c|}
\hline Caso & CT1 & CT2 & CT3 \\
\hline $\begin{array}{c}\text { Força de esmaga- } \\
\text { mento [N/mm/sa- } \\
\text { pata] }\end{array}$ & 773,438 & 656,250 & 750,000 \\
\hline $\begin{array}{c}\text { Tensão na arma- } \\
\text { dura de pressão } \\
\text { [MPa] }\end{array}$ & 635,938 & 642,986 & 636,189 \\
\hline $\begin{array}{c}\text { Tensão na carcaça } \\
\text { [MPa] }\end{array}$ & 639,911 & 626,496 & 634,253 \\
\hline $\begin{array}{c}\text { Fator de utilização } \\
\text { N2409 }\end{array}$ & 1,067 & 1,044 & 1,057 \\
\hline
\end{tabular}


Tabela 27 - Dados de falha do tubo com a adição da camada polimérica externa e variação do contato entre o tubo e as sapatas.

\begin{tabular}{|c|c|c|c|}
\hline \multicolumn{4}{|c|}{ Falha do Tubo } \\
\hline Caso & CT1 & CT2 & CT3 \\
\hline $\begin{array}{c}\text { Força de esmaga- } \\
\text { mento }[\mathrm{N} / \mathrm{mm} / \mathrm{sa}- \\
\text { pata] }\end{array}$ & 632,813 & 492,188 & 609,375 \\
\hline $\begin{array}{c}\text { Tensão na carcaça } \\
{[\mathrm{MPa}]}\end{array}$ & 520,905 & 492,463 & 509,053 \\
\hline $\begin{array}{c}\text { Tensão na arma- } \\
\text { dura de pressão } \\
{[\mathrm{MPa}]}\end{array}$ & 516,410 & 505,818 & 509,107 \\
\hline $\begin{array}{l}\text { Fator de utilização } \\
\qquad \text { N2409 }\end{array}$ & 0,794 & 0,778 & 0,783 \\
\hline
\end{tabular}

A Figura 44 apresenta a relação entre a evolução do carregamento de esmagamento até a falha do tubo e o deslocamento radial para a armadura de pressão e a carcaça intertravada, considerando os três casos de contato. Para os casos OA5, CT1 e CT3, o deslocamento radial da armadura de pressão é equivalente. Nota-se que para carcaça, o caso OA5 apresentou um deslocamento radial elevado em relação aos outros casos. Percebe-se ainda que, para o contato bonded, o deslocamento radial da armadura de pressão é maior se comparada aos outros casos, enquanto para a carcaça esse comportamento se inverte. 


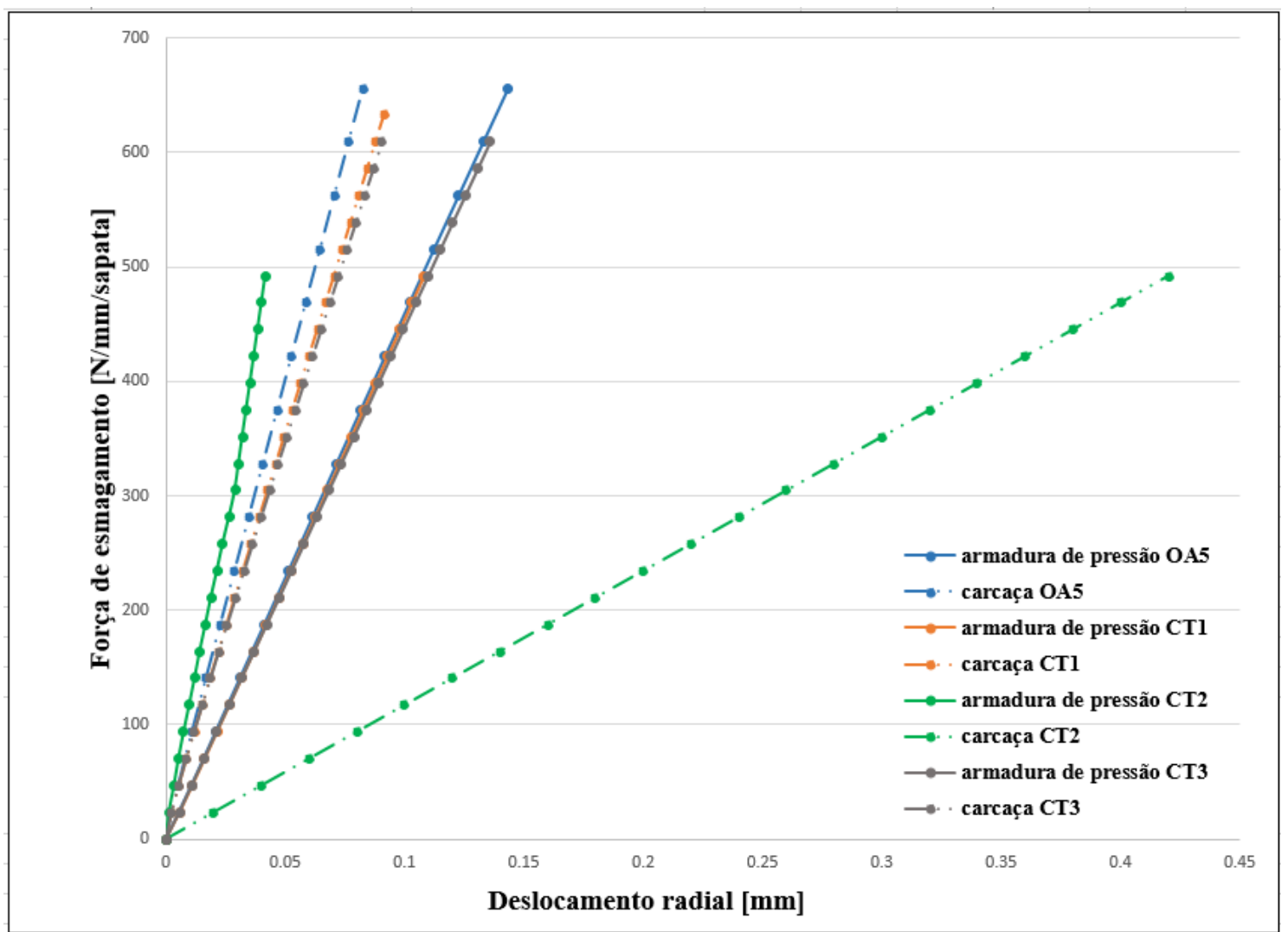

Figura 44 - Relação entre força de esmagamento x deslocamento radial para o caso de estudo com adição da capa polimérica externa e variação do contato entre o tubo e as sapatas.

A Figura 45 apresenta as tensões de von Mises para os casos CT1, CT2 e CT3 até o ponto de falha. Usualmente, o tipo de contato entre o tubo e as sapatas é por atrito. Embora o contato bonded apresente resultados a favor da segurança, pois é o primeiro a falhar, o contato frictionless foi adotado como padrão para analisar os casos de estudo subsequentes. A capa plástica também foi incorporada para prosseguir com os estudos. 


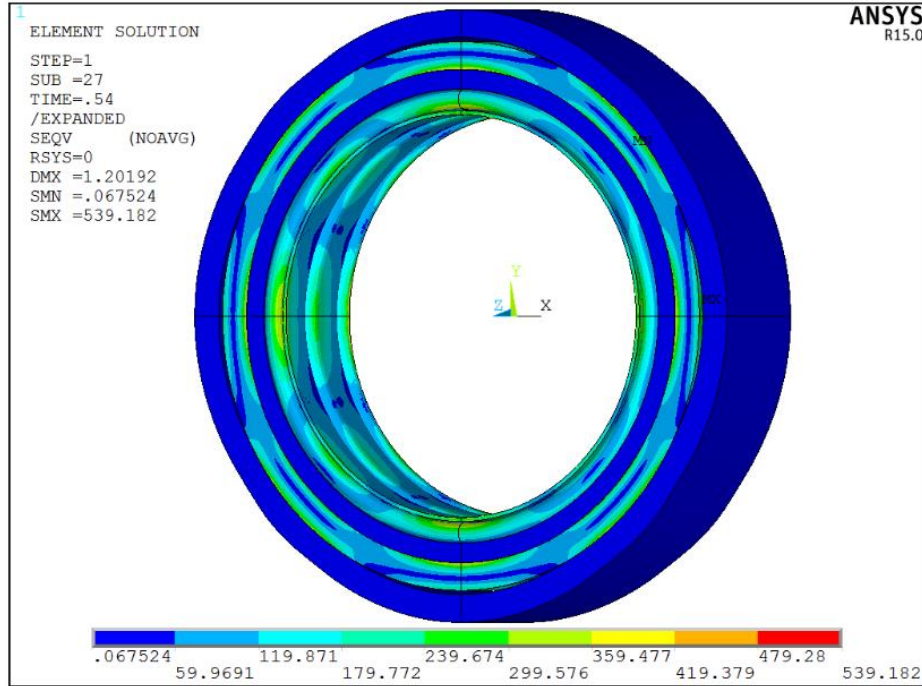

(a)

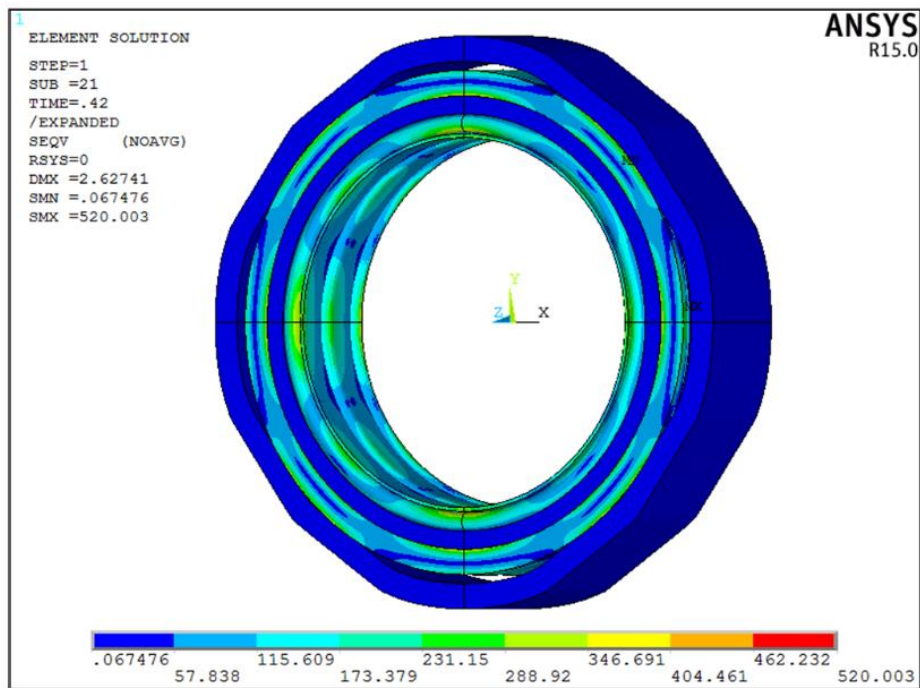

(b)

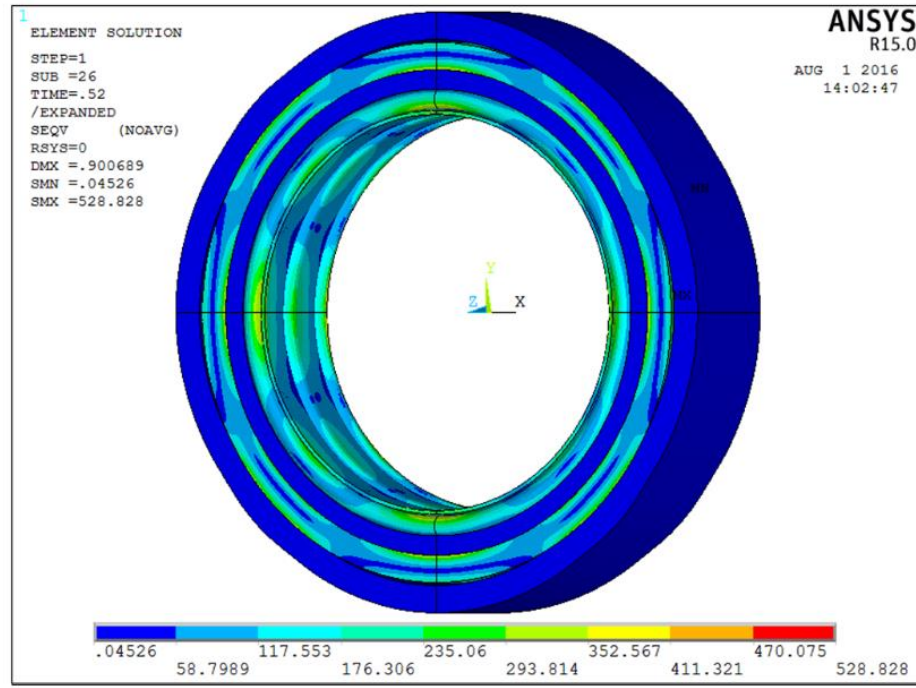

(c)

Figura 45 - Tensão de von Mises [MPa] registrada no ponto de falha, com a adição da capa polimérica externa, para os pares de contato entre o tubo e as sapatas: (a) frictionless; (b) bonded; (c) rough. 


\subsection{Rigidez das Sapatas}

O quarto caso de estudo avalia a influência da variação da rigidez das sapatas na falha do tubo. Foram analisados nove módulos de elasticidade com ordem de grandeza distintas: $10^{7}$ (RS1), $10^{8}$ (RS2), $10^{9}$ (RS3), $10^{10}$ (RS4), $10^{11}$ (RS5), $10^{12}$ (RS6), $10^{13}$ (RS7), $10^{14}$ (RS8), $10^{15}$ (RS9) Pa. A Tabela 28 apresenta a carga de esmagamento necessária para que ocorra o escoamento da carcaça intertravada e as tensões de von Mises registradas nesse momento. A Tabela 29 indica os mesmos dados, porém para o escoamento da armadura de pressão, e a Tabela 30 contém as tensões de falha do tubo e fator de utilização para cada caso.

Tabela 28 - Dados de escoamento da carcaça com a variação da rigidez das sapatas.

\begin{tabular}{|c|c|c|c|c|}
\hline \multicolumn{5}{|c|}{ Escoamento da carcaça } \\
\hline Caso & $\begin{array}{c}\text { Força de esma- } \\
\text { gamento } \\
\text { [N/mm/sapata] }\end{array}$ & $\begin{array}{c}\text { Tensão na car- } \\
\text { caça [MPa] }\end{array}$ & $\begin{array}{c}\text { Tensão na ar- } \\
\text { madura de } \\
\text { pressão [MPa] }\end{array}$ & $\begin{array}{c}\text { Fator de utili- } \\
\text { zação N2409 }\end{array}$ \\
\hline RS1 & - & - & - & - \\
\hline RS2 & 632,813 & 586,544 & 645,620 & 0,993 \\
\hline RS3 & 679,688 & 578,703 & 586,502 & 0,902 \\
\hline RS4 & 703,125 & 583,248 & 579,950 & 0,892 \\
\hline RS5 & 703,125 & 581,205 & 574,716 & 0,884 \\
\hline RS6 & 703,125 & 580,980 & 574,289 & 0,884 \\
\hline RS7 & 703,125 & 580,958 & 574,247 & 0,883 \\
\hline RS8 & 703,125 & 580,955 & 574,243 & 0,883 \\
\hline RS9 & 703,125 & 580,955 & 574,242 & 0,883 \\
\hline
\end{tabular}


Tabela 29 - Dados de escoamento da armadura de pressão com a variação da rigidez das sapatas.

Escoamento da armadura de pressão

\begin{tabular}{|c|c|c|c|c|}
\hline Caso & $\begin{array}{c}\text { Força de esma- } \\
\text { gamento } \\
\text { [N/mm/sapata] }\end{array}$ & $\begin{array}{c}\text { Tensão na ar- } \\
\text { madura de } \\
\text { pressão [MPa] }\end{array}$ & $\begin{array}{c}\text { Tensão na car- } \\
\text { caça [MPa] }\end{array}$ & $\begin{array}{c}\text { Fator de utiliza- } \\
\text { ção N2409 }\end{array}$ \\
\hline RS1 & - & - & - & - \\
\hline RS2 & 632,813 & 645,620 & 586,544 & 0,978 \\
\hline RS3 & 726,563 & 631,397 & 621,441 & 1,036 \\
\hline RS4 & 773,438 & 639,519 & 642,734 & 1,071 \\
\hline RS5 & 773,438 & 633,203 & 640,200 & 1,067 \\
\hline RS6 & 773,438 & 632,716 & 639,940 & 1,067 \\
\hline RS7 & 773,438 & 632,667 & 639,914 & 1,067 \\
\hline RS8 & 773,438 & 632,662 & 639,911 & 1,067 \\
\hline
\end{tabular}

Para o caso RS1, módulo de elasticidade igual a 0,21 GPa, a solução não convergiu devido à excessiva distorção dos elementos das sapatas. Isso ocorre em virtude das elevadas deformações na estrutura resultantes da baixa rigidez da mesma. Assim, esse caso mostrou-se inviável, e não será apresentado nos resultados abaixo.

Para os casos RS4 a RS9, módulo de elasticidade com ordem de grandeza de $10^{9}$ a $10^{15} \mathrm{MPa}$, o tubo suporta o mesmo carregamento de esmagamento. A carcaça intertravada é a primeira camada a falhar em todos os casos, exceto para o RS2 em que o escoamento da carcaça intertravada e da armadura de pressão ocorrem simultaneamente. Para todos os outros, o padrão observado no terceiro caso de estudo, com adição da capa polimérica externa, se repete. Para o caso RS4, módulo de elasticidade igual a $21 \mathrm{GPa}$, a força de esmagamento suportada pelo tubo cai em 3,63\% em relação àqueles de maior rigidez. Para o caso RS2 essa diferença é ainda mais crítica, de 18,5\%. 
Tabela 30 - Dados de falha do tubo com a variação da rigidez das sapatas.

\begin{tabular}{|l|c|c|c|c|}
\hline \multicolumn{5}{|c|}{ Falha do tubo } \\
\hline Caso & $\begin{array}{c}\text { Força de esma- } \\
\text { gamento } \\
\text { [N/mm/sapata] }\end{array}$ & $\begin{array}{c}\text { Tensão na ar- } \\
\text { madura de } \\
\text { pressão [MPa] }\end{array}$ & $\begin{array}{c}\text { Tensão na car- } \\
\text { caça [MPa] }\end{array}$ & $\begin{array}{c}\text { Fator de utili- } \\
\text { zação N2409 }\end{array}$ \\
\hline RS1 & - & - & - & - \\
\hline RS2 & 515,625 & 468,581 & 511,893 & 0,788 \\
\hline RS3 & 609,375 & 515,378 & 520,000 & 0,800 \\
\hline RS4 & 632,813 & 522,873 & 519,021 & 0,798 \\
\hline RS5 & 632,813 & 521,106 & 514,484 & 0,792 \\
\hline RS6 & 632,813 & 520,926 & 514,133 & 0,791 \\
\hline RS7 & 632,813 & 520,907 & 514,098 & 0,791 \\
\hline RS8 & 632,813 & 520,906 & 514,049 & 0,791 \\
\hline
\end{tabular}

A Figura 46 apresenta a relação entre força e deslocamento radial para a carcaça intertravada até o ponto de falha do tubo, para todos os valores de rigidez das sapatas analisados. A Figura 47 mostra a mesma relação, porém para a armadura de pressão. Nota-se que, como já observado na Tabela 30, o deslocamento radial da carcaça e da armadura de pressão para os casos RS2 e RS3 são menores comparativamente aos outros. 


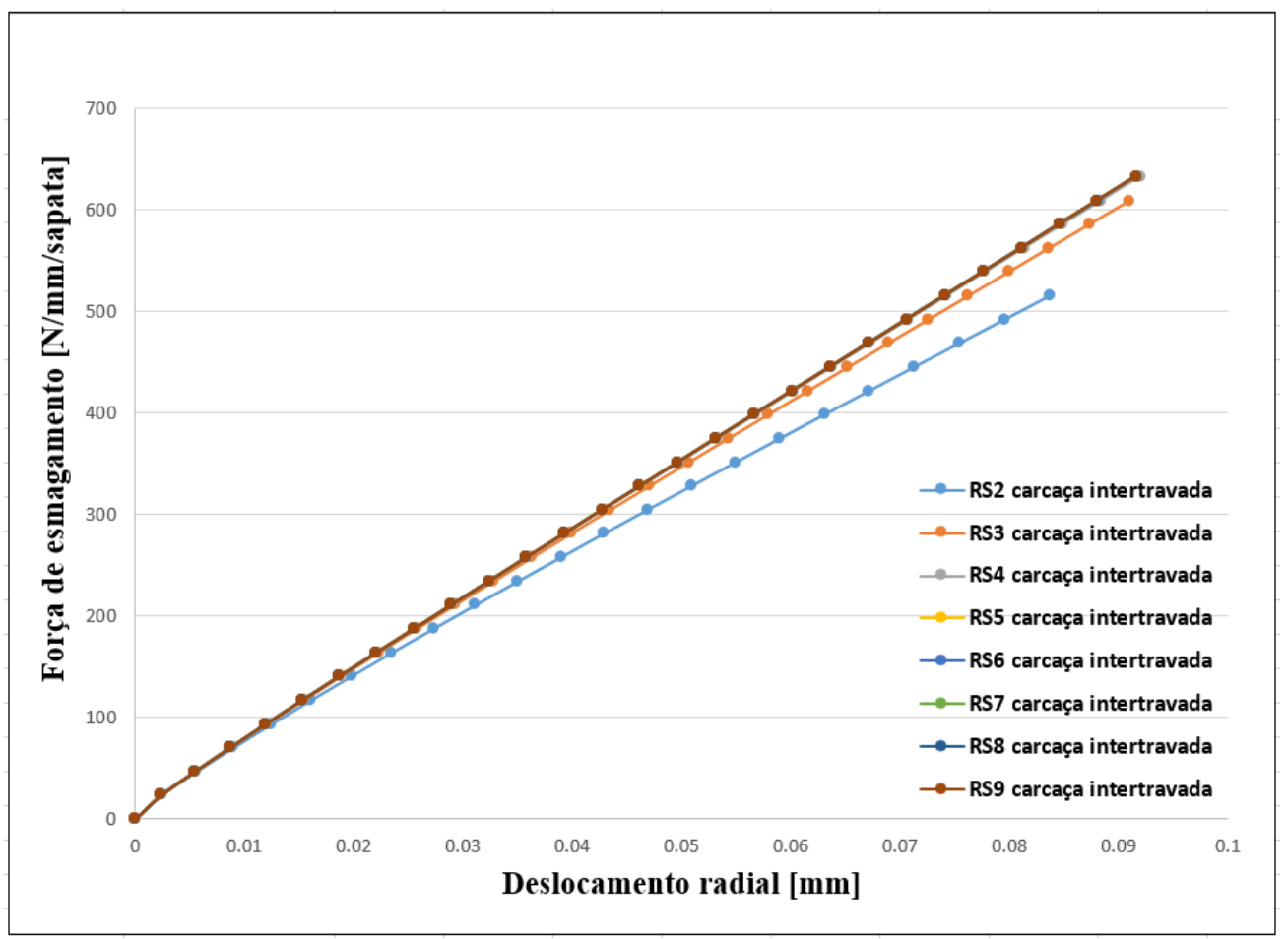

Figura 46 - Relação força de esmagamento x deslocamento radial para a carcaça com a variação da rigidez das sapatas.

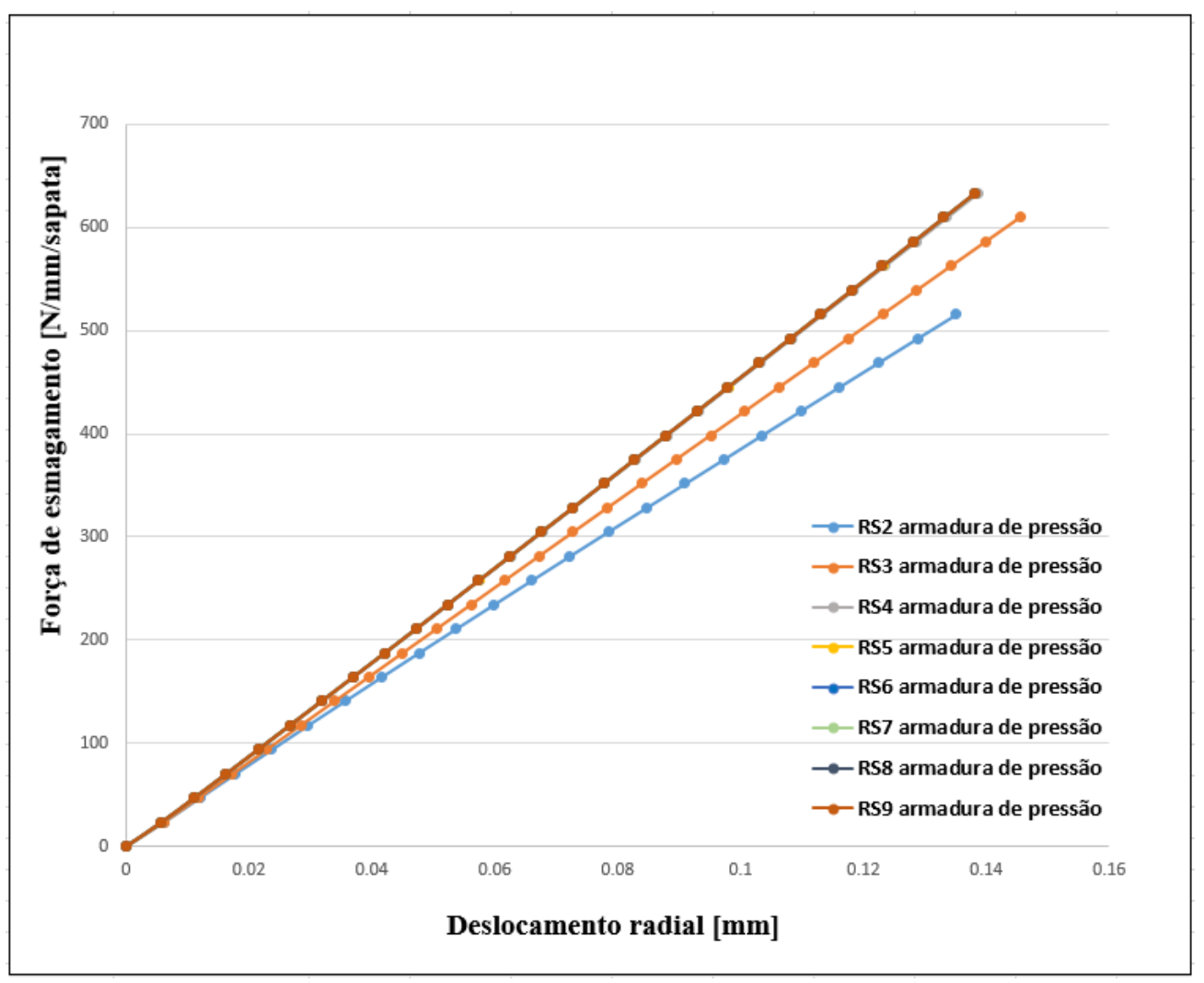

Figura 47 - Relação força de esmagamento x deslocamento radial para armadura de pressão com a variação da rigidez das sapatas. 
A Figura 48 indica o campo de tensões no tubo no momento da falha. Percebe-se que a distribuição das tensões não é afetada com a variação da rigidez das sapatas. No entanto, o limite do carregamento de crushing resistido pode variar substancialmente. Assim, esse estudo indica que o material das sapatas pode ser representado com módulo de elasticidade equivalente ou superior ao do aço sem comprometimento dos resultados de escoamento das camadas metálicas. No entanto, para módulos de elasticidade inferior ao aço e análogo ao dos polímeros, há uma queda da resistência do tubo às cargas de esmagamento. Em casos extremos (RS1), as sapatas sofrem grandes deformações, não suportando a carga de esmagamento necessária para conduzir as camadas metálicas à plastificação. 

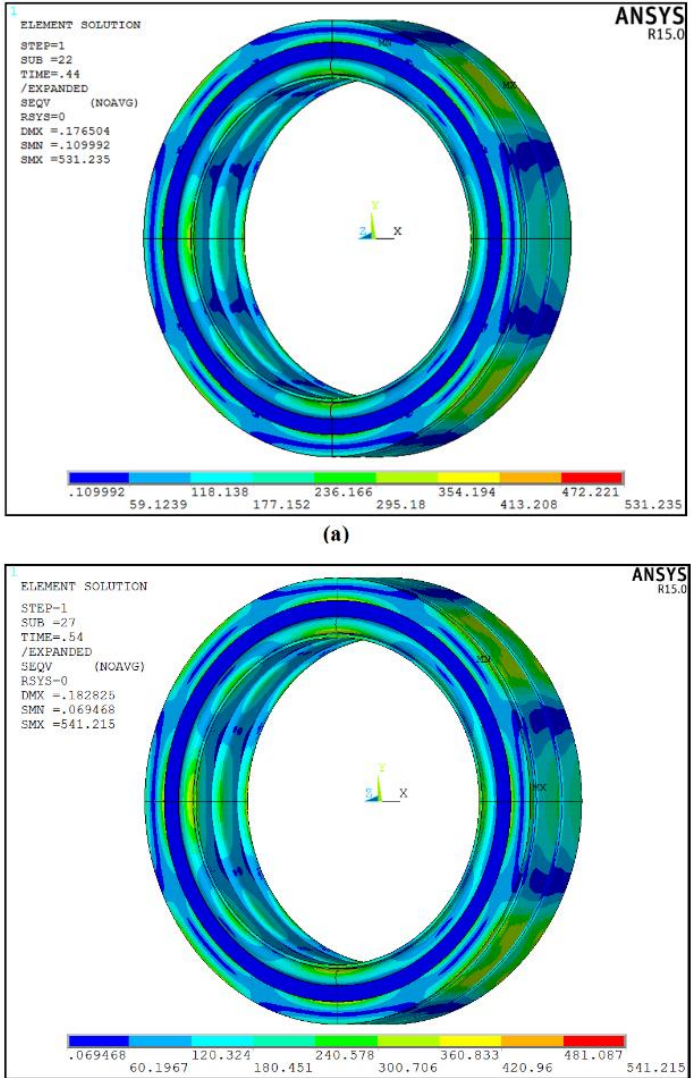

(c)

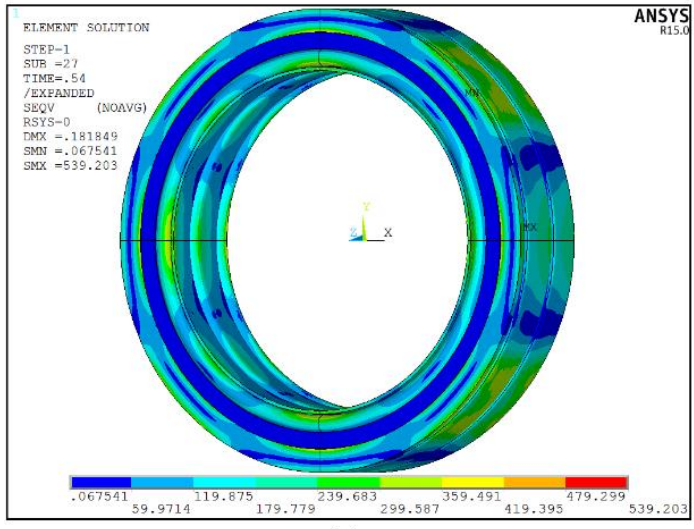

(e)

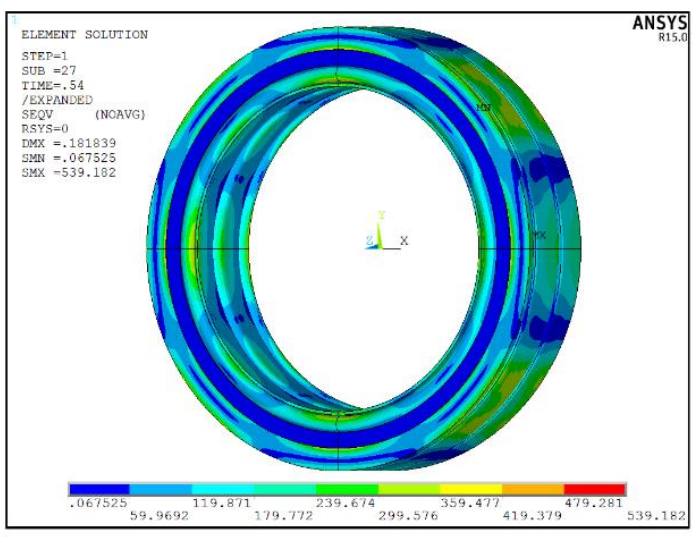

(g)

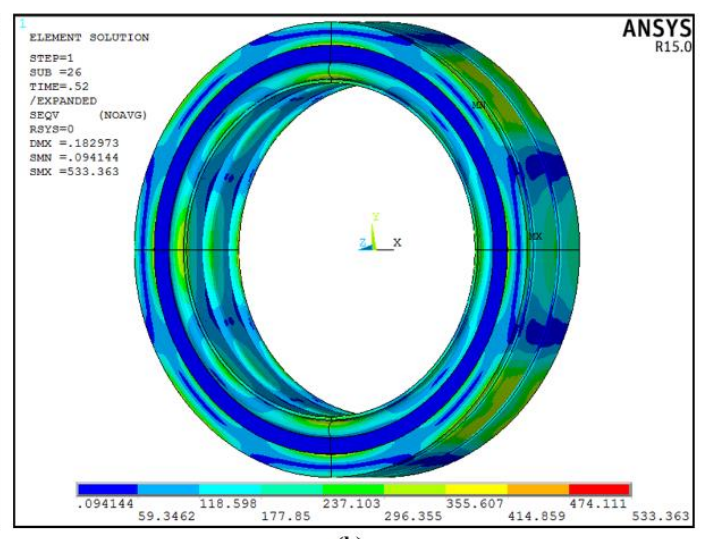

(b)

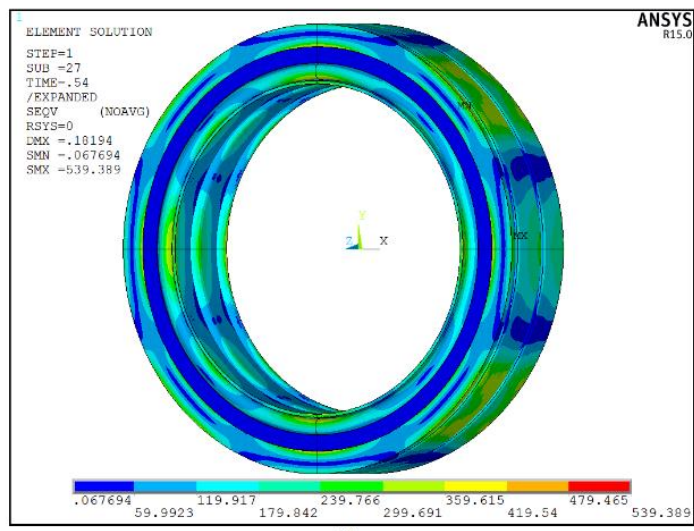

(d)

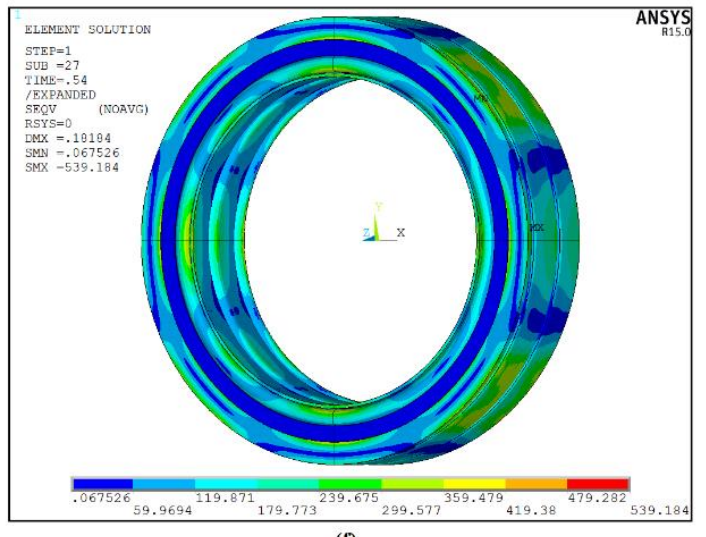

(f)

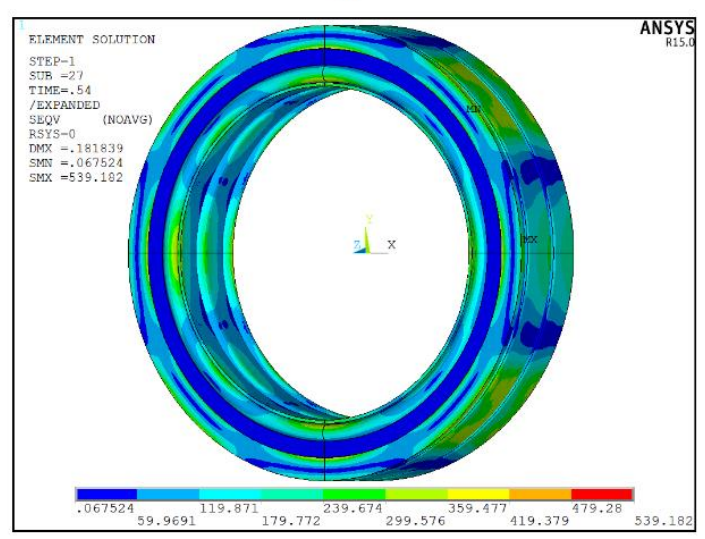

(h)

Figura 48 - Tensão de von Mises [MPa] registrada no ponto de falha do tubo para rigidez das sapatas igual a: (a) $2.1 \mathrm{GPa}$; (b) $21 \mathrm{GPa}$; (c) $210 \mathrm{GPa}$; (d) $2100 \mathrm{GPa}$; (e) $21000 \mathrm{GPa}$; (f) 210000 GPa; (g) $2100000 \mathrm{GPa}$; e (h) $21000000 \mathrm{GPa}$. 


\subsection{Profundidade de Lançamento}

O sexto e último caso de estudo avalia o impacto das cargas de esmagamento e estrangulamento no tubo com a profundidade de lançamento. Para isso, foi estudado o caso em que se têm os carregamentos de esmagamento e estrangulamento aplicados simultaneamente, e a carga de esmagamento aplicada isoladamente. Foram tomadas profundidades de lançamento a partir de $100 \mathrm{~m}$, variando em intervalos de $100 \mathrm{~m}$ até o escoamento das camadas metálicas. Com isso, foi possível identificar a profundidade de falha do tubo e a contribuição do crushing e squeezing na plastificação da carcaça e armadura de pressão durante a instalação do tubo flexível. Para simplificar, os resultados serão apresentados separadamente, de acordo com os carregamentos aplicados.

- $\quad$ Carregamento I - Esmagamento e estrangulamento: A Tabela 31 apresenta a variação da tensão de von Mises nas camadas metálicas com a variação da profundidade de lançamento. A Tabela 32 apresenta os dados de escoamento da carcaça intertravada e fator de utilização da armadura de pressão. A Tabela 33 apresenta esses resultados para armadura de pressão A Tabela 34 indica as tensões registradas nas camadas no momento da falha do tubo.

Tabela 31 - Variação da Tensão de von Mises registrada nas camadas metálicas, de acordo com a profundidade de lançamento, e com aplicação dos carregamentos de esmagamento e estrangulamento.

\begin{tabular}{|c|c|c|c|c|}
\hline Caso & $\begin{array}{c}\text { Força de esma- } \\
\text { gamento } \\
\text { [N/mm/sapata] }\end{array}$ & $\begin{array}{c}\text { Tensão na car- } \\
\text { caça [MPa] }\end{array}$ & $\begin{array}{c}\text { Tensão na ar- } \\
\text { madura de } \\
\text { pressão [MPa] }\end{array}$ & $\begin{array}{c}\text { Fator de utili- } \\
\text { zação N2409 }\end{array}$ \\
\hline PL1 & 126,071 & 103,368 & 106,887 & 0,164 \\
\hline PL2 & 255,743 & 223,839 & 215,569 & 0,332 \\
\hline PL3 & 384,980 & 347,061 & 323,488 & 0,498 \\
\hline PL4 & 514,637 & 472,916 & 438,486 & 0,675 \\
\hline PL5 & 644,193 & 601,068 & 558,291 & 0,859 \\
\hline PL6 & 774,380 & 732,377 & 681,246 & 1,048 \\
\hline
\end{tabular}


Tabela 32 - Dados de escoamento da carcaça intertravada, a $500 \mathrm{~m}$ de profundidade, com a aplicação dos carregamentos de esmagamento e estrangulamento.

\begin{tabular}{|c|c|c|c|c|}
\hline \multicolumn{5}{|c|}{ Escoamento da carcaça } \\
\hline Caso & $\begin{array}{c}\text { Força de esma- } \\
\text { gamento } \\
{[\mathbf{N} / \mathbf{m m} / \text { sapata] }}\end{array}$ & $\begin{array}{c}\text { Tensão na car- } \\
\text { caça [MPa] }\end{array}$ & $\begin{array}{c}\text { Tensão na ar- } \\
\text { madura de } \\
\text { pressão [MPa] }\end{array}$ & $\begin{array}{c}\text { Fator de } \\
\text { utilização } \\
\text { N2409 }\end{array}$ \\
\hline PL5 & 631,310 & 588,265 & 546,282 & 0,840 \\
\hline
\end{tabular}

Tabela 33 - Dados de escoamento da armadura de pressão, a $600 \mathrm{~m}$ de profundidade, com a aplicação dos carregamentos de esmagamento e estrangulamento.

\begin{tabular}{|c|c|c|c|c|}
\hline \multicolumn{5}{|c|}{ Escoamento da armadura de pressão } \\
\hline Caso & $\begin{array}{c}\text { Força de esma- } \\
\text { gamento } \\
\text { [N/mm/sapata] }\end{array}$ & $\begin{array}{c}\text { Tensão na ar- } \\
\text { madura de } \\
\text { pressão [MPa] }\end{array}$ & $\begin{array}{c}\text { Tensão na car- } \\
\text { caça [MPa] }\end{array}$ & $\begin{array}{c}\text { Fator de uti- } \\
\text { lização } \\
\text { N2409 }\end{array}$ \\
\hline PL6 & 727,918 & 637,111 & 685,194 & 1,142 \\
\hline
\end{tabular}

Tabela 34 - Dados de falha do tubo, a $500 \mathrm{~m}$ de profundidade, com aplicação dos carregamentos de esmagamento e estrangulamento.

\begin{tabular}{|c|c|c|c|c|}
\hline \multicolumn{5}{|c|}{ Falha do tubo } \\
\hline Caso & $\begin{array}{c}\text { Força de esma- } \\
\text { gamento } \\
{[\text { [N/mm/sapata] }}\end{array}$ & $\begin{array}{c}\text { Tensão na car- } \\
\text { caça [MPa] }\end{array}$ & $\begin{array}{c}\text { Tensão na ar- } \\
\text { madura de } \\
\text { pressão [MPa] }\end{array}$ & $\begin{array}{c}\text { Fator de utili- } \\
\text { zação N2409 }\end{array}$ \\
\hline PL5 & 592,658 & 510,325 & 549,947 & 0,785 \\
\hline
\end{tabular}

Pela Tabela 31 pode-se perceber que a profundidade máxima alcançada pelo tubo é de pouco menos de $500 \mathrm{~m}$ já que o fator de utilização ultrapassa os 0,8 definidos pela norma no caso PL5. A plastificação da carcaça ocorre a uma profundidade de $500 \mathrm{~m}$ como indicado na Tabela 32. Já a armadura de pressão suporta maiores carregamentos radiais, e seu escoamento ocorre próximo aos $600 \mathrm{~m}$ de profundidade. A falha do tubo ocorre aos $500 \mathrm{~m}$ de profundidade, antes de atingir o fundo do mar, conhecido como TDP (Touch Down Point). O tubo falha logo após o escoamento da carcaça, e respeitando o fator de utilização da armadura de pressão. 
- $\quad$ Carregamento II - Esmagamento: A Tabela 35 indica as tensões de von Mises nas camadas metálicas com a variação da profundidade de lançamento. A Tabela 36 mostra os dados de escoamento da carcaça intertravada e fator de utilização da armadura de pressão. A Tabela 37 traz os mesmos resultados, porém para armadura de pressão. A Tabela 38 apresenta as tensões nas camadas metálicas para a falha do tubo.

Tabela 35 - Variação da Tensão de von Mises resgistrada nas camadas metálicas, de acordo com a profundidade de lançamento, e com aplicação apenas do carregamento de esmagamento.

\begin{tabular}{|c|c|c|c|c|}
\hline Caso & $\begin{array}{c}\text { Força de esma- } \\
\text { gamento } \\
\text { [N/mm/sapata] }\end{array}$ & $\begin{array}{c}\text { Tensão na car- } \\
\text { caça [MPa] }\end{array}$ & $\begin{array}{c}\text { Tensão na ar- } \\
\text { madura de } \\
\text { pressão [MPa] }\end{array}$ & $\begin{array}{c}\text { Fator de uti- } \\
\text { lização } \\
\text { N2409 }\end{array}$ \\
\hline PL1 & 126,071 & 96,134 & 104,133 & 0,160 \\
\hline PL2 & 255,743 & 208,108 & 209,579 & 0,322 \\
\hline PL3 & 384,980 & 322,386 & 313,921 & 0,483 \\
\hline PL4 & 514,637 & 438,860 & 423,573 & 0,652 \\
\hline PL5 & 644,930 & 556,987 & 538,283 & 0,828 \\
\hline PL6 & 774,380 & 677,734 & 655,615 & 1,009 \\
\hline
\end{tabular}

Tabela 36 - Dados de escoamento da carcaça intertravada, a $600 \mathrm{~m}$ de profundidade, com a aplicação do carregamento de esmagamento.

\begin{tabular}{|c|c|c|c|c|}
\hline \multicolumn{5}{|c|}{ Escoamento da carcaça } \\
\hline Caso & $\begin{array}{c}\text { Força de esma- } \\
\text { gamento } \\
\text { [N/mm/sapata] }\end{array}$ & $\begin{array}{c}\text { Tensão na car- } \\
\text { caça [MPa] }\end{array}$ & $\begin{array}{c}\text { Tensão na ar- } \\
\text { madura de } \\
\text { pressão [MPa] }\end{array}$ & $\begin{array}{c}\text { Fator de uti- } \\
\text { lização } \\
\text { N2409 }\end{array}$ \\
\hline PL6 & 681,456 & 591,287 & 571,668 & 0,879 \\
\hline
\end{tabular}


Tabela 37 - Dados de escoamento da armadura de pressão, a $600 \mathrm{~m}$ de profundidade, com aplicação do carregamento de esmagamento.

\section{Escoamento da armadura de pressão}

\begin{tabular}{|c|c|c|c|c|}
\hline Caso & $\begin{array}{c}\text { Força de esma- } \\
\text { gamento } \\
\text { [N/mm/sapata] }\end{array}$ & $\begin{array}{c}\text { Tensão na ar- } \\
\text { madura de } \\
\text { pressão [MPa] }\end{array}$ & $\begin{array}{c}\text { Tensão na car- } \\
\text { caça [MPa] }\end{array}$ & $\begin{array}{c}\text { Fator de utili- } \\
\text { zação N2409 }\end{array}$ \\
\hline PL6 & 758,893 & 641,702 & 663,339 & 1,106 \\
\hline
\end{tabular}

Tabela 38 - Dados de falha do tubo, a 500 m de profundidade, com aplicação do carregamento de esmagamento.

Falha do tubo

\begin{tabular}{|c|c|c|c|c|}
\hline Caso & $\begin{array}{c}\text { Força de esmaga- } \\
\text { mento [N/mm/sa- } \\
\text { pata] }\end{array}$ & $\begin{array}{c}\text { Tensão na car- } \\
\text { caça [MPa] }\end{array}$ & $\begin{array}{c}\text { Tensão na ar- } \\
\text { madura de } \\
\text { pressão [MPa] }\end{array}$ & $\begin{array}{c}\text { Fator de } \\
\text { utilizaçãa } \\
\text { N2409 }\end{array}$ \\
\hline PL5 & 619,505 & 515,353 & 533,433 & 0,793 \\
\hline
\end{tabular}

Nota-se, pela Tabela 31 e Tabela 35, que a falha do tubo para o carregamento II ocorre próximo aos $600 \mathrm{~m}$ de profundidade, assim como identificado no carregamento I. A Figura 49 e a Figura 50 apresentam a evolução das tensões no tubo para os carregamentos I e II, respectivamente. Nota-se que a distribuição das tensões nos tubos para os carregamentos I e II são similares, indicando que as regiões críticas para cada um dos casos é a mesma. A partir dos resultados apresentados percebe-se que a contribuição do carregamento de estrangulamento para a falha do tubo é mínima já que o tubo falha em profundidades próximas para os carregamentos I e II. A diferença entre os carregamentos de falha para o caso I e o caso II é de apenas 14,98\%. Isso indica que o esmagamento é a carga crítica para a falha do tubo, e outros parâmetros, além daqueles já abordados neste trabalho, devem ser estudados a fim de se ter uma previsão mais completa do fenômeno. As Figura 51 a Figura 56 apresentam a relação entre força de esmagamento e deslocamento radial para a carcaça intertravada e armadura de pressão para as profundidades de 100m a $600 \mathrm{~m}$, considerando os dois carregamentos estudados. 

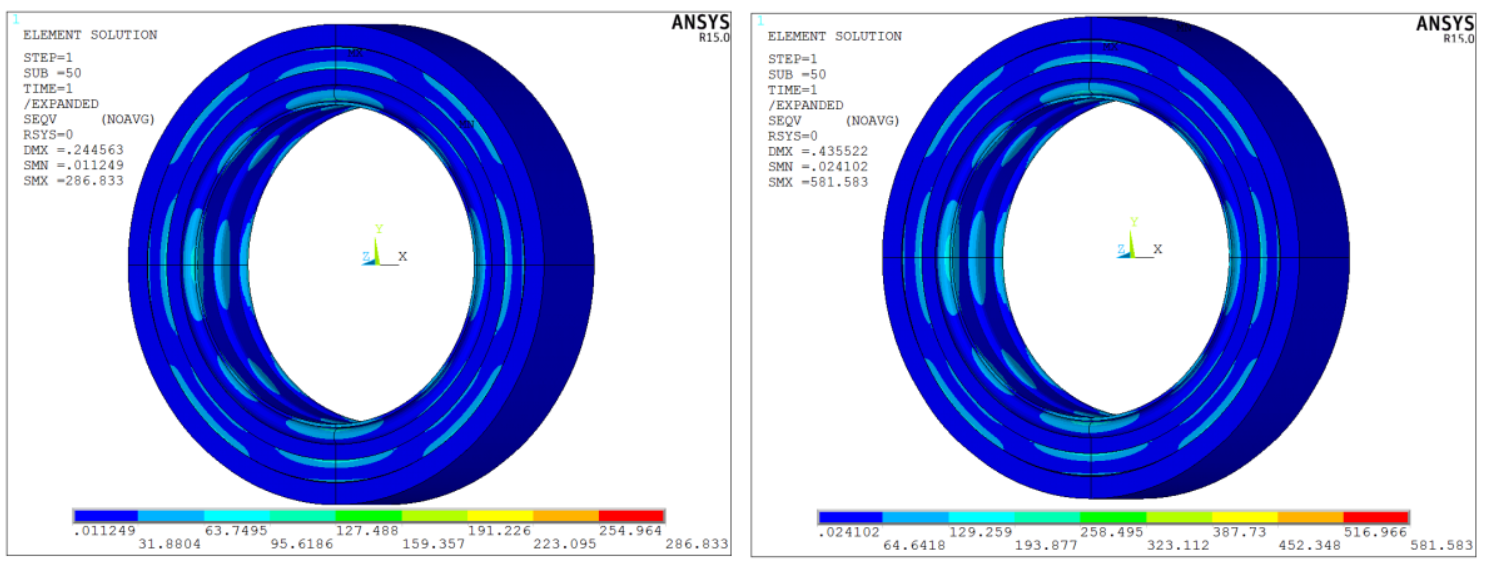

(a)

(b)

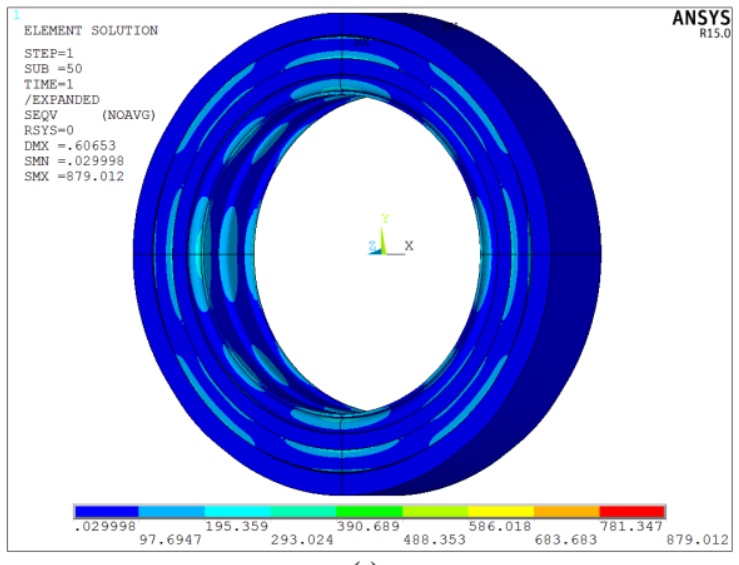

(c)

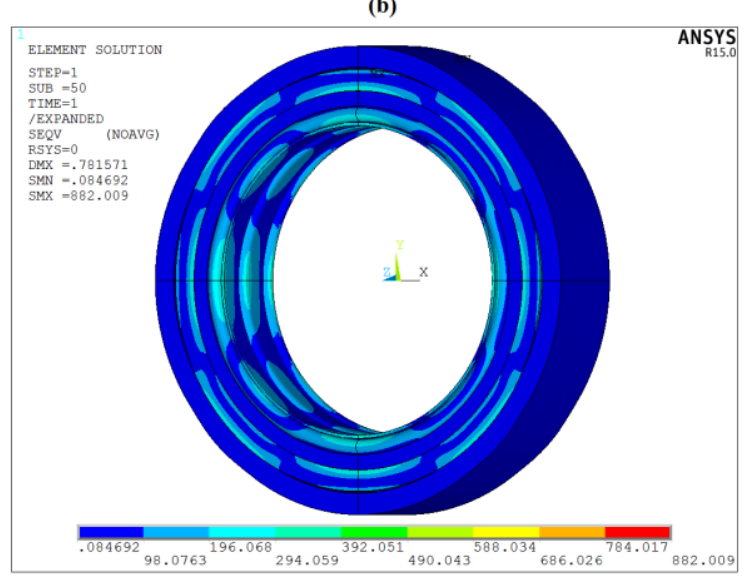

(d)

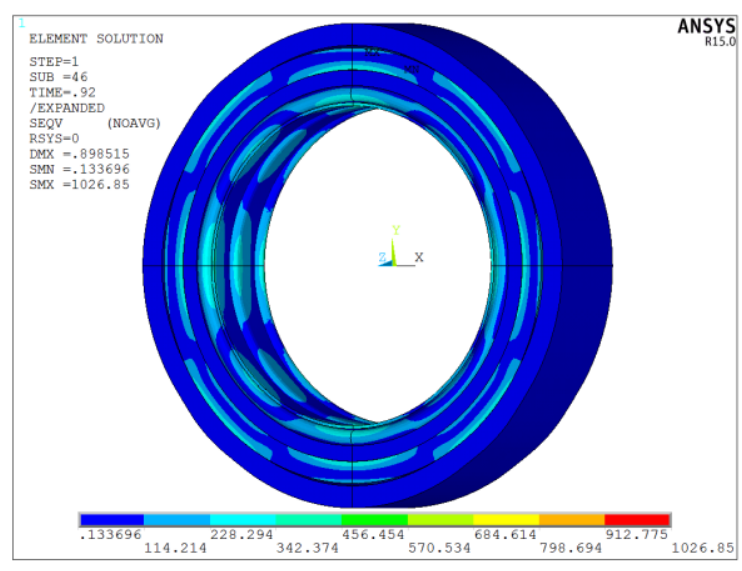

(e)

Figura 49 - Tensão de von Mises [MPa] registrada no ponto de falha do tubo para para o carregamento I e profundidades de a: (a) $100 \mathrm{~m}$; (b) $200 \mathrm{~m}$; (c) $300 \mathrm{~m}$; (d) $400 \mathrm{~m}$; (e) $500 \mathrm{~m}$. 

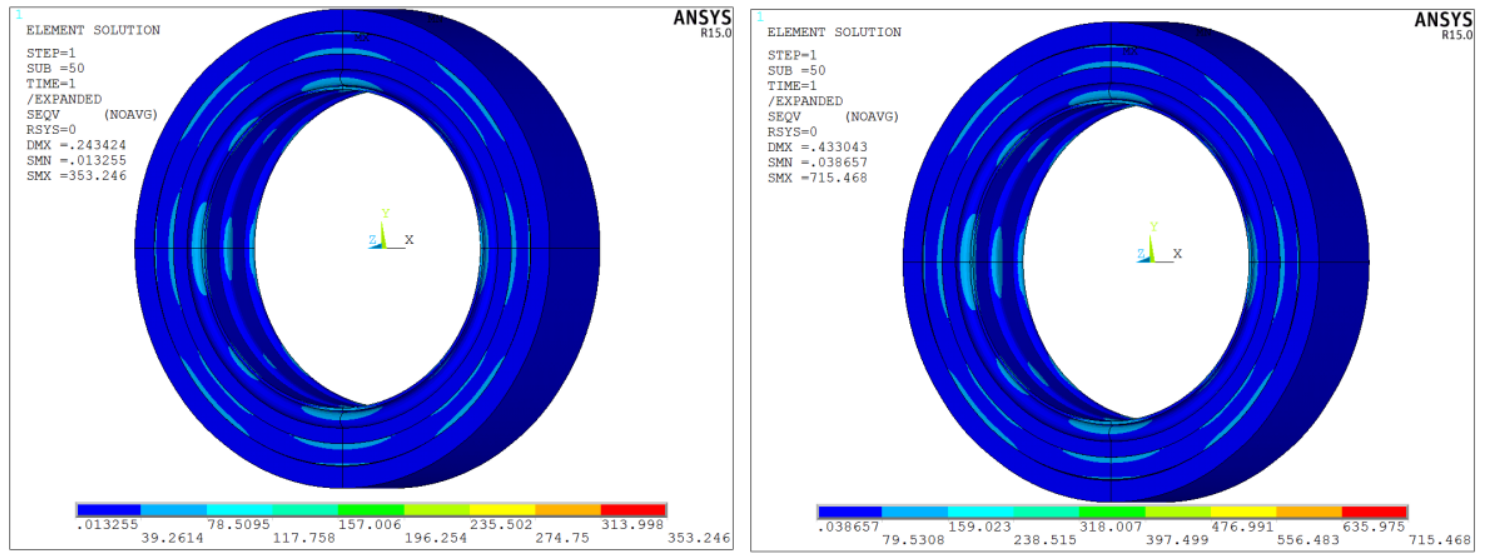

(a)

(b)
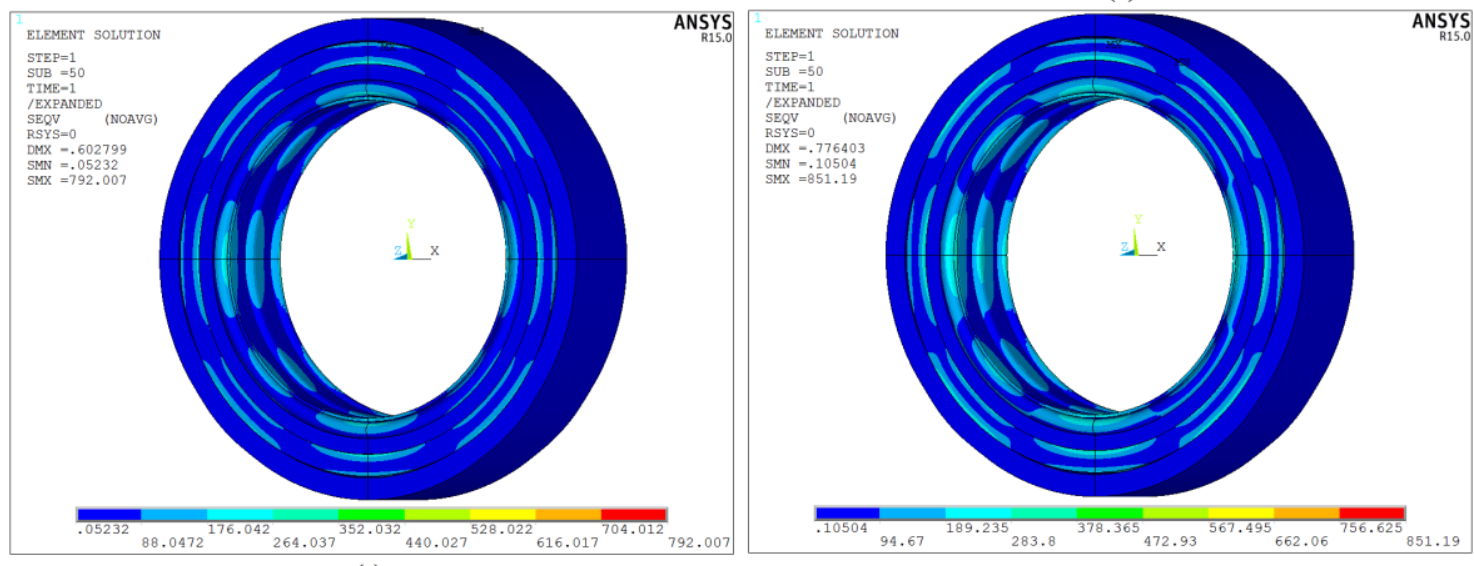

(c)

(d)

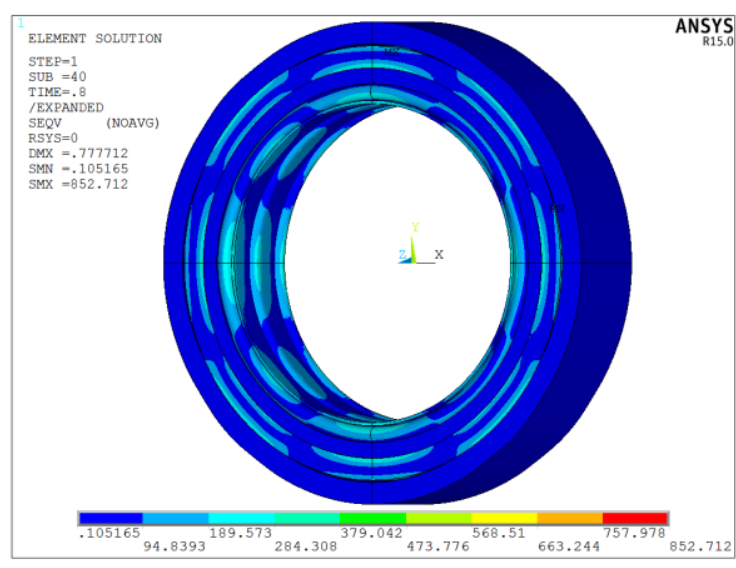

(e)

Figura 50 - Tensão de von Mises [MPa] registrada no ponto de falha do tubo para para o carregamento II e profundidades de a: (a) $100 \mathrm{~m}$; (b) $200 \mathrm{~m}$; (c) $300 \mathrm{~m}$; (d) $400 \mathrm{~m}$; (e) $500 \mathrm{~m}$. 


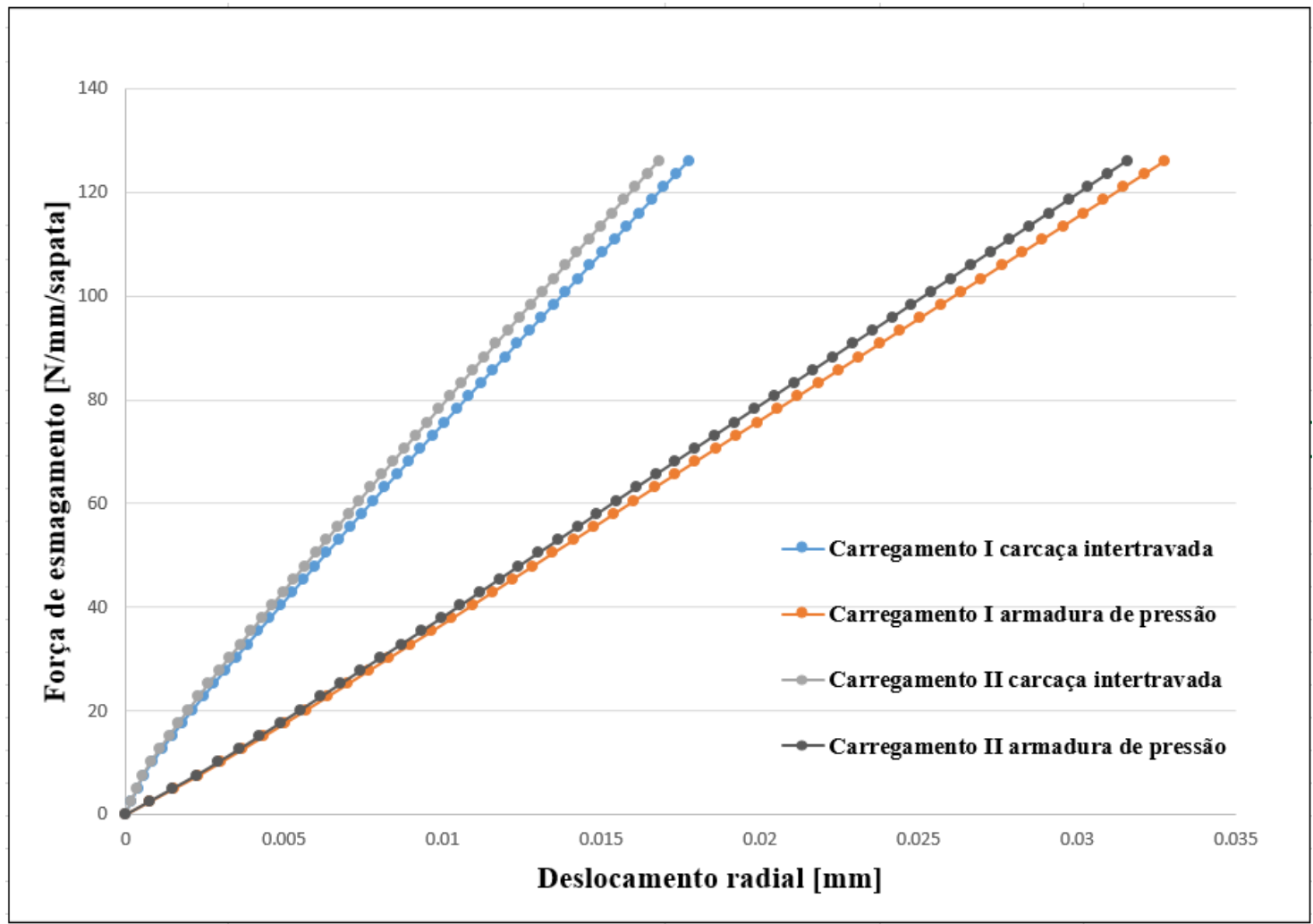

Figura 51 - Relação entre força de esmagamento x deslocamento radial para armadura de pressão e carcaça intertravada para os carregamentos I e II a $100 \mathrm{~m}$ de profundidade.

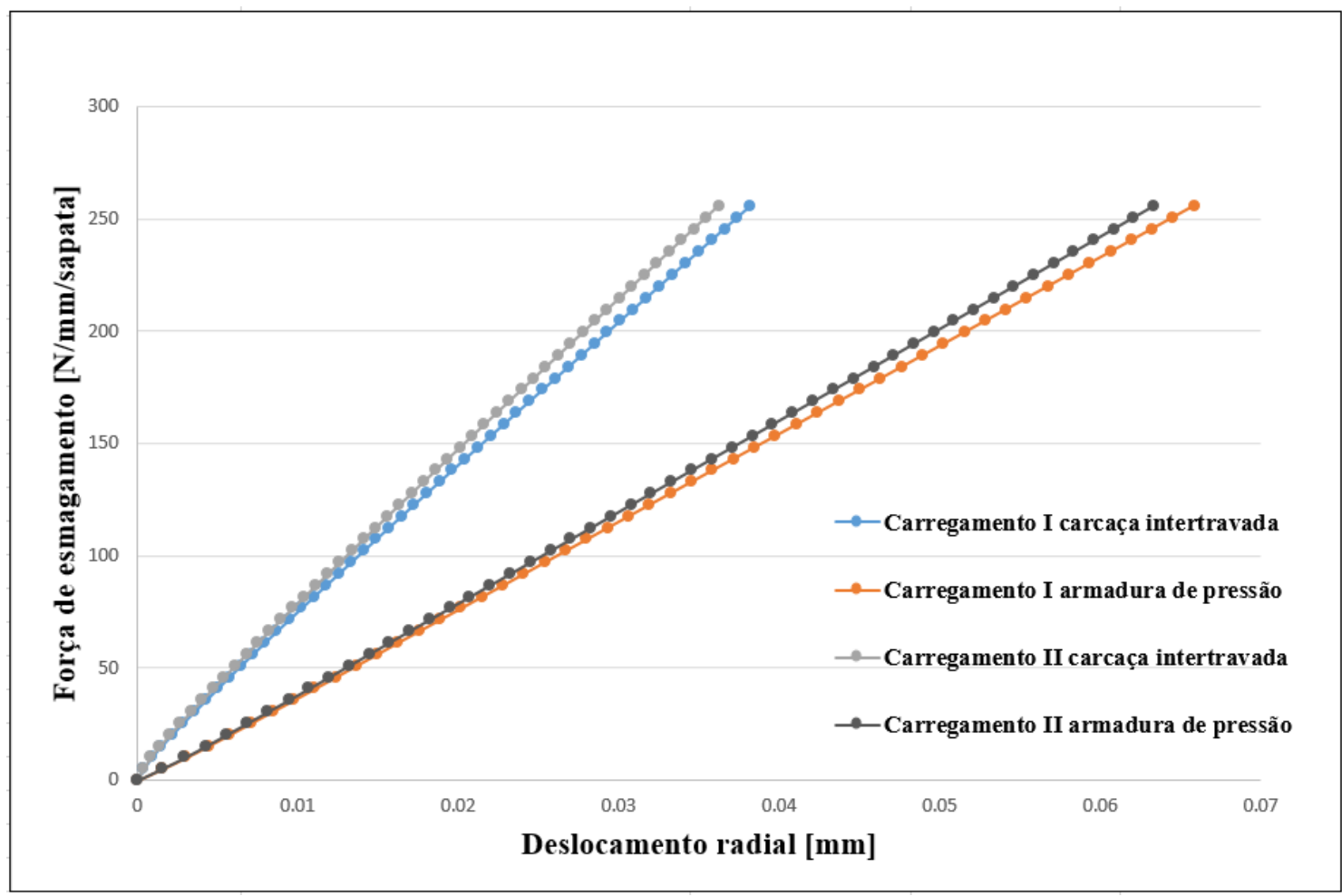

Figura 52 - Relação entre força de esmagamento $\mathrm{x}$ deslocamento radial para armadura de pressão e carcaça intertravada para os carregamentos I e II a $200 \mathrm{~m}$ de profundidade. 


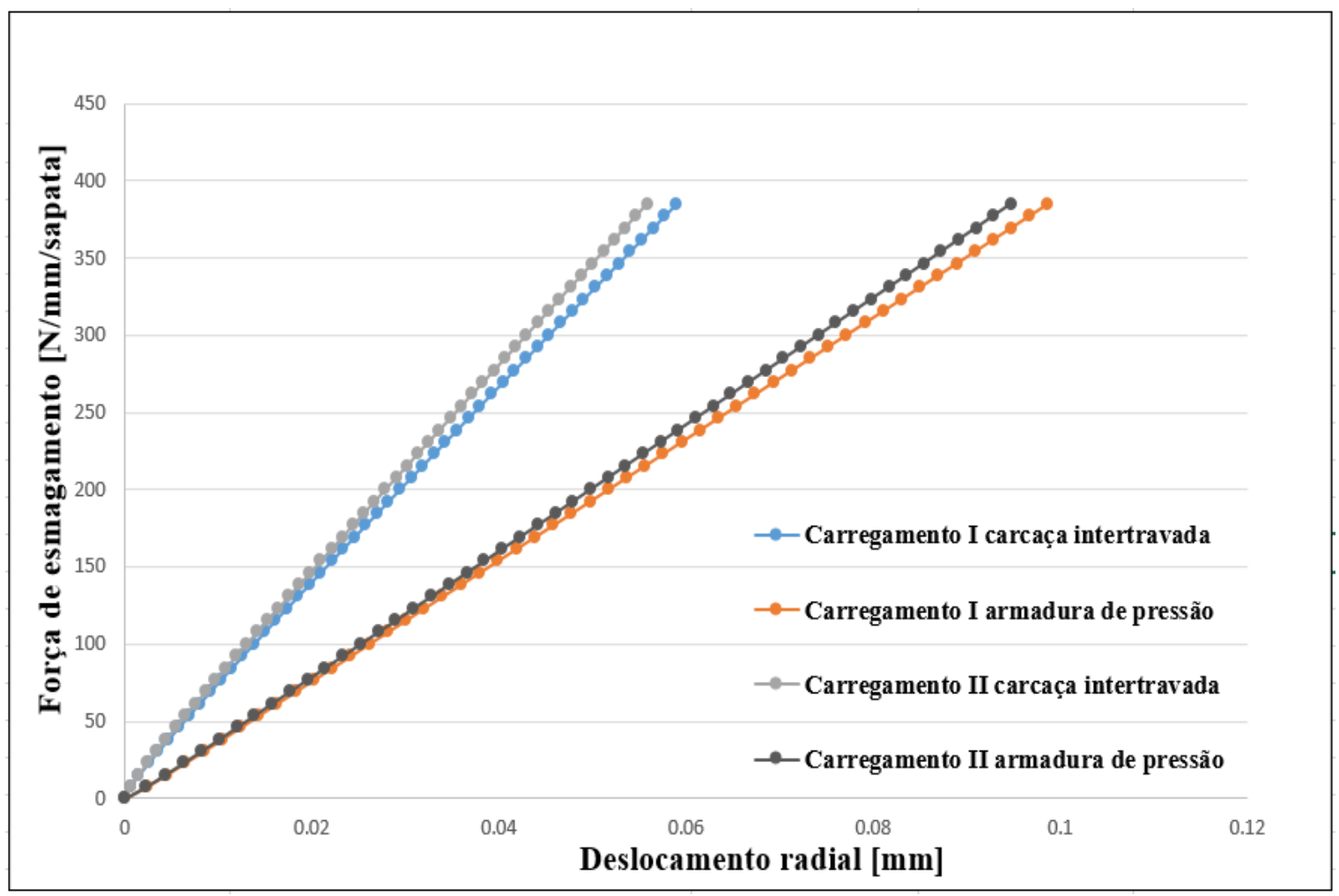

Figura 53 - Relação entre força de esmagamento x deslocamento radial para armadura de pressão e carcaça intertravada para os carregamentos I e II a $300 \mathrm{~m}$ de profundidade.

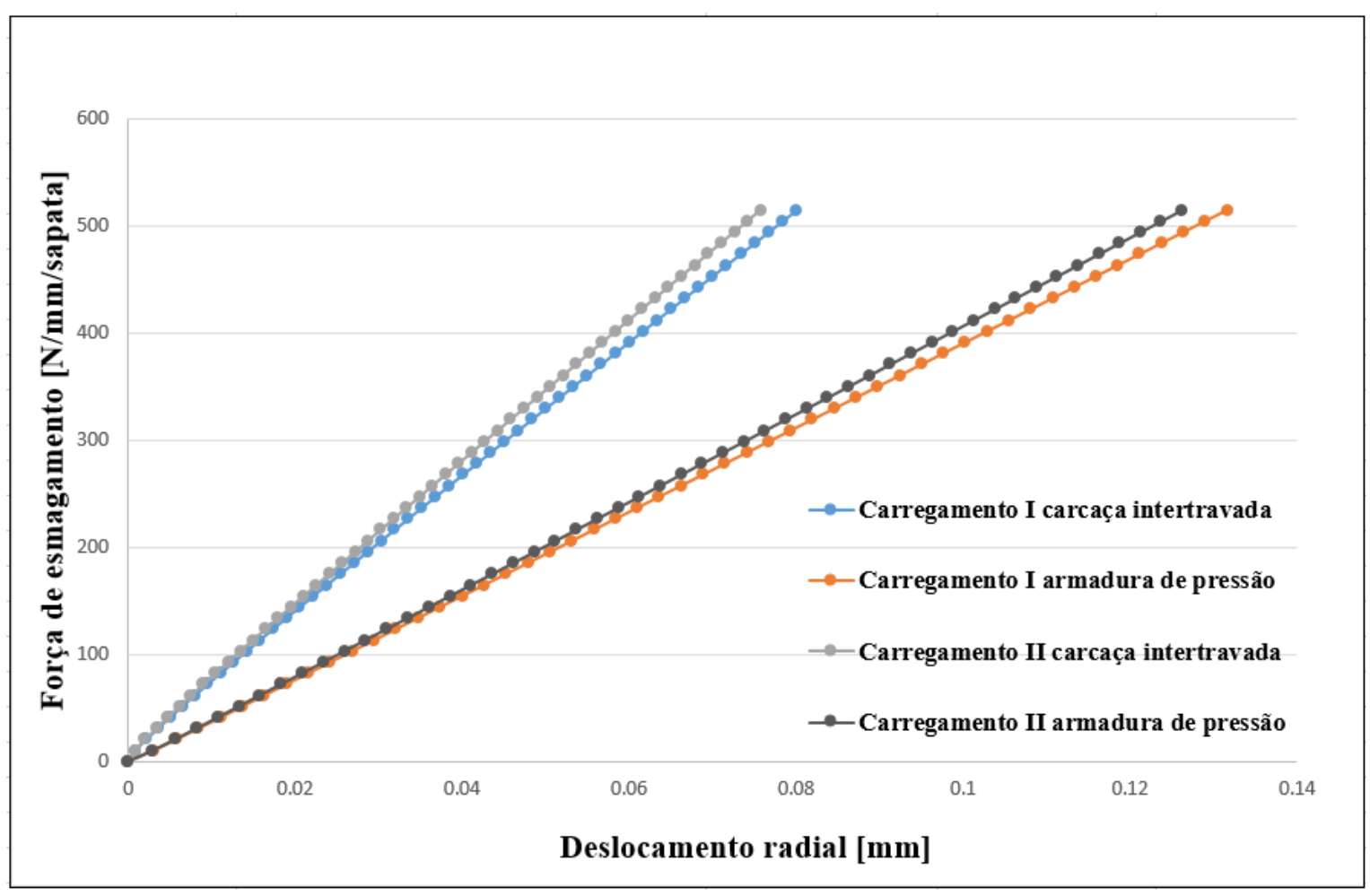

Figura 54 - Relação entre força de esmagamento x deslocamento radial para armadura de pressão e carcaça intertravada para os carregamentos I e II a $400 \mathrm{~m}$ de profundidade. 


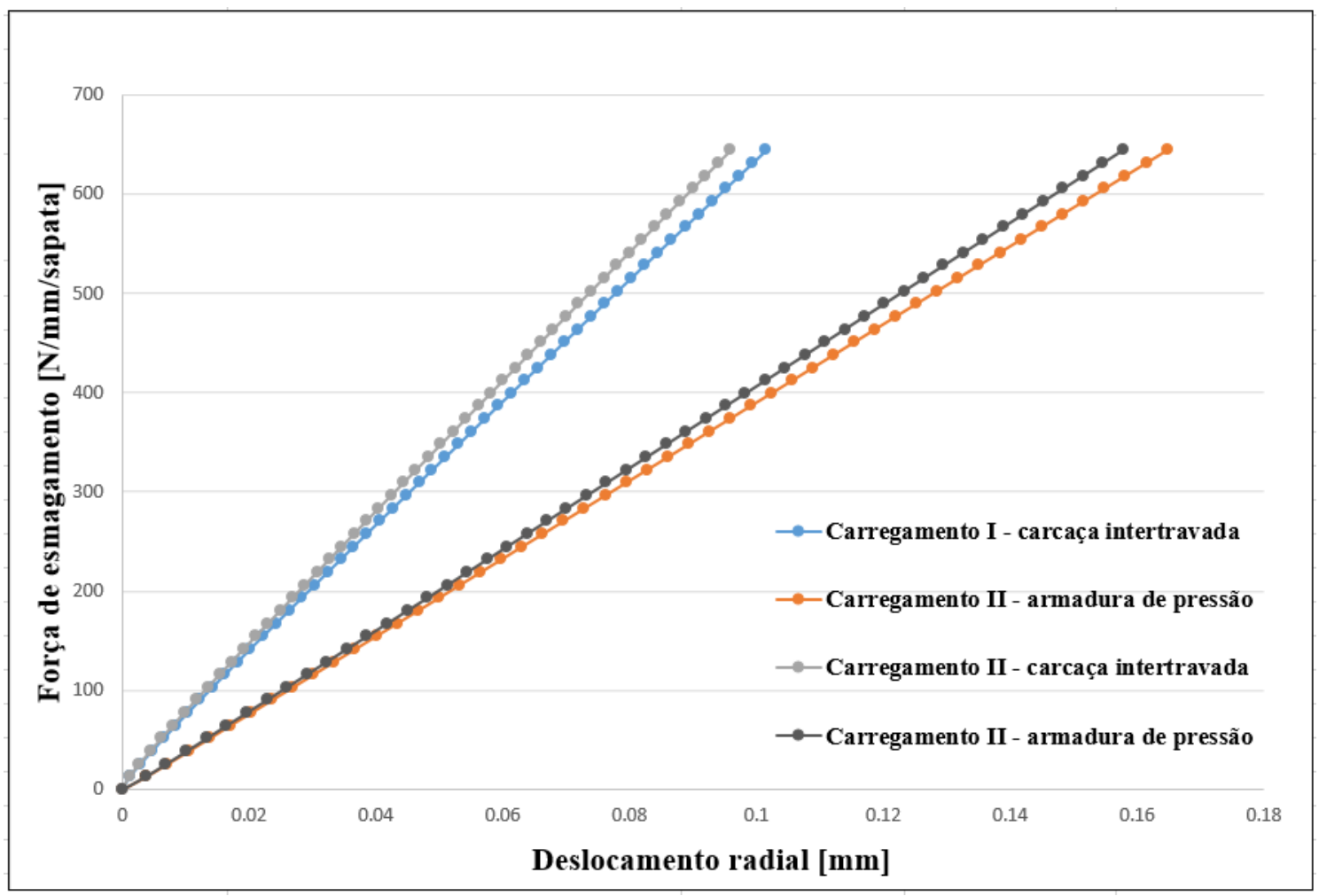

Figura 55 - Relação entre força de esmagamento x deslocamento radial para armadura de pressão e carcaça intertravada para os carregamentos I e II a $500 \mathrm{~m}$ de profundidade.

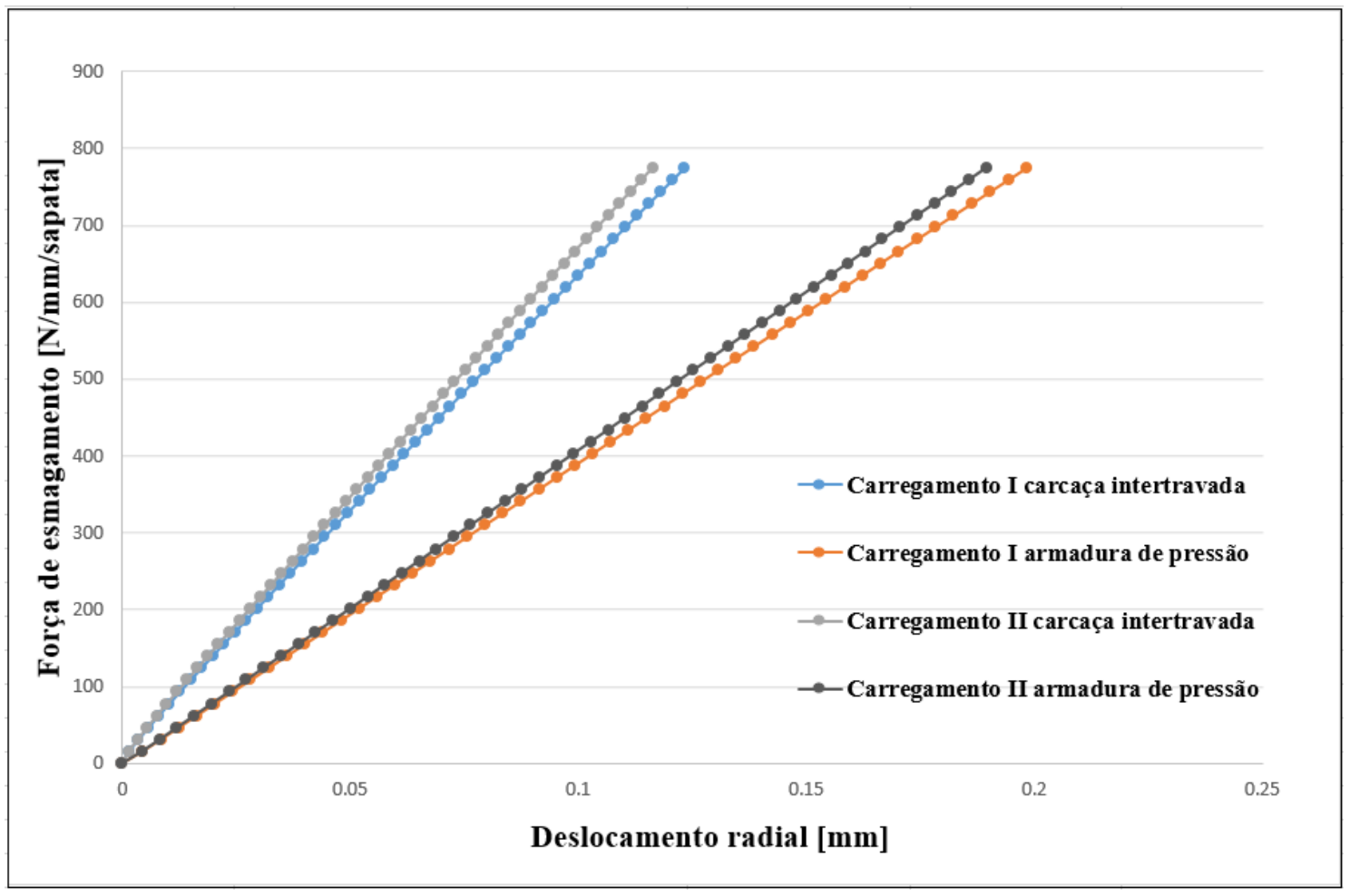

Figura 56 - Relação entre força de esmagamento x deslocamento radial para armadura de pressão e carcaça intertravada para os carregamentos I e II a $600 \mathrm{~m}$ de profundidade. 
Através das Figura 51 a Figura 56 pode-se perceber que os maiores deslocamentos ocorrem para as profundidades com o carregamento I, como já era esperado. O deslocamento radial das camadas metálicas para os casos em que se tem os carregamentos I e II são equivalentes no início do lançamento. Percebe-se uma diference acentuada à medida que a profundidade aumenta em razão do aumento da força de esmagamento e da pressão de estrangulamento. O comportamento das camadas é similar para as profundidades de 100m a 500m, e não sendo possível perceber a curva bilinear de material para esse intervalo. Essa curva pode ser percebida para tensões muito altas, como já foi percebido na análise da quantidade de sapatas, após o ponto de escoamento das camadas metálicas. A fim de se repetir essa curva, foi feita uma análise da influência dos carregamentos I e II a 2000m de profundidade, como indicado na Figura 57. Percebe-se que a armadura de pressão apresenta maiores deslocamentos radiais em relação à carcaça intertravada para o mesmo carregamento de esmagamento. O comportamento bilinear, característico da transição do regime linear elástico para o plástico, pode ser percebido a partir de do carregamento de esmagamento equivalente a $1500 \mathrm{~N} / \mathrm{mm} / \mathrm{sapata}$.

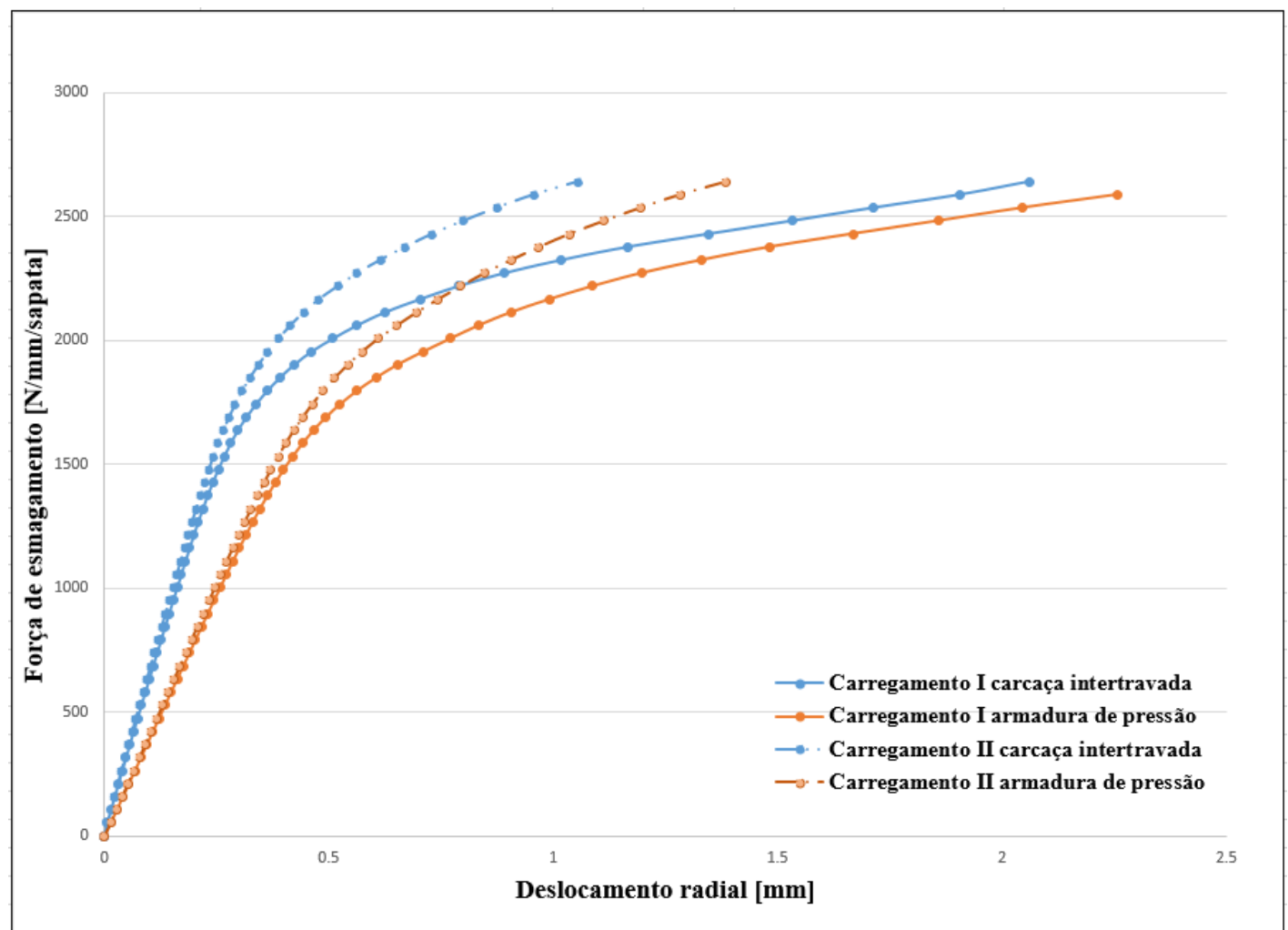

Figura 57 - Relação força de esmagamento $\mathrm{x}$ deslocamento radial para armadura de pressão e carcaça intertravada para os carregamentos I e II a $2000 \mathrm{~m}$ de profundidade. 


\section{CONSIDERAÇÕES FINAIS}

Neste trabalho foram construídos vários modelos a fim de se avaliar os principais parâmetros responsáveis pela falha do tubo flexível durante o lançamento. Esses modelos foram derivados de dois principais, distintos entre si apenas na composição das camadas. Enquanto o primeiro continha as camadas presentes no núcleo estrutural, o segundo teve a capa polimérica externa incluída. Foram então realizados estudos a partir da variação dos parâmetros desejados bem como hipóteses de modelagem. Os estudos realizados foram então feitos a partir: da variação da quantidade de sapatas e seu ângulo de abertura; da adição da camada polimérica externa; do estudo do par de contato entre o tubo e as sapatas; da variação de rigidez das sapatas; e do estudo conjunto do impacto dos carregamentos de esmagamento e estrangulamento com a profundidade de lançamento.

Foram obtidos como resultados que a melhor configuração das sapatas são aquelas em quantidade de 4 e com ângulos de abertura de $130^{\circ}$ e $140^{\circ}$. Com essa composição, o tubo pode ser submetido a carregamentos maiores de esmagamento até a ocorrência da falha. Em relação à adição da capa polimérica externa percebeu-se que essa estrutura proporciona uma melhor distribuição de tensão entre as camadas metálicas. Isso faz com que a falha dessas estruturas ocorra em pontos muito próximos. A avaliação do contato entre o tubo e as sapatas mostrou ser o contato bonded a favor da segurança já que nessa situação a falha do tubo ocorre para carregamentos inferiores aos daqueles registrados para os contatos frictionless e rough. Através do estudo da variação da rigidez das sapatas foi possível identificar que para um intervalo de ordem de grandeza do módulo de elasticidade do material adotado a falha do tubo ocorre no mesmo ponto. O valor mínimo adotado para esse parâmetro foi identificado a partir da queda na tensão de esmagamento suportada pelo tubo durante o lançamento. Por fim, foi possível identificar a profundidade de falha do tubo a partir da investigação do impacto dos carregamentos de esmagamento e estrangulamento atuando simultaneamente na estrutura. A carga de estrangulamento não apresentou impacto substancial na falha do tubo, sendo a carga de esmagamento a mais crítica e com maior parcela na falha do tubo. 


\section{REFERÊNCIAS BIBLIOGRÁFICAS}

[1] General Electric Company. Disponivel em: <http://site.geenergy.com/businesses/ge_oilandgas/en/techinsights/analysis-creep-behavior-1.html>. Acesso em: 05 jan. 2016.

[2] maritime connector. Disponivel em: <http://maritimeconnector.com/wiki/Specialised-vessels/> . Acesso em: 09 Dezembro 2015.

[3] 17B, A. Specifications for Unbonded Flexible Pipe. American Petroleum Institute. Wahsington. 2002.

[4] 17J, A. S. Specification for Unbonded Flexible. America Petroleum Institute. Washington, D.C. , p. 73. 2008.

[5] ANSYS. ANSYS Mechanical User's Guide. Release 15.0, 2013. 1832.

[6] BAHTUI, A.; BAHAI, H.; ALFANO, G. Numerical and Analytical Modeling of Unbonded flexible Risers. Journal of Offshore Mechanics and Artic Engineering, v. 130, May 2008.

[7] BAI, Q.; BAI, Y. Subsea Pipeline Design, Analysis, and Installation. Massachusetts: Elsevier, v. 1, 2014. 824 p p.

[8] BRAESTRUP, M. et al. Design and Installation of Marine Pipelines. Australia: Wiley-Blackwell, 2005.

[9] CHAKRABARTY, J. Theory of Plasticity. Oxford: Elsevier, v. 3, 2006.

[10] CHAKRABARTY, J. Applied Plasticity. New York: Springer, 2010.

[11] CHEN, B.; NIELSEN, R.; COLQUHOUN, R. S. Theoretical Models for Prediction of Burst \& Collapse and their Verification by Testing. Proceedings of the International Seminar on Recent Research and Development within Flexible Pipe Technology, Trondheim, Noruega, p. 355-398, 1992.

[12] ClAUSEN, T. . D. R. Dynamic Risers: Key Component for Deepwater Drilling, Floating Production. Offshore Magazine. [S.1.], p. pp. 89-92. 2001.

[13] COELHO, P. P. S. C. ESTUDO DA SUSCEPTIBILIDADE À CORROSÃO SOB TENSÃO EM ATMOSFERA DE H2S DAS ARMADURAS DE TRAÇÃO DE DUTOS FLEXÍVEIS. CEFET/RJ. Rio de Janeiro, p. 60. 2013.

[14] CRUZ, F. T. L. Análise Estrutural de Linhas Flexíveis pelo Método dos Elementos Finitos. Tese de MSc., EPUSP. São Paulo, SP, BRASIL. 1996. 
[15] DYNAMIC Flexible Risers. National Oilwell Varco. Disponivel em: <http://www.nov.com/fps_landing/products/dynamic-flexible-risers.html >. Acesso em: 05 jan. 2016.

[16] FÉRET, J. J.; BOURNAZEL, C. L. Calculation of Stresses and Slip in Structural Layers of Unbonded Flexible Pipes. Journal of Offshore Mechanics and Arctic Engineering, Agosto 1987. 263-269.

[17] FRANZINI, G. R. et al. Crushing of flexible pipes under traction: A theoreticalexperimental assessment. SME 2011 30th International Conference on Ocean, Offshore and Arctic Engineering, p. 503-512, 2011.

[18] GAY NETO, A. E. A. Study of Pipe Integrity and Kinematic Assumptions. OMAE-32nd International Conference on Ocean, Offshore and Artic Engineering., Nantes, France, p. 1-10, 2013.

[19] GAY NETO, A.. M. C. A.. M. E. R.. T. C. A.. G. Simplified Finite Element Models to Study the Dry Collapse of Straight and Curved Flexible Pipes. Journal of Offshore Mechanics and Arctic Engineering, Abril 2016. Journal of Offshore Mechanics and Arctic Engineering.

[20] GAY NETO, A.; MARTINS, C. A. A comparative buckling study for the carcass layer of flexible pipes. Proceeding of the 28th International Conference on Offshore Mechanics and Arctic Engineering, 2009.

[21] GAY NETO, A.; MARTINS, C. A. A Comparative Wet Collapse Buckling Study for the Carcass Layer of Flexible Pipes. Journal of Offshore Mechanics and Arctic Engineering, Agosto 2012. 031701 1-9.

[22] GAY NETO, A.; MARTINS, C. A.; PESCE, C. P. A numerical simulation of crushing in flexible pipes. 20th International Congress of Mechanical Engineering , Gramado, RS, Brasil, p. 1-10, Novembro 2009.

[23] HERPNER, Q. G. Estudo Analítico de Abandono e Recolhimento de Dutos. Dissertação (Trabalho de Conclusão de Curso em Engenharia Naval). [S.l.]. 2008.

[24] KELLY, P. Plasticity Strain Hardening. Solid Mechanics Part II: Engineering Solid Mechanics - small strain, 01 set. 2016. Disponivel em: <http://homepages.engineering.auckland.ac.nz/ pkel015/SolidMechanicsBooks/Part_I $\mathrm{I} />$.

[25] KING, A. C. P. A. R. A. Subsea Pipeline Engineering. Tulsa: PennWell Corporation, 2008.

[26] MALTA, E. R. E. A. Finite element modeling of flexible pipes under crushing loads. OMAE- 32nd International Conference on Ocean, Offshore and Artic Engineering., Nantes, France, p. 1-9, 2013. 
[27] MARTINS, C. A.; PESCE, C. P.; ARANHA, J. A. P. Structural Behavior of Flexible Pipe Carcass During Launching. 22nd International Conference on Offshore Mechanics and Artic Engineering. Cancun, Mexico: [s.n.]. 2003.

[28] MODEC. Offshore Oil \& Gas Industry, 2016. Disponivel em: <http://www.modec.com/about/industry/oil_gas.html>. Acesso em: 08 ago. 2016.

[29] OCEANICA. OCEANICA UFRJ. Disponivel em: <http://www.oceanica.ufrj.br/deno/prod_academic/relatorios/2015/Luanda/relat1/plsv _luanda_rel1_c.htm>. Acesso em: 08 ago. 2016.

[30] RAMOS JR., R. Modelos Analíticos no Estudo do Comportamento Estrutural de Tubos Flexíveis e Cabos Umbilicais. Tese de Doutorado, Escola Politécnica da Universidade de São Paulo. [S.1.]: [s.n.]. 2001.

[31] RAMOS JR., R.; PESCE, C. P. A Consistent Analytical Model to Predict the Structural Behavior of Flexible Risers Subjeted to Combined Loads. Journal of Offshore Mechanics and Artic Engineering. [S.1.]: [s.n.]. 2004. p. pp.141-146.

[32] SA, P. B. Norma 2409. Petrobras. Rio de Janeiro, Brasil, p. 1-80. 2003.

[33] SOUSA, J. R. M. Análise Local de Linhas Flexíveis pelo Método dos Elementos Finitos. COPPE/UFRJ. Rio de Janeiro, p. 746. 2005.

[34] SOUSA, J. R. M. et al. LOCAL MECHANICAL BEHAVIOUR OF FLEXIBLE PIPES SUBJECTED TO INSTALLATION LOADS. 20th International Conference on Offshore Mechanics and Artic Engineering, Rio de Janeiro, Brasil, p. 1-9, Junho 2001.

[35] SOUSA, J. R. M. et al. AN ANALYTICAL MODEL TO PREDICT THE LOCAL MECHANICAL BEHAVIOUR OF FLEXIBLE RISERS SUBJECTED TO CRUSHING LOADS. Jornadas Sul-Americanas de Engenharia Estrutural, Brasília, Brasil, p. 1-19, Maio 2002.

[36] TADAHIRO SHIMA, W.; ORTIZ NETO, J. B. Trajetórias Tecnológicas no Segmento Offshore: Ambiente e Oportunidades, Rio de Janeiro, v. 12, p. pp.301-332, 2008 .

[37] TECHNIP. Flexible Pipe Systems, 2006. Disponivel em: $<$ http://www.technip.com/sites/default/files/technip/page/attachments/Flexible_system s.pdf>. Acesso em: 08 ago. 2016. 


\section{APÊNDICE A - MODELOS DE PLASTICIDADE DOS METAIS}

Esse apêndice apresenta conceitos importante sobre a plasticidade dos metais a fim de proporcionar um melhor esclarecimento do comportamento dos materiais selecionados na metodologia deste trabalho.

\section{Plasticidade}

A expressão plasticidade é usada para descrever o comportamento de materiais que são carregados acima do limite de escoamento. Modelos de materiais com comportamento linear elástico são amplamente empregados na literatura, em procedimentos analíticos e numéricos, a fim de se ter problemas simplificados. Com isso é possível que se tenha uma idealização do comportamento estrutural do problema estudado. No entanto, para casos em que é premente a análise da falha dos materiais após o ponto de escoamento, a aplicação do comportamento linear elástico levará a resultados inconsistentes. Nesses casos, é imprescindível que o comportamento plástico dos materiais seja analisado. Esse Apêndice apresentará conceitos básicos da plastificação com a definição mais detalhada dos comportamentos de materiais aplicados ao longo desta dissertação.

A teoria da plasticidade estuda o comportamento de um corpo deformado permanentemente após a combinação de tensões e deformações. O problema plástico é essencialmente incremental já que a distorção total do corpo é dada pela soma dos incrementos ao longo do caminho de deformação.

\section{COMPORTAMENTO TENSÃO-DEFORMAÇÃO DOS METAIS}

A curva tensão-deformação apresenta o comportamento dos materiais a partir da análise da deformação sob um estado de tração uniaxial. A Figura 58 apresenta a curva 
de tensão-deformação típica de um metal. Segundo Chakrabarty (2006), o material se comportará elasticamente enquanto a tensão aplicada for suficientemente pequena. Essa região é indicada pelo trecho AO. A tensão de escoamento é indicada por $\mathrm{Y}$, e o ponto de escoamento por B. Acima do ponto de escoamento a tensão continua aumentando, porém com deformação plástica. Na região $\mathrm{BC}$ a inclinação da curva diminui com o aumento da tensão. A região CD indica a recuperação elástica de um determinado objeto que é carregamento até o ponto $\mathrm{C}$ e posteriormente descarregado. A deformação permanente que permanece até o descarregamento é representada pelo caminho OE. Se uma nova carga é aplicada ao mesmo objeto, um novo ponto de escoamento será definido por F, e o caminho BC será substituído por FG como a região plástica. Essa curva apresenta diferentes configurações de acordo com o tipo de comportamento do material, e o tipo de encruamento.

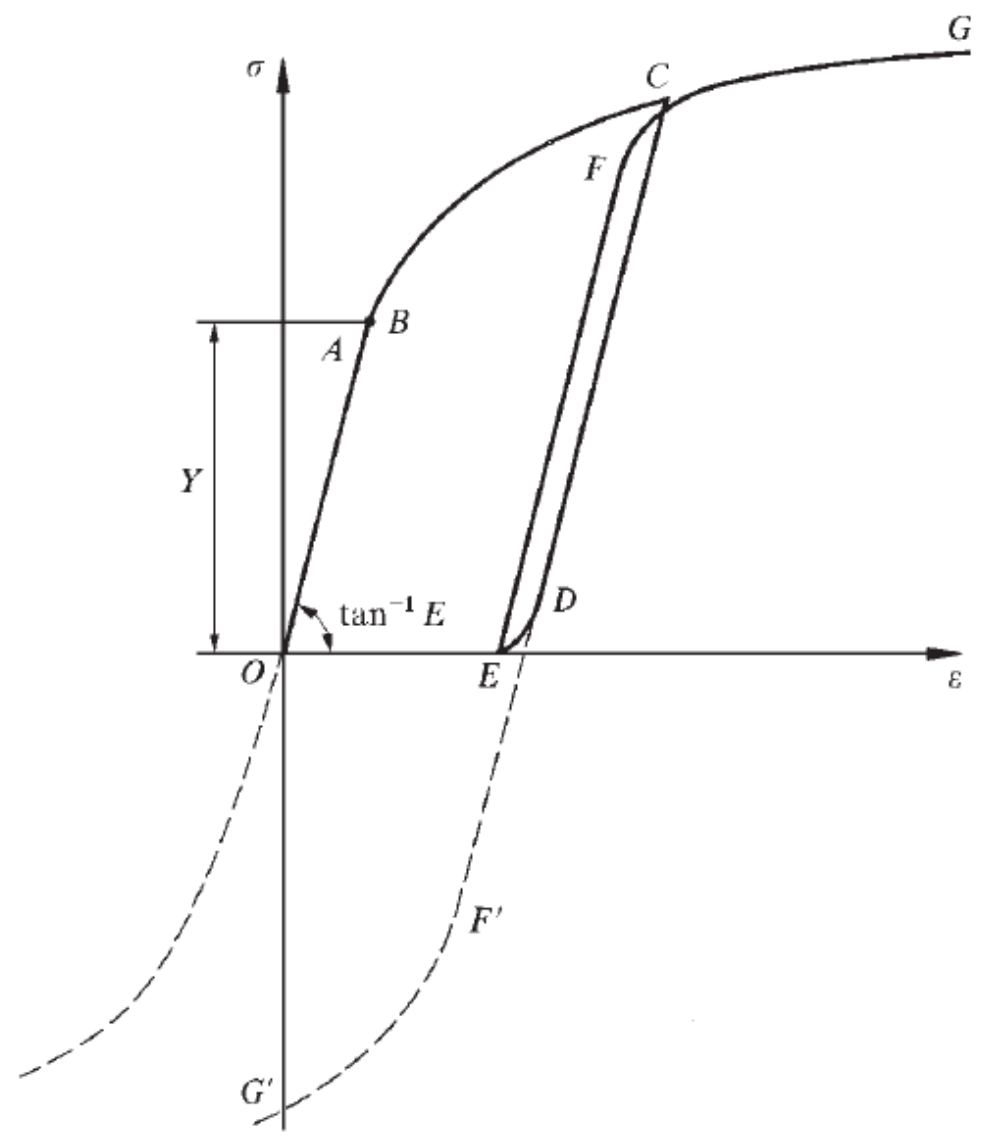

Figura 58 - Curva tensão-deformação dos metais com o efeito do carregamento e descarregamento Fonte: Chakrabarty (2006). 


\section{CRITÉRIO DE ESCOAMENTO DOS METAIS}

Critério de escoamento é a definição para a lei que determina o comportamento do material na transição do regime elástico para o plástico, e quando submetido aos diferentes tipos de carregamentos. Chakrabarty (2006) define o critério de escoamento por meio da análise de uma representação geométrica em que são consideradas algumas hipóteses: as taxas de deformação e efeitos térmicos são ignorados; são desconsiderados os efeitos Bauschinger (perda da isotropia durante o processo de plastificação) e o ciclo de histerese na tensão-deformação; o material é considerado isotrópico. A Figura 59 representa o critério de escoamento através de uma representação geométrica. Qualquer estado de tensões pode ser representado com vetores a partir da origem O. O vetor de tensão $O Q$, definido pelas tensões principais $\sigma_{1}, \sigma_{2}$ e $\sigma_{3}$ têm resultantes OG sobre a linha OH e OP, perpendicular à $\mathrm{OH}$. $\mathrm{O}$ vetor $\mathrm{OP}$ é conhecido como tensão desviadora, enquanto o vetor OG é conhecido como a componente hidrostática. O escoamento é definido unicamente pela direção e magnitude do vetor desviador. A componente hidrostática não apresenta contribuição para o escoamento. Assim, a superfície de escoamento é definida por um cilindro com componentes perpendiculares ao plano desviador.

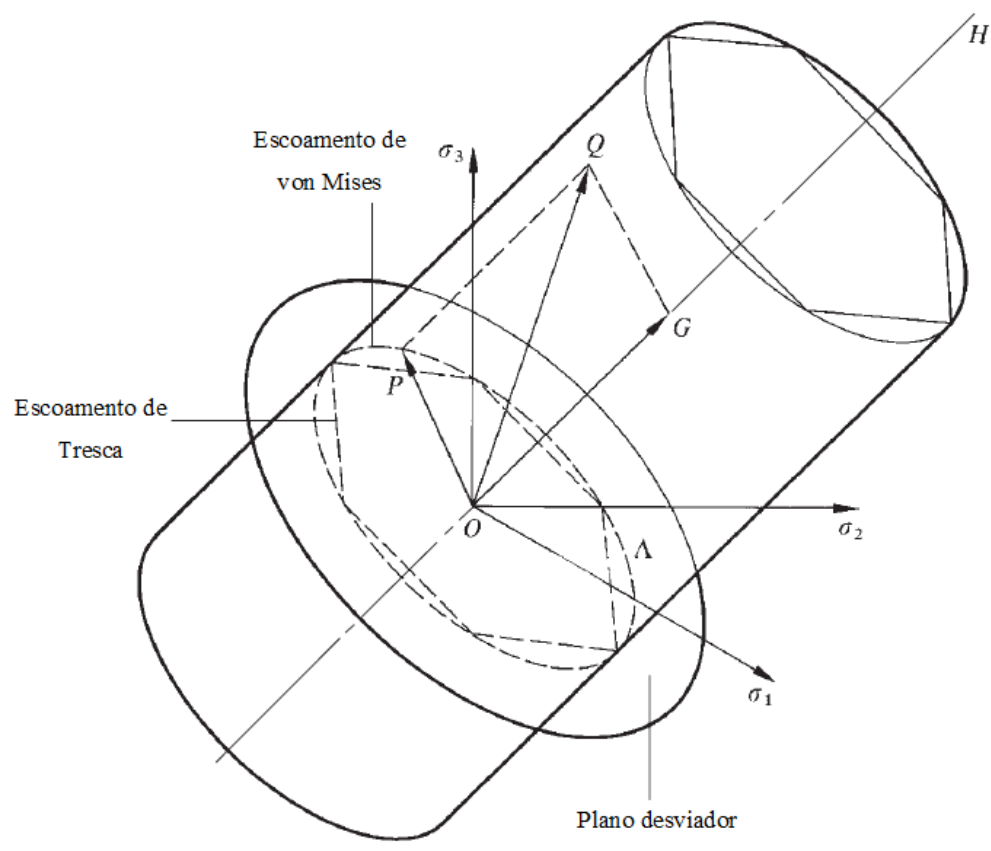

Figura 59 - Representação do critério de escoamento no plano de tensão principal Fonte: Chakrabarty (2006). 
O local de escoamento é definido pela intersecção entre o plano desviador e a curva $\Lambda$. O material é elástico quando a projeção do estado de tensão sobre o plano desviador está localizada dentro do cilindro. O critério de escoamento é definido pela interseção entre o plano desviador e o cilindro. Existem vários critérios de escoamento dos materiais, sendo o de Tresca e von Mises os mais conhecidos. O regime plástico é definido quando a projeção do vetor de tensões extrapola o limite do cilindro no plano desviador.

Os conceitos relacionados a representação geométrica do escoamento no plano de tensão principal é fundamental para o entendimento dos tipos de endurecimento dos materiais: isotrópico e cinemático.

\section{TIPOS DE ENDURECIMENTO POR DEFORMAÇÃO PLÁSTICA}

A resistência ao escoamento de um material aumenta quando ele é recarregado após atingir o limite plástico. Esse fenômeno é conhecido como endurecimento por deformação plástica, sendo dividido em: endurecimento isotrópico e cinemático. Cada um desses endurecimentos ainda pode assumir a forma bilinear ou multilinear, que nada mais é que a quantidade de curvas definidas durante a evolução elasto-plástica.

\section{ENDURECIMENTO ISOTRÓPICO}

Esse comportamento é caracterizado pela expansão da superfície de escoamento com o aumento da tensão, mantendo a mesma forma inicial, como indicado na Figura 60. O estado de tensões muda ao longo do caminho $P_{0} P$, e a superfície de escoamento é expandida uniformemente. As resistências ao escoamento tanto para a tensão quanto para a compressão aumentam uniformemente na mesma quantidade. Esse tipo de endurecimento é comumente aplicado em modelos matemáticos para pacotes de elementos finitos. 


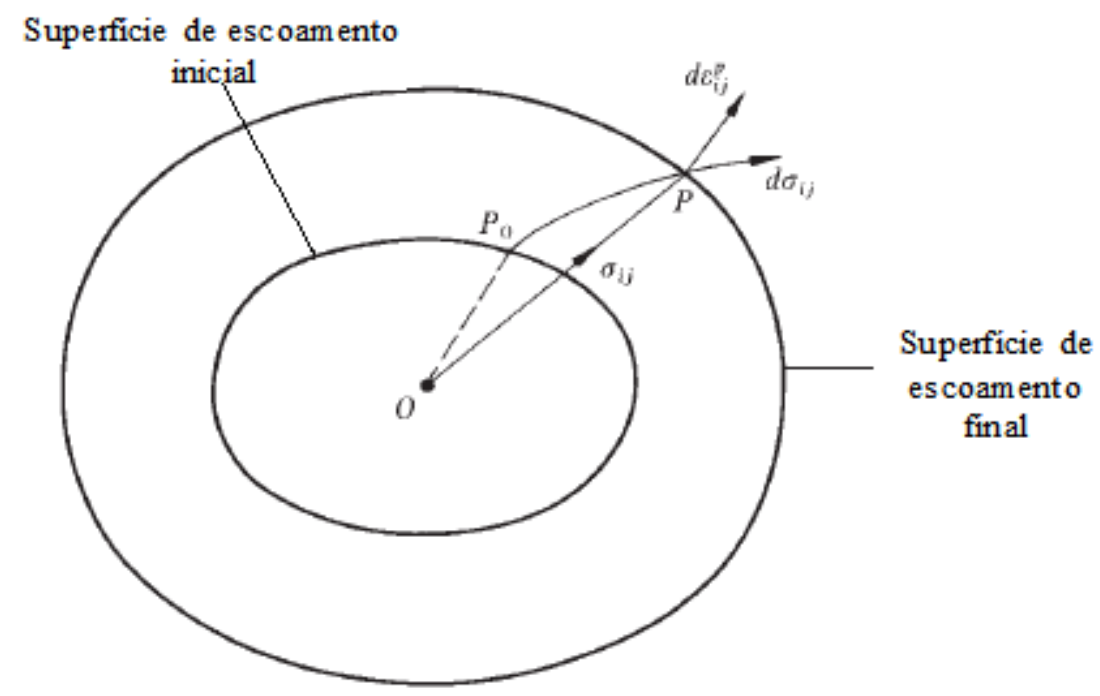

Figura 60 - Representação geométrica para o endurecimento isotrópico Fonte: Chakrabarty (2006).

\section{ENDURECIMENTO CINEMÁTICO}

Esse comportamento é aplicado para representar o efeito Baushinger e respostas equivalentes, quando o endurecimento na tração levará a mudança do escoamento na compressão. A superfície de escoamento permanece com o mesmo formato e tamanho, mas sofre uma translação no espaço de tensões como indicado na Figura 61.

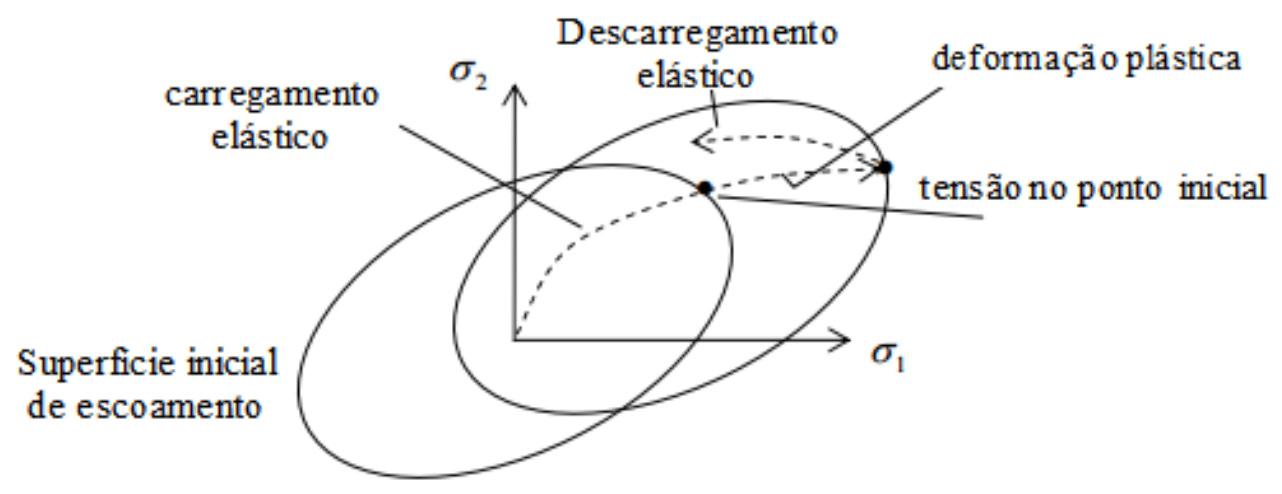

Figura 61 - Representação geométrica para o endurecimento cinemático Fonte: [24]. 


\section{APÊNDICE B - MODELO ANALÍTICO APLICADO NO CÁLCULO DA PRESSÃO DE ESTRANGULAMENTO}

A metodologia de cálculo apresentada neste apêndice é baseada em Ramos (2001). Nesta tese, o autor apresenta modelos analíticos para o cálculo estrutural dos tubos flexíveis e cabos umbilicais. São consideradas várias configurações para elaboração da metodologia de cálculo, a partir dos tipos de carregamentos aplicados. Parte-se então do tubo não deformado e sem carregamentos como a primeira dessas configurações. Em seguida, são estudados os casos com cargas axissimétricas. Os dois últimos casos tratam de carregamentos combinados incluindo flexão e as hipóteses de presença e ausência do escorregamento entre as armaduras de tração e as camadas adjacentes.

A rotina Pipe Design calcula a pressão de contato entre as camadas a partir da configuração de carregamentos fornecida pelo usuário. Assim, serão apresentadas brevemente as hipóteses adotadas e o cálculo da pressão de contato entre as camadas helicoidais para cada uma das configurações propostas. A tese de Ramos (2001) pode ser consultada para que se tenha uma maior compreensão da formulação matemática.

\section{APLICAÇÃO DE CARREGAMENTOS AXISSIMÉTRICOS}

Nessa primeira análise, são abordadas as configurações não deformada do tubo e a deformada com carregamentos axissimétricos. São então aplicadas as seguintes hipóteses:

i. Os carregamentos são aplicados de forma a manter o eixo central do tubo reto;

ii. $\quad \mathrm{O}$ atrito interno entre as camadas é desprezado;

iii. As seções planas antes da deformação permanecem plana também após a deformação, mantendo o alongamento;

iv. A rotação por unidade de comprimento do riser será equivalente para todas as camadas; 
v. Os materiais apresentam comportamento linear elástico, são homogêneos e isótropos;

vi. O problema é tratado com linearidade geométrica.

A partir de equações de equilíbrio, relações constitutivas e das hipóteses iniciais, é feito o equacionamento individual das camadas helicoidais e plásticas. O conjunto de equações que definem a diferença entre a pressão de contato entre as camadas é dado pela relação entre os esforços solicitantes que atuam nos tendões das armaduras e a pressão de contato entre armaduras vizinhas.

Considerando-se a configuração inicial do tubo não deformada, dada por $\Sigma_{1}$ e a configuração final, deformada, dada por $\Sigma_{2}$, tem-se que as componentes da curvatura e torção são dadas por:

$$
\begin{gathered}
k_{x 1}=0 \\
k_{y 1}=\chi_{1}=\frac{\operatorname{sen}^{2} \alpha_{1}}{R_{1}} \\
k_{t 1}=\tau_{1}=\frac{\operatorname{sen} \alpha_{1} \cos \alpha_{1}}{R_{1}} \\
k_{x 2}=0 \\
k_{y 2}=\chi_{2}=\frac{\operatorname{sen}^{2} \alpha_{2}}{R_{2}} \\
k_{t 2}=\tau_{2}=\frac{\operatorname{sen}_{2} \cos \alpha_{2}}{R_{2}}
\end{gathered}
$$

As equações acima com subscrito 1 se referem a configuração não deformada do tubo e aquelas com subscrito 2 se referem a configuração deformada. Os componentes acima são as curvaturas de torção segundo as componentes principais de flexo-torção.

Partindo das relações entre os esforços solicitantes de tração e momento nas componentes de deformação, têm-se:

$$
T=E A \varepsilon_{t, 2}
$$




$$
\begin{aligned}
& M_{y}=E I_{y}\left(k_{y 2}-k y_{1}\right)=E I_{y}\left(\chi_{2}-\chi_{1}\right) \\
& M_{x}=E I_{x}\left(k x_{2}-k_{x 1}\right)=0
\end{aligned}
$$

Sendo EA e EI a rigidez axial e flexional, respectivamente. As curvaturas na configuração não deformada e deformada são $\chi_{2}, \chi_{1}$.

Considerando que os tendões adjacentes de uma mesma camada helicoidal não estejam em contanto e desprezando o atrito, tem-se que:

$$
f_{y}=0 ; \quad f_{z}=0 ; \quad m_{x}=0
$$

Sendo $f_{y}$ e $f_{z}$ as forças distribuídas nas direções y e z e $m_{x}$ o momento distribuído na direção principal $x$.

Após manipulação das equações B1 a B6 e B7 a B9, e considerando que a força cortante é nula na direção normal e as componentes dos momentos distribuídos na direção principal y também são nulas, tem-se:

$$
\begin{aligned}
& -Q_{y} \tau_{2}+T \chi_{2}+f_{x}=0 \\
& -M_{y} \tau_{2}+M_{z} \chi_{2}-Q_{y}=0
\end{aligned}
$$

O momento de torção da seção transversal do tendão é definido como:

$$
M_{z}=G I_{t}\left(k_{t 2}-K_{t 1}\right)
$$

Substituindo as equações B.7, B.8 e B.9 na equação B.12, temos a força cortante $Q_{y}$ é equivalente a:

$$
Q_{y}=-E I_{y}\left(\chi_{2}-\chi_{1}\right) \tau_{2}+G I\left(\tau_{2}-\tau_{1}\right) \chi_{2}
$$

Considerando que as forças distribuídas $f_{x}$ possam ser expressas em função da diferença das pressões de contato externa $\left(P_{c, e}\right)$ e interna $\left(P_{c, i}\right)$ à camada, tem-se que: 


$$
f_{x}=b \Delta_{p c}=b\left(p_{c, e}-p_{c, i}\right)
$$

Sendo b a largura do tendão.

Substituindo B.14 e B.15 em B.11 e linearizando a expressão em torno da variação do raio $(\Delta R=0)$ e do ângulo de assentamento nas camadas helicoidais $(\Delta \alpha=0)$, temos a expressão para a variação da pressão de contato interna e externa em cada camada:

$$
\begin{aligned}
b\left(p_{c, i}-p_{c, e}\right)= & T \chi_{1}+\left[2 T \tau_{1}+\frac{\chi_{1} \tau_{1}}{R_{1}}\left(2 E I_{y} \cos ^{2} \alpha_{1}-G I_{t} \cos \left(2 \alpha_{1}\right)\right)\right] \Delta \alpha+ \\
& +\left[\chi_{1}^{2} \tau_{1}\left(G I_{t}-E I_{y}\right)-T \chi_{1}\right] \frac{\Delta R}{R_{1}}
\end{aligned}
$$

\section{APLICAÇÃO DE CARREGAMENTOS COMBINADOS}

Além dos carregamentos axissimétricos já considerados anteriormente, também é adicionada a flexão do tubo. O principal objetivo de se adicionar a análise da flexão é a obtenção da rigidez flexional da linha e o nível de tensão nas camadas. São então tratados os casos em com presença e ausência de escorregamento entre as camadas considerando as cargas de momento fletor, força axial, momento de torção, pressão interna e externa com as seguintes hipóteses:

i. Todas as seções transversais possuem a mesma torção por unidade de comprimento;

ii. Não há contato entre tendões adjacentes de uma mesma camada helicoidal;

iii. Todos os materiais são homogêneos, isótropos, e com comportamento linear elástico;

iv. Não há folgas entre as camadas na configuração não deformada;

v. Considera-se a linearidade geométrica;

vi. A ovalização é desprezada;

vii. As variações espessura e raio médio são uniformes para todas as camadas; 
viii. Uma das direções principais de flexão para o tendão das camadas helicoidais é ortogonal à superfície sobre a qual o tendão se assenta;

ix. Não há escorregamento relativo entre as camadas adjacentes;

Considerando apenas o caso sem escorregamento, temos:

A variação de raio de acordo com a compatibilidade de deslocamentos é dada por:

$$
\Delta R_{i+1}=\Delta R_{i}+\frac{1}{2}\left(\Delta t_{i+1}+\Delta t_{i}\right)+g_{i}
$$

Em que $\Delta R_{i}$ é a variação de raio da i-ésima camada, $\Delta t_{i}$ a variação de espessura e $g_{i}$ o afastamento entre as camadas.

A força axial suportada pela camada devido, principalmente, à carregamentos axiais:

$$
\begin{aligned}
\frac{F_{i}}{A_{i}}= & E_{i}\left(\frac{\Delta L}{L}\right)+\left(1-\frac{t_{i}}{2 R_{i}}\right) v_{i}\left(2 R_{i}-t_{i}\right)\left(p_{c, i-1}+\mu_{i n} p_{i n}\right)- \\
& -\left(1+\frac{t_{i}}{2 R_{i}}\right) \frac{v_{i}\left(2 R_{i}+t_{i}\right)\left(P_{c, i}+\mu_{0} p_{0}\right)}{2 t_{i}}
\end{aligned}
$$

As variáveis são:

$F_{i}$ é a força axial na i-ésima camada;

$A_{i}$ é a área da seção da camada;

$\frac{\Delta L}{L}$ é a deformação axial da linha;

$E_{i}$ é o módulo de elasticidade;

$t_{i}$ é a espessura da i-ésima camada;

$R_{i}$ é o raio médio da i-ésima camada;

$p_{c, i-1}$ é pressão na camada interna à i-ésima;

$p_{\text {in }}$ é a pressão interna;

$\mu_{\text {in }}$ e $\mu_{0}$ retornam o valor 1 quando a camada analisada é a primeira. 
O momento de torção suportado por cada camada é relacionado com a torção por unidade de comprimento da linha, e o momento fletor suportado com a curvatura da linha são dados por:

$$
\begin{array}{r}
M_{t, i}=\left(G I_{t}\right)_{i} \frac{\Delta \varphi}{L_{1}} \\
M_{f, i}=(E I)_{i} K
\end{array}
$$

$\left(G I_{t}\right)_{i}$ e $(E I)_{i}$ são a rigidez torcional e flexional, respectivamente, para a i-ésima camada, $K$ é a curvatura da linha e $\frac{\Delta \varphi}{L_{1}}$ é a rotação da linha por unidade de comprimento.

A manipulação das expressões B.17 a B.20, juntamente com algumas relações adicionais dão a diferença da pressão de contato entre duas camadas subsequentes por:

$$
\begin{aligned}
\left(p_{c, i}-p_{c, i-i}\right) b_{i}= & {\left[\frac{E_{i} A_{i} \sin ^{2} \alpha_{i} \cos ^{2} \alpha_{i}}{R_{i}}\right] \frac{\Delta L}{L_{1}}-\left[E_{i} A_{i} \sin ^{3} \alpha_{i} \cos \alpha_{i}\right] \frac{\Delta \varphi}{L_{1}}-} \\
& -\left[\frac{E_{i} A_{i} \sin ^{4} \alpha_{i}}{R_{i}^{2}}\right] \Delta R_{i}
\end{aligned}
$$

Em que $b_{i}$ é a espessura da i-ésima camada, $E_{i} A_{i}$ é a rigidez flexional dessa camada, e $\alpha_{i}$ é seu ângulo de assentamento.

Para o caso com escorregamento, há uma diferença nas equações B.18, B.19 e B.20, mas a expressão para a diferença de pressão entre as camadas permanece igual a fornecida pela equação B.21.

A pressão de estrangulamento é então calculada nesta dissertação pela diferença de pressão entre as camadas a partir do carregamento de tração dinâmica que atua na linha durante o lançamento. A metodologia presente em Ramos (2001) foi então usada para a elaboração da rotina Pipe Design desenvolvida no Laboratório de Mecânica Offshore. As Figuras 62 e 63 apresentam a entrada e saída dos parâmetros na rotina Pipe Desing, respectivamente. 

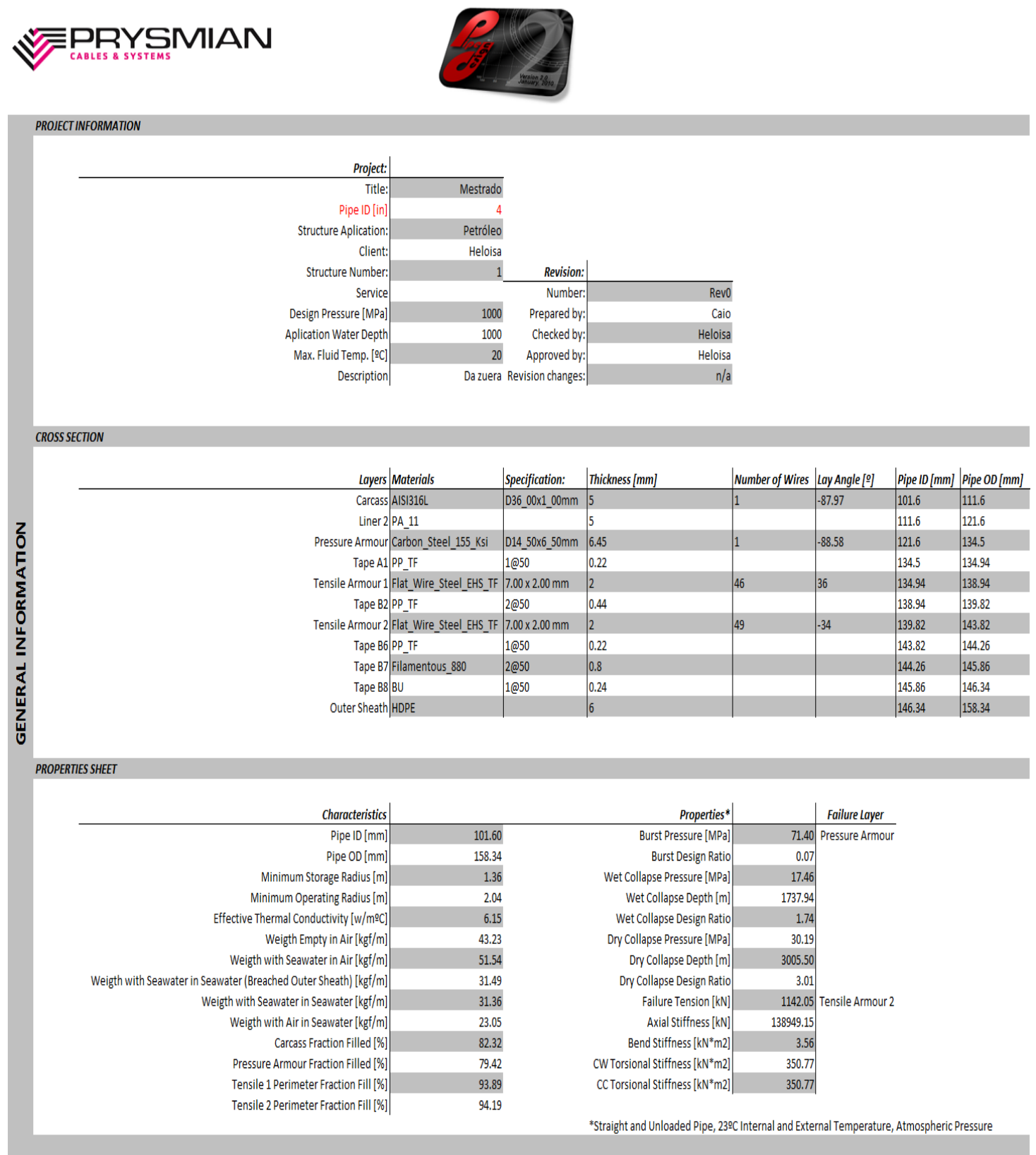

Figura 62 - Exemplo de entrada dos parâmetros na rotina Pipe Design. 
PROPERTY SHEET

\begin{tabular}{r|r} 
Property & \\
\hline Axial Stiffness $[\mathrm{kN}]$ & 139058.14 \\
Bend Stiffness $\left[\mathrm{kN}^{*} \mathrm{~m} 2\right]$ & 4.65 \\
$\mathrm{CW}$ Torsional Stiffness $\left[\mathrm{kN}^{*} \mathrm{~m} 2\right]$ & 350.90 \\
$\mathrm{CC}$ Torsional Stiffness $\left[\mathrm{kN}^{*} \mathrm{~m} 2\right]$ & 350.90 \\
Torque Balance $[\mathrm{deg} / \mathrm{m}]$ & 0.01
\end{tabular}

Torque Balance $[\mathrm{deg} / \mathrm{ml}] \quad 0.01$

REQUIREMENT VERIFICATION

\begin{tabular}{|c|c|c|c|c|c|c|c|}
\hline & & & & & & & REQUIREMENT VERIFICATION \\
\hline Layer & UF & & Limit & Result & Utilization factor & Utilization ratio & \\
\hline Carcass & 0.8 & Stress [MPa] & 690 & $2.05 E+00$ & 0.003 & 0.004 & \\
\hline Liner 2 & $7.70 \%$ & Strain & N/A & $2.57 \mathrm{E}-04$ & 0.000 & 0.003 & \\
\hline Pressure Armour & 0.55 & Stress [MPa] & 855 & $6.32 E+00$ & 0.007 & 0.013 & \\
\hline Tape A1 & N/A & N/A & N/A & N/A & N/A & N/A & \\
\hline Tensile Armour 1 & 0.67 & Stress [MPa] & 1080 & $3.35 E+01$ & 0.031 & 0.046 & \\
\hline Tape B2 & N/A & N/A & N/A & N/A & N/A & N/A & \\
\hline Tensile Armour 2 & 0.67 & Stress [MPa] & 1080 & $3.27 E+01$ & 0.030 & 0.045 & \\
\hline Tape B6 & N/A & N/A & N/A & N/A & N/A & N/A & \\
\hline Tape B7 & 0.55 & Stress $[\mathrm{MPa}]$ & 214.362 & $9.09 \mathrm{E}-02$ & 0.000 & 0.001 & \\
\hline Tape B8 & N/A & N/A & N/A & N/A & N/A & N/A & \\
\hline Outer Sheath & $7.70 \%$ & Strain & N/A & $2.57 \mathrm{E}-04$ & 0.000 & 0.003 & \\
\hline & & & & & & & IDVANCED PROPERTY SHEET \\
\hline Interface & Pressure $[\mathrm{MPa}]$ & $\operatorname{Gap}[\mathrm{m}]$ & & & Elongation & $2.57 E-04$ & \\
\hline Layers 1-2 & $1.57 \mathrm{E}-01$ & $0.00 E+00$ & & & Pipe Rotation $[\mathrm{deg} / \mathrm{m}]$ & $1.09 \mathrm{E}-02$ & \\
\hline Layers 2-3 & $1.52 \mathrm{E}-01$ & $0.00 E+00$ & & & & & \\
\hline Layers 3-4 & $6.19 \mathrm{E}-01$ & $0.00 E+00$ & & & & & \\
\hline Layers 4-5 & $2.87 \mathrm{E}-01$ & $0.00 E+00$ & & & & & \\
\hline Layers 5-6 & $3.32 \mathrm{E}-03$ & $0.00 E+00$ & & & & & \\
\hline Layers 6-7 & $3.81 \mathrm{E}-03$ & $0.00 E+00$ & & & & & \\
\hline Layer & $F[k N]$ & $M t[k N m]$ & $M f[k N m]$ & $d R[m]$ & $d t[m]$ & dalfa [으 & Temperature[ㅇ] \\
\hline Carcass & $-2.23 E-03$ & $3.35 \mathrm{E}-03$ & $0.00 E+00$ & $-4.91 E-07$ & $1.12 \mathrm{E}-08$ & $5.40 \mathrm{E}-04$ & 20.00 \\
\hline Liner 2 & $-8.59 \mathrm{E}-02$ & $1.14 \mathrm{E}-04$ & $0.00 E+00$ & $-1.23 E-06$ & $-1.50 \mathrm{E}-06$ & $0.00 E+00$ & 20.00 \\
\hline Pressure Armour & $-8.20 E-03$ & $2.12 \mathrm{E}-02$ & $0.00 E+00$ & $-1.96 \mathrm{E}-06$ & $3.55 \mathrm{E}-08$ & $4.08 E-04$ & 20.00 \\
\hline Tensile Armour 1 & $1.71 E+01$ & $8.51 \mathrm{E}-01$ & $0.00 E+00$ & $-2.00 E-06$ & $-1.03 E-07$ & $-7.30 E-03$ & 20.00 \\
\hline Tensile Armour 2 & $1.83 \mathrm{E}+01$ & $-8.76 E-01$ & $0.00 E+00$ & $-2.10 E-06$ & $-9.80 \mathrm{E}-08$ & $8.14 \mathrm{E}-03$ & 20.00 \\
\hline Tape B7 & $-3.97 E-04$ & $-2.60 E-04$ & $0.00 E+00$ & $-2.14 E-06$ & $8.31 \mathrm{E}-09$ & $-1.77 E-03$ & 20.00 \\
\hline Outer Sheath & $3.86 \mathrm{E}-01$ & $4.76 \mathrm{E}-04$ & $0.00 E+00$ & $-2.73 \mathrm{E}-06$ & $-1.18 E-06$ & $0.00 E+00$ & 20.00 \\
\hline
\end{tabular}

Figura 63 - Exemplo da saída dos parâmetros na rotina Pipe Design. 